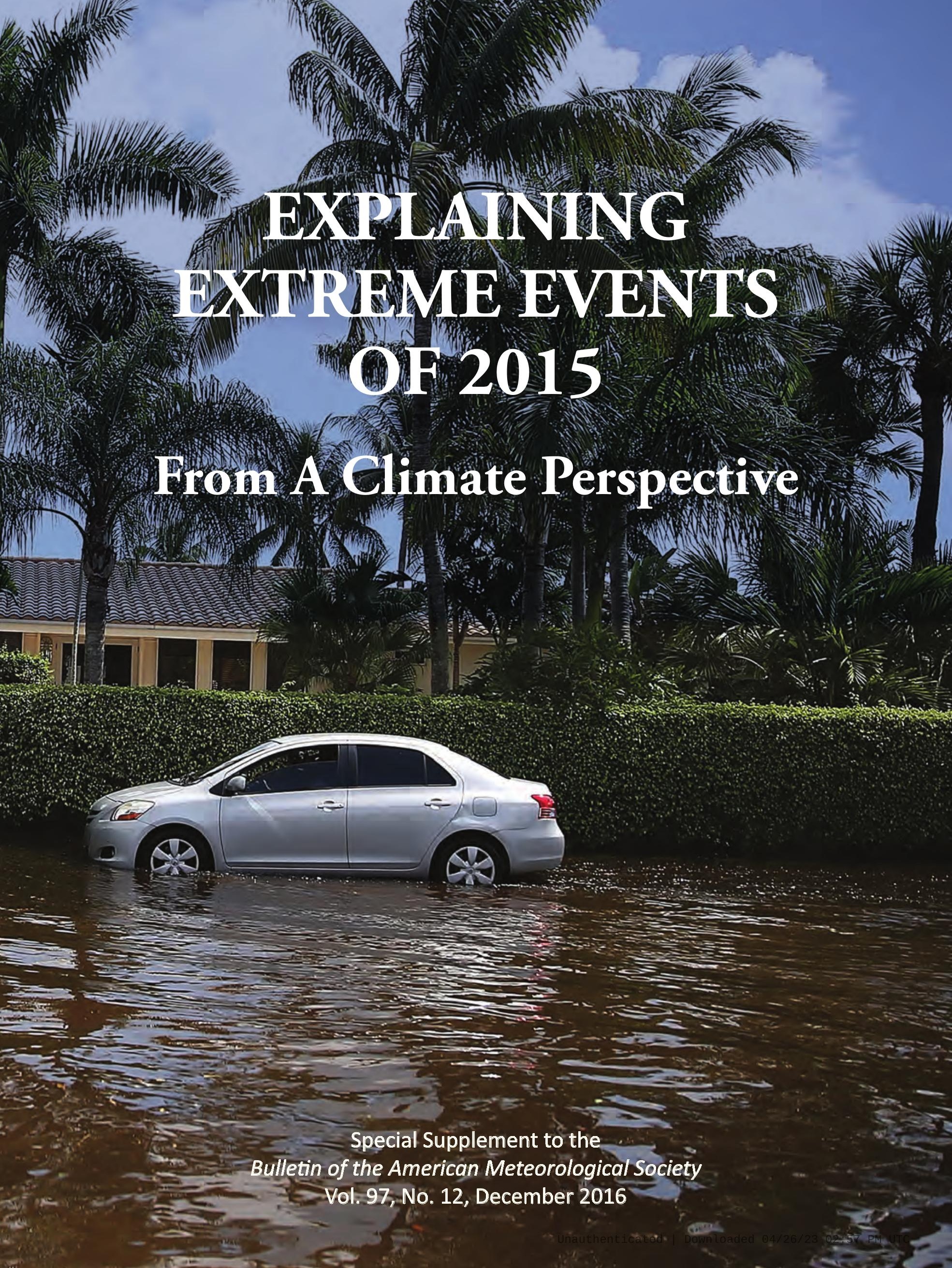




\section{EXPLAINING EXTREME \\ EVENTS OF 20I5 FROM A \\ CLIMATE PERSPECTIVE}

\section{Editors}

Stephanie C. Herring, Andrew Hoell, Martin P. Hoerling, James P. Kossin,

Carl J. Schreck III, and Peter A. Stott

Special Supplement to the

Bulletin of the American Meteorological Society

Vol. 97, No. 12, December 2016

American Meteorological Society 


\section{CORRESPONDING EDITOR:}

Stephanie C. Herring, PhD

NOAA National Centers for Environmental Information

325 Broadway, E/CC23, Rm IB-I3I

Boulder, CO, 80305-3328

E-mail: stephanie.herring@noaa.gov

\section{Cover CRedit:}

CPhoto by Joe Raedle/Getty Images-A vehicle drives through flooded streets caused by a combination of the lunar orbit which caused seasonal high tides and what many believe is the rising sea levels due to climate change on September 30, 20I5, in Fort Lauderdale, Florida. South Florida is projected to continue to feel the effects of climate change, and many of the cities have begun programs such as installing pumps or building up sea walls to try and combat the rising oceans.

\section{HOW TO CITETHIS DOCUMENT}

Citing the complete report:

Herring, S. C., A. Hoell, M. P. Hoerling, J. P. Kossin, C. J. Schreck III, and P.A. Stott, Eds., 20I6: Explaining Extreme Events of 2015 from a Climate Perspective. Bull.Amer. Meteor. Soc., 97 (I2), SI-SI45, doi:I0.I I75/BAMS

-ExplainingExtremeEvents2015.I.

Citing a section (example):

Partain, J. L., and Coauthors, 2016: An assessment of the role of anthropogenic climate change in the Alaska fire season of 2015 [in "Explaining Extremes of 2015 from a Climate Perspective"]. Bull. Amer. Meteor. Soc., 97 (I2), SI4-SI8, doi:I0.II75/BAMS-D-16-0149.

\section{EDITORIAL AND PRODUCTION TEAM}

Riddle, Deborah B., Lead Graphics Production, NOAA/NESDIS National Centers for Environmental Information, Asheville, NC

Veasey, Sara W., Visual Communications Team Lead, NOAA/ NESDIS National Centers for Environmental Information, Asheville, NC

Love-Brotak, S. Elizabeth, Graphics Support, NOAA/NESDIS National Centers for Environmental Information, Asheville, NC

Fulford, Jennifer, Editorial Support, Telesolv Consulting LLC, NOAA/NESDIS National Centers for Environmental Information, Asheville, NC

Griffin, Jessicca, Graphics Support, Cooperative Institute for Climate and Satellites-NC, North Carolina State University, Asheville, NC
Maycock, Tom, Editorial Support, Cooperative Institute for Climate and Satellites-NC, North Carolina State University, Asheville, NC Misch, Deborah J., Graphics Support, Telesolv Consulting LLC, NOAA/NESDIS National Centers for Environmental Information, Asheville, NC

Osborne, Susan, Editorial Support, Telesolv Consulting LLC, NOAA/NESDIS National Centers for Environmental Information, Asheville, NC

Sprain, Mara, Editorial Support, LAC Group, NOAA/NESDIS National Centers for Environmental Information, Asheville, NC

Young, Teresa, Graphics Support, STG, Inc., NOAA/NESDIS National Centers for Environmental Information, Asheville, NC 


\section{TABLE OF CONTENTS}

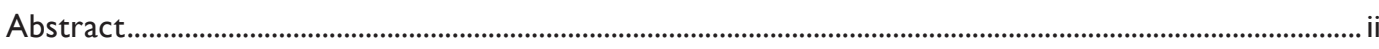

I. Introduction to Explaining Extreme Events of 2015 from a Climate Perspective.................................

2. Multimodel Assessment of Anthropogenic Influence on Record Global and Regional Warmth

During 2015 .......................................................................................................................................

3. What History Tells Us About 2015 U.S. Daily Rainfall Extremes ..........................................................

4. An Assessment of the Role of Anthropogenic Climate Change in the Alaska Fire Season

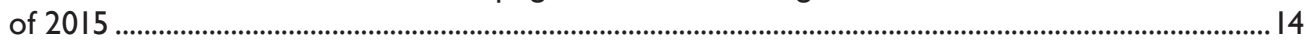

5. The 2014/15 Snowpack Drought in Washington State and its Climate Forcing ................................ 19

6. In Tide's Way: Southeast Florida's September 2015 Sunny-day Flood .................................................. 25

7. Extreme Eastern U.S. Winter of 2015 Not Symptomatic of Climate Change .....................................

8. The Role of Arctic Sea Ice and Sea Surface Temperatures on the Cold 2015 February

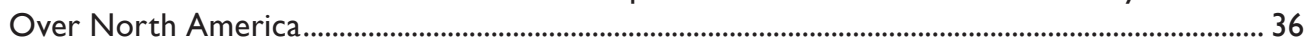

9. The 2015 Extreme Drought in Western Canada ................................................................................ 42

10. Human Contribution to the Record Sunshine of Winter 2014/15 in the United Kingdom ..............47

II. The Role of Anthropogenic Warming in 2015 Central European Heat Waves ...................................5I

12. The 2015 European Heat Wave ..................................................................................................................

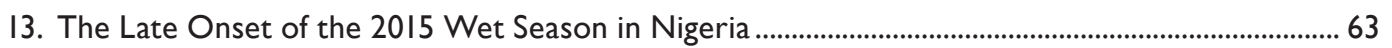

14. Human Influences on Heat-Related Health Indicators During the 2015 Egyptian

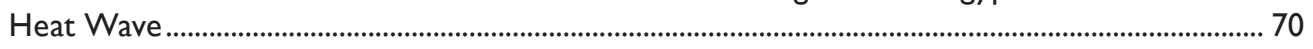

15. Assessing the Contributions of Local and East Pacific Warming to the 2015

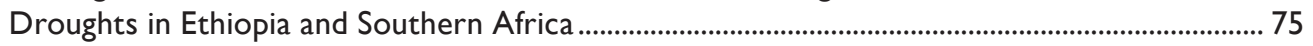

16. The Deadly Combination of Heat and Humidity in India and Pakistan in Summer 2015..................8

17. The Heavy Precipitation Event of December 2015 in Chennai, India................................................... 87

18. Attribution of Extreme Rainfall in Southeast China During May 2015 ............................................ 92

19. Record-Breaking Heat in Northwest China in July 2015: Analysis of the Severity and Underlying Causes ......................................................................................................................... 97

20. Human Influence on the 2015 Extreme High Temperature Events in Western China................... 102

21. A Persistent Japanese Heat Wave in Early August 2015: Roles of Natural Variability and

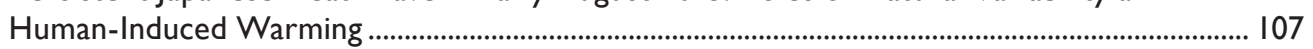

22. Climate Change and El Niño Increase Likelihood of Indonesian Heat and Drought........................ 113

23. Southern Australia's Warmest October on Record: The Role of ENSO and Climate Change....................................................................................................................................... 118

24. What Caused the Record-Breaking Heat Across Australia in October 2015? .............................. 122

25. The Roles of Climate Change and El Niño in the Record Low Rainfall in October 2015 in Tasmania, Australia.

26. Influences of Natural Variability and Anthropogenic Forcing on the Extreme 2015 Accumulated Cyclone Energy in the Western North Pacific

27. Record Low Northern Hemisphere Sea Ice Extent in March 2015 ............................................... 136

28. Summary and Broader Context.....................................................................................................141 
This fifth edition of explaining extreme events of the previous year (2015) from a climate perspective continues to provide evidence that climate change is altering some extreme event risk. Without exception, all the heat-related events studied in this year's report were found to have been made more intense or likely due to human-induced climate change, and this was discernible even for those events strongly influenced by the $2015 \mathrm{El}$ Niño. Furthermore, many papers in this year's report demonstrate that attribution science is capable of separating the effects of natural drivers including the strong 2015 El Niño from the influences of long-term human-induced climate change.

Other event types investigated include cold winters, tropical cyclone activity, extreme sunshine in the United Kingdom, tidal flooding, precipitation, drought, reduced snowpack in the U.S. mountain west, arctic sea ice extent, and wildfires in Alaska. Two studies investigated extreme cold waves and monthly-mean cold conditions over eastern North America during 2015, and find these not to have been symptomatic of human-induced climate change. Instead, they find the cold conditions were caused primarily by internally generated natural variability. One of these studies shows winters are becoming warmer, less variable, with no increase in daily temperature extremes over the eastern United States. Tropical cyclone activity was extreme in 2015 in the western North Pacific (WNP) as measured by accumulated cyclone energy (ACE). In this report, a study finds that human-caused climate change largely increased the odds of this extreme cyclone activity season. The 2015 Alaska fire season burned the second largest number of acres since records began in 1940 . Investigators find that human-induced climate change has increased the likelihood of a fire season of this severity.

Confidence in results and ability to quickly do an attribution analysis depend on the "three pillars" of event attribution: the quality of the observational record, the ability of models to simulate the event, and our understanding of the physical processes that drive the event and how they are being impacted by climate change. A result that does not find a role for climate change may be because one or more of these three elements is insufficient to draw a clear conclusion. As these pillars are strengthened for different event types, confidence in the presence and absence of a climate change influence will increase.

This year researchers also link how changes in extreme event risk impact human health and discomfort during heat waves, specifically by looking at the role of climate change on the wet bulb globe temperature during a deadly heat wave in Egypt. This report reflects a growing interest within the attribution community to connect attribution science to societal impacts to inform risk management through "impact attribution." Many will watch with great interest as this area of research evolves in the coming years. 


\title{
I. INTRODUCTION TO EXPLAINING EXTREME EVENTS OF 2015 FROM A CLIMATE PERSPECTIVE
}

\author{
Stephanie C. Herring, Andrew Hoell, Martin P. Hoerling, James P. Kossin, \\ Carl J. Schreck III, and Peter A. Stott
}

In the first years of this report, we answered questions such as: "What is event attribution?" and "Is it even possible to address the effects of long-term changes on extreme events using event attribution?" The science has now advanced to the point that we can detect the effects of climate change on some events with high confidence (e.g., especially those linked to temperature), although results are necessarily probabilistic and not deterministic. The growing popular interest in event-attribution is feeding back to the science, for example by requiring it to more carefully consider the impacts of various interpretations and framings of the causation question. We thus now ask: "What is the confidence of the results?" and "How should the results be interpreted?" We are conscious of the importance of the precise question being asked, for instance "What are long-term contributions to event frequency?" versus "What are long-term contributions to event intensity?" (e.g., Dole et al. 2011). There remains an ongoing need to reconcile attribution results pertaining to different aspects of extreme event behavior (e.g., Otto et al. 2012).

To state that event attribution is complex, especially for extreme rainfall and related storm systems including tropical cyclones, is obvious. Yet, such complexities mean that the analytic work to pull numerous pieces together to establish probable cause continues to require considerable time, even as computers become more powerful to aid the effort. Thus, the reliability and realism of "real time" attribution for which there is great public appetite, continues to be an open question. The scope of information demand is also multifaceted, not only to explain "why the event happened," but also "how well

\footnotetext{
AFFILIATIONS: HeRRING-NOAA/National Centers for Environmental Information, Boulder, Colorado; HOELL AND HoERLING -NOAA/Earth System Research Laboratory, Physical Sciences Division, Boulder, Colorado; Kossin—NOAA/National Centers for Environmental Information, Madison, Wisconsin; SCHRECK - NOAA/National Centers for Environmental Information and Cooperative Institute for Climate and SatellitesNorth Carolina, North Carolina State University, Asheville, North Carolina; Sтотт—Met Office Hadley Centre and University of Exeter, Exeter, United Kingdom
}

DOI: 10.1175/BAMS-D-I5-0313.I the event was anticipated." These new questions are far more challenging to address and are increasingly relevant to the concerns of society. Attribution science has made progress in answering these questions, though considerably more work needs to be done.

This last year has been exciting for attribution science, as the U.S. National Academy of Sciences released its report on the topic (NAS 2016). To date, it is the most comprehensive look at the state of event attribution science, including how the framing of attribution questions impacts the results. For example, in a complex event such as drought, a study of precipitation versus a study of temperature may yield different results regarding the role of climate change. The report also addresses how attribution results are presented, interpreted, and communicated. It provides the most robust description to date of the various methodologies used in event attribution and addresses the issues around both the confidence of the results and the current capabilities of near-real time attribution. No single methodology exists for the entire field of event attribution, and each event type must be examined individually. Confidence in results of an attribution analysis depends on what has been referred to as the "three pillars" of event attribution: the quality of the observational record, the ability of models to simulate the event, and our understanding of the physical processes that drive the event and how they are being impacted by climate change.

A recently published paper (Mitchell et al. 2016) marks the beginning of an important new undertaking for the event attribution field by providing an example of how to apply event attribution science to understanding and preparing for impacts. For many years, the scientific community has discussed linking event attribution to the impacts of these events and the role climate change has played in altering those impacts. This year, for the first time, attribution scientists partnered with public health officials to assess the role climate change played in increased mortality from a specific event-the 2003 European heatwave (Mitchell et al. 2016). Their results concluded that in the summer of 2003, "out of the estimated $\sim 315$ and $\sim 735$ summer deaths directly 


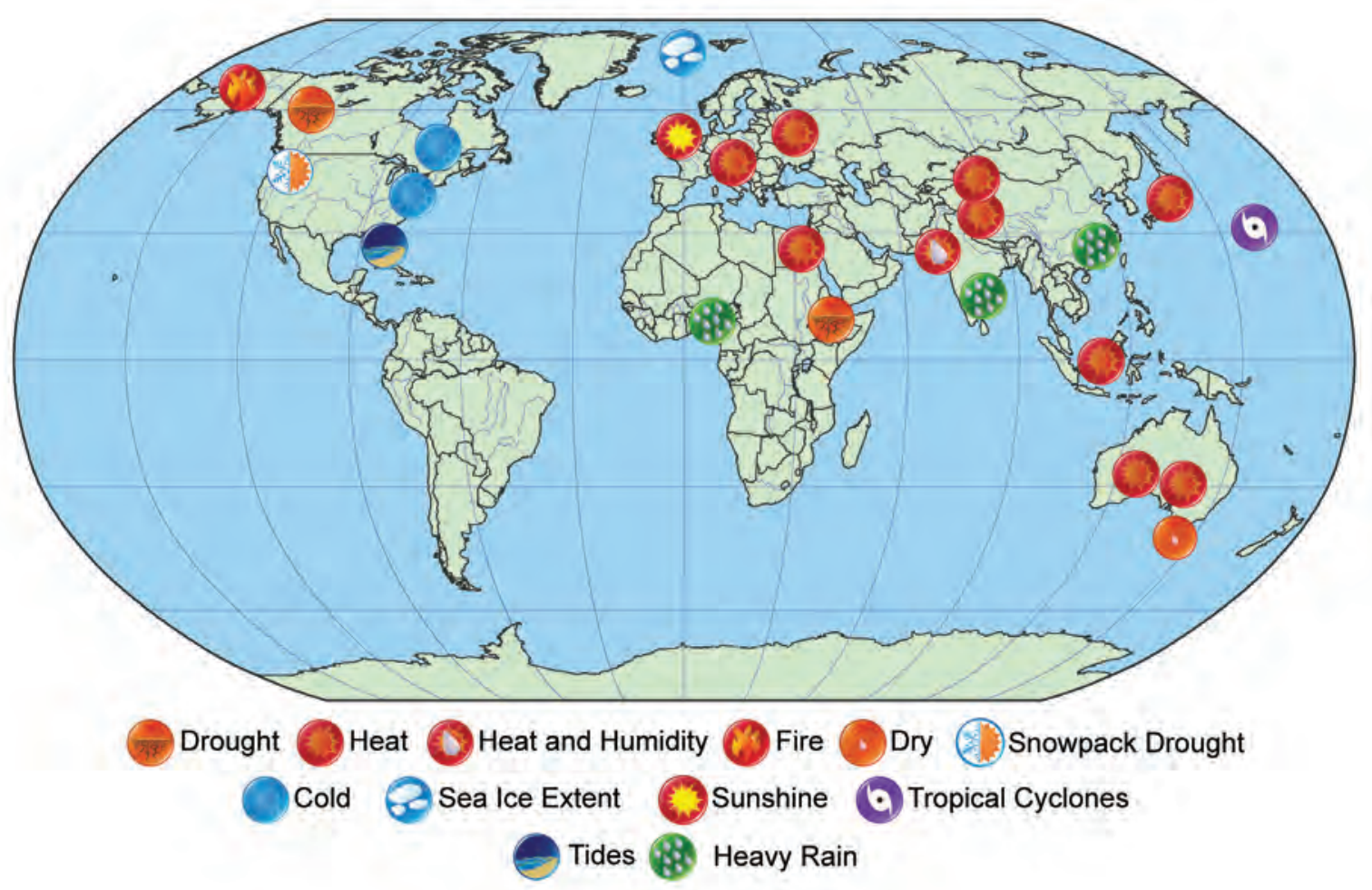

FIG. I.I. Location and types of events analyzed in this publication.

attributed to the heatwave event in Greater London and Central Paris, respectively, $64( \pm 3)$ deaths were attributable to anthropogenic climate change in London, and 506 ( \pm 51) in Paris." While the numbers for this heat wave are noteworthy, especially for Paris, the paper makes a larger contribution than just its analysis of the 2003 event. It lays out a methodology for linking the role of climate change on an extreme heat event and, subsequently, the impacts of that event on human health. Clearly, multiple approaches could be taken to address these questions, and the paper by Mitchell et al. lays out just one. Also, it is no accident that this work addresses a heat event, where the climate change signal is strongest and confidence in attribution results is highest.

Even so, it would be premature to regard this result-that $506( \pm 51)$ deaths in Paris in summer 2003 are attributable to anthropogenic climate change-as the last word on the matter. Unquantified uncertainties need to be further explored owing to different observational, modeling, and methodological strategies for both climate attribution and health sciences. And the confidence with which a linkage can be made between anthropogenic emissions and impacts is different for other event types. However, as the science advances we hope to see more papers connecting a line between climate change and impacts, not only for heat but also for other event types. Friederike Otto put it well in a recent paper where she wrote, "The event attribution community has come a long way towards applying different methodologies and combining meteorological variables to indices of relevance to people, making impact attribution the challenge for the coming years" (Otto 2016). Mitchell's paper begins to address this challenge.

Meaningful connections between weather and climate events and impacts will require that the event attribution community collaborate with the impacts community. Furthermore, event attribution would be most useful to the impacts community if potential users engage closely with scientists in the co-production of knowledge relevant to decisionmaking. The European Climate and Weather Events: Interpretation and Attribution (EUCLEIA) project has engaged with such stakeholders and found that different sectors often have different uses for such information and different requirements (Stott et al. 2015). For example, the insurance industry may value robustness over speed in the assessment of climate risks. By contrast, the World Weather Attribution project has worked with Red Cross/Red Crescent 
which require information on faster time scales. They find value in rapid assessments of recent disastrous weather and climate events during the relatively short window of opportunity when resources may be available to enable communities to become more resilient to such shocks in the future (https://www .climatecentral.org/about/partners/).

A common characteristic for all these impact attribution efforts is that they have been cross disciplinary. In support of the IPCC's $1.5^{\circ} \mathrm{C}$ impacts report, collaborations between science disciplines have been established that will hopefully continue to increase the applicability of event attribution science in decision-making.

In addition to the literature, Mother Nature also made this year an interesting one because of the strong El Niño. Although we had anticipated that we would focus on event types other than heat in this year's report, the heat proposals we received put an interesting twist on the heat attribution question. With the presence of a strong El Niño in 2015, these papers asked whether attribution could effectively disentangle the effects of El Niño from longer-term human-caused warming. Without exception, the analyses in this report were successfully able to do this. All investigations of heat events found an increased risk from human-caused climate change separate from the role of El Niño and other drivers from natural variability.

As we look back at five years of this BAMS Explaining Extreme Events from a Climate Perspective report, we are excited to see the overall progress made to date. That progress is not merely in the climate science, but also in the growth of capabilities to share that information with others and to communicate that knowledge clearly. Also, the range of event types being examined with a focus on attribution has broadened over the years, and the ability of analyses to distinguish between natural and human-caused drivers continues to increase. It is also worth noting that this publication does not discriminate between papers that do and do not find a role for climate change. A large number of papers published in this report over the past five years $(\sim 35 \%)$ did not find any role for climate change on the risk of the event, and we expect to continue receiving and publishing similarly-themed manuscripts in the future.

Looking ahead, over the next half decade there is certainly a great deal of work still to be done in improving the reliability of event attribution results and how they are communicated. We will be closely watching to see how the effort to meet the challenge of "impact attribution" advances in the coming years. We are seeing the start of bridges being built between the disciplines of climate attribution, the practice of weather forecasting, and socioeconomic science, which are each truly essential next steps in using attribution analysis to inform risk management decisions. However, progress in managing risks from extreme events can only be made if the foundational pillars of observations, modeling, and our understanding of the physical processes that drive extreme events and their relationship to climate change also continue to improve. Continued investments in climate science at all levels are crucial not only in the next five years, but for the foreseeable future.

\section{REFERENCES}

Dole, R., and Coauthors, 2011: Was there a basis for anticipating the 2010 Russian heat wave? Geophys. Res. Lett., 38, L06702, doi:10.1029/2010GL046582.

Mitchell, D., and Coauthors, 2016: Attributing human mortality during extreme heat waves to anthropogenic climate change. Environ. Res. Lett., 11, 074006, doi:10.1088/1748-9326/11/7/074006.

NAS, 2016: Attribution of Extreme Weather Events in the Context of Climate Change. National Academies Press, 186 pp., doi:10.17226/21852.

Otto, F. E. L., 2016: Extreme events: The art of attribution. Nat. Climate Change, 6, 342-343, doi:10.1038 /nclimate2971.

Otto, F. E. L., N. Massey, G. J. van Oldenborgh, R. G. Jones, and M. R. Allen, 2012: Reconciling two approaches to attribution of the 2010 Russian heat wave. Geophys. Res. Lett., 39, L04702, doi:10.1029/2011GL050422.

Stott, P. A., and Coauthors, 2016: Attribution of extreme climate events. Wiley Interdiscip. Rev.: Climate Change, 7, 23-41, doi:10.1002/wcc.380. 


\title{
2. MULTIMODEL ASSESSMENT OF ANTHROPOGENIC INFLUENCE ON RECORD GLOBAL AND REGIONAL WARMTH DURING 2015
}

\author{
Jonghun Kam, Thomas R. Knutson, Fanrong Zeng, and Andrew T. Wittenberg \\ In 2015, record warm surface temperatures were observed for the global mean, India, and the \\ equatorial central Pacific. CMIP5 simulations suggest that for the globe and India, \\ anthropogenic warming was largely to blame.
}

Introduction. HadCRUT4v4 observed surface temperature data (Morice et al. 2012; $5^{\circ} \times 5^{\circ}$ lat.-lon. grid boxes) indicates that 2015 was a clear recordbreaking year for global annual mean temperatures (Figs. 2.1a,b,e). In this analysis, we consider only grid boxes with at least 100 years of historical data, which narrows the focus mainly to the Atlantic and Indian Oceans, the North Pacific Ocean, Europe, the United States, southern Asia, and Australia (Fig. 2.1d). Sixteen percent of this analyzed area experienced record annual warmth during 2015 (Fig. 2.1d).

Observed global temperatures over the past decade had been warming at a rate less than the ensemble mean warming in the Coupled Model Intercomparison Project phase 5 all-forcing historical runs (CMIP5-ALL; Taylor et al. 2012). However, the record global temperature of 2015 (Fig. 2.1e), including the influence of a strong El Niño event (Fig. 2.1f), was warmer globally than the mean of the CMIP5-ALL model ensemble levels for 2015, relative to their respective 1881-1920 means.

Major regions with unprecedented annual mean warmth in 2015 included the northeast Pacific and northwest Atlantic, while during SeptemberNovember (SON) 2015, southern India/Sri Lanka stood out with record seasonal warmth (Fig. 2.1g; our region of focus in southern India and Sri Lanka does include some SST influence, as we used the combined SST/Tair dataset; see Supplemental Material). Only a small region south of Greenland $(0.2 \%$ of the

AFFILIATIONS: KAM—NOAA/Geophysical Fluid Dynamics Laboratory and the Cooperative Institute for Climate Science, Princeton University, Princeton, New Jersey; KnUtson, Zeng, AND WiTTENBERG - NOAA/Geophysical Fluid Dynamics Laboratory, Princeton, New Jersey.

DOI:10.1175/BAMS-D-16-0138.I

A supplement to this article is available online (10.II75 /BAMS-D-16-0138.2) globe) experienced record annual mean cold surface temperatures (Fig. 2.1d).

We constructed our regions of focus based on areas highlighted in Fig. 2.1d. These regions had some irregular shapes and were constructed to be mostly covered by new record annual or seasonal temperatures in 2015. In addition to global mean temperatures, we focused on two main regions and temporal domains-the Niño-4 region (annual means) and a region including southern India and Sri Lanka (SON means). To demonstrate the robustness for annual mean record warmth in 2015 over the Niño-4 region (Fig. 2.1g), we also showed extended reconstructed sea surface temperature (ERSST.v4; Huang et al. 2016) and Hadley Centre sea ice and sea surface temperature (HadISST1.1; Rayner et al. 2003) data reconstructions and found that these also show unprecedented annual mean warmth during 2015.

This study investigates the causes of these record warm events using an eight-model set of all-forcing (anthropogenic + natural) historical climate model runs, associated long-term control (unforced) runs, and natural forcing runs (CMIP5-ALL, -CONT, and -NAT, respectively). These eight models (listed in Supplemental Material) were selected, as they were the ones with CMIP5-NAT runs extending to 2012. Our methods follow the studies of Knutson et al. (2013 and 2014); some of the descriptive text below is drawn from those reports.

Time-evolving trend analyses for long-term global and regional anthropogenic warming. Figures $2.2 \mathrm{a}-\mathrm{c}$ show analyses for long-term global and regional trends using different start years, but with a common end year (2012 for CMIP5-NAT and 2015 for CMIP5ALL; the latter are extended with simulations forced by the RCP4.5 emissions scenario). Observed trends ending in 2012 and 2015 are shown for comparison. 

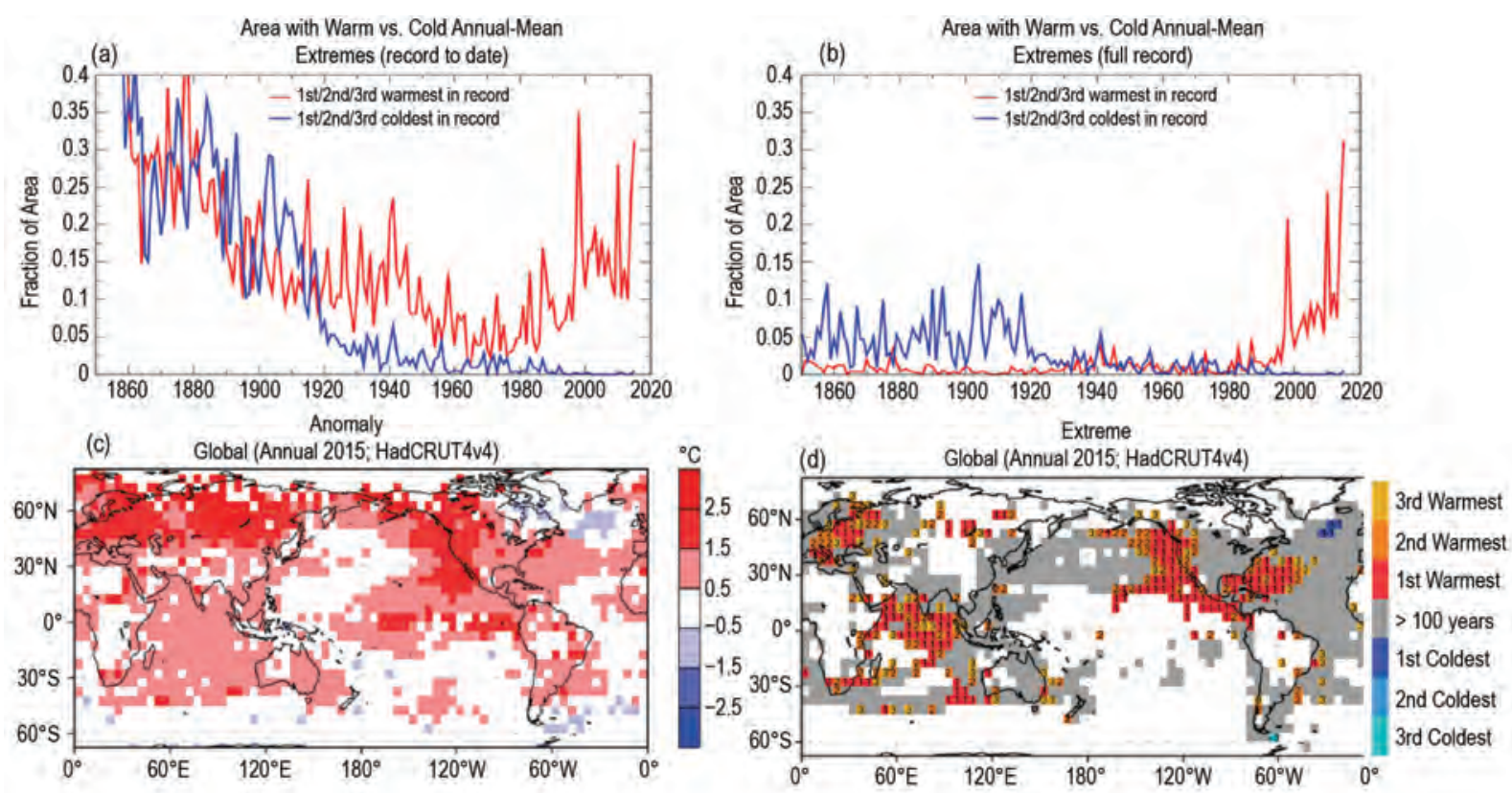

(e)
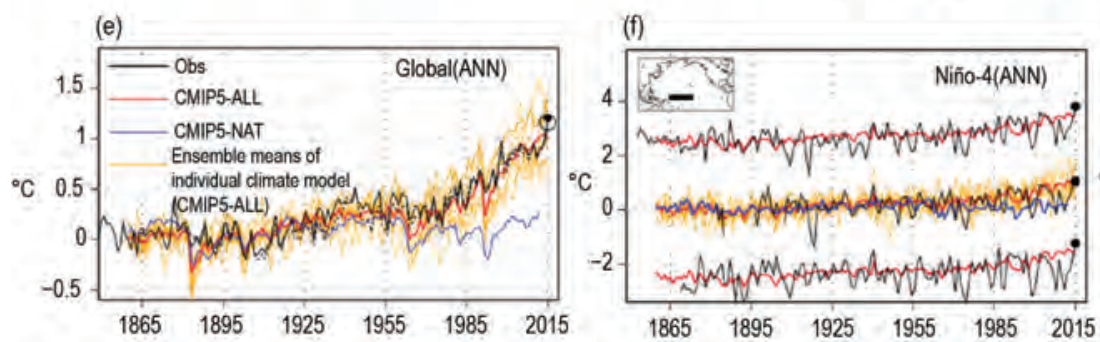

(g)

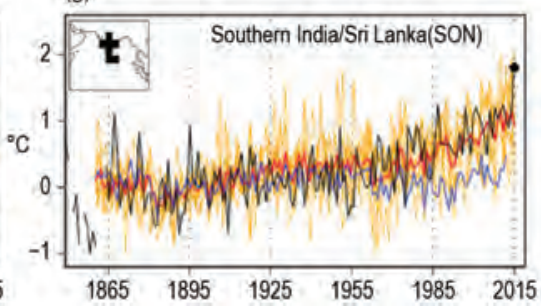

Fig. 2.I. (a),(b) Annual time series of the fractions of available global area with the top three warmest (red curve) and coldest (blue curve) annual mean temperatures in the available record (a) to that date and (b) to the entire record through 2015. (c) Annual mean surface air temperature anomalies $\left({ }^{\circ} \mathrm{C}\right.$ ) for 2015 (relative to the 196I-90 base period) from the HadCRUT4v4 dataset. (d) Colors identify grid boxes with annual mean anomalies that rank Ist (dark red), 2nd (orange-red), or 3rd (yellow-orange) warmest in the available observed record. Only colored and gray areas have sufficiently long records, defined here as containing at least 100 available annual means, which require at least four available months. (e)-(g) Annual mean surface temperature anomalies $\left({ }^{\circ} \mathrm{C}\right)$ for the globe, Niño-4 region, and southern India/Sri Lanka (SON). Red (CMIP5-ALL) and blue (CMIP5-NAT) curves indicate ensemble mean simulated anomalies through 2015 and 2012, respectively, with each available model weighted equally; orange curves indicate individual CMIP5-ALL ensemble members. Black curves indicate observed estimates from HadCRUT4v4 (solid) and NOAA NCEI (dotted). All time series are adjusted to have zero mean over the period 188I-1920. For the Niño-4 region, alternative observed anomalies from the ERSST.v4 and HadISSTI.I reconstructions and the ensemble anomalies for CMIP5-ALL are shown with $+2.5^{\circ} \mathrm{C}$ and $-2.5^{\circ} \mathrm{C}$ offsets from zero for display purposes.

For the sliding trends, we require at least $33 \%$ areal coverage in the region for at least the start year of the trend (Knutson et al. 2013), resulting in the gaps shown. The global mean analysis shows a pronounced observed warming, consistent with CMIP5-ALL yet statistically distinct from CMIP5-NAT, for all start years before about 1990. While the CMIP5-ALL runs occasionally are inconsistent with observed global trends through 2012 (at least for recent trends beginning in the 1990s), now that the record has been extended to 2015, we find that CMIP5-ALL trends beginning in the late 1990s now are generally consistent with observations.

For the Niño-4 region (Fig. 2.2b), we compare results from three different observational datasets. The ERSST.v4 shows the strongest indication of a detectable warming, consistent with the CMIP5-ALL runs but inconsistent with the CMIP5-NAT runs for start years up to around 1960. In contrast, the HadISST1.1 estimated trends are hardly distinguishable from the CMIP5-NAT runs, and also inconsistent with the CMIP5-ALL runs through most of the period. The observed seasonal mean time series (SON) 


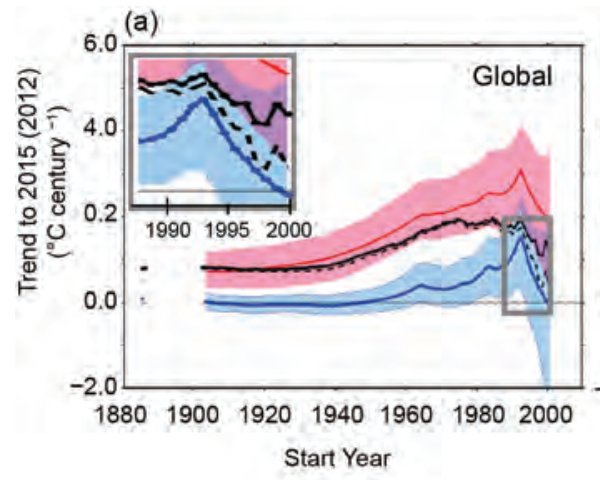

Start Year

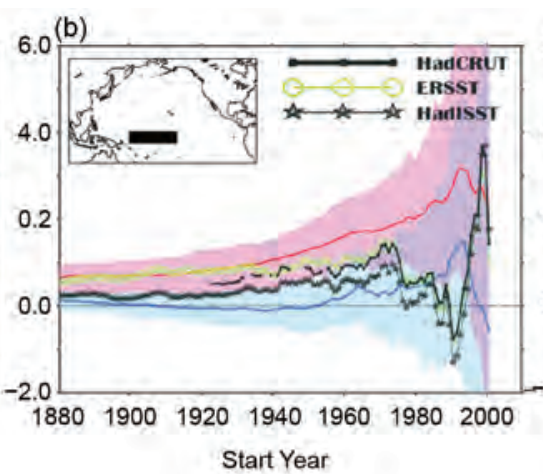

Start Year

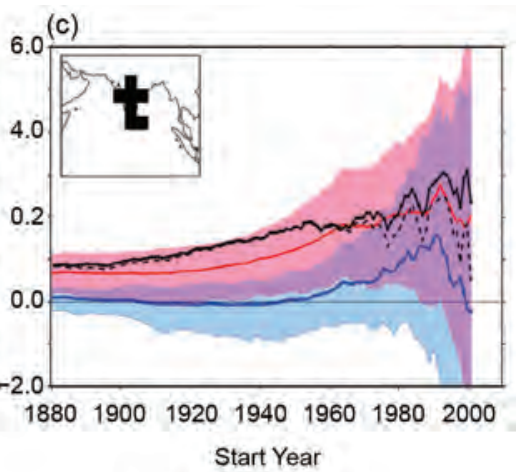

(e) Histogram for Niño-4 (8 GCMs)

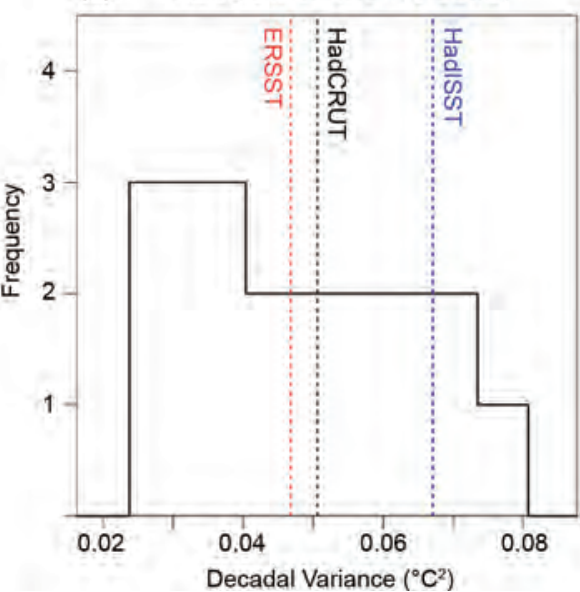

FIG. 2.2. (a)-(c) Sliding trends as a function of starting year, with ending year 2015 (black solid line) or 2012 (black dashed line) $\left[{ }^{\circ} \mathrm{C}(100 \mathrm{yr})^{-1}\right]$ for the globe, the Niño-4 region, and southern India/Sri Lanka. Black, red, and blue curves depict observations, CMIP5-ALL ensemble mean, and CMIP5-NAT ensemble mean, respectively. Black line/dots, green line/circles, and black line/stars depict observed trends from HadCRUT4, ERSST, and HadISST, respectively. Red (blue) lines depict the mean of trends from the CMIP5-ALL (CMIP5-NAT) runs, while pink (blue) bands depict the 5th-95th percentile range for an individual realization chosen randomly from the simulations, with equal representation for each model. Purple shading indicates the overlap of the pink and blue region. (d) Estimates of the FAR of exceeding the first- (20I5) and second-ranked observed temperature anomaly thresholds from the CMIP5 multimodel ensemble (large red and orange circle, respectively); black solid circles correspond to the FAR estimated from the eight paired CMIP5-ALL and -NAT runs from individual CMIP5 models, for the second-ranked observed anomalies. (e) Histogram of the Niño-4 region variances for non-overlapping 155-year epochs of the eight individual model control runs, along with estimates from three observational datasets from which the model-estimated forced response has been removed (I86I-20I5).

over southern India/Sri Lanka (Fig. 2.2c) shows a pronounced warming, consistent with CMIP5-ALL regardless of trend start year, and detectable relative to CMIP5-NAT for start years up to the 1970s.

Overall, the trend analysis using the CMIP5 models shows a long-term warming over the globe and southern India/Sri Lanka (very likely attributable in part to anthropogenic forcing), and long-term trend results for the Niño-4 region that strongly depend on observational data uncertainties.

Model-based attributable risk assessment for the 2015 extreme warm anomalies. Considering the anomalies and new record-breaking temperatures in 2015, there are many regions that could have been selected for the fraction of attributable risk (FAR; Stott et al. 2004) analysis. The major regions of records include global, eastern Pacific, western Atlantic, Indian Ocean, Europe, and south of Greenland (cold record). For our report, we chose to compute the FAR for global temperature, the Niño-4 region (with the prominent El Niño in 2015), and southern India/Sri Lanka (SON). The FAR compares the event tail probabilities (P) between the CMIP5-NAT and CMIP5-ALL runs $\left(F A R=1-\mathrm{P}_{\text {nat }} / \mathrm{P}_{\text {all }}\right)$. Forced responses are derived from the multimodel ensemble means of the 
CMIP5-ALL and CMIP5-NAT simulations, while the impact of internal variability on the modeled trend distributions was estimated using the CMIP5CONT runs (Knutson et al. 2013). Our FAR estimates use the first- (2015) and second-ranked observed positive anomaly as the extreme event thresholds (Fig. 2.2d). For extremely large anomalies, the FAR can be particularly difficult to estimate, as it is based on a ratio of very small areas under the distribution tails (Kam et al. 2015). Therefore we used the secondranked observed anomalies as the threshold values for our primary FAR estimates, as these anomalies are not quite as extreme as the top-ranked ones.

According to the HadCRUT4v4, the secondranked anomalies over the globe, southern India/ Sri Lanka, and the Niño-4 region occurred in 2014, 2010, and 1888, respectively, while the ERSST.v4 and HadISST1.1 datasets show the second-ranked anomalies over the Niño-4 region occurred in different years (2002 and 1987, respectively). Based on the HadCRUT4v4, the simulated probabilities of exceeding the second-ranked anomalies for the globe, southern India/Sri Lanka, and the Niño-4 region are 58\% (0.005\%), 23\% (0.3\%), and 32\% (1.5\%) for the CMIP5-ALL (CMIP5-NAT) runs, respectively. Sensitivity tests for the Niño-4 region using the second-ranked anomalies from the ERSST.v4 and HadISST1.1 datasets are consistent with the results from the HadCRUT4v4 (not shown). The FAR estimates are $0.99,0.98$, and 0.95 for the globe, southern India/Sri Lanka (SON), and the Niño-4 regions, respectively. Uncertainties in the FAR estimates were explored by computing the spread of FAR estimates across individual CMIP5 models (Fig. 2.2d). These sensitivity tests show that, using the second-ranked year threshold values, the estimated FAR is above 0.9 for seven, five, and five out of eight individual models for the globe, Niño-4 region, and southern India/Sri Lanka, respectively (See Supplemental Material).

A crucial assumption of our study is that the internal variability simulated by the models represents the real-world variability adequately. The modeled variability is used as the null hypothesis for explaining trends, and if it is underestimated (overestimated) this makes it too easy (difficult) to detect significant trends and too difficult (easy) for model simulations to be consistent with observations (Knutson et al. 2013). Therefore, we evaluated the decadal variability of temperature anomalies over the Niño- 4 region by comparing a derived observed variability with CMIP5 control run variability. Variability comparisons for other regions have been previously summarized in
Knutson et al. (2013), and plots similar to Fig. 2.2e for global temperature and the southern India/Sri Lanka region are shown in the supplemental material.

To isolate the decadal variability, we apply a lowpass filter with a half-power point at nine years. For the observed internal variability temperature estimate, we subtracted the grand ensemble mean of the CMIP5-ALL runs from observations to attempt to remove the forced component of the observed variations. We have not adjusted the forced component estimate to better fit the observations as done in Mann et al. (2014) and Steinmann et al. (2015), which would be a further refinement beyond the scope of this study. As a sensitivity test for Niño-4, we compared the modeled variability (8 GCMs shown in Fig. 2.2e and 23 GCMs in the Supplemental Materials) with that estimated from three different observational datasets. To estimate the model internal variability, we compute the temperature anomaly variance using each model's entire control run. Details for these calculations, and control run lengths used, are described in Knutson et al. (2013). The eight GCM control runs show a wide range of the simulated decadal variances, between $0.025^{\circ}$ and $0.08^{\circ} \mathrm{C}^{2}$. The analogous estimates of the unforced component of the variance from the observational reanalyses are $0.048^{\circ} \mathrm{C}^{2}$ (ERSST.v4) and $0.051^{\circ} \mathrm{C}^{2}$ (HadCRUT4v4), both of which are located near the center of the intermodel histogram of the control run decadal variances, while the HadISST1.1 shows a somewhat larger decadal variance $\left(0.068^{\circ} \mathrm{C}^{2}\right)$ which is greater than that from five of the eight models. The sensitivity tests for observed decadal variances, and our earlier sliding trend analyses, indicate that for the Niño-4 region, observational uncertainties significantly obscure the detection and attribution of past trends or recent extreme events.

Conclusions. For 2015, the tendency for a greater ratio of global area covered by extreme annual-mean warm versus cold events, as seen in recent decades, has continued. According to the CMIP5 models, the risk of events exceeding the extreme (first- or secondranked) thresholds for the globe, the Niño-4 region, and southern India/Sri Lanka is almost entirely attributable to anthropogenic forcing, with the ensemble mean FAR above 0.9 , and with strong agreement regarding relatively high FAR estimates among the eight GCMs that provided natural-forcing simulations. The strongest model-based evidence for detectable long-term anthropogenic warming, and the highest confidence in a large fraction of attributable risk, was found for the global mean and southern India/ 
Sri Lanka (SON). In the Niño-4 region, confidence in long-term trend assessment and in the FAR estimates is limited, due to uncertainties in the observational data and a wide range of simulated decadal variances from the control runs.

ACKNOWLEDGEMENTS. We thank the WCRP's Working Group on Coupled Modeling, participating CMIP5 modeling groups, for making available the CMIP5. This study was partly funded by NOAA grant NA14OAR4320106.

\section{REFERENCES}

Huang, B., and Coauthors, 2014: Extended Reconstructed Sea Surface Temperature version 4 (ERSST. v4): Part I. Upgrades and intercomparisons. J. Climate, 28, 911-930, doi:10.1175/JCLI-D-14-00006.1.

Kam, J., T. R. Knutson, F. Zeng, and A. T. Wittenberg, 2015: Record annual-mean warmth over Europe, the northeast Pacific, and the northwest Atlantic during 2014: Assessment of anthropogenic influence [in "Explaining Extreme Events of 2014 from a Climate Perspective"]. Bull. Amer. Meteor. Soc., 96 (12), S61S65, doi:10.1175/BAMS-D-15-00101.1.

Knutson, T. R., F. Zeng, and A. T. Wittenberg, 2013: Multimodel assessment of regional surface temperature trends: CMIP3 and CMIP5 Twentieth Century simulations. J. Climate, 26, 8709-8743, doi:10.1175 /JCLI-D-12-00567.1.

- — — extreme annual-mean warm anomalies during 2013 over regions of Australia and the western tropical Pacific [in "Explaining Extreme Events of 2013 from a Climate Perspective"]. Bull. Amer. Meteor. Soc., 95 (9), S26-S30.

Mann, M. E., B. A. Steinman, and S. K. Miller, 2014: On forced temperature changes, internal variability, and the AMO. Geophys. Res. Lett., 41, 3211-3219, doi:10.1002/2014GL059233.

Morice, C. P., J. J. Kennedy, N. A. Rayner, and P. D. Jones, 2012: Quantifying uncertainties in global and regional temperature change using an ensemble of observational estimates: The Had-
CRUT4 data set. J. Geophys. Res., 117, D08101, doi:10.1029/2011JD017187.

Rayner, N. A., D. E. Parker, E. B. Horton, C. K. Folland, L. V. Alexander, D. P. Rowell, E. C. Kent, and A. Kaplan, 2003: Global analyses of sea surface temperature, sea ice, and night marine air temperature since the late nineteenth century. J. Geophys. Res., 108, 4407, doi:10.1029/2002JD002670.

Steinman, B. A., M. E. Mann, and S. K. Miller, 2015: Atlantic and Pacific multidecadal oscillations and northern hemisphere temperatures. Science, 347, 988-991, doi:10.1126/science.1257856.

Stott, P. A., D. A. Stone, and M. R. Allen, 2004: Human contribution to the European heatwave of 2003. Nature, 432, 610-614, doi:10.1038/nature03089.

Taylor, K. E., R. J. Stouffer, and G. A. Meehl, 2012: An overview of CMIP5 and the experimental design. Bull. Amer. Meteor. Soc., 93, 485-498, doi:10.1175 /BAMS-D-00094.1. 


\title{
3. WHAT HISTORY TELLS US ABOUT 2015 U.S. DAILY RAINFALL EXTREMES
}

\author{
Klaus Wolter, Martin Hoerling, Jon K. Eischeid, and Linyin Cheng
}

The United States experienced above-normal daily rainfall extremes in 2015, consistent with national upward trends. However, the most abundant regional extremes were not foreshadowed by

co-located long-term seasonal trends.

Introduction. Three extreme rainfall events occurred over the contiguous United States in 2015 associated with damages in excess of $\$ 1$ billion (U.S. dollars): ${ }^{1}$ 1) drought-ending May rains and flash floods in Texas ${ }^{1,2,3}$ and surrounding states (Wang et al. 2015), 2) near land-falling Hurricane Joaquin in early October associated with catastrophic flooding in South Carolina, ${ }^{1,4}$ and 3) unseasonable December rains that inundated the Mississippi basin.1,5 Recognizing the $a$ posteriori nature of case study selections, we present a large-scale assessment of extreme daily rainfall events ( $\geq 20$-yr return threshold exceedances) over the entire contiguous United States during 2015. Our evaluation facilitates broader discussions on heavy daily precipitation by placing the 2015 high-impact events into both a national and historical context.

The contiguous United States has experienced a statistically significant upward trend in heavy precipitation over the last century (e.g., Karl et al. 1995; Groisman et al. 2004, 2005; Kunkel et al. 2012, 2013). Much of the long-term increase has occurred during recent decades, consistent with early modeling evidence that heavy precipitation events increase in response to doubled $\mathrm{CO}_{2}$ (e.g., Noda and Tokioka 1989; Gregory and Mitchell 1995; Cubasch et al. 1995; Mearns et al. 1995), a finding confirmed also in mod-

\footnotetext{
${ }^{1}$ www.ncdc.noaa.gov/billions/events

${ }^{2}$ ww.wired.com/2015/05/texas-floods-big-ended-states-drought/ $3 \mathrm{http}: / /$ today.tamu.edu/2015/11/04/historic-rains-pound-texas -and-more-may-be-coming

4https://en.wikipedia.org/wiki/October_2015_North_American _storm_complex/

5https://en.wikipedia.org/wiki/Late_December_2015_North _American_storm_complex
}

AFFILIATIONS: WolTER, EISCHEID, AND CHENG-Cooperative Institute for Research in Environmental Sciences, Boulder, Colorado; HoERLING-NOAA/Earth System Research Laboratory, Boulder, Colorado

DOI:10.1175/BAMS-D-16-0166.I

A supplement to this article is available online (10.1175 /BAMS-D-16-0166.2) els used for the Intergovernmental Panel on Climate Change AR5 (IPCC 2013).

Here we discuss U.S. aggregate occurrences of extreme daily rainfall events observed in 2015 compared to century-long trends. While not providing an attribution of impacts by human-induced climate change, the history of extreme daily rainfall since 1901 offers insight into whether such events could have been anticipated from a long-term change perspective of altered likelihoods. We specifically ask whether 2015 recorded an unusual frequency of extreme daily rainfall over the United States as a whole. And, we ask if the regionality and seasonality characterizing 2015 extreme daily rainfall events were consistent with corresponding attributes of long-term trends.

Data and Methods. We utilize 987 meteorological stations extracted from GHCN-D (Menne et al. 2012) having at least 100 years of nonmissing daily observations during 1901-2014, as well as mostly complete data in 2015. While the coverage is not homogenous, it is much more complete than outside the United States, rendering a global analysis more problematic. Two extreme indices, RX1day ( $\max$ 1-day precipitation) and R99p (extremely wet days), as defined by Sillmann et al. (2013), are computed at each station for all annual cases (base period 1901-80). The RX1day index is calculated for bimonthly seasons as well. We applied the generalized extreme value (GEV) distribution, known as the block or annual maxima approach for analysis of 20 -yr precipitation events (e.g., Coles 2001; Ferreira and de Haan 2015), using the Matlab NEVA package (Cheng et al. 2014), and described further in the Supplemental Material. We validated these results against the empirical estimates of the 20 -yr events by ranking the annual and seasonal maxima at each station. About $90 \%$ of the empirical estimates lie within the $95 \%$ credible interval of the 20 -yr return levels estimated using the Bayesian-GEV approach, reassuring the robustness 
of our results. This is important since there is considerable variability across the United States in terms of the shape of daily precipitation distributions, in particular its tails (Kharin and Zwiers 2005; Cavanaugh et al. 2015). The lower confidence bounds (2.5th percentile) of the GEV-estimated return level for 20-yr events are applied in order to include all cases that might be considered of that intensity.

To provide long-term climate context, we refer to NCEI's national to global mean temperature time series, ${ }^{6}$ as well as the extended Multivariate ENSO Index 7,8 (Wolter and Timlin 2011).

Results. a. National Scale-Annual Highlights. During 2015, the contiguous United States had its third wettest year since 1895.6 This was anchored by

$\overline{{ }^{6} \text { www.ncdc.noaa.gov/sotc/national/201513 }}$

${ }^{7}$ www.esrl.noaa.gov/psd/enso/mei.ext/index.html

${ }^{8}$ www.esrl.noaa.gov/psd/enso/climaterisks/years/ record wetness in portions of the Great Plains, ${ }^{6}$ but counterbalanced by California's fourth consecutive drought year (Fig. 3.1a). Consistent with the overall wetness, 143 of 910 reporting stations in 2015 registered daily 20 -yr events, or $15.7 \%$ (Fig. 3.1b). This 20 -yr event coverage of daily extremes was the fifth highest on record (Fig. 3.2a), consistent with a long-term upward trend that has clustered all five most extreme years after 1989. Our time series of national coverage (Fig. 3.2a) correlates at $+0.54(0.53)$ with the global (Northern Hemisphere) surface temperature time series for 1901-2014, consistent with previous results (e.g., Kunkel et al. 2013), compared to +0.21 with just the U.S. temperature time series. ${ }^{6}$ Removal of linear trends in all time series lowers these correlations to $+0.27(0.27)$ and -0.02 , respectively, showing a rather modest linkage between year-to-

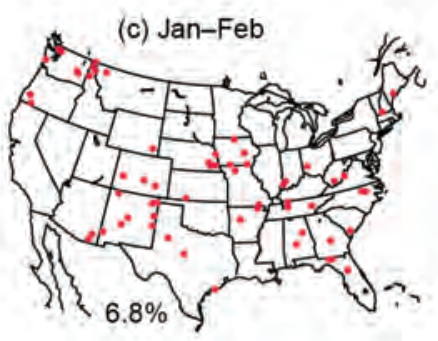

(d) Mar-Apr
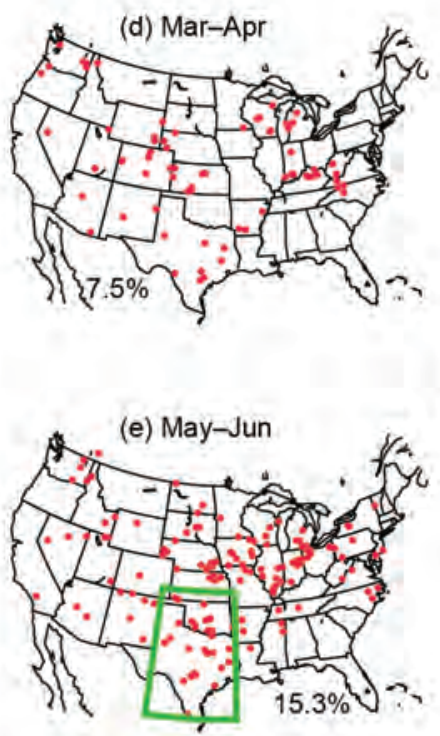

(a) 2015 Annual Departure

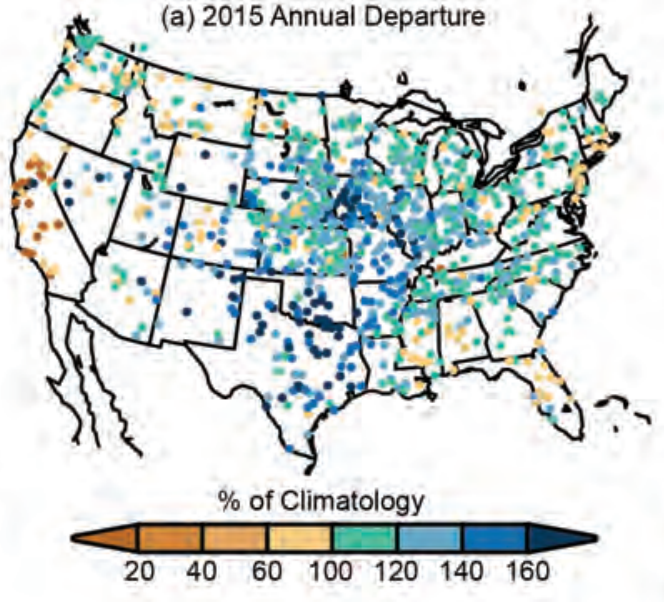

(b) 2015 Daily Extreme

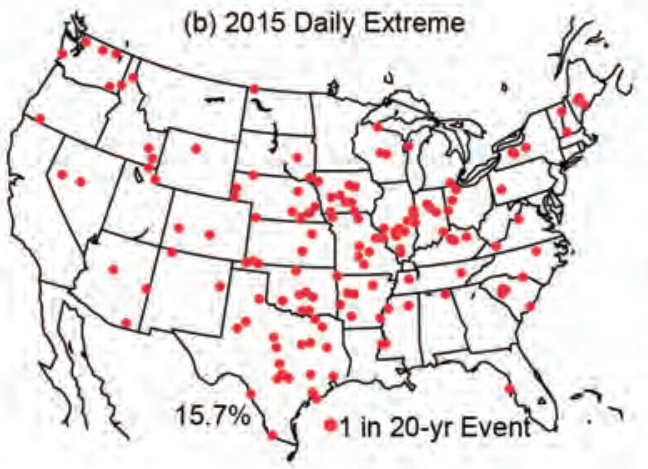

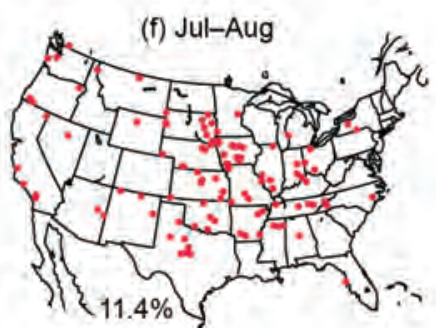

(g) Sep-Oct

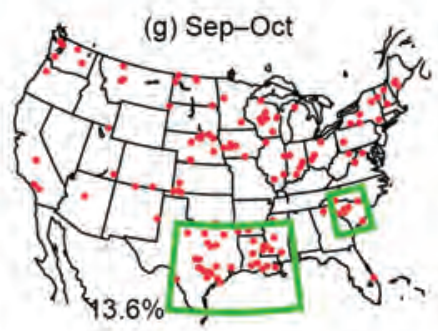

(h) Nov-Dec

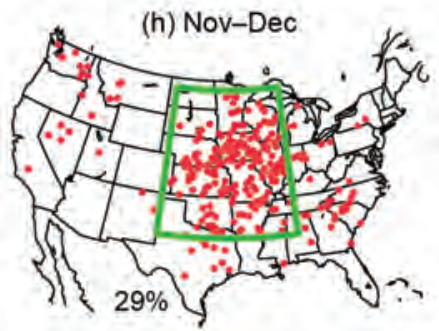

FIG. 3.I. (a) (center top) Annual precipitation anomaly compared to $1901-80$ in 2015 for 910 stations in conterminous United States. (b) Annual 2015 daily extremes in excess of the GEV-lower estimate for 20-yr events (Cheng et al. 20I4). (c)-(e) Bimonthly 2015 daily extremes in excess of the GEV-lower estimate for 20yr events for Jan-Feb, Mar-Apr, and May-Jun. (f)-(h) As in (c)-(e), but for Jul-Aug, Sep-Oct, and Nov-Dec. Regions of interest are outlined in green for May-Jun (Texas/Oklahoma), Sep-Oct (Texas/Louisiana, and South Carolina), and Nov-Dec (central United States). 

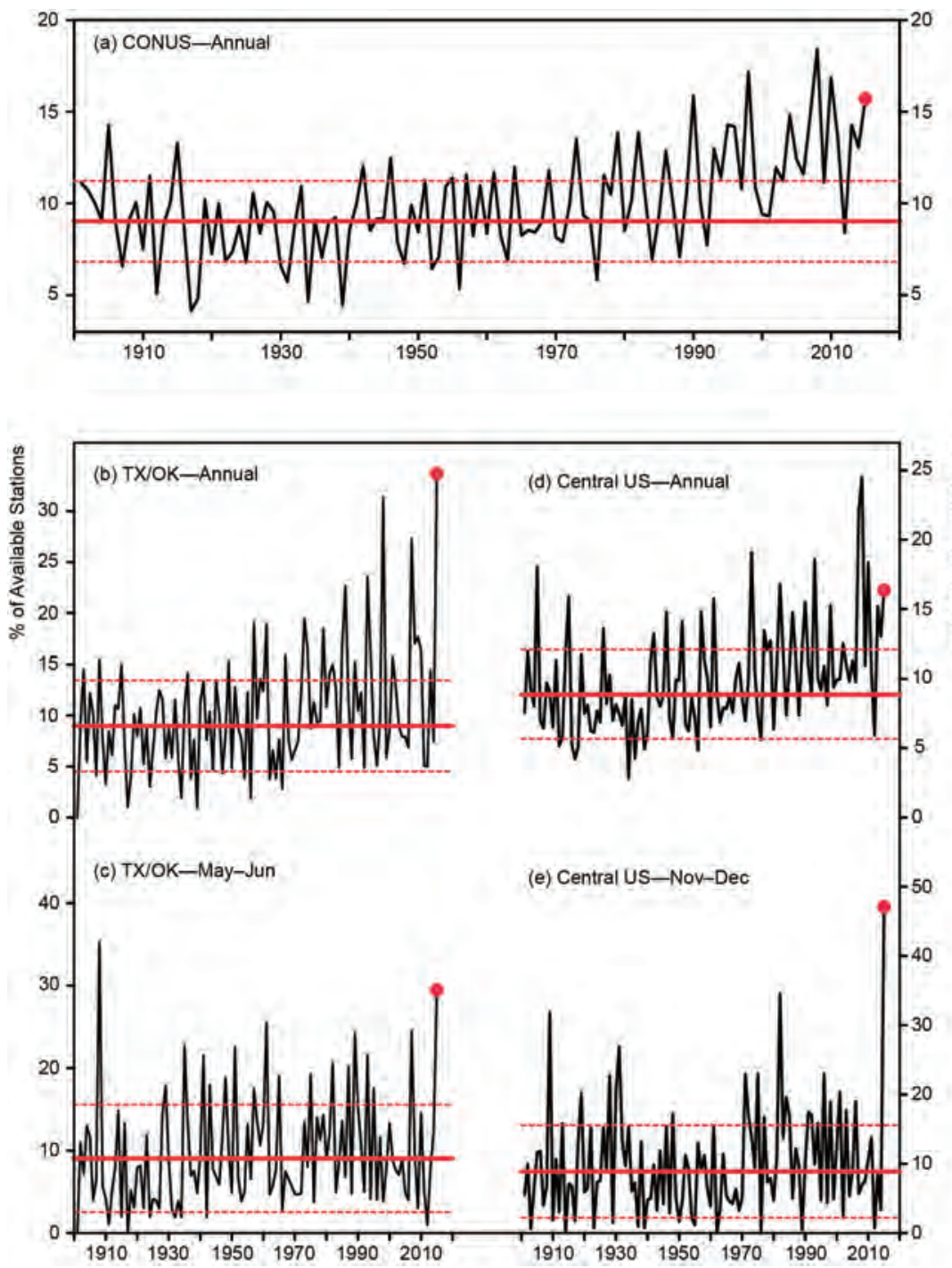

Fig. 3.2. (a) Time series of annual 20 -yr event counts (percent of available stations in any given year) since 1901 , with an average percentage of $9.0 \%$ for 190I-80 (solid red line) and a standard deviation (sigma) of $\pm-2.2 \%$ (stippled red lines). (b) Texas/Oklahoma annual 20-yr event counts (percentages of available stations), with an average percentage of $9.0 \%$ and a sigma of $4.5 \%$. (c) Texas/Oklahoma seasonal May-Jun count of 20-yr events (percentages of available stations), with an average of $9.0 \%$ and a sigma of $6.5 \%$. (d) As in (b), but for the central United States, with an average of $8.9 \%$ and a sigma of $3.2 \%$. (e) As in (c), but for the central United States, with an average of $8.9 \%$ and sigma of $6.7 \%$. A red dot marks 2015 in all five time series, denoting a record year in (b) and (e).

year variations of global (northern hemispheric) temperatures and extreme U.S. rainfall.

b. National Scale-Seasonal Highlights. Stations recording at least one 20-yr extreme event in 2015 are highlighted by red dots for each of the six bimonthly seasons in Figs. 3.1c-h. The percentage of all reporting U.S. stations that experienced a 20 - yr event is also plotted. These fractional coverages are placed into a historical context in Fig. 3.2 and in the supplemental material. The long-term average (1901-80) coverage of such extreme rainfall events is around $9 \%$ during each season. This was far exceeded in May-June (Fig. 3.1e; 4th ranked since 1901 with $15.3 \%$ ) and November-December (Fig. 3.1h; highest ranked for any season on record with $29.0 \%$ ), discussed further in the next subsection.

The third highest coverage occurred in September-October $(13.6 \%$ in Fig. $3.1 \mathrm{~g})$, due to the aforementioned South Carolina flooding in early October, as well as yet another record-breaking wet month (October) in and around Texas, ${ }^{3}$ both analyzed further in the supplemental material. The remaining seasons January-February, March-April, and July-August (Figs. 3.1c,d, f) did not feature exceptional coverage nor any $\$ 1$ billion flooding disasters.

Because 2015 saw not only the warmest global mean temperatures since $1880,{ }^{6}$ but also El Niño conditions from March onwards ${ }^{9}$ that became extreme late in the year, we examined the linear relationships between extreme precipitation events and ENSO. Prior to our analysis, this relationship has been mainly studied for the winter season (e.g., Zhang et al. 2010; Feldl and Roe 2011; Cannon 2015). During that season, El Niño appears to increase the likelihood of the most extreme daily totals for much of the contiguous United States (Zhang et al. 2010; Cannon 2015), but with notable exceptions (see in particular Feldl and Roe 2011, for the southwestern United States). Our own analyses show weak correlations $(r<0.2)$ on a

\footnotetext{
${ }^{9}$ www.noaanews.noaa.gov/stories2015/20150305-noaa-advisory elnino-arrives.html
} 
national scale for all seasons, both with the full time series and the detrended versions.

c. Regional Scale-The Two Most Extreme Events. For the Texas/Oklahoma region (see outline in Fig. 3.1e), we document the historical 20 -yr daily extreme rainfall fractional coverage for annual and May-June data in Figs. 3.2b and 3.2c, respectively. The annual event analysis reveals 2015 to be the most extreme year on record $(33.7 \%$ of all stations reporting in this region), consistent with a significant $(r=0.31)$ upward trend for 1901-2014, as well as a modest positive correlation with the extended multivariate ENSO index (MEI; $r=0.24$ ). The May-June analysis indicates the tally of daily extremes (29.5\%) did not quite reach the record set in 1908 (35.3\%). Furthermore, the annual trend is not symptomatic of that season's negligible trend preceding neither the 2015 spring nor a noteworthy correlation with the seasonal MEI (both < 0.2). The abundance of extreme spring rain events would thus not have been anticipated from a historical perspective, though for the year as a whole more extreme rainfall events than the 1901-80 mean could have been expected.

For the central U.S. region (see outline in Fig. $3.1 \mathrm{~h}$ ), we document the historical 20 -yr daily extreme coverage for annual and November-December events, in Figs. 3.2d and e, respectively. The annual coverage for this region is high in 2015 (ranked 8th), matching a significant long-term trend that also correlates at +0.45 with the 1901-2014 global annual temperature time series, as well as a modest relationship with ENSO $(r=0.25)$. The November-December coverage registered at an astonishing $47 \%$, far above the previous record for this season in 1909. This recordsetting number of 20 -yr events was not preceded by a significant upward trend. Nor does the historical time series of extreme rainfall events exhibit a significant relationship with the MEI (both $<0.2$ ). Thus, one could again view this event as a "climate surprise" not obviously related to the two most important climate drivers examined here.

Discussion and Conclusions. In answer to our introduction's first question, 2015 experienced a high frequency of extreme daily rainfall events over the contiguous United States, consistent with a well-known national upward trend (e.g., Fischer and Knutti 2014; Hoerling et al. 2016), ending up in the top 5 of all years since 1901. This elevated number of occurrences in 2015 appears unusual only when viewed in the context of a stationary climate.
However, it was not that unusual if one considers the upward trend that relates strongly to global mean temperatures, and the fact that 9 out of the top 10 years of most extensive extreme daily rainfall event coverage occurred since 1990. Not only is the longterm trend of such events upwards, the spatial pattern of 2015 extremes is congruent with trend maps for 1901-2014 ( $c=0.56$; Supplemental Fig. S3.1). Though no formal attribution was done, an interpretation that climate change forcing is likely a major contributor to the upward trend in U.S. extreme daily rainfall events, and thus likely also contributed to its high count in 2015 , is consistent with the body of literature cited in the introduction. That relation also appears more compelling as a causal effect for the outcome in 2015 than the occurrence of a strong El Niño event.

In answer to the introduction's second question, neither of the two most remarkable extreme events that occurred in May and December over Texas/Oklahoma and the central United States, respectively (each linked to $\$ 1$ billion disasters), were foreshadowed by any obvious seasonal upward trend in extreme daily rainfall. While both the greater Texas and central U.S. regions have upward trends in the annual tallies of 20-yr daily rainfall extremes, those events have tended to occur in other seasons. The least anticipated event, from a perspective of the region's climate time series of extreme rainfall might very well have been the October South Carolina flood that came about despite no prior seasonal or annual trends (Supplemental Fig. S3.2).

ACKNOWLEDGEMENTS. Two anonymous reviews helped to improve our manuscript. This work was supported by the NASA MAP program under the funded MAP12-0072 project.

\section{REFERENCES}

Cannon, A. J., 2015: Revisiting the nonlinear relationship between ENSO and winter extreme station precipitation in North America. Int. J. Climatol., 35, 4001-4014, doi:10.1002/joc.4263.

Cavanaugh, N. R., A. Gershunov, A. K. Panorska, and T. J. Kozubowski, 2015: The probability distribution of intense daily precipitation. Geophys. Res. Lett., 42, 1560-1567, doi:10.1002/2015GL063238.

Cheng, L., A. AghaKouchak, E. Gilleland, and R. W. Katz, 2014: Non-stationary extreme value analysis in a changing climate. Climatic Change, 127, 353-369, doi:10.1007/s10584-014-1254-5. 
Coles, S., 2001: An Introduction to Statistical Modeling of Extreme Values. Springer, 208 pp.

Cubasch, U., J. Waszkewitz, G. Hegerl, and J. Perlwitz, 1995: Regional climate changes as simulated in timeslice experiments. Climatic Change, 31, 273-304, doi:10.1007/BF01095150.

Feldl, N., and G. H. Roe, 2011: Climate variability and the shape of daily precipitation: A case study of ENSO and the American West. J. Climate, 24, $2483-$ 2499, doi:10.1175/2010JCLI3555.1.

Ferreira, A., and L. de Haan, 2015: On the block maxima method in extreme value theory: PWM estimators. Ann. Stat., 43, 276-298, doi:10.1214/14 -AOS1280.

Fischer, E. M., and R. Knutti, 2014: Detection of spatially aggregated changes in temperature and precipitation extremes. Geophys. Res. Lett., 41, 547554, doi:10.1002/2013GL058499.

Gregory, J. M., and J. F. B. Mitchell, 1995: Simulation of daily variability of surface temperature and precipitation over Europe in the current and $23 \mathrm{CO} 2$ climates using the UKMO climate model. Quart. J. Roy. Meteor. Soc., 121, 1451-1476, doi:10.1002 /qj.49712152611.

Groisman, P. Ya., R. Knight, T. Karl, D. Easterling, B. Sun, and J. Lawrimore, 2004: Contemporary changes of the hydrologic cycle over the contiguous United States: Trends derived from in situ observations. J. Hydrometeor., 5, 64-85.

,-- , D. Easterling, T. Karl, G. C. Hegerl, and V. N. Razuvaev, 2005: Trend in intense precipitation in the climate record. J. Climate, 18, 1326-1350.

Hoerling, M., J. Eischeid, J. Perlwitz, X. Quan, and K. Wolter, 2016: Characterizing recent trends in U.S. heavy precipitation. J. Climate, 29, 2313-2332, doi:10.1175/JCLI-D-15-0441.1.

IPCC, 2013: Summary for policymakers. Climate Change 2013: The Physical Science Basis, T. F. Stocker et al., Eds., Cambridge University Press, 1-29.

Karl, T. R., W. J. Koss, and N. Plummer, 1995: Trends in high-frequency climate variability in the twentieth century. Nature, 377, 217-220, doi:10.1038/377217a0.

Kharin, V. V., and F. W. Zwiers, 2005: Estimating extremes in transient climate change simulations. $J$. Climate, 18, 1156-1168.

Kunkel, K. E., D. R. Easterling, D. A. R. Kristovich, B. Gleason, L. Stoecker, and R. Smith, 2012: Meteorological causes of the secular variations in observed extreme precipitation events for the conterminous United States. J. Hydrometeor., 13, 1131-1141, doi:10.1175/ JHM-D-11-0108.1.
_- and Coauthors, 2013: Monitoring and understanding trends in extreme storms: State of knowledge. Bull. Amer. Meteor. Soc., 94, 499-514, doi:10.1175/BAMS-D-11-00262.1.

Mearns, L. O., F. Giorgi, L. McDaniel, and C. Shields, 1995: Analysis of daily variability of precipitation in a nested regional climate model: Comparison with observations and doubled $\mathrm{CO} 2$ results. Global Planet. Change, 10, 55-78, doi:10.1016/09218181(94)00020-E.

Menne, M. J., I. Durre, R. S. Vose, B. E. Gleason, and T. G. Houston, 2012: An overview of the Global Historical Climatology Network-Daily Database. J. Atmos. Oceanic Tech., 29, 897-910, doi:10.1175 /JTECH-D-11-00103.1.

Noda, A., and T. Tokioka, 1989: The effect of doubling the $\mathrm{CO} 2$ concentration on convective and non-convective precipitation in a general circulation model coupled with a simple mixed layer ocean model. J. Meteor. Soc. Japan, 67, 1057-1069.

Sillmann, J., V. V. Kharin, X. Zhang, F. W. Zwiers, and D. Bronaugh, 2013: Climate extreme indices in the CMIP5 multimodel ensemble: Part 1. Model evaluation in the present climate. J. Geophys. Res. Atmos., 118, 1716-1733, doi:10.1002/jgrd.50203.

Wang, S.-Y., W.-R. Huang, H.-H. Hsu, and R.R. Gillies, 2015: Role of strengthened El Niño teleconnection in the May 2015 floods over the southern Great Plains. Geophys. Res. Lett., 42, 8140-8146, doi:10.1002/2015GL065211.

Wolter, K., and M. S. Timlin, 2011: El Niño/Southern Oscillation behaviour since 1871 as diagnosed in an extended multivariate ENSO index (MEI.ext). Int. J. Climatology, 31, 1074-1087, doi:10.1002/joc.2336.

Zhang, X., J. Wang, F. W. Zwiers, and P. Ya. Groisman, 2010: The influence of large-scale climate variability on winter maximum daily precipitation over North America. J. Climate, 23, 2903-2915, doi:10.1175/2010JCLI3249.1. 


\title{
4. AN ASSESSMENT OF THE ROLE OF ANTHROPOGENIC CLIMATE CHANGE IN THE ALASKA FIRE SEASON OF 2015
}

\author{
James L. Partain Jr., Sharon Alden, Uma S. Bhatt, Peter A. Bieniek, Brian R. Brettschneider, \\ Rick T. Lader, Peter Q. Olsson, T. Scott Rupp, Heidi Strader, Richard L. Thoman JR., \\ John E. Walsh, Alison D. York, and Robert H. Ziel
}

The 2015 Alaska fire season burned the second largest number of acres since records began in 1940 . Human-induced climate change may have increased the risk of a fire season of this severity by $34 \%-60 \%$.

Introduction. The 2015 Alaska fire season burned 5.1 million acres, the second largest burned area since 1940, exceeded only by the 2004 Alaska fire season when 6.2 million acres burned (Fig. 4.1a). Despite a below normal end-of-winter snowpack and an unseasonably warm spring with earlier snowmelt, which dried fuels early in the season, scattered showers and cool temperatures kept 2015 fire activity near normal through early June. During the first half of June, several days of maximum temperatures exceeded $30^{\circ} \mathrm{C}$, relative humidity $(\mathrm{RH})$ values were in the teens, and long daylight hours quickly dried surface and subsurface (duff) forest-floor fuels.

Beginning June 19, a period of vigorous thunderstorm activity resulted in an unprecedented weeklong

AFFILIATIONS: PARTAIN- NOAA/National Centers for Environmental Information, Anchorage, Alaska; ALDEN AND STRADER-Alaska Interagency Coordination Center and Alaska Fire Service, Fort Wainwright, Alaska; BHATT—Department of Atmospheric Sciences, College of Natural Science and Mathematics, University of Alaska-Fairbanks (UAF), and UAF/ Geophysical Institute, and NOAA/Cooperative Institute for Alaska Research, Fairbanks, Alaska; BIENIEK, BRETTSCHNEIDER, AND WALSHUAF/International Arctic Research Center (IARC), Fairbanks, Alaska; LADER - UAF/Department of Atmospheric Sciences, UAF/ Geophysical Institute, and IARC, Fairbanks, Alaska; OLssonAlaska State Climate Center, University of Alaska-Anchorage, Anchorage, Alaska; RUpp-IARC, and UAF/Scenarios Network for Alaska and Arctic Planning, Fairbanks, Alaska, and Alaska Climate Science Center, Anchorage, Alaska; THOMAN-NOAA/National Weather Service, Alaska Region, Anchorage, Alaska; YoRKAlaska Fire Science Consortium, IARC, and UAF, Fairbanks, Alaska; ZIEL-Alaska Interagency Coordination Center, Alaska Department of Natural Resources-Division of Forestry, and UAF/ Alaska Fire Science Consortium, Fairbanks, Alaska

DOI:10.II75/BAMS-D-16-0149.I

A supplement to this article is available online (I0.II75 /BAMS-D-16-0149.2) lightning event with 36000 strikes in three days. During this period, 65000+ strikes in Alaska gave rise to nearly 270 ignitions of the preconditioned fuels. Burned acreage increased by 3.8 million acres (Fig. 4.1b) in the two and a half weeks following those starts (Fig. 4.1c). Lightning ignitions caused $99.5 \%$ of the acreage burned in Alaska in 2015. A westerly shift in upper-level winds by mid-July brought cool and damp weather that curtailed fire growth, and most extant fires burned little acreage after July 15 .

This pattern highlights a significant difference between Alaska's top two fire seasons: 2004 burned significant acreage in July and again in August during extended warm and dry late summer weather, while 2015 saw the bulk of fire activity concentrated from mid-June to mid-July. These different pathways to large fire seasons demonstrate the importance of intraseasonal weather variability and the timing of dynamical features. Yet, underlying each case are the common requirements of: heat, extremely dry fuels, and ignition. One question that arises is whether the extremely warm and dry, yet convective, conditions of 2015 might be driven by anthropogenic climate change. This attribution study is a model-based test of the hypothesis that anthropogenic climate change increases the likelihood of fire seasons as extreme as 2015 through increasing flammability of fuels.

Measuring Fire Risk through the Buildup Index. This assessment uses the Buildup Index (BUI; Lawson and Armitage 2008), which is part of the Canadian Forest Fire Danger Rating System's Fire Weather Index system and represents potential fuel availability and flammability, based on cumulative scoring of daily temperature, relative humidity, and precipitation. 
(a)

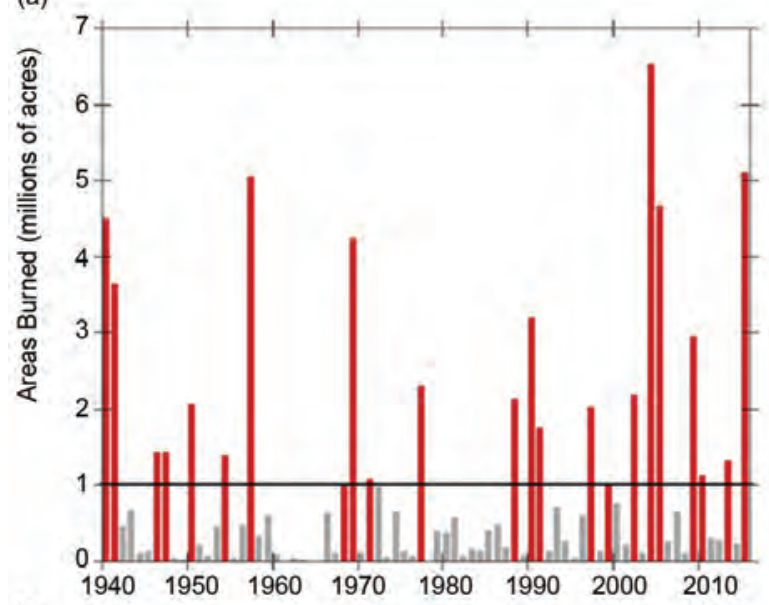

(b)

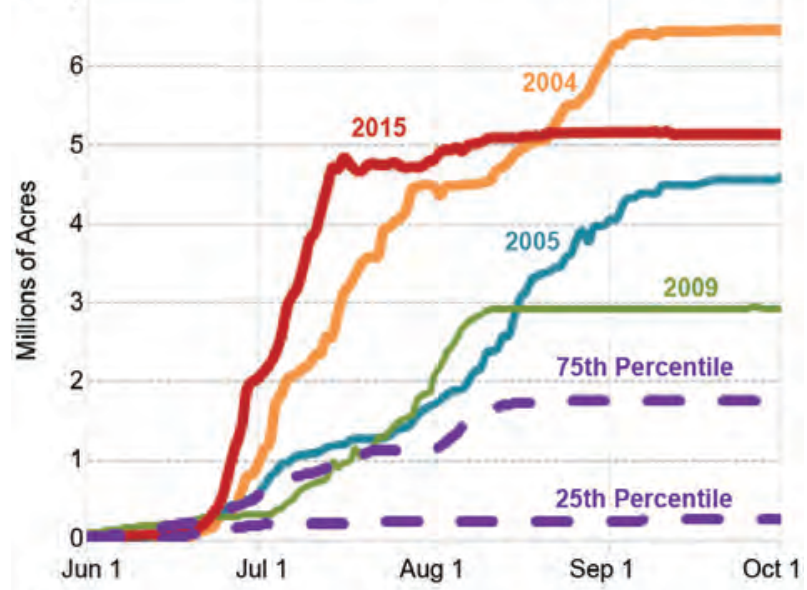

(c)

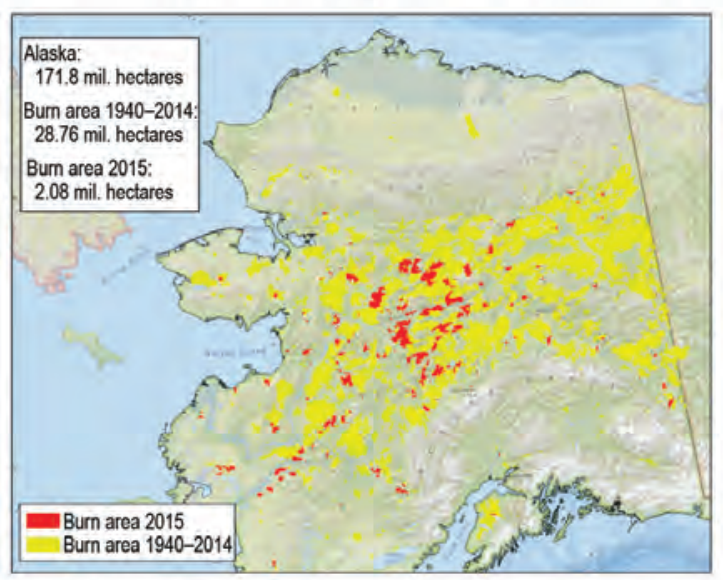

FIG. 4.I. (a) Annual time series of acres burned in Alaska and (b) averaged daily cumulative acres burned for specific high-fire years compared to the climatological 25th and 75th percentile (1994-2015) levels. The other above-75th percentile years of 1997 and 2002 are not shown for clarity because they lie close to the 75th percentile. (c) Displays fire perimeters for 2015 (red) and for the historical period of 1940-2014 (yellow). The area burned in 2015 is $7 \%$ of that which burned in the previous 75 years.
High BUI values generally represent periods of high fire danger (Ziel et al. 2015). BUI is often derived from meteorological station observations; however, gridded downscaled data (i.e., Bieniek et al. 2016) are used here because observations in Alaska are temporally and spatially spotty.

BUI is well suited for describing most fire seasons in northern boreal regions so is widely used by managers in Canada and Alaska. BUI begins to increase after the snowmelt, reaches its peak in June-July, and declines thereafter. Figure 4.2a displays BUI trends (April-September) for the Alaska boreal forest region ( $<600$ m elevation) from 1979-2015. The BUI values represent the number of days (averaged over forest grids) that BUI exceeded 60, which marks the threshold for high fire danger in Alaska (Ziel et al. 2015). As an integrated metric, BUI effectively captures seasonal fire danger in Alaska, as per the large areas burned in 2004, 2015, and 2005. The exception is 2013, which, despite an extremely high BUI, had low fire activity because of few lightning strikes, highlighting ignitions as a necessary prerequisite for fires.

Modeling Wildfire Probability in Alaska. The attribution assessment was based on dynamical downscaling over the Alaska region by a regional model, the Advanced Research (ARW) version of the Weather Research and Forecasting (WRF) Model (Skamarock et al. 2008). An optimized configuration of the WRF model physical parameterizations for Alaska (Zhang et al. 2013) was employed. The downscaling covered a $262 x$ 262 grid-point domain that encompassed all of Alaska and portions of eastern Russia and northern Canada at $20 \mathrm{~km}$ spatial resolution with 49 vertical model levels. The European Centre for Medium-Range Weather Forecasts (ECMWF) interim reanalysis (ERA-Interim) data was downscaled for the 19792015 historical period (Bieniek et al. 2016), and a 60year downscaling of the Geophysical Fluid Dynamics Laboratory Climate Model, version 3 (GFDL CM3) was completed to address the present climate and counterfactual (preindustrial) climate. Specifically, the GFDL CM3 was downscaled using WRF for a 60-year period (1986-2045) centered on 2015 based on historical (1986-2005) and RCP8.5 (2006-2045) simulations from CMIP5.

A 60-year subperiod (1986-2045) of a GFDL CM3 prescribed constant $\mathrm{CO}_{2}(280 \mathrm{ppm})$ and aerosol concentrations (Donner et al. 2011) simulation represented the counterfactual or preindustrial world without anthropogenic climate change. Monthly difference fields between the two 60 -year means 
(a)

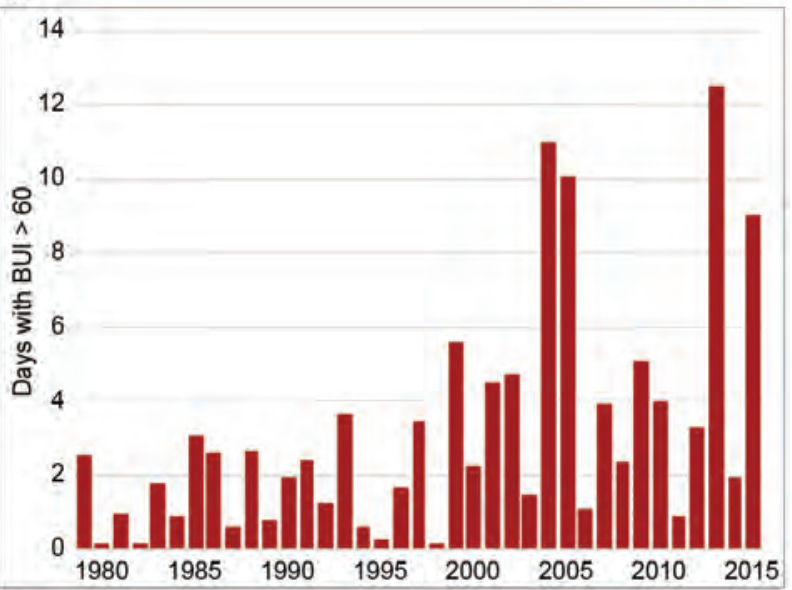

(b)

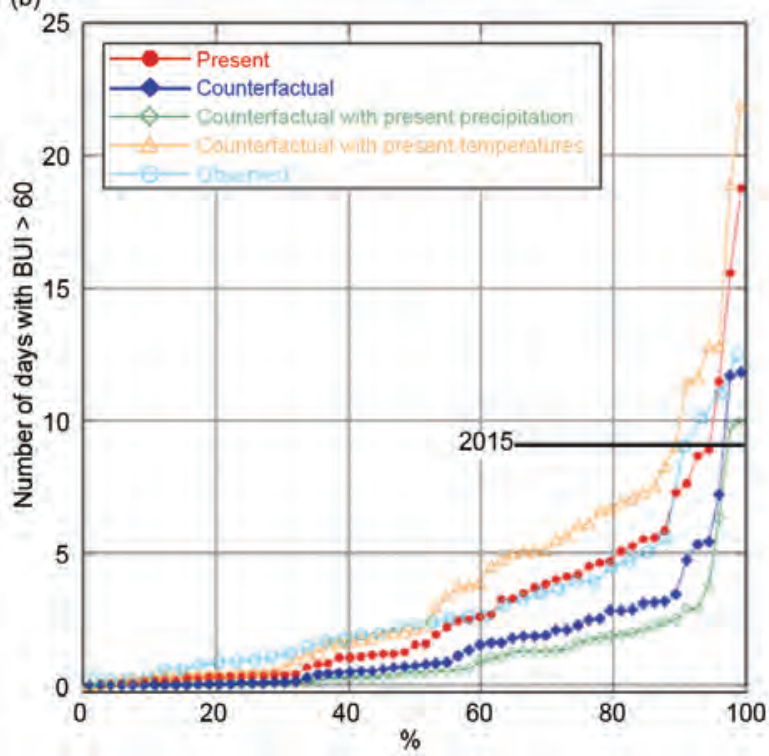

Fig. 4.2. (a) Number of days when the BUI index exceeds 60 when computed from the ERA-driven dynamical downscaling over the boreal forest region of Alaska and (b) cumulative frequency distribution of the number of days that BUI exceeds 60 when computed from the 1986-2045 GFDL-driven dynamical downscaling (red), the preindustrial (counterfactual) (blue), the 1986-2045 GFDL-driven downscaling in which only precipitation differs from the preindustrial (green), the 1986-2045 GFDL-driven downscaling in which only temperature differs from the preindustrial (orange), and observations based on the downscaled ERA-Interim reanalysis (cyan). The number of days of BUI greater than 60 for the 2015 fire season is marked on the plot with the horizontal black line and corresponds to approximately the 95th percentile of the model's present-day (present) distribution.

(present-day minus preindustrial) show that the spring-summer climate of Alaska has warmed (by $\left.1^{\circ}-3^{\circ} \mathrm{C}\right)$ and become wetter $\left(2-10 \mathrm{~mm} \mathrm{mo}^{-1}\right.$ additional precipitation in May-July, with the largest increase in June, not shown). In nature, Alaska temperatures display a statewide warming of about $1^{\circ} \mathrm{C}$ in the annual mean and about $1.5^{\circ} \mathrm{C}$ in May-July since 1920 ; precipitation trends over the same period are mixed (Bieniek et al. 2014; see also NOAA's Climate at a Glance, www.ncdc.noaa.gov/cag). Possible reasons for differences in modeled-versus-observed trends in precipitation are discussed in the online supplemental material.

The model-derived differences were used to compute two 60-year time series of the BUI averaged over the Alaska boreal region from 1986-2045: one that included the influence of anthropogenic climate change [based on the original downscaled WRF output (i.e., using anthropogenic forcing)] and the other for the preindustrial control [based on the original downscaled WRF output adjusted by the differences between the GFDL monthly means for the two 60 year periods (i.e., not using anthropogenic forcing)]. The precipitation adjustment factors were the ratios of the two 60-year means to avoid negative values.

The GFDL-derived time series of BUI captures the observed (ERA-Interim) annual variability in BUI shown in Fig. 4.2a (comparison of observed BUI with GFDL BUI values not shown); however, the downscaled GFDL precipitation amounts are generally higher than the downscaled ERA-Interim for 1986-2015. Consequently, the downscaled GFDL BUI values were smaller than those obtained from downscaled ERA-Interim values. Therefore, all GFDL-derived BUI values were multiplied by 2.4 , the ratio of the mean ERA-derived BUI for 1986-2015 to the corresponding GFDL-derived mean. This adjustment does not affect the percentile ranks that form the basis of our attribution assessment below.

Results. The anthropogenic contribution to the likelihood of a fire season of 2015's severity based on BUI was assessed using the fraction of attributable risk metric (Stott et al. 2004; National Academies 2016). Figure $4.2 \mathrm{~b}$ shows the cumulative frequency distributions of the April-September integrated BUI values for observed and modeled scenarios. The 2015 observed value of nine days with BUI $>60$, indicated by the black horizontal bar, was exceeded by 3 of 60 values $\left(P_{1}=3 / 60=0.05\right)$ in the GFDLsimulated present climate (red) and by 2 of 60 values in the GFDL-simulated preindustrial (counterfactual) (dark blue) $\left(\mathrm{P}_{\mathrm{o}}=2 / 60=0.033\right)$, yielding a fraction of attributable risk to climate change of FAR $=1$ $0.033 / 0.050=0.34$. Noting that two additional points 
on the GFDL present-climate curve (red) are nearly identical to the 2015 observed value, an alternative estimate of FAR based on the number of years in which the 2015 value was essentially matched or exceeded (five) is FAR $=1-0.033 / 0.083=0.60$. With the caveat that it is based on one ensemble member from one climate model, we conclude from this experiment that climate change has increased the risk of a fire year as severe as 2015 by $34 \%-60 \%$.

Several sources of uncertainty are inherent in these estimates of increased risk of a severe fire season in Alaska. First, the sample size of events is small, as the number of fire years more severe than 2015 is 2 and 3 (for a total of 5) in the modeled preindustrial and the modeled present, respectively. Nevertheless, although there may be such uncertainty in the exceedance of the 2015 threshold, the results clearly indicate that the present climate (red line in Fig. 4.2b) has increased the risk of days with BUI $>60$ relative to the preindustrial (dark blue line). Second, the results are based on only one model, GFDL CM3 (downscaled using WRF). While the GFDL model is one of the betterperforming global models for Alaska (www.snap.uaf .edu/methods/models), simulated changes of temperature and precipitation since the preindustrial period vary among models. Third, our evaluation focused on an index (the BUI) of climate-driven potential for summer wildfire, not on the shorter-term weather variables of wind, humidity, and temperature that affect the rate of wildfire growth.

Sensitivity tests (orange and green lines) shown in Fig. 4.2b highlight the competing effects of temperature and precipitation as climate changes. If precipitation does not change within the model, the postindustrial warming increases the severity of the fire years in the upper half of the distribution (orange line). An increase of precipitation, in the absence of any temperature change, decreases the severity of the uppermost half of the distribution (green line). The impact of increased temperatures outweighs the impact of increased precipitation in the change from the preindustrial. For the future, annual average temperatures in Alaska are projected to increase by $1^{\circ} \mathrm{C}$ to $2^{\circ} \mathrm{C}$ above present values by 2050 , while precipitation is projected to increase by $15 \%-30 \%$ by the end of the century (Chapin et al. 2014).

Conclusion. The 2015 fire season in Alaska was remarkable for its early-season total acres burned, which resulted from 1) fuel flammability due to the warm and dry conditions of May and June, and 2) lightning-induced ignitions in June. The rains of mid-summer likely prevented a new record for area burned in Alaska in 2015. An attribution analysis indicates that 2015's fuel conditions reached a level that is $34 \%-60 \%$ more likely to occur in today's anthropogenically changed climate than in the past. The major uncertainty in such an attribution assessment is the as-yet unknown relationship between climate change and the major lightning events that ignite widespread fires.

This study's conclusion is consistent with the similar finding by Yoon et al. (2015) for wildfires in California, where an increased wildfire risk relative to the preindustrial climate emerged in the 1990s. Similar model-derived results were found for the western United States (Luo et al. 2013; Yue et al. 2013), Canada (Flannigan et al. 2015), and Alaska (Young et al. 2016).

ACKNOWLEDGEMENTS. This work was supported by the Alaska Climate Science Center through a Cooperative Agreement G10AC00588 from the USGS and by NOAA's Climate Program Office's Modeling, Analysis, Predictions, and Projections Program, NA16OAR4310142.

\section{REFERENCES}

Bieniek, P. A., J. W. Walsh, R. L. Thoman, and U. S. Bhatt, 2014: Using climate divisions to analyze variations and trends in Alaska temperature and precipitation. J. Climate, 27, 2800-2818, doi:10.1175 /JCLI-D-13-00342.1.

—, U. S. Bhatt, J. E. Walsh, T. S. Rupp. J. Zhang, J. Krieger, and R. Lader, 2016: Dynamical downscaling of ERA-Interim temperature and precipitation for Alaska. J. Appl. Meteor. Climatol., 55, 635-654, doi:10.1175/JAMC-D-15-0153.1.

Chapin, F. S., III, S. F. Trainor, P. Cochran, H. Huntington, C. Markon, M. McCammon, A. D. McGuire, and M. Serreze, 2014: Alaska. Climate Change Impacts in the United States: The Third National Climate Assessment, J. M. Melillo et al., Eds., 514-536, doi:10.7930/J00Z7150.

Donner, L. J., and Coauthors, 2011: The dynamical core, physical parameterizations, and basic simulation characteristics of the atmospheric component AM3 of the GFDL global coupled mdel CM3. J. Climate, 24, 3484-3519, doi:10.1175/2011JCLI3955.1. 
Flannigan, M. D., B. M. Wotton, G. A. Marshall, W. J. de Groot, J. Johnston, N. Jurko, and A. S. Cantin, 2015: Fuel moisture sensitivity to temperature and precipitation: Climatic change implications. Climatic Change, 134, 59-71, doi:10.1007/s10584 -015-1521-0.

Lawson, B. D., and O. B. Armitage, 2008: Weather guide for the Canadian forest fire danger rating system. Canadian Forest Service, 73 pp. [Available online at http://fire.ak.blm.gov/content/weather /2008\%20CFFDRS\%20Weather\%20Guide.pdf.]

Luo, L. F., Y. Tang, S.-Y. Zhong, X. D. Bian, and W. E. Heilman, 2013: Will future climate favor more erratic wildfires in the western United States? J. Appl. Meteor. Climatol., 52, 2410-2417, doi:10.1175 /JAMC-D-12-0317.1.

National Academies, 2016: Attribution of Extreme Weather Events in the Context of Climate Change. National Academies Press, 186 pp., doi:10.17226/21852.

Skamarock, W. C., and Coauthors, 2008: A description of the Advanced Research WRF version 3. NCAR Tech Note, NCAR/TN-475+STR, 113 pp. [Available online at www2.mmm.ucar.edu/wrf/users/docs /arw_v3.pdf.]

Stott, P., D. A. Stone, and M. R. Allen, 2004: Human contribution to the European heatwave of 2003. Nature, 432, 610-614, doi:10.1038/nature03089.

Yoon, J. H., S.-Y.S. Wang, R. R. Gillies, L. Hipps, B. Kravitz, and P. J. Rasch, 2015: Extreme fire season severity in California: A glimpse into the future? [in "Explaining Extremes of 2014 from a Climate Perspective"]. Bull. Amer. Meteor. Soc., 96 (12), S5S9, doi:10.1175/BAMS-D-15-00114.1.

Young, A. M., P. E. Higuera, P. A. Duffy, and F. S. Hu, 2016: Climate thresholds shape northern high latitude fire regimes and imply vulnerability to future climate change. Ecogeography, in press doi:10.1111 lecog.02205.

Yue, X., L. J. Mickley, J. A. Logan, and J. O. Kaplan, 2013: Ensemble projections of wildfire activity and carbonaceous aerosol concentrations over the western United States in the mid-21 st century. Atmos. Environ., 77, 767-780, doi:10.1016/j .atmosenv.2013.06.003.

Zhang, X., and Coauthors, 2013: Beaufort and Chukchi Seas Mesoscale Meteorology Modeling Study, final project report. Bureau of Ocean Energy Management Tech. Rep. BOEM 2013-0119, 204 pp. [Available online at www.boem.gov/BOEM-2013-0119/.]
Ziel, R. H., and Coauthors; 2015: Modeling fire growth potential by emphasizing significant growth events: characterizing climatology of fire growth days in Alaska's boreal forest. 11th Symp. on Fire and Forest Meteorology, Minneapolis MN, Amer. Meteor. Soc., 1.2. [Available online at https://ams.confex.com /ams/11FIRE/webprogram/Paper272864.html.] 


\title{
5. THE 20I4/I5 SNOWPACK DROUGHT IN WASHINGTON STATE AND ITS CLIMATE FORCING
}

\author{
Boniface O. Fosu, S.-Y. Simon Wang, and Jin-Ho Yoon
}
The 20/4/I5 snowpack drought resulted from exceedingly high temperatures notwithstanding normal precipitation-a drought type that may reoccur due to accelerated anthropogenic warming and aggravated by naturally driven low precipitation.

Introduction. The state of Washington declared a drought emergency in May 2015 following a drastic decline in snowpack over the adjoining Cascades (Fig. 5.1a). Unlike past droughts that were mainly caused by precipitation deficits (e.g., the 2005 drought; Anderson et al. 2006), the 2014/15 cold season (November-March) produced near-normal precipitation statewide (Fig. 5.1b). In what has since been nicknamed the "snowpack drought" of 2015 (www.ecy.wa.gov/drought/), the drought was more a result of unprecedented warmth (Fig. 5.1c) that caused cold-season precipitation to fall as rain rather than snow on the mountains. A small change in temperature can alter the water balance by reducing the precipitation falling as snow, which results in declined snow water equivalent and summer streamflow (Mote 2006; Stewart et al. 2004). This 2014/15 situation thereby sets an example for the known effect of atmospheric warming on reducing mountain snowpack in the Pacific Northwest (PNW), a known risk that has been reported by a sizable body of research (e.g., Stoelinga et al. 2010; Mote et al. 2014; Abatzoglou et al. 2014).

Reduction in the PNW snowpack also increases the risk of wildfires, the latter of which is evidenced by the remarkable 2015 wildfire season, the largest in the state's history. A Washington Department of Agriculture report (http://agr.wa.gov/FP/Pubs /docs/104-495InterimDroughtReport2015.pdf) estimates the 2015 drought alone has caused more

\footnotetext{
AFFILIATIONS: FosU-Department of Plants, Soils, and Climate, Utah State University, Logan, Utah; WANG-Utah Climate Center and Department of Plants, Soils, and Climate, Utah State University, Logan, Utah; Yoon-School of Earth Sciences and Environmental Engineering, Gwangju Institute of Science and Technology, Gwangju, South Korea
}

DOI:I0.II75/BAMS-D-16-0I54.I

A supplement to this article is available online (I0.II75 /BAMS-D-I6-0154.2) than \$335 million (U.S. dollars) of loss for the state's agricultural industry. In this study, we investigate the role natural climate variability played in the 2015 Washington state drought and situate it in the context of anthropogenic climate change.

Data and Model Sources. The observed mean surface air temperatures and precipitation were obtained from monthly records of PRISM's high-resolution spatial climate data (https://climatedataguide.ucar .edu). For the analysis of northern Pacific climate variability, NOAA's extended reconstructed sea surface temperature (SST) v4 was used (Huang et al. 2015). Circulation patterns were based on streamfunction $(\Psi)$ derived from the NCEP-NCAR global wind reanalysis (Kalnay et al. 1996). NCEP's daily two-meter $\left(\mathrm{T}_{2 \mathrm{~m}}\right)$ air temperature dataset (Kristler et al. 2001) and CPC's unified gauge-based analysis of daily precipitation were used for the estimation of snow-precipitation ratio $(\mathrm{S} / \mathrm{P})$ and snow frequency (SF); the latter was also used to characterize dry spells following Gillies et al. (2012). Precipitation was fully classified as snow at $\mathrm{T}_{2 \mathrm{~m}} \leq 0^{\circ} \mathrm{C}$. Because the majority of Washington's snowpack is stored in the Cascades, we focused on the cold season of November-March over the mountain ranges outlined in Fig. 5.1a (i.e., all time series were area-averaged from the domain referred to as the Cascades).

Historical and future simulations with the Community Earth System Model version 1 (CESM1) (Hurrell et al. 2013) were analyzed to examine external climate forcing to drought variability in the region and to project possible long-term changes. Thirty ensemble members produced by CESM1 with a spatial resolution of $0.9^{\circ}$ longitude $\times$ $1.25^{\circ}$ latitude through the Large Ensemble Project (Kay et al. 2015) were used. The simulations cover two periods: 1) 1920-2005 with historical forcing, including greenhouse gases, aerosols, ozone, land-use 


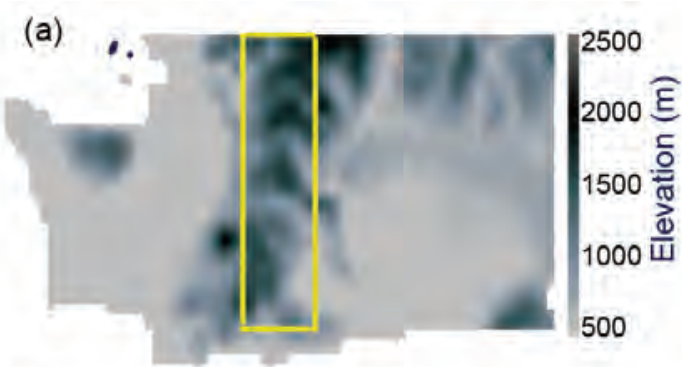

(b)

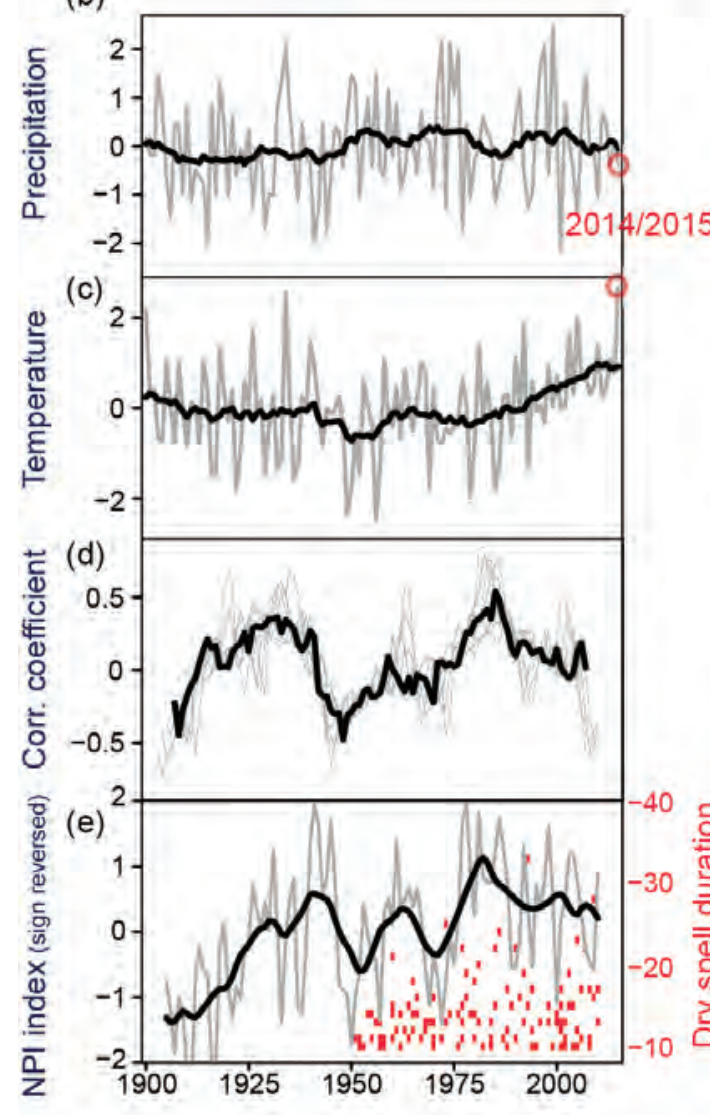

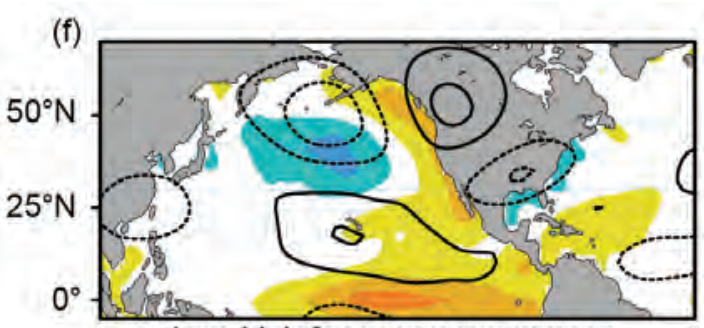
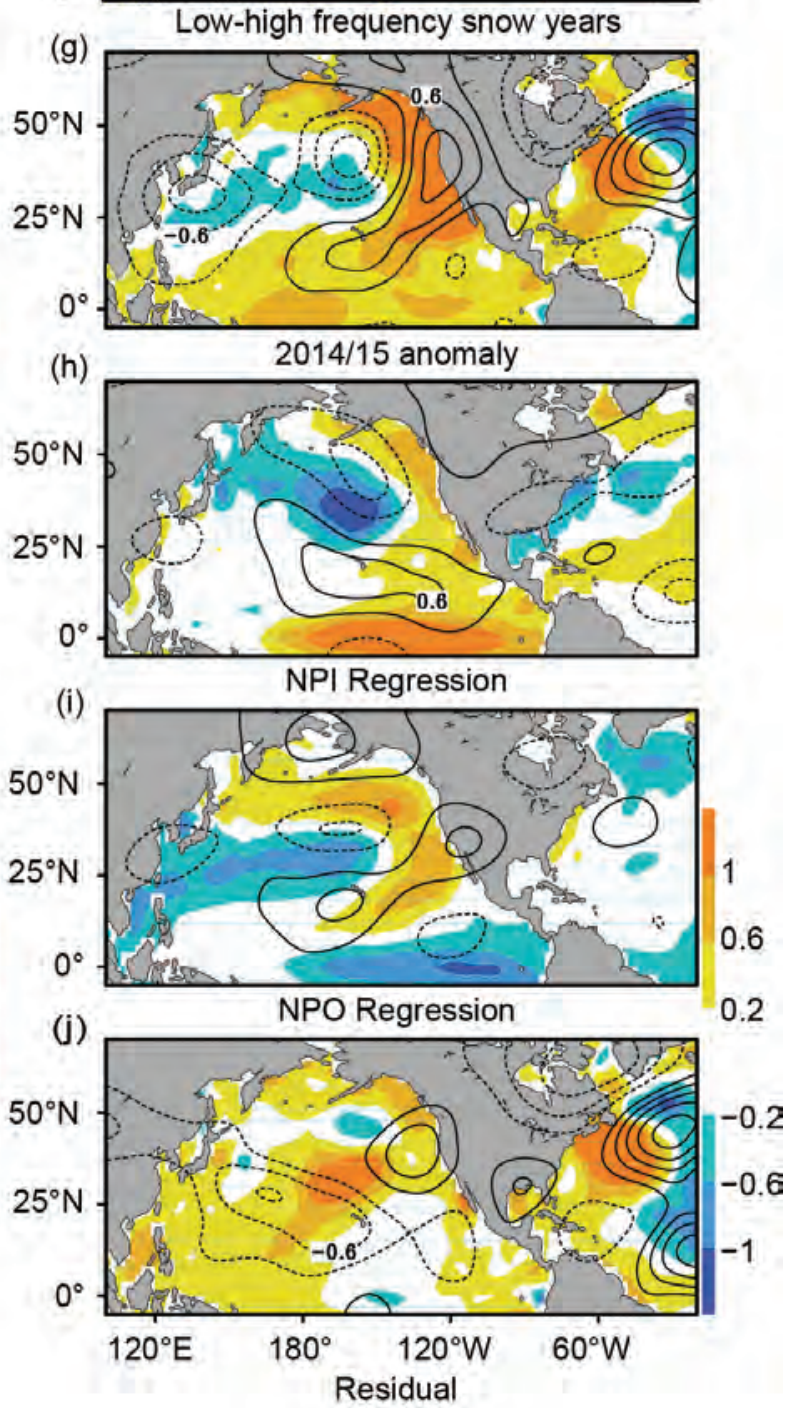

Fig. 5.I. (a) Topographical map of Washington; the yellow box delineates the study domain. (b),(c) Domain averaged time series of normalized cold season precipitation and temperature, both in gray, and their respective I5-year low-pass curves in black. (d) I5-year sliding correlation between $P$ and $T$, in black. The gray lines show the sliding correlation curves for different windows ranging from 7 to 21 years in 2-year increments. Years on the $x$ axis represent the central year of the sliding window. (e) 15-year running mean (black) of the NP index (gray), constructed from the area-weighted sea level pressure over the region $30^{\circ}-65^{\circ} \mathrm{N}, 160^{\circ} \mathrm{E}-140^{\circ} \mathrm{W}$. The NPI sign has been flipped so that positive refers to a deepening of the Aleutian low, which also will correspond to positive PDO phase. The red dots are intense dry spells and their duration (days). (f) Composite differences in cold season circulation ( $250 \mathrm{mb} \Psi$ in contours, interval: $0.310^{6} \mathrm{~m}^{2} \mathrm{~s}^{-1}$ ) and SST (shading) between 31 low and 31 high snow frequency years selected between 1950 and 20l4. (g) The observed SST and $250 \mathrm{mb}$ streamfunction anomalies for 2014/15 cold season. (h) A linearly regressed reconstruction of SST and $250 \mathrm{mb}$ streamfunction anomalies related to the NPI, from the $1949 / 50$ cold season to $2013 / 14$, weighed against the strength of the NPI in the 2014/15 season NPI. (i) Same as (h) but for the NPO. (j) Difference between (g) and (h),(i) (i.e., the leftover not linearly explained by the NPI). 
change, solar, and volcanic activity, and 2) 2006-80 with RCP8.5 forcing that represents a high-emission pathway (Taylor et al. 2012). The ensemble spread of initial conditions is generated by the commonly used "round-off differences" method (Kay et al. 2014).

Result and Discussion. To examine the unique combination of high temperatures $(\mathrm{T})$ and nearnormal precipitation (P) experienced in 2014/15, we computed the correlation between observed $\mathrm{P}$ and $\mathrm{T}$ over the Cascades. The simultaneous correlation between $\mathrm{P}$ and $\mathrm{T}$ in the past century has been weak $(r<0.1)$; however, the coherency between $\mathrm{P}$ and $\mathrm{T}$ appears to fluctuate over time. Figure $5.1 \mathrm{~d}$ shows the sliding correlation (SCORR) between $\mathrm{P}$ and $\mathrm{T}$ within various windows ranging from 7 to 21 years, revealing a cyclical pattern in the coherency of $\mathrm{P}$ with $\mathrm{T}$ on interdecadal timescales. The correlation between $\mathrm{P}$ and $\mathrm{T}$ was mostly positive during the first third of the century, after which negative correlations prevailed until the late 1970s, then the correlation pattern reversed back to positive. Even though the correlation coefficients are only marginally significant at the peaks and troughs (for the 15-year window the significant SCORR at the 95\% interval is .48), the SCORR pattern bears a visual similarity to the low frequency variations within the North Pacific, expressed in Fig. 5.1e by the North Pacific index (NPI; Fig. 5.1e). Calculated from the area-weighted sea level pressure over the region $30^{\circ}-65^{\circ} \mathrm{N}, 160^{\circ} \mathrm{E}-140^{\circ} \mathrm{W}$, the NPI measures the intensity changes of the Aleutian low, which affects cyclone frequency and passages over the PNW (Trenberth and Hurrell 1994). The SCORR pattern mimics the timing of major shifts in the sign of the NPI; a negative regime from 1947-76, with positives dominating from 1925-46 and from 1977 through the present. Since the NPI and the Pacific decadal oscillation (PDO) are significantly correlated, the PDO has a similar interdecadal coherence with $\mathrm{P}$ and $\mathrm{T}$ (not shown). Here, we focus on the NPI because the PDO is deemed an oceanic response to integrated atmospheric forcing (Newman et al. 2016) and, strictly speaking, should not be directly regarded as a climate driver of the PNW. In Supplemental Table S5.1, we list an array of climate indices and their correlation coefficient with the P-T SCORR using the 15-year window, and both the NPI and PDO stand out as being significant at $p<0.01$.

Next, the weather processes that encompass the NPI regimes and dry spells in the Cascades are examined. An extreme dry spell was defined as a prolonged period of at least 10 days without substantial precipitation accumulation $(<5 \mathrm{~mm})$. As shown in Fig. 5.1e, more and prolonged dry spells (red dots) tend to occur in the positive NPI regime during which temperature and precipitation tend to be positively correlated. In the opposing phase, less intense dry spells are observed, with negative correlations between temperature and precipitation. A third scenario exists, whereupon a correlation of near zero exists between P and T. The 2014/15 event falls under such zero correlation regime and is evidence that natural climate variability can drive years of extreme warmth and drought even when precipitation is normal.

To understand the circulation and SST patterns associated with wet and dry spells along the Cascades, Fig. 5.1f shows the $250 \mathrm{mb}$ streamfunction and SST differences between low and high snow frequency years. Low snow years are associated with a SST pattern that is analogous to the positive phase of the PDO (or to the interdecadal Pacific oscillation, which has a stronger tropical signal), with a warm tongue of water situated off the coast of California accompanied by an anomalous ridge over the PNW. The 2014/15 circulation anomalies (Fig. 5.1g) produced a similar yet amplified pattern, including the high pressure over the West Coast and a low pressure over northeastern North America. This pair of circulations echo the dipole pattern associated with the 2013/14 California drought (Wang et al. 2014, 2015; Funk et al. 2015) that occurred again in 2015. The circulation anomalies associated with the NPI (Fig. 5.1h) resembles the low snow frequency situation, as was previous documented (e.g., Mote 2006). By comparison, the 2014/15 circulation also bears resemblance to the pattern of North Pacific oscillation (NPO; Rogers 1981) (Fig. 5.1i), with a similar (yet shifted) high pressure ridge over the western United States and warm SST anomalies in the northeastern Pacific. However, the 2014/15 SST anomalies feature an area of much warmer water around the PNW coast, referred to as a "blob" of warmer water consolidated into the PDO's region of ocean fluctuation that was strengthened by the stagnation of high pressure in the Gulf of Alaska (Bond et al. 2015).

To analyze further the collective effects of NPI and NPO on the 2014/15 circulation anomalies, we computed the regression coefficients of streamfunction and SST anomalies with the NPI and NPO from 1949/50 to 2013/14 and weighted the coefficients against the observed values of the 2014/15 season; this led to a statistical estimate of the anomalies that are individually attributable to 
each mode. Then, a linear "attribution" analysis was carried out by removing the combined regressed patterns of the NPI and NPO from the 2014/15 anomalies (the NPO signal was "regressed out" from the NPI). The residual (Fig. 5.1j) shows a weak swath of warmer SST across the North Pacific with some patches of cool waters, suggesting that the key SST feature in the 2014/15 situation near the PNW has been considerably reduced. The drought-inducing ridge engulfing the West Coast (Fig. 5.1g) was also reduced by more than one half with a displaced center. The residual SST could be explained by possible warming effects of anthropogenic greenhouse gases, as was argued by Weller et al. (2015). Because the Cascades' surface air temperature is significantly correlated with the offshore SST (Supplemental Fig. S5.1), these results hint a collective effect from anthropogenic warming and combined NPI-NPO modulation on the $2014 / 15$ anomaly that led to low snowfall.

The limited length of observational data poses a challenge in verifying the inferred NPI modulation on the fluctuating $\mathrm{P}-\mathrm{T}$ relationship. We note that the CESM1's 30-member ensemble appears to capture the NPI in both the historical and future runs (using the same definition as in the observation), without any noticeable trend in the RCP8.5 runs (Fig. 5.2a). Likewise, the model does not suggest any perceptible future deviation from the SCORR pattern between $\mathrm{P}$ and $\mathrm{T}$ (Fig. 5.2b) either. This result suggests that the P-T SCORR and the NPI modulation are natural variability that are not projected to change. Additionally, the spectral coherence between the observed NPI (15-year low-pass) and the 15-year SCORR between $\mathrm{P}$ and $\mathrm{T}$ was computed. To address uncertainty in the coherence at low frequencies/long periods, we computed the spectral coherence for two periods: 101 (Fig. 5.2c) and 59 (Fig. 5.2d) years. The spectral coherency reveals dominant periodicities at 30-50 years, which is consistent with the NPI's periodicity. The low frequency band should be interpreted with caution owing to the limited data length. Nonetheless, both the historical (Fig. 5.2e) and future (Fig. 5.2f) simulations of the CESM1 reproduced this 30-50-year spectral peak of the coherency. This performance is in line with the CESM1's noted ability in reproducing the broad North Pacific SST variability (Yoon et al. 2015) and the supposed stationarity of the NPI (Fig. 5.2a). Under the future scenario, the model projects an amplified spectral coherency of SCORR with NPI while the frequency remains unchanged. However, the increase in spectral coherency only marginally passes the red noise spectrum (not shown) and therefore does not suggest confidently that global warming would change the correspondence between the $\mathrm{P}-\mathrm{T}$ regime and the NPI.

In spite of these results, anthropogenic warming continues to pose a threat to the Cascades snowpack as shown in Supplemental Fig. S5.2a. The post-1970 increase in observed $\mathrm{T}$ coincides with the rising trend of simulated $\mathrm{T}$, and these correspond to the expected decreasing trend in the projected S/P (Supplemental Fig. S5.2b). However, the accelerated increase in observed temperature and the record warmth in 2014/15 could be an early indication that, even though precipitation in the PNW does not change in the future, the persistent warming will increase the likelihood of a normal $\mathrm{P}$ and high $\mathrm{T}$ situation like 2014/15 or worse, a high T and low P scenario as suggested in the negative SCORR regime of Fig. 5.1d. In terms of risk assessment, these results suggest that any superimposition of a high $\mathrm{T}$ with low $\mathrm{P}$ would exacerbate drought, making it potentially more severe than the 2014/15 situation with normal P. The CESM1 projections lend support to such a possibility in the future.

Summary. In the winter of 2014/15, the average temperature along the Cascades was the highest on record and occurred in tandem with the emergence of extremely positive SST anomalies that developed off the coast of the PNW. The high pressure ridge increased the PNW temperatures to a record level while reducing the snow frequency. Diagnostic analysis suggests that a significant portion of the circulation patterns associated with the 2014/15 snowpack drought can be explained by the North Pacific climate variability in the form of the NPI with a modulation from the NPO. Even though the effect of North Pacific climate variability on the PNW is well known (Stoelinga et al. 2010, Mote et al. 2014, Abatzoglou et al. 2014), this study uncovered a unique cyclical relationship between temperature and precipitation that is apparently driven by the low frequency variability of the NPI. This process is especially concerning in light of recent findings that despite little long-term trend in average West Coast precipitation, precipitation may be falling in more concentrated bursts (Prein et al. 2016) due to changes in certain circulation patterns (Swain et al. 2016; Lehmann and Coumou 2015). Under the warming climate, increasing air temperature embedded in stagnated ridge systems off the West Coast (Diffenbaugh et al. 2015) can reduce snowpack 

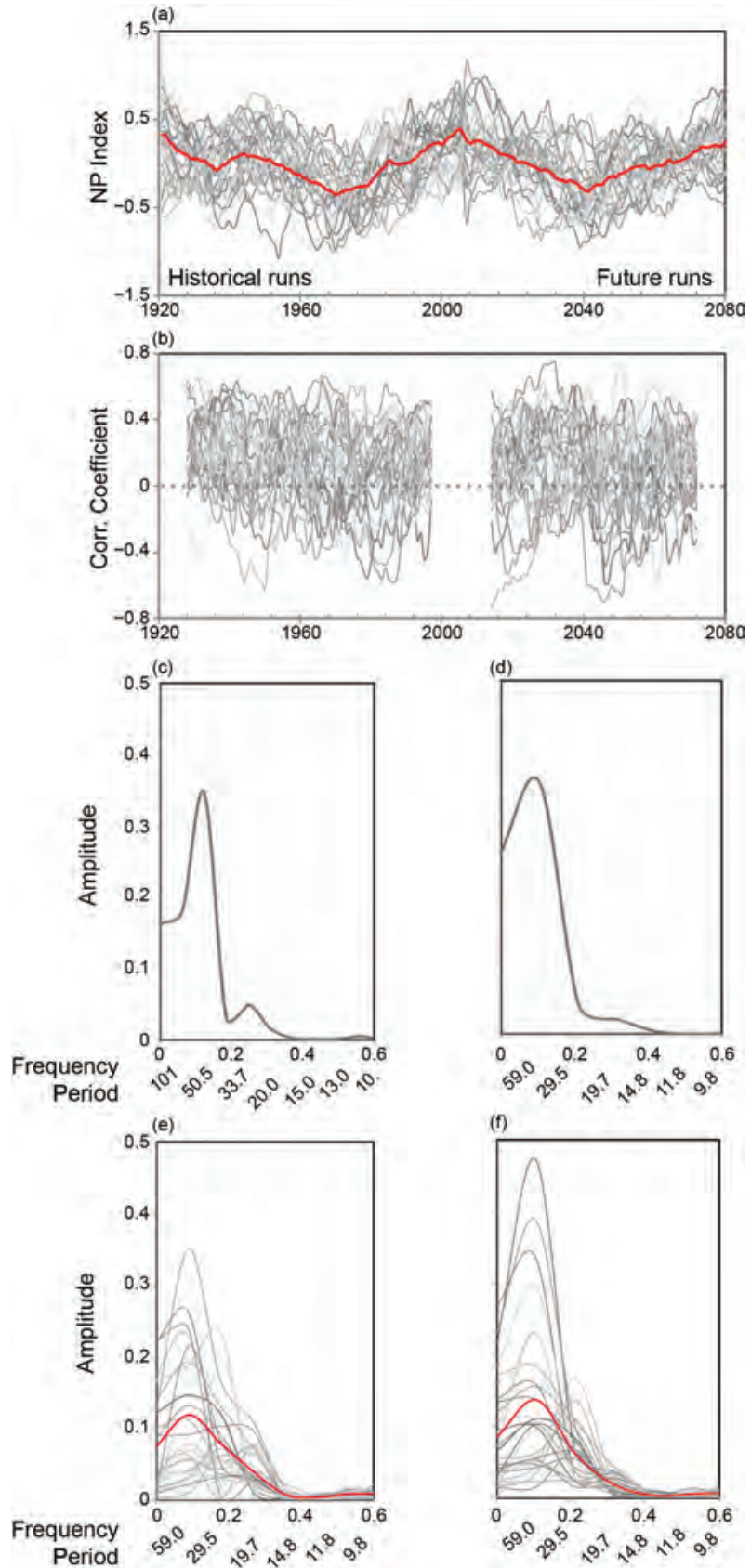

even without an apparent precipitation deficit-a situation that was realized in the 2014/15 snowpack drought of Washington.

ACKNOWLEDGEMENTS. This study was supported by WaterSMART Grant R13AC80039, the Utah Agricultural Experiment Station, and partially DE-SC0016605. Yoon was supported by the Global University Project Startup fund project through a grant provided by GIST in 2016. The CESM Large Ensemble Community Project and supercomputing resources are provided by NSF/CISL/Yellowstone.
FIG. 5.2. (a) The I5-year running mean of the NPI, constructed as the area-weighted sea level pressure over the region $30^{\circ}-65^{\circ} \mathrm{N}, 160^{\circ} \mathrm{E}-140^{\circ} \mathrm{W}$ for $30 \mathrm{CESMI}$ ensemble members (in gray), and their ensemble mean (in red), for both historical and future RCP8.5 runs, adjoined. (b) I5-year sliding correlation between temperature and precipitation. Years on the $x$ axis represent the central year of the 15-year sliding window. (c) Spectral coherence amplitude between the NPI and the I5-year sliding correlation of observed cold season precipitation and temperature from 1908-2008. (d) Same as (c) but from 1928-86. (e),(f) Same as (d) but for CESMI derived historical (1928-97) and future (2014-72) PDO and SCORR outputs. The minimum number of time steps that could be used was $\mathbf{5 9}$ years because of the limited extent of CESMI's future run. As a result, only a comparable number of years in observations could be used to allow for easy comparisons. Similarly, red curves represent the ensemble mean.

\section{REFERENCES}

Abatzoglou, J. T., D. E. Rupp, and P. W. Mote, 2014: Seasonal climate variability and change in the Pacific Northwest of the United States. J. Climate, 27, 2125-2142, doi:10.1175/JCLI-D-13-00218.1.

Anderson, B., and Coauthors, 2006: 2005 Drought Response Report to the Legislature. Washington Department of Ecology and Water Resources Program, Publication 06-11-001, 56 pp. [Available online at https://fortress.wa.gov/ecy/publications /documents/0611001.pdf.]

Bond, N. A., M. F. Cronin, H. Freeland, and N. Mantua, 2015: Causes and impacts of the 2014 warm anomaly in the NE Pacific. Geophys. Res. Lett., 42, 3414-3420, doi:10.1002/2015GL063306.

Diffenbaugh, N. S., D. L. Swain, and D. Touma, 2015: Anthropogenic warming has increased drought risk in California. Proc. Natl. Acad. Sci. USA, 112, 39313936, doi:10.1073/pnas.142238511.

Funk, C., S. Shukla, A. Hoell, and B. Livneh, 2015: Assessing the contributions of East African and west Pacific warming to the 2014 boreal spring East African drought [in "Explaining Extreme Events of 2014 From a Climate Perspective"]. Bull. Amer. Meteor. Soc., 96 (12), S77-S81, doi:10.1175/ BAMS-D-15-00106.1.

Gillies, R. R., S.-Y. Wang, and M. R. Booth, 2012: Observational and synoptic analyses of the winter precipitation regime change over Utah. J. Climate, 25, 4679-4698, doi:10.1175/JCLI-D-11-00084.1. 
Huang, B., and Coauthors, 2015:Extended reconstructed sea surface temperature version 4 (ERSST.v4). Part I: Upgrades and intercomparisons. J. Climate, 28, 911-930, doi:10.1175/JCLI-D-14-00006.1.

Hurrell, J. W., and Coauthors, 2013: The Community Earth System Model: A framework for collaborative research. Bull. Amer. Meteor. Soc., 94, 1339-1360, doi:10.1175/BAMS-D-12-00121.1.

Kalnay, E., and Coauthors, 1996: The NMC/NCAR 40Year Reanalysis Project. Bull. Amer. Meteor. Soc., 77, 437-471.

Kay, J. E., and Coauthors, 2015: The Community Earth System Model (CESM) large ensemble project: A community resource for studying climate change in the presence of internal climate variability. Bull. Amer. Meteor. Soc., 96, 1333-1349, doi:10.1175 /BAMS-D-13-00255.1.

Kistler, R., and Coauthors, 2001: The NCEP-NCAR 50-year reanalysis: Monthly means CD-ROM and documentation. Bull. Amer. Meteor. Soc., 82, 247267.

Lehmann, J., and D. Coumou, 2015: The influence of mid-latitude storm tracks on hot, cold, dry and wet extremes. Sci. Rep., 5, 17491, doi:10.1038/srep17491.

Mote, P. W., 2006: Climate-driven variability and trends in mountain snowpack in western North America. J. Climate, 19, 6209-6220, doi:10.1175 /JCLI3971.1.

Mote, P., A. K. Snover, S. Capalbo, S. D. Eigenbrode, P. Glick, J. Littell, R. Raymondi, and S. Reeder, 2014: Northwest. Climate Change Impacts in the United States: The Third National Climate Assessment, J. M. Melillo et al., Eds., U.S. Global Change Research Program, 487-513, doi:10.7930/J04Q7RWX.

Newman, M. and Coauthors, 2016: The Pacific decadal oscillation, revisited. J. Climate, 29, 4399-4427, doi:10.1175/JCLI-D-15-0508.1.

Prein, A. F., G. J. Holland, R. M. Rasmussen, M. P. Clark, and M. R. Tye, 2016: Running dry: The U.S. Southwest's drift into a drier climate state. Geophys. Res. Lett., 43, 1272-1279, doi:10.1002/2015GL066727.

Rogers, J. C., 1981: The North Pacific oscillation. J. Climatol., 1, 39-57.

Stewart, I. T., D. R. Cayan, and M. D. Dettinger, 2004: Changes in snowmelt runoff timing in western North America under a 'business as usual' climate change scenario. Climatic Change, 62, 217-232, doi:10.1023/B:CLIM.0000013702.22656.e8.
Stoelinga, M. T., M. D. Albright, and C. F. Mass, 2010: A new look at snowpack trends in the Cascade Mountains. J. Climate, 23, 2473-2491, doi: 10.1175/2009JCLI2911.1.

Swain, D. L., D. E. Horton, D. Singh, and N. S. Diffenbaugh, 2016: Trends in atmospheric patterns conducive to seasonal precipitation and temperature extremes in California. Sci. Adv., 2, e1501344, doi:10.1126/sciadv.1501344.

Taylor, K. E., R. J. Stouffer, and G. A. Meehl, 2012: An overview of CMIP5 and the experiment design. Bull. Amer. Meteor. Soc., 93, 485-498, doi:10.1175/BAMS -D-11-00094.1.

Trenberth, K. E., and J. W. Hurrell, 1994: Decadal atmosphere-ocean variations in the Pacific. Climate Dyn., 9, 303-319, doi:10.1007/BF00204745.

Wang, S. Y., L. Hipps, R. R. Gillies, and J. H. Yoon, 2014: Probable causes of the abnormal ridge accompanying the 2013-2014 California drought: ENSO precursor and anthropogenic warming footprint. Geophys. Res. Lett., 41, 3220-3226, doi:10.1002/2014GL059748.

Wang, S. Y. S., W. R. Huang, and J. H. Yoon, 2015: The North American winter "dipole" and extremes activity: A CMIP5 assessment. Atmos. Sci. Lett., 345, 338-345, doi:10.1002/asl2.565.

Weller, E., S.-K Min, D. Lee, W. Cai, S.-W. Yeh, and J.-S. Kug, 2015: Human contribution to the 2014 record high sea surface temperatures over the western tropical and northeast Pacific Ocean [in "Explaining Extremes of 2014 from a Climate Perspective"]. Bull. Amer. Meteor. Soc., 96 (12), S100-S104, doi:10.1175 /BAMS-D-15-00055.1

Yoon, J.-H., S.-Y. Wang, R. R. Gillies, B. Kravitz, L. Hipps, and P. Rasch, 2015: Increasing water cycle extremes in California and in relation to ENSO cycle under global warming. Nature Comm., 6, 8657, doi:10.1038/ncomms9657. 


\title{
6. IN TIDE'S WAY: SOUTHEAST FLORIDA'S SEPTEMBER 2015 SUNNY-DAY FLOOD
}

\author{
William V. Sweet, Melisa Menendez, Ayesha Genz, Jayantha Obeysekera, \\ Joseph Park, and John J. Marra
}

The probability of a $0.57-m$ tidal flood within the Miami region has increased by $>500 \%$ since 1994 from a 10.9-cm sea level rise (SLR)-related trend in monthly highest tides.

The Flood Event. High tides on 27 September 2015 flooded several Miami-region communities with $0.57 \mathrm{~m}$ of ocean water. The flooding was concerning because of the sunny-day conditions and awareness that trends of such events are accelerating within U.S. Atlantic Coast cities from rising seas (Sweet et al. 2014; Ezer and Atkinson 2014; Sweet and Marra 2016). It was the sixth largest flood measured by the National Oceanic and Atmospheric Administration (NOAA) tide gauge in Virginia Key, Florida (Miami region), since its 1994 installation (Fig. 6.1a). The five higher floods were in response to hurricanes.

The flood had substantial astronomical underpinnings (Fig. 6.1b); it occurred during spring tides and near the peak of the seasonal mean sea level (MSL), the lunar 8.8-year perigee, and the 18.6-year nodal cycles. These factors explain the 0.24 -m NOAA tide prediction relative to mean higher high water (MHHW) tidal datum that delineates typical tidal inundation (Schureman 2001; Parker 2007). Yet, tide forcing alone was insufficient to produce the observed impacts as minor "nuisance" flooding begins in excess of 0.4 meters in this region (Sweet et al. 2014).

Other dynamics were at play. A nontidal sea level anomaly (Fig. 6.1b, green line), which exceeded 0.15 $\mathrm{m}$ for a month starting September 22, reached 0.33 $m$ during the flood and even higher for weeks afterwards. Strong high pressure over Eastern Canada (Fig. 6.1c) with $>15 \mathrm{~m} \mathrm{~s}^{-1}$ northeasterlies offshore of

AFFILIATIONS: SWEET-NOAA National Ocean Service, Silver Spring, Maryland; Menendez-Environmental Hydraulic Institute, E.T.S., Universidad de Cantabria, Santander, Spain; GENZUniversity of Hawaii, Honolulu, Hawaii; OBEYSEKERA-South Florida Water Management District, West Palm Beach, Florida; PARKNational Park Service, Everglades National Park, Homestead, Florida; MARRA-NOAA National Centers for Environmental Information, Honolulu, Hawaii.

DOI:I0.II75/BAMS-D-I6-0II7.I

A supplement to this article is available online ( 10.1175 /BAMS-D-16-0117.2) the mid-Atlantic Bight (not shown) drove an Ekmanrelated setup along much of the U.S. East Coast. During the flood, setup was $>20 \mathrm{~cm}$ along the southeast Florida coast as modeled by NOAA's extratropical surge and tide operational forecast system (Funakoshi et al. 2013). Local winds, however, were calm $(<3 \mathrm{~m}$ $\mathrm{s}^{-1}$; http://tidesandcurrents.noaa.gov/met), inverse barometer effects nonexistent (Fig. 6.1c), and dynamical wave effects minimal as inferred by the $\sim 1 \mathrm{~cm}$ standard deviations during tide measurements (Sweet et al. 2015). Interestingly, Gulf Stream transport measured upstream in the Florida Current (FC) slowed to a monthly minimum of 23.4 Sverdrup (Sv; $1 \mathrm{~Sv} \equiv 10^{6}$ $\mathrm{m}^{3} \mathrm{~s}^{-1}$ ) on 25 September (Fig. 6.1d), which persisted through the flood. Transport slowdowns raise MSL along the US southeast (Zhao and Johns 2014; Ezer 2016) and Florida coasts (Park and Sweet 2015) from adjustments to meridional Ekman transport (Lee and Williams 1988) and shelf-wave dynamics (Czeschel et al. 2012; Ezer 2016). Previous studies report a 0.5-1.5 $\mathrm{cm}$ rise in coastal MSL per 1-Sv decline in Gulf Stream system transport (Ezer et al. 2013; Woodworth et al. 2014; Goddard et al. 2015; Ezer 2016); when it slows, local tidal-flood risks increase (Sweet et al. 2009; Ezer and Atkinson 2014; Wdowinski et al. 2016).

Here, we derive a contemporary return period of the flood using a time-dependent extreme value statistical model. Then, we assess the degree that (i) seasonal variability, (ii) tide cycles, (iii) FC monthly transport minimums, and (iv) a multidecadal trend have independently affected Virginia Key's extreme water level distribution and estimate their attribution during the flood. We conclude by analyzing how the flood's return period changes under future SLR projections for the Miami region forced by three representative concentration pathways (RCP).

Data and Methods. Verified 6-minute and monthly water levels, sampling standard deviations, and tide 
(a) Monthly Maximum Water Levels (WL) at Virginia Key, FL
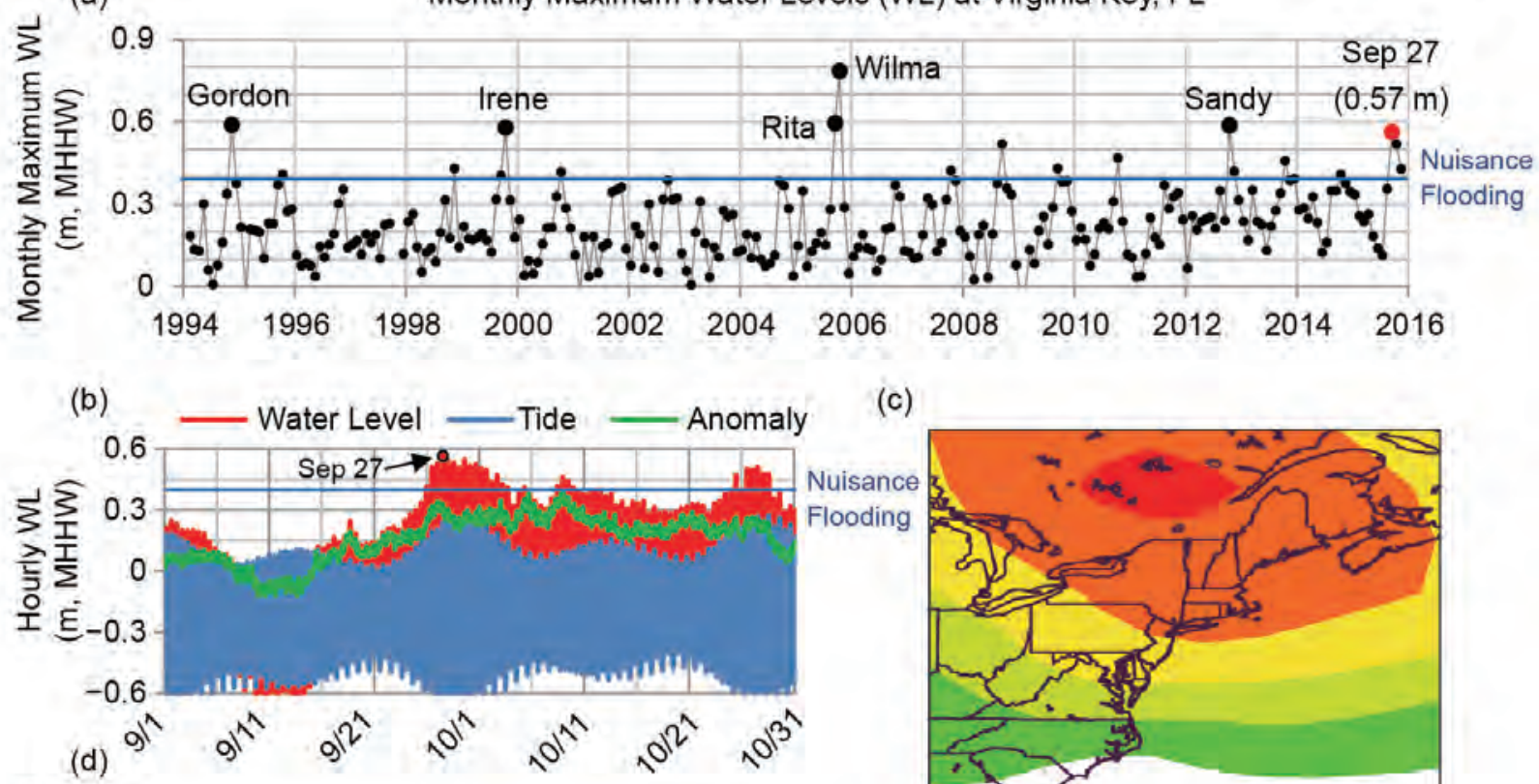

(c)
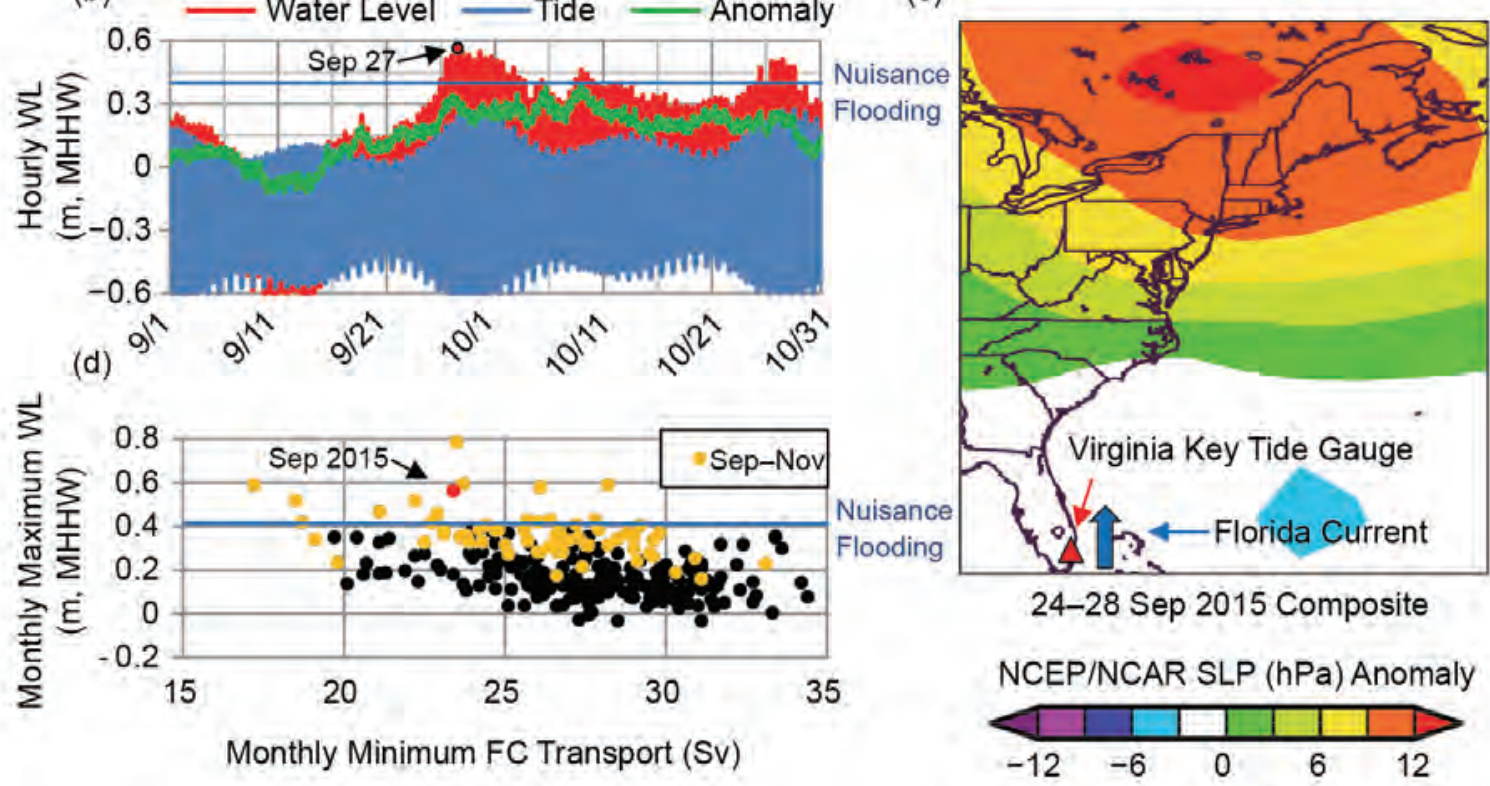

FIG. 6.I. (a) Highest monthly water levels (m) since 1994 at NOAA tide gauge Virginia Key, FL, indicating the local "nuisance" flood level; (b) hourly water levels $(\mathrm{m})$ in Sep and Oct 2015 showing tidal and nontidal anomaly components highlighting the 27 Sep flood; (c) 5-day composite (www.esrl.noaa.gov/psd) of SLP (hPa) anomaly during the flood showing location of the tide gauge and FC measurements; and (d) scatterplot between monthly minimum FC transport (Sv) and monthly maximum water level (WL; $\mathrm{m}$ ) highlighting Sep-Nov months (yellow) and the Sep 2015 event (red).

predictions are used for NOAA tide gauge Virginia Key (http://tidesandcurrents.noaa.gov). Daily FC transport is available from www.aoml.noaa.gov /phod/floridacurrent. We analyze monthly highest water levels using a generalized extreme value (GEV) model to assess flood height probabilities and decompose independent time-dependencies in the model's location parameter. We follow methods of Menendez and Woodworth (2010) described in the online supplemental information.

Return level interval curves (Coles 2001) are constructed on a monthly and a 2015-annualized (12-month integrated) basis. Monthly return interval curves are vertically shifted by the time-dependent location parameter components (equation 2 in the online supplemental information) to assess climate variability and trend effects on the flood's return period. We use the classic (annual scale) curves to compute future projections for annual relevancy purposes. Return periods are approximated as $-1 / \ln \left(\mathrm{F}_{\mathrm{z}}\right)$, where $\mathrm{F}$ is the cumulative probability of a flood with height $\mathrm{z}$, instead of the traditional $1 /\left(1-\mathrm{F}_{\mathrm{z}}\right)$ method (Beran and Nozdryn-Plotnicki 1977; Coles 2001) to better estimate shorter return periods (e.g., $<1$ year).

What role did climatic variability and trends play in the September 2015 flood? Our model estimates that a $0.57-\mathrm{m}$ flood has a 6 -year return period (black curve in Fig. 6.2a) during Septembers assuming conditions (e.g., nodal cycle, FC transport) match those during September 2015. The flood has a 3 -year return period when considering (integrating across) all months 
(a)

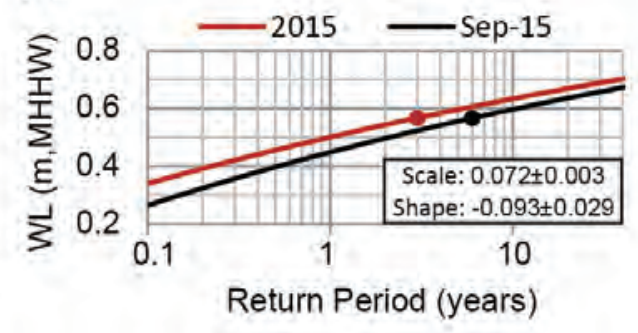

(c)
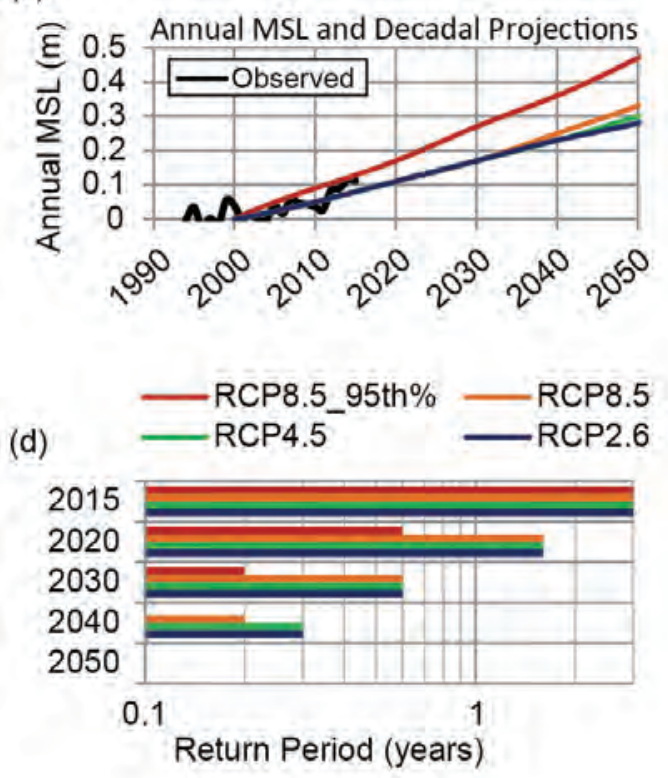

(b)

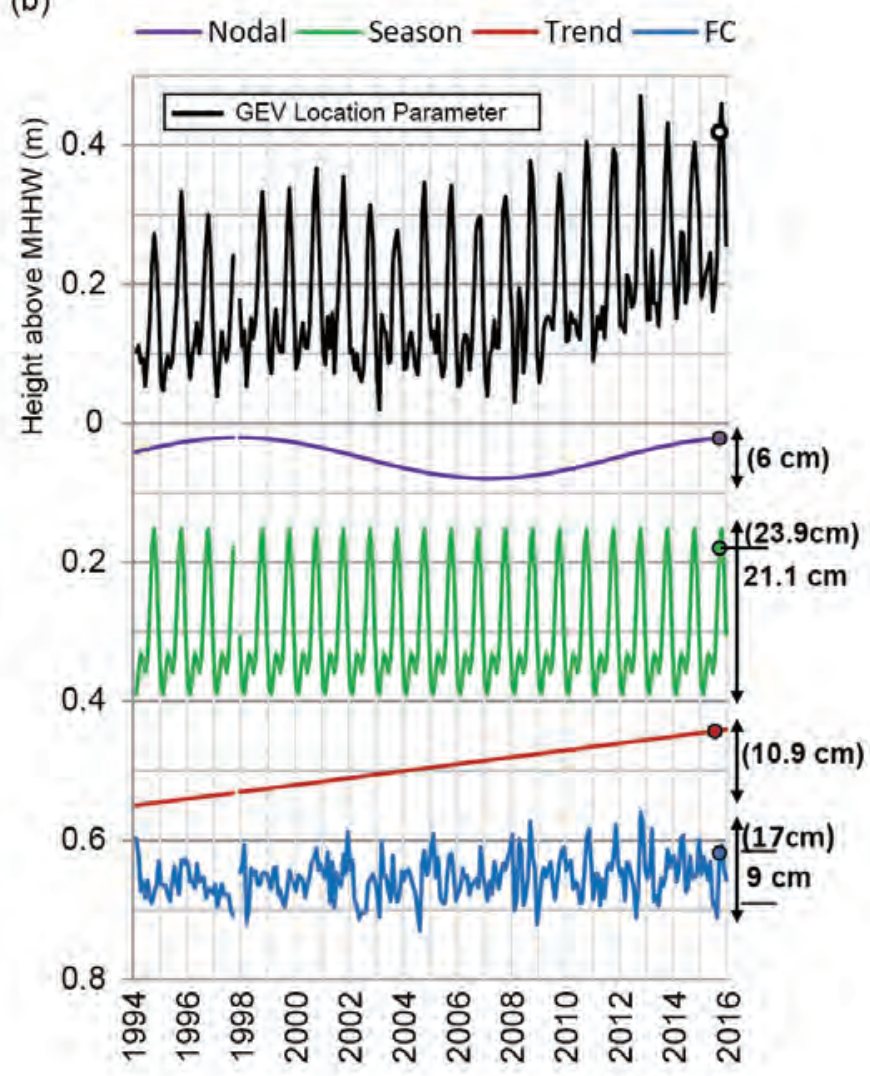

Fig. 6.2. (a) GEV-estimated return level interval curves from monthly maximum $W L(m)$ at Virginia Key for Sep 2015 (black curve) and annualized for all months in 2015 (red curve) indicating the 27 Sep flood level (dots) and GEV model parameter standard errors. (b) Time-varying location parameter (black line) and its components (plotted to scale but with arbitrary values) with component magnitudes (m) during the 27 Sep flood (circles) and their total ranges in parenthesis. (c) Annual MSL (m) at Virginia Key since 1994 overlaid upon local RCPbased SLR projections of Kopp et al. (2014). (d) Return periods by decade of the Sep 2015 flood height $(0.57 \mathrm{~m}$ above MHHW) in response to SLR projections.

during 2015 (red curve in Fig. 6.2a), reflecting the peak seasonal location parameter during Octobers (Fig. 6.2b, green line). Highest water levels occur September-November (Fig. 6.1d, yellow dots), typically during Octobers. If a $0.57-\mathrm{m}$ flood occurred in February 2015 when the seasonal location parameter is minimum ( $21.1 \mathrm{~cm}$ lower than in September), a higher (less probable) water level would be required; it would have a $>100$-year return period. Our estimates (Fig.6. 2a) are based upon a 22-year data record with a sample size 7 times longer than the flood's annualized return period, which results in low GEV-parameter estimate uncertainties (Fig. 6.2a). We note our return periods agree with those from a 50-year record from the nearby historic Miami NOAA gauge (http:// tidesandcurrents.noaa.gov/est; Zervas 2013) and our seasonal location-parameter range of $23.9 \mathrm{~cm}$ matches its 23.7-cm MSL cycle (Zervas 2009).

The 18.6-year lunar nodal cycle is estimated as having a $6-\mathrm{cm}$ location-parameter range, which was near-peak during the flood (Fig. 6.2b). If at its minimum (and all other factors the same), the return period of this flood occurring in a September would have been 16.5 years instead of 6 years $(>150 \%$ probability increase). The periodicity of the lunar perigee, which amplifies the tidal range on a $\sim 4.4-$ year cycle (Haigh et al. 2011), was included in our model but found to be insignificant. Similarly, had the flood occurred during a September with higher FC transport (e.g., 33.1 Sv in September 1997 and a 9-cm location parameter decrease shown in Fig. 6.2b), the return period would have been 29 years instead 
of 6 years ( $>350 \%$ probability increase). Our model estimates a $17-\mathrm{cm}$ total range in location parameter due to co-variability with FC transport minimums, equating to a $0.9 \pm 0.2 \mathrm{~cm}$ increase for every $1-\mathrm{Sv}$ decline, which agrees with previous estimates. Lastly, our model estimates a long-term trend in the location parameter of $0.5 \pm 0.1 \mathrm{~cm}_{\text {year-1 }}^{-1}(10.9 \mathrm{~cm}$ rise since beginning of 1994), which closely matches the trend in MSL ( $11 \mathrm{~cm}$ in Fig. 6.2c). If the flood had occurred in September 1994, its return period would have been 39 years instead of 6 years ( $>500 \%$ probability increase)

What does the future hold in terms of more September 2015 flooding? The logical question is how much more frequent will these kinds of floods become in the future? To answer this question, the September 2015 flood is assessed in terms of its annualized return period ( 3 years; red curve in Fig. 6.2a), although flood frequencies will likely remain most prevalent during the fall (e.g., Fig. 6.1d). It is assumed that future changes in tidal flooding will occur only in response to local SLR, though variability (shown here) is significant. We use the 50th and 95th\% SLR projections for Virginia Key forced by RCPs modeled by Kopp et al. (2014), which correspond to global SLR of 0.5-1.21 $\mathrm{m}$ by 2100. An overlay of Virginia Key's annual MSL (Fig. 6.2c) shows a current trajectory between the 50th and 95th\% of the RCP 8.5 SLR projections. By 2030, the flood is likely to become a 0.6 -year event ( twice a year) under the median RCP 2.6, 4.5, and 8.5 projections (Fig. 6.2d) and a 0.2 -year event ( $\geq 5$ times a year) under the 95 th $\%$ of the RCP 8.5 projection. With $0.2 \mathrm{~m}$ more local SLR, which is exceeded under all local SLR projections between 2040-2050, the flood will occur $>10$ times a year $(<0.1$ year return period).

Conclusion. Our time-dependent GEV model disentangles and probabilistically decomposes independent contributions from concurrent processes attributing to the Miami-region floods during 27 September 2015. Seasonal and tide cycles are quite predictable, whereas FC transport variability is less so (e.g., DiNezio et al. 2009). In terms of decadesold infrastructure, two major factors were at play: a 9- $\mathrm{cm}$ increase from FC variability and a $10.9-\mathrm{cm}$ rise from a climate-related SLR trend since 1994 of which a fraction $(\sim 0.05 \mathrm{~cm}$ year-1) is downward vertical land motion (Zervas et al. 2013; Kopp et al. 2014) common to south Florida. There is a decreasing trend (significant at the 99\% level) in monthly minimum FC transport of 2.3 Sv since 1994, which likely contributed $\sim 2 \mathrm{~cm}$ to the SLR-related trend (Fig.6.2b, blue line).

A decline in the large-scale Gulf Stream transport, which is expected this century (Yin 2012) to exacerbate flooding along the mid-Atlantic (Hall et al. 2016), is not well resolved for the FC locally within the SLR projections (Kopp et al. 2014). Because of this, and since we use a parametric extreme distribution to quantify the transition to a more recurrent event better estimated empirically (Sweet and Park 2014), our flood-frequency projections should be considered conservative underestimates. In closing, flooding on 27 September inundated $0.57 \mathrm{~m}$ of normally dry land ( 2 feet; https://coast.noaa.gov/slr) and capped a weeklong event in which daily high tides exceeded the local nuisance flood threshold (Fig. 6.1b). Tidal floods of this magnitude occur only every few years now but will become commonplace in the coming decades.

ACKNOWLEDGEMENTS. The authors thank NOAA for hosting and providing public access to their ocean and atmospheric data, without which, this work would not be possible. Melisa Menendez's contribution was made possible through the Spanish Ramon y Cajal program (RYC-2014-16469)

\section{REFERENCES}

Beran, M. A., and M. K. Nozdryn-Plotnicki, 1977: Estimation of low return period floods. Hydrol. Sci. Bull., 2, 275-282, doi:10.1080/02626667709491717.

Coles, S., 2001: An Introduction to Statistical Modeling of Extreme Values. Springer, 208 pp.

Czeschel, L., C. Eden, and R. J. Greatbatch, 2012: On the driving mechanism of the annual cycle of the Florida current transport. J. Phys. Oceanogr., 42, 824-839, doi:10.1175/JPO-D-11-0109.1.

DiNezio, P. N., L. J. Gramer, W. E. Johns, C. S. Meinen, and M. O. Baringer, 2009: Observed interannual variability of the Florida Current: wind forcing and the North Atlantic Oscillation. J. Phys. Oceanogr., 39, 721-736, doi: 10.1175/ 2008JPO4001.1.

Ezer, T., 2016: Can the Gulf Stream induce coherent short-term fluctuations in sea level along the U.S. East Coast?: A modeling study. Ocean Dyn., 66, 207220, doi:10.1007/s10236-016-0928-0.

—, and L. P. Atkinson, 2014: Accelerated flooding along the U.S. East Coast: On the impact of sea level rise, tides, storms, the Gulf Stream and NAO. Earth's Future, 2, 362-382, doi:10.1002/2014EF000252. 
,-- , W. B. Corlett, and J. L. Blanco, 2013: Gulf Stream's induced sea level rise and variability along the U.S. mid-Atlantic coast. J. Geophys. Res. Oceans, 118, 685-697, doi:10.1002/jgrc.20091.

Funakoshi, Y., J. C. Feyen, F. Aikman III, A. van der Westhuysen, and H. Tolman, 2013: The Extratropical Surge and Tide Operational Forecast System (ESTOFS) Atlantic Implementation and Skill Assessment. NOAA Tech. Rep. NOS CS 32, 147 pp. [Available online at www.nauticalcharts.noaa.gov /csdl/publications/TR_NOS-CS32-FY14_01_Yuji_ ESTOFS_SKILL_ASSESSMENT.pdf.]

Goddard, P. B., J. Yin, S. M. Griffies, and S. Zhang, 2015: An extreme event of sea-level rise along the Northeast coast of North America in 2009-2010. Nature Comm., 6, 6346, doi:10.1038/ncomms7346.

Haigh, I. D., M. Eliot, and C. Pattiaratchi, 2011: Global influences of the 18.61 year nodal cycle and 8.85 year cycle of lunar perigee on high tidal levels. J. Geophys. Res., 116, C06025, doi:10.1029/2010JC006645.

Hall, J. A., S. Gill, J. Obeysekera, W. Sweet, K. Knuuti, and J. Marburger, 2016: Regional sea level scenarios for coastal risk management: Managing the uncertainty of future sea level change and extreme water levels for Department of Defense coastal sites worldwide. U.S. Department of Defense, Strategic Environmental Research and Development Program, 224 pp. [Available online at www.usfsp.edu/icar /files/2015/08/CARSWG-SLR-FINAL-April-2016. pdf.]

Kopp, R. W., R. M. Horton, C. M. Little, J. X. Mitrovica, M. Oppenheimer, D. J. Rasmussen, B. H. Strauss, and C. Tebaldi, 2014: Probabilistic 21st and 22nd century sea-level projections at a global network of tide gauge sites. Earth's Future, 2, 383-406, doi:10.1111 left2.2014EF000239.

Lee, T. N., and E. Williams, 1988: Wind-forced transport fluctuations of the Florida Current. J. Phys. Oceanogr., 18, 937-946.

Menéndez, M., and P. L. Woodworth, 2010: Changes in extreme high water levels based on a quasi-global tide-gauge data set. J. Geophys. Res., 115, C10011, doi:10.1175/2011JCLI3932.1.

Park, J., and W. Sweet, 2015: Accelerated sea level rise and Florida current transport. Ocean Sci. 11, 607615, doi:10.5194/os-11-607-2015.

Parker, B. B., 2007: Tidal analysis and prediction. NOAA Special Report NOS CO-OPS 3, 378 pp. [Available online at www.co-ops.nos.noaa .gov/publications/Tidal_Analysis_and_Predictions .pdf.]
Schureman, P., 2001: Manual of harmonic analysis and prediction and tides. Special Publication 98, U.S. Department of Commerce Coast and Geodetic Survey, 317 pp.

Sweet, W. V. and J. Park, 2014: From the extreme to the mean: Acceleration and tipping points of coastal inundation from sea level rise. Earth's Future, 2, 579600, doi:10.1002/2014EF000272.

__ , and J. J. Marra, 2016: 2015 State of U.S. "nuisance" tidal flooding. Supplement to State of the Climate: National Overview for May 2016. [Available online at www.ncdc.noaa.gov/monitoring-content/sotc /national/2016/may/sweet-marra-nuisance-flooding-2015.pdf.]

— C. Zervas, and S. Gill, 2009: Elevated East Coast sea level anomaly: June-July 2009. NOAA Tech. Rep. NOS CO-OPS 051, 30 pp. [Available online at http:// tidesandcurrents.noaa.gov/publications/EastCoastSeaLevelAnomaly_2009.pdf.]

— , J. Park, J. J. Marra, C. Zervas, and S. Gill, 2014: Sea level rise and nuisance flood frequency changes around the United States. NOAA Tech. Rep. NOS CO-OPS 73, 53 pp. [Available online at http:// tidesandcurrents.noaa.gov/publications/NOAA _Technical_Report_NOS_COOPS_073.pdf.]

,$- \ldots$, S. Gill, and J. Marra, 2015: New ways to measure waves and their effects at NOAA tide gauges: A Hawaiian-network perspective. Geophys. Res. Lett., 42, doi:10.1002/2015GL066030.

Wdowinski, S., B. Ronald, B. P. Kirtman, and Z. $\mathrm{Wu}, 2016$ : Increasing flooding hazard in coastal communities due to rising sea level: Case study of Miami Beach, Florida. Ocean Coastal Manage., 126, 1-8, doi:10.1016/j.ocecoaman.2016.03.002.

Woodworth, P. L., M. Maqueda, M. Á. Roussenov, V. M. Williams, and R. G. Hughes, 2014: Mean sea level variability along the northeast American Atlantic coast, and the roles of the wind and the overturning circulation. J. Geophys. Res. Oceans, 119, 8916-8935, doi:10.1002/2014JC010520.

Yin, J., 2012: Century to multi-century sea level rise projections from CMIP5 models. Geophys. Res. Lett., 39, L17709, doi:10.1029/2012GL052947.

Zervas, C., 2009: Sea level variations of the United States 1854-2006. NOAA Tech. Rep. NOS CO-OPS 053, Appendices I-V. [Available online at http:// tidesandcurrents.noaa.gov/publications/Tech _rpt_53.pdf.] 
_- 2013: Extreme water levels of the United States 1893-2010. NOAA Tech. Rep. NOS CO-OPS 67, Appendices I-VIII. [Available online at http:// tidesandcurrents.noaa.gov/publications/NOAA _Technical_Report_NOS_COOPS_067a.pdf.]

Zervas, C., S. Gill, and W. V. Sweet, 2013: Estimating vertical land motion from long-term tide gauge records. Tech. Rep. NOS CO-OPS 65, 22 pp . [Available online at http://tidesandcurrents.noaa. gov/publications/Technical_Report_NOS_CO -OPS_065.pdf.]

Zhao, J., and W. Johns, 2014: Wind-forced interannual variability of the Atlantic Meridional Overturning Circulation at $26.5^{\circ}$ N. J. Geophys. Res. Oceans, 119, 2403-2419, doi:10.1002/2013JC009407. 


\title{
7. EXTREME EASTERN U.S. WINTER OF 2015 NOT SYMPTOMATIC OF CLIMATE CHANGE
}

\author{
Laurie Trenary, Timothy DelSole, Michael K. Tippett, and Brian Doty
}

Despite severe cold waves and record-breaking extreme cold-day occurrences during 2015, no long-term increase in winter daily temperature extremes has occurred in the eastern United States-winters have become warmer and less variable.

Introduction. In late February 2015, a massive cold wave struck the entire U.S. eastern seaboard, bringing record cold temperatures from Maine to Florida (NOAA 2015). Due to the persistent cold, February 2015 ranked in the top ten coldest Februarys on record for a number of eastern seaboard states. Blizzard conditions accompanied the cold wave, placing the month among the top twenty snowiest for most of the northeastern United States (NOAA 2015). Collectively, the heavy snowfall and frigid temperatures were responsible for more than $\$ 3$ billion (U.S. dollars) in insured losses and 87 deaths (Bevere et al. 2016; NOAA 2016).

The 2015 winter was the second in a row characterized by extreme cold along the East Coast. These cold events have occurred even while human-related climate change has led to long-term global declines in extreme cold temperatures (Seneviratne et al. 2012). However, global warming has been hypothesized by some to not only shift the temperature distribution toward warmer temperatures, but also to increase the probability of cold extremes in certain regions by enhancing the meandering of the midlatitude jet stream (Francis and Vavrus 2015). Trenary et al. (2015), however, demonstrated that the variance of winter daily temperature along the U.S. eastern seaboard has been decreasing, suggesting a decrease in variability and in the likelihood of cold waves. Decreased variance combined with increasing mean temperatures indirectly indicates a reduction in the likelihood of cold extremes. In this study, we apply extreme value theory to directly quantify the intensity

AFFILIATIONS: Trenary AND DelSole-George Mason University and Center for Ocean-Land-Atmosphere Studies, Fairfax, Virginia; TIPPETT-Department of Applied Physics and Applied Mathematics, Columbia University, New York, New York, and Center of Excellence for Climate Change Research, Department of Meteorology, King Abdulaziz University, Jeddah, Saudi Arabia; Doty-George Mason University and Center for Ocean-Land-Atmosphere Studies, Fairfax, Virginia

DOI:I0.II75/BAMS-D-16-0156.I and duration of the eastern U.S. 2015 cold wave and long-term changes in the likelihood of cold extremes.

Data and Methods. Daily temperatures are estimated by averaging the minimum and maximum surface temperatures from station data from the Global Historical Climatology Network-Daily Database (Menne et al. 2012). Since the 2015 cold wave was concentrated in February, we analyze 1 January-31 March (i.e., February and the two adjacent months) over the period 1950-2015. Area average time series are computed for the North, South, and mid-Atlantic United States. The spatial distribution of the February 2015 temperatures is evaluated using NCEP/NCAR reanalysis and shown in Fig. 7.1a.

We also analyze climate model simulations from phase 5 of the Coupled Model Intercomparison Project (CMIP5; Taylor et al. 2012). Models with daily surface temperature data were selected (see Table 7.1 for model list). Historical simulations for 1950-2004 contain both anthropogenic and natural forcing, and the historical simulations were extended to 2015 using the representative concentration pathway experiment 8.5. For consistency with our observational analysis, model data are area averaged over the North $\left(40^{\circ}-\right.$ $\left.48^{\circ} \mathrm{N}, 83^{\circ}-65^{\circ} \mathrm{W}\right)$, the mid- $\left(35^{\circ}-40^{\circ} \mathrm{N}, 83^{\circ}-72^{\circ} \mathrm{W}\right)$, and the South Atlantic $\left(25^{\circ}-35^{\circ} \mathrm{N}, 89^{\circ}-75^{\circ} \mathrm{W}\right)$.

Daily temperature anomalies are evaluated as departures from the mean seasonal cycle (a third order polynomial fit of the January-March daily temperature) for the period 1950-2015.

The intensity of the 2015 cold wave is quantified by the minimum daily temperature anomaly during JFM of that year, and its corresponding return period is estimated from a generalized extreme value (GEV) distribution. Long-term changes are modeled as a linear trend in the location parameter of the GEV distribution (Coles 2001; Zwiers et al. 2011; Gilland and Katz 2011). The duration of the event is quantified by the number of days the temperature anomaly falls 

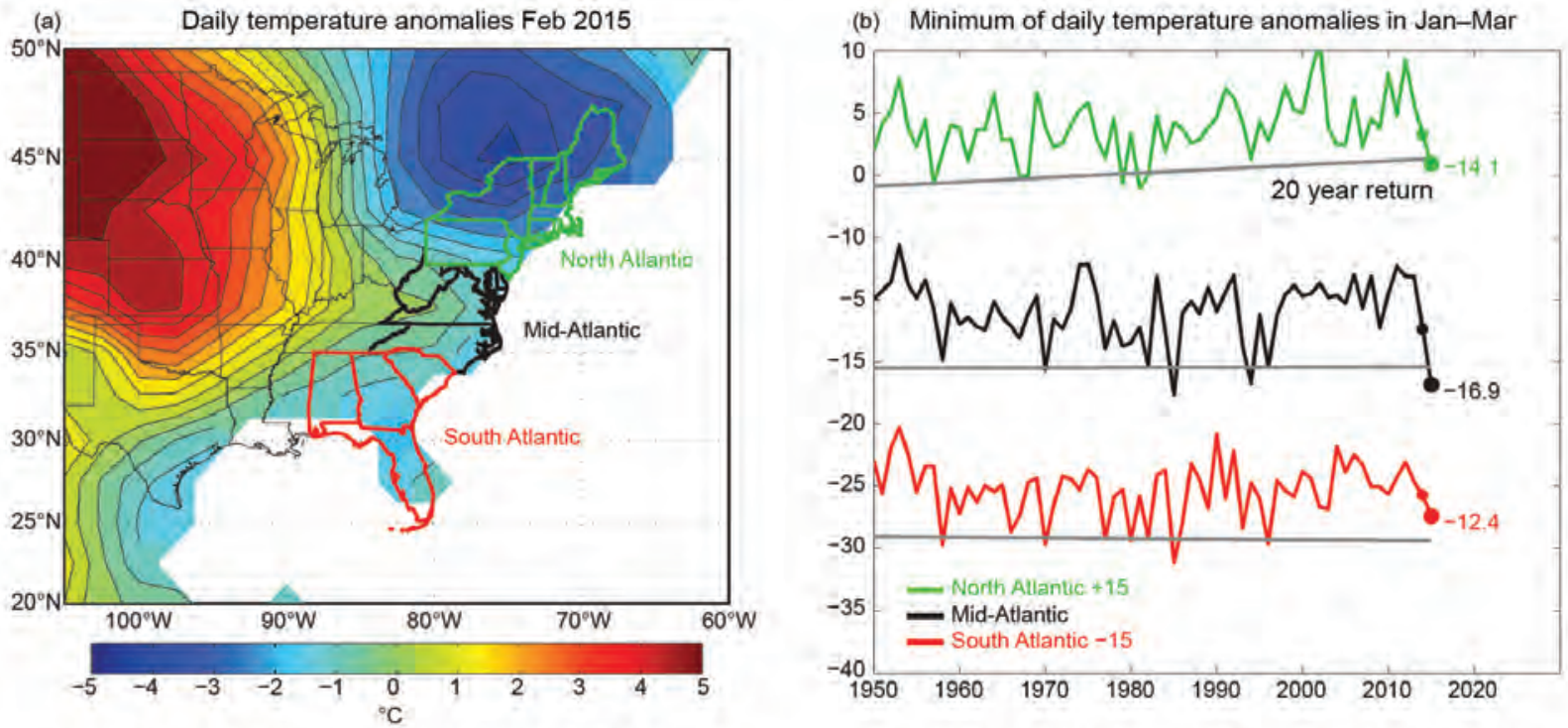

(c) Number of days temperature falls below the 10th percentile

(d) Return level plot for number of cold days in North Atlantic
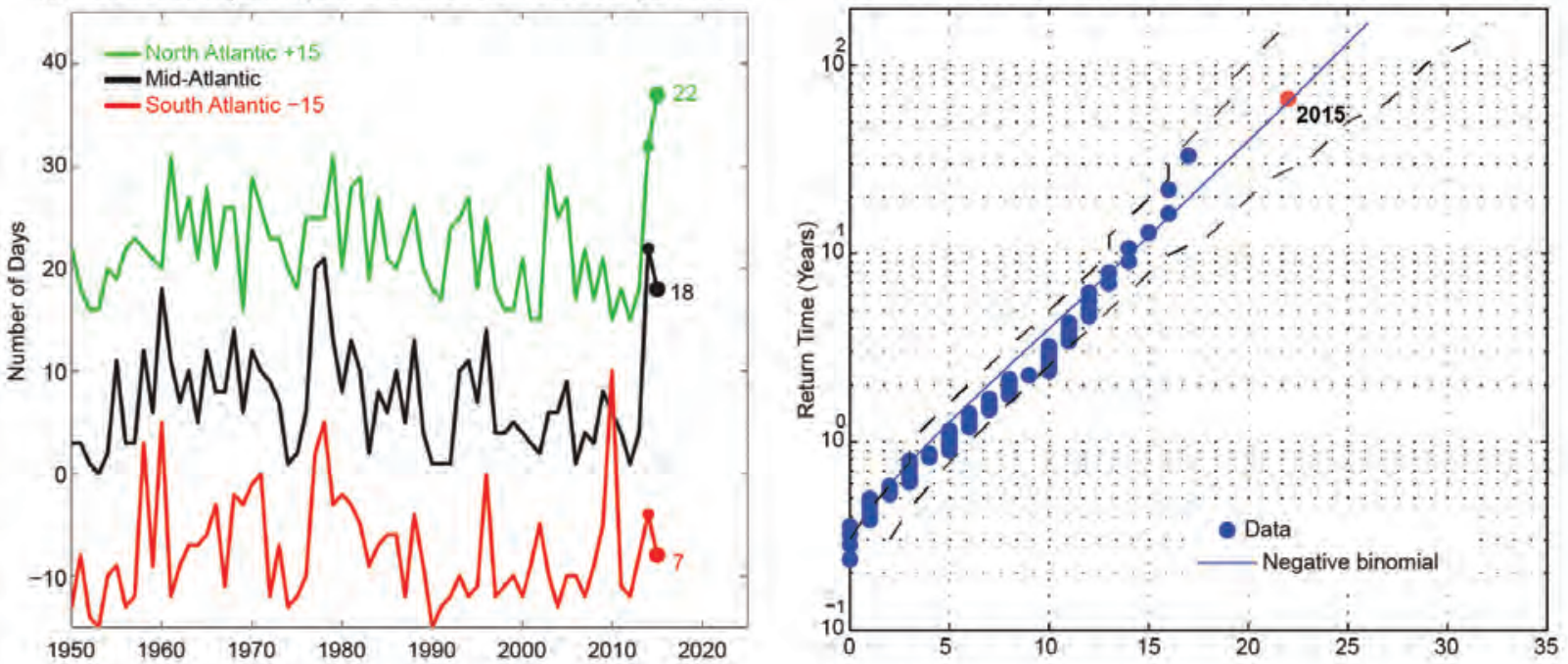

FIG. 7.I. (a) Feb 2015 average temperature anomaly (relative to 1950-20I5). Colored state boundaries indicate regions analyzed here. (b) Minimum Jan-Mar daily temperature anomalies in the North, mid-, and South Atlantic regions. North/South Atlantic time series are offset by $+15^{\circ}$ and $-15^{\circ} \mathrm{C}$, respectively. The gray lines show the 20-year return level, estimated from a GEV distribution in which the location parameter is fit as a linear function of time. (c) Number of days in which daily temperatures during Jan-Mar fall below the I0th percentile (relative to 1961-90) in the North, mid-, and South Atlantic. North/South time series are offset by $+15^{\circ} /-15^{\circ} \mathrm{C}$. (d) Return period for the number of extremely cold days in the North Atlantic (blue circles) and fit to a negative binomial (solid blue line). The red dot shows the return level for 2015 . The $95 \%$ confidence intervals for the negative binomial fit are shown as dashed curves.

below the tenth percentile. The return period for the 2015 duration is estimated from a negative binomial distribution (Winkelmann 2008).

Results. Figure 7.1b shows the winter (JFM) daily minimum temperature anomalies in the North (green), South (red), and mid-Atlantic (black) regions for 1950-2015. The magnitude of the 2015 winter daily minimum temperature anomaly for each region is displayed next to the respective curve. Both the North (Fig 7.1b, large green dot) and mid-Atlantic (Fig 7.1.b, large black dot) regions experienced notably colder temperatures during 2015, where minimum daily temperatures were the 7 th and 2 nd coldest, respectively. It was the 13th coldest minimum daily temperature in the South Atlantic. According to the GEV fit, these minimum temperatures roughly correspond to 15-year return levels for both the North 


\begin{tabular}{|c|c|}
\hline $\begin{array}{l}\text { CMIP5 I.D. } \\
\text { (Experiment) }\end{array}$ & Modeling Center \\
\hline CanESM2 (rlilpl) & Canadian Centre for Climate Modeling and Analysis - Canada \\
\hline CNRM-CM5 (rlilpI) & National Centre for Meteorological Research - France \\
\hline CSIRO-BOMO (rlilpI) & Commonwealth Scientific and Industrial Research Organisation - Australia \\
\hline HADGem2-CC (rlilpI) & Met Office Hadley Centre - United Kingdom \\
\hline IPSL-CM5A-LR (rlilpI) & Institute Pierre Simon Laplace - France \\
\hline IPSL-CM5A-MR (rlilpI) & Institute Pierre Simon Laplace - France \\
\hline IPSL-CM5B-LR (rlilpI) & Institute Pierre Simon Laplace - France \\
\hline MIROC5-ESM-CHEM (rlilpI) & CCSR/NIES/FRCGC - Japan \\
\hline MRI-CGCM3 (rlilpI) & Meteorological Research Institute - Japan \\
\hline NCC-NorESMI-M (rlilpI) & Norwegian Climate Centre - Norway \\
\hline GFDL-ESM2G (rlilpl) & NOAA/Geophysical Fluid Dynamics Laboratory - United States \\
\hline GFDL-ESM2M (rlilpI) & NOAA/Geophysical Fluid Dynamics Laboratory - United States \\
\hline
\end{tabular}

and mid-Atlantic, indicating that the intensity of cold temperatures was not all that extreme.

Trends in the 20-year return level for each region are shown as gray lines in Fig. 7.1b. A statistically significant trend was found only for the north Atlantic region. Because the 20-year return level has increased over the past 66 years, cold events considered normal by 1950s standards are now rare in a warming climate.

The number of days with daily JFM temperature anomalies below the 10th percentile ("extremely cold days") is shown for the three regions in Fig. 7.1c, and the number observed in 2015 is displayed next to each respective curve. The 2015 event in the North Atlantic broke last year's record (Fig 7.1c, small green dot). In the mid-Atlantic, this quantity dropped relative to 2014 but was still high, with 2015 having the 5th largest number of extremely cold days in the region (Fig 7.1c, large black dot). There is no systematic trend in the number of extremely cold days, thus no evidence to suggest that the frequency or persistence of cold events is systematically changing. We estimate the return period for the duration of the cold event by fitting the number of extremely cold days to a negative binomial distribution. We focus our analysis on the North Atlantic, where the duration of cold was record breaking. The negative binomial distribution (blue line in Fig. 7.1d) fits reasonably well the return times for the number of North Atlantic extremely cold days (blue circles in Fig. 7.1d) and indicates that the 2015 event (red dot in Fig. 7.1d) was approximately a one-in-64-year event in terms of the number of extremely cold days.

Observational analysis alone is unable to isolate the relative importance of natural versus human forcing in driving the above changes. To do so, we estimate the trend in the location parameter of the GEV distribution fit to the minimum JFM daily temperature from a suite of CMIP5 climate experiments. The location trends and corresponding 95\% 
confidence intervals for the historical simulations (black) and observations (red) are shown in Fig. 7.2. The observed trend in the North Atlantic is positive and statistically significant. Observed trends in the other two regions are not statistically significant and are not shown. Like observations, all of the climate models have an upward trend (warmer minimum temperatures) in the location parameters of the GEV for North Atlantic minimum JFM daily temperature anomaly, and this positive trend is statistically significant in more than half of the models. These results suggest that events like the 2015 cold wave are becoming less likely in response to climate change.

Discussion. The 2015 cold wave that impacted the eastern United States can be described as a one-in15 -year event in terms of intensity and a one-in-64 year event in terms of duration. Only the magnitude of cold extremes in the North Atlantic United States shows significant long-term trend. Consistent with observations, the majority of climate models find that climate change has led to a shift in the distribution of winter daily minimum temperatures toward warmer conditions, and subsequently a decrease in the likelihood of extreme cold waves in the North Atlantic. This result contradicts the hypothesis that cold winter temperatures are becoming more extreme (Francis and Vaurus 2015). Rather we find observed trends toward a warmer, less variable climate, and

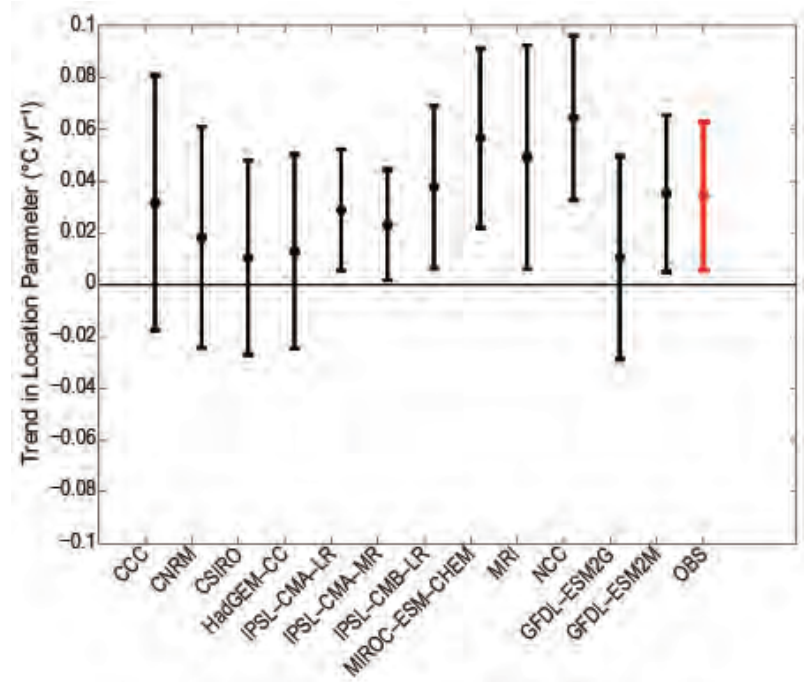

FIG. 7.2. Trend in the location parameter of the GEV distribution fit to the minima of JFM daily temperature from observations (red) and CMIP5 historical simulations (black) for the North Atlantic region during the period 1950-2015. The bars indicate the $95 \%$ confidence intervals. The fit of the location parameter is assumed to change linearly over time. a decrease in the likelihood of such cold winter extremes.

ACKNOWLEDGEMENTS. This research was supported primarily by the National Oceanic and Atmospheric Administration, under the Climate Test Bed program (NA14OAR4310187). Additional support was provided by the National Science Foundation (AGS-1338427), National Aeronautics and Space Administration (NNX14AM19G), the National Oceanic and Atmospheric Administration (NA14OAR4310160). MKT was partially supported by the Office of Naval Research (N00014-12-1-0911 and N00014-16-1-2073). The views expressed herein are those of the authors and do not necessarily reflect the views of these agencies.

\section{REFERENCES}

Bevere, L., R. Sharan, and K. S. Vipin, 2016: Natural catastrophes and man-made disasters in 2015: Asia suffers substantial losses. Swiss Re Sigma No. 1, 48 pp. Coles, S., 2001: An Introduction to Statistical Modeling of Extreme Values. Springer, 208 pp.

Gilleland, E., and R. W. Katz, 2011: New software to analyze how extremes change over time. Eos, Trans. Amer. Geophys. Union, 92 (2), 13-14, doi:10.1029/2011EO020001.

Francis, J. A, and S. J. Vavrus, 2015: Evidence for a wavier jet stream in response to rapid Artic warming. Environ. Res. Lett., 10, 014005, doi:10.1088/1748 $-9326 / 10 / 1 / 014005$.

Menne, M., I. Durre, R. Vose, B. Gleason, and T. Houston, 2012: An overview of the Global Historical Climatology Network-Daily database. J. Atmos. Oceanic Technol., 29, 897-910, doi:10.1175 /JTECH-D-11-00103.1.

NOAA, 2015: State of the climate: National overview for February 2015. National Centers for Environmental Information. [Available online at www.ncdc. noaa.gov/sotc/national/201502.]

_ 2016: Billion-dollar weather and climate disasters: Table of events (Winter storm 2015). National Centers for Environmental Information. [Available online at www.ncdc.noaa.gov/billions/events.]

Seneviratne, S. I., and Coauthors, 2012: Changes in climate extremes and their impacts on the natural physical environment. Managing the Risks of Extreme Events and Disasters to Advance Climate Change Adaptation, C. B. Field et al., Eds., Cambridge University Press, 109-230. 
Taylor, K. E., R. J. Stouffer, and G. A. Meehl, 2012: An overview of CMIP5 and the experiment design. Bull. Amer. Meteor. Soc., 93, 485-498, doi:10.1175/BAMS -D-11-00094.1.

Trenary, L., T. DelSole, M. Tippett, and B. Doty, 2015: Was the cold eastern US winter of 2014 due to increased variability? [in "Explaining Extremes of 2014 from a Climate Perspective"]. Bull. Amer. Meteor. Soc., 96(12), S15-S19, doi:10.1175 /BAMS-D-15-00138.1.

Winkelmann, R., 2008: Econometric Analysis of Count Data., 5th edition. SpringerVerlag, $333 \mathrm{pp}$.

Zwiers, F. W., X. Zhang, and Y. Feng, 2011: Anthropogenic influence on long return period daily temperature extremes at regional scales. J. Climate, 24, 881-892, doi: 10.1175/2010JCLI3908.1. 


\title{
8. THE ROLE OF ARCTIC SEA ICE AND SEA SURFACE TEMPERATURES ON THE COLD 2015 FEBRUARY OVER NORTH AMERICA
}

\author{
Omar Bellprat, François Massonnet, Javier García-Serrano, Neven S. Fučkar, Virginie Guemas, \\ and Francisco J. Doblas-ReYES
}

\begin{abstract}
The cold spell of February 2015 in North America was predominantly internally generated; reduced Arctic sea ice and anomalous sea surface temperatures may have contributed in establishing and sustaining the anomalous flow.
\end{abstract}

Introduction. North America (NA) has experienced a series of cold winters in the last decade that have repeatedly broken records (van Oldenborgh et al. 2015; Hartmann 2015). The winter of $2014 / 15$ was no exception. Montreal recorded the coldest February ever observed and the eastern North American region (ENA; land points only, black box in Fig. 8.1a) experienced the second coldest month since 1900 (see Supplemental Fig. S8.1). The severe February anomaly was accompanied with several intense snowstorms leading to power outages and associated large economic losses (Munich Re, press release, 4 January 2016). The record is surprising given that the region has experienced a $1.4^{\circ} \mathrm{C}$ warming since 1900, compatible with global warming (Tebaldi et al. 2013). Taking this warming into account (following van Oldenborgh et al. 2015), the return period of such an extreme cold event in 2015 is approximately 1000 years, while in 1900 the same event would have occurred on average every 100 years.

Low temperatures over the Northeast in winter are generally associated with pronounced and stationary meandering of the jet stream that channels cold Arctic air into lower latitudes (Diaz and Quayle 1978).

AfFiliations: Bellprat, García-Serrano, FučKarEarth Sciences Dept., Barcelona Supercomputing Centre, Barcelona, Spain; MASSONNET-Earth Sciences Dept., Barcelona Supercomputing Centre, Barcelona, Spain, and Georges Lemaître Center for Earth and Climate Research, Earth and Life Institute, Université catholique de Louvain, Louvain-la-Neuve, Belgium; Guemas-Earth Sciences Dept., Barcelona Supercomputing Centre, Barcelona, Spain, and Centre National de Recherches Météorologiques, Météo-France, Toulouse, France; DoBLASREYES-Earth Sciences Dept., Barcelona Supercomputing Centre, and Institució Catalana de Recerca i Estudis Avançats, Barcelona, Spain

DOI:10.1175/BAMS-D-16-0159.I

A supplement to this article is available online (10.1I75 /BAMS-D-I6-0159.2)
Although the winter yielded a persistent, strong positive North Atlantic Oscillation (NAO) ${ }^{1}$, a wavy structure over NA prevailed in February 2015 as shown in Fig. $8.1 \mathrm{~b}$ for the geopotential height at $500 \mathrm{hPa}$. The anomaly started to develop in the troposphere in January but intensified and became more meridional in February, concomitant with a strengthening of the polar vortex (Supplemental Fig. S8.2). We investigate in this article the potential drivers of both the surface cold anomaly and the anomalous meander of the jet stream in 2015 using an index which measures the meridional wind component at $500 \mathrm{hPa}$ averaged over central North America (CAN; black box in Fig. 8.1b and time-series Supplemental Fig. S8.1).

Although these atmospheric conditions may be part of the natural atmospheric variability, their recurrence during the last decade is striking (Francis and Vavrus 2012), and recent studies have proposed mechanisms to explain its prevalence. The most debated cause points toward the Arctic amplification and the associated accelerated Arctic sea ice retreat (Overland et al. 2015). Reduced sea ice concentration (SIC) leads to strong heat release from the ocean that could modify the meridional temperature gradient and, thus, alter the jet stream and sea level pressure patterns at midlatitudes (e.g., Cohen et al. 2014). A direct, local atmospheric response to the Arctic surface warming could also force anticyclonic circulation anomalies at the surface and project onto a wave-like structure at mid-upper-tropospheric levels (Kug et al. 2015). February 2015 Arctic sea ice conditions depicted in Fig. 8.1c show the third lowest extent since 1979.

A significant body of literature questions this relationship and argues that recent cold winter can

${ }_{1}$ The monthly NAO index based on Z500 reached 1.86, 1.79, and 1.32 in December, January, and February, respectively (Source: NOAA/CPC). 
(a)
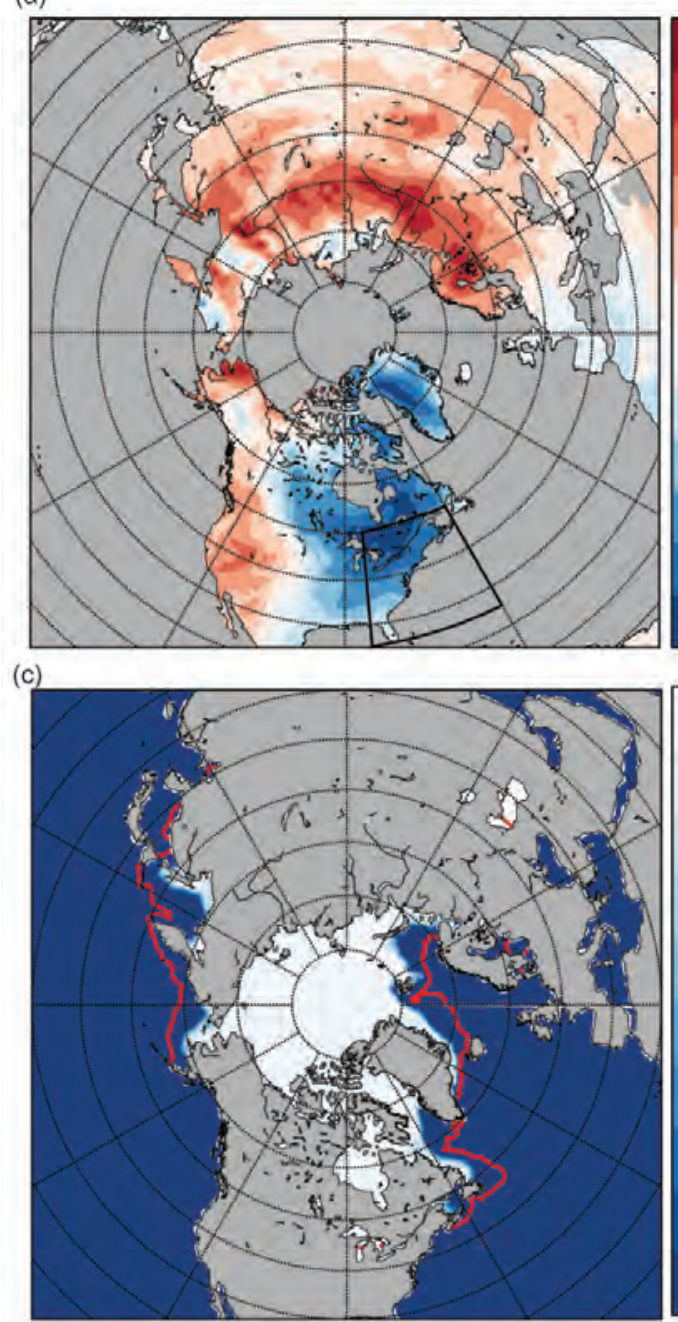

(e)

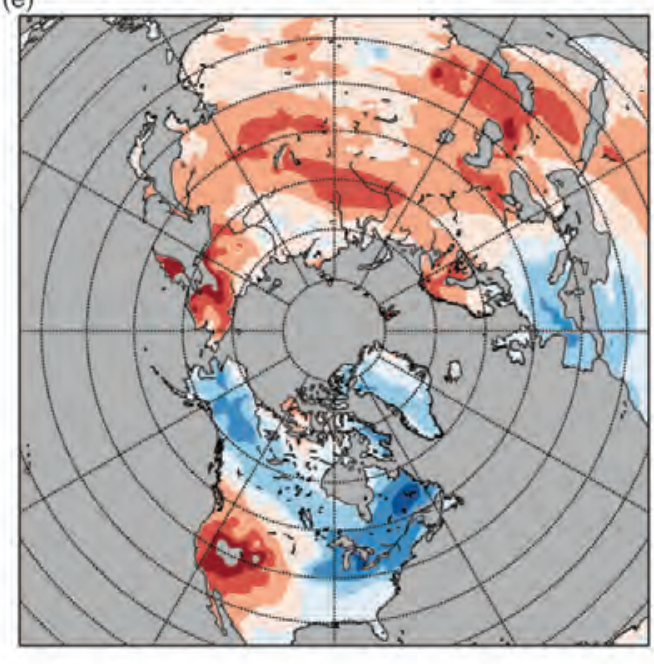

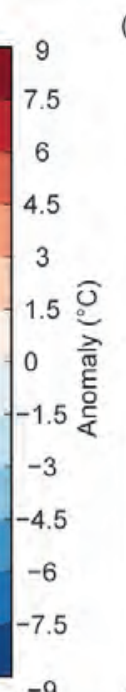

$-9 \quad($ d $)$

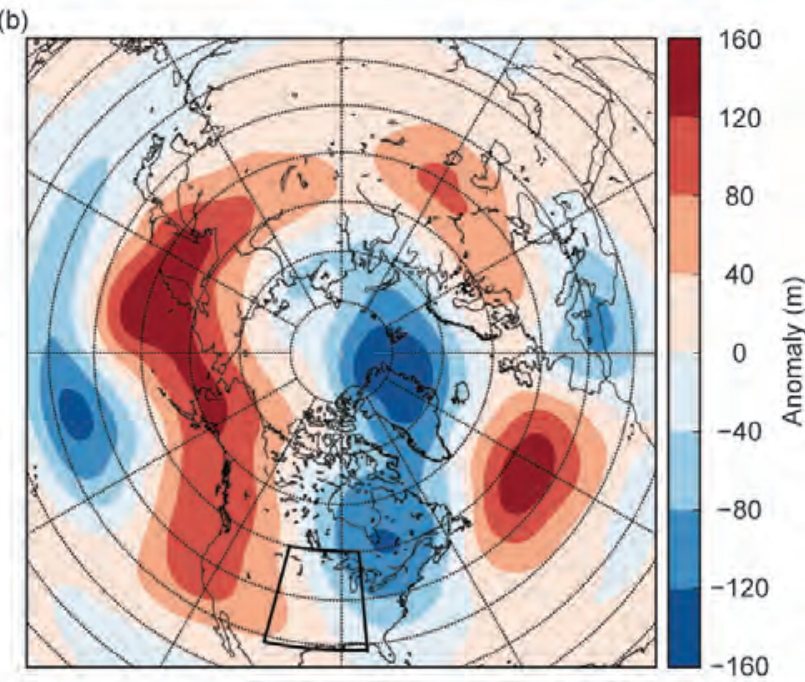

(d)

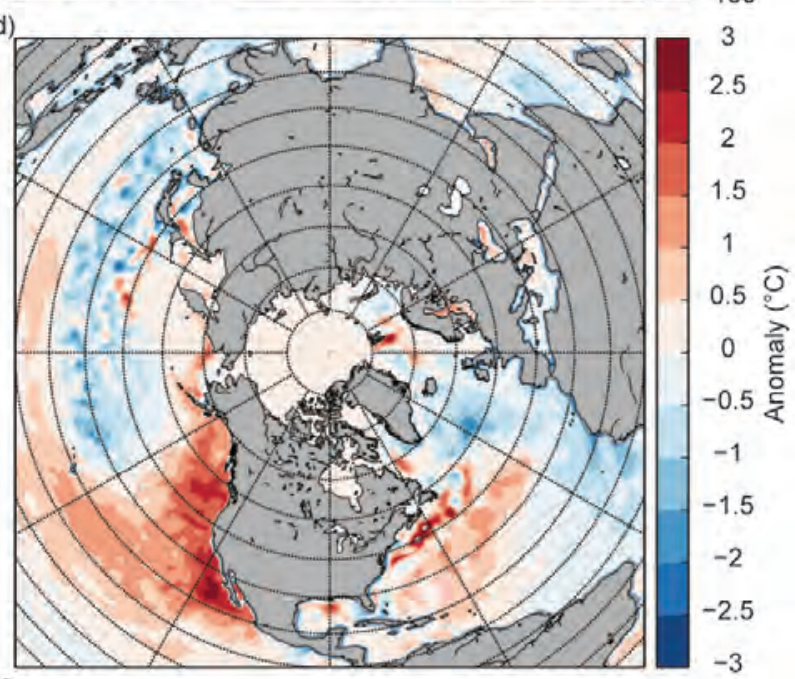

(f)

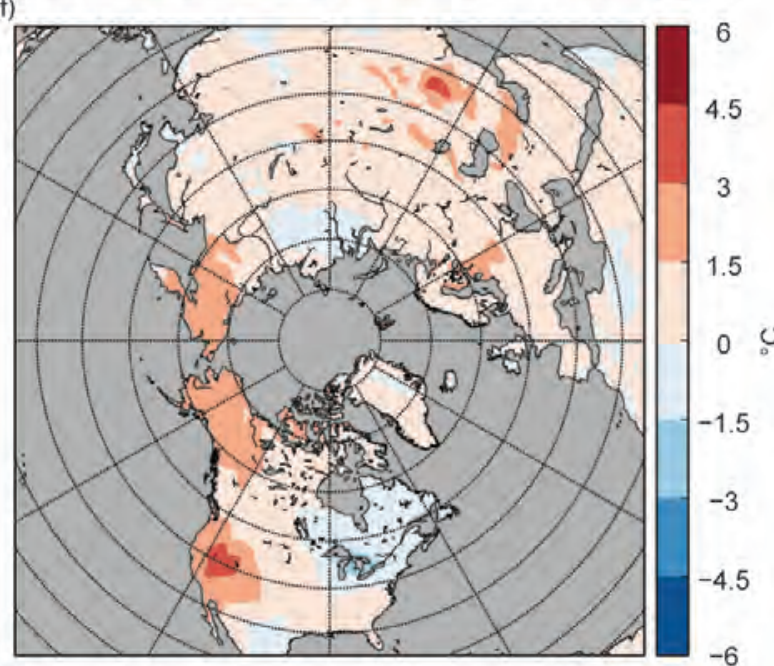

FIG. 8.I. The cold Feb 2015 as observed in the ERA-Interim reanalysis (a)-(d) and simulated 2-m temperature with the atmosphere-only IFS model. (c) The red line shows the SIC climatology (198I-2000) while all other panels show the anomaly from the climatology 198I-2010. Model predictions show the ensemble mean of 100 members starting on (e) I Feb and (f) I Jan. The amplitude of the model predictions is scaled to a smaller range than for the observations. (a) The black box denotes the ENA region and (b) the CAN region used to define the event. 
not be understood by Arctic sea ice decline (e.g., Barnes 2013) and find that these are an articulation of internal atmospheric variability (Sun et al. 2016). Hartmann (2015) relates the recent series of cold NA events to an oceanic internal anomaly of sea surface temperature (SST) prevailing over the east Pacific in 2015, and referred to as the North Pacific mode (NPM; Deser and Blackmon 1995). However, the NPM decayed to an almost neutral state at the beginning of 2015 (Supplemental Fig. S8.3), although a confined positive anomaly along the west coast of NA markedly remained (Fig. 8.1d and globally Supplemental Fig. S8.4).

Reforecasting the cold February 2015. The aim of this study is to assess, using retrospective climate predictions, the contributions of the described anomalous SST pattern (of predominantly natural origin; Hartman 2015) and Arctic sea ice retreat (mainly attributable to anthropogenic climate change; Bindoff 2013) to the occurrence of the cold NA and its associated flow. The predictions rely on simulations using the atmosphere-only integrated forecast system (IFS; cycle 36r4) forced by SST and SIC from the ERAInterim reanalysis (Dee et al. 2011). Three types of retrospective predictions of February 2015 are carried out. A first experiment aims at reproducing the event using actual atmospheric conditions in 2015 as initial conditions and surface boundary forcings (hereafter referred to as INI). Two additional experiments test the sensitivity to either SST (using a 1981-2010 SST climatology instead of the 2015 state as boundary conditions, CLIMSST) or SIC (using a 1981-2000 SIC climatology, hereafter CLIMICE, omitting the last decade in order to exclude Arctic sea ice decline in the climatology). Note that prescribing SSTs bears the risk of exaggerated ocean heat release due to the lack of coupling with the ocean and thus potentially overestimates the influence of anomalous SSTs.

Each experiment is initialized from observational estimates of the atmospheric state from ERA-Interim including singular vector perturbations (Buizza and Palmer 1994) to generate 100 ensemble members. The experiments are initialized on 1 January and 1 February to assess timescales at which predictability of the event emerges. Furthermore, a hindcast set of the 1981-2010 period has been carried out using three-monthly predictions initialized each 1 January and 1 February with ten ensemble members in order to evaluate the reliability of the model to simulate cold events over North America and identify systematic biases in the mean for bias correction.
The ensemble-mean prediction starting in February (Fig. 8.1e) captures the event shown with a pronounced cold anomaly in the Northeast and a warming in the Southwest. Both experiments using either climatological SSTs or climatological SIC reproduce the event as well, demonstrating that the atmospheric initial state holds the main sources of predictability of the event. The ensemble-mean prediction starting in January (Fig. 8.1f) shows much less pronounced temperature anomalies over the target region and does not reproduce the spatial pattern. This suggests that surface boundary conditions did not force the core of the event, neither did potential stratospheric precursors (Supplemental Fig. S8.5) or anomalies linked to sea ice conditions preceding the predictions (Kim et al. 2014).

Attribution to surface boundary conditions. Retrospective predictions of the extreme cold February 2015 suggest that the atmospheric flow established in late Januaryearly February was mainly internally generated, yet surface boundary conditions could still have played a role in altering the probability that such an unlikely event occurred. To answer this question, we compare the probabilities to observe the recorded temperatures anomalies and their associated anomalous flow in the CLIMSST, CLIMICE, and INI experiments. The attribution relying on predictions starting in January and February is seemingly similar, but addresses a different question since the atmospheric anomaly is largely set in on 1 February. The attribution relying on the February and January predictions therefore quantifies how surface boundary conditions have contributed in sustaining or establishing the anomaly, respectively. The model ensembles are calibrated following Bellprat and Doblas-Reyes (2016), in order to correct for model limitations in representing this type of events (more details in the online supplemental material).

The calibrated probability density functions (PDFs) of the 100 members of the model ensembles are shown in Figs. 8.2a,b (temperature) and Figs. $8.2 \mathrm{e}, \mathrm{f}$ (jet). The predictions starting in February are shifted towards the observed anomalies (black lines) while the predictions starting in January have almost no ensemble-mean anomaly as discussed in the previous section. The picture is overall consistent between temperature and the jet index. Changes in the surface boundary forcing reduce the ensemble variability in all cases, yet only significantly for the jet index (F-test at $5 \%$ significance level). The ensemblemean is slightly colder in CLIMSST, possibly linked to 

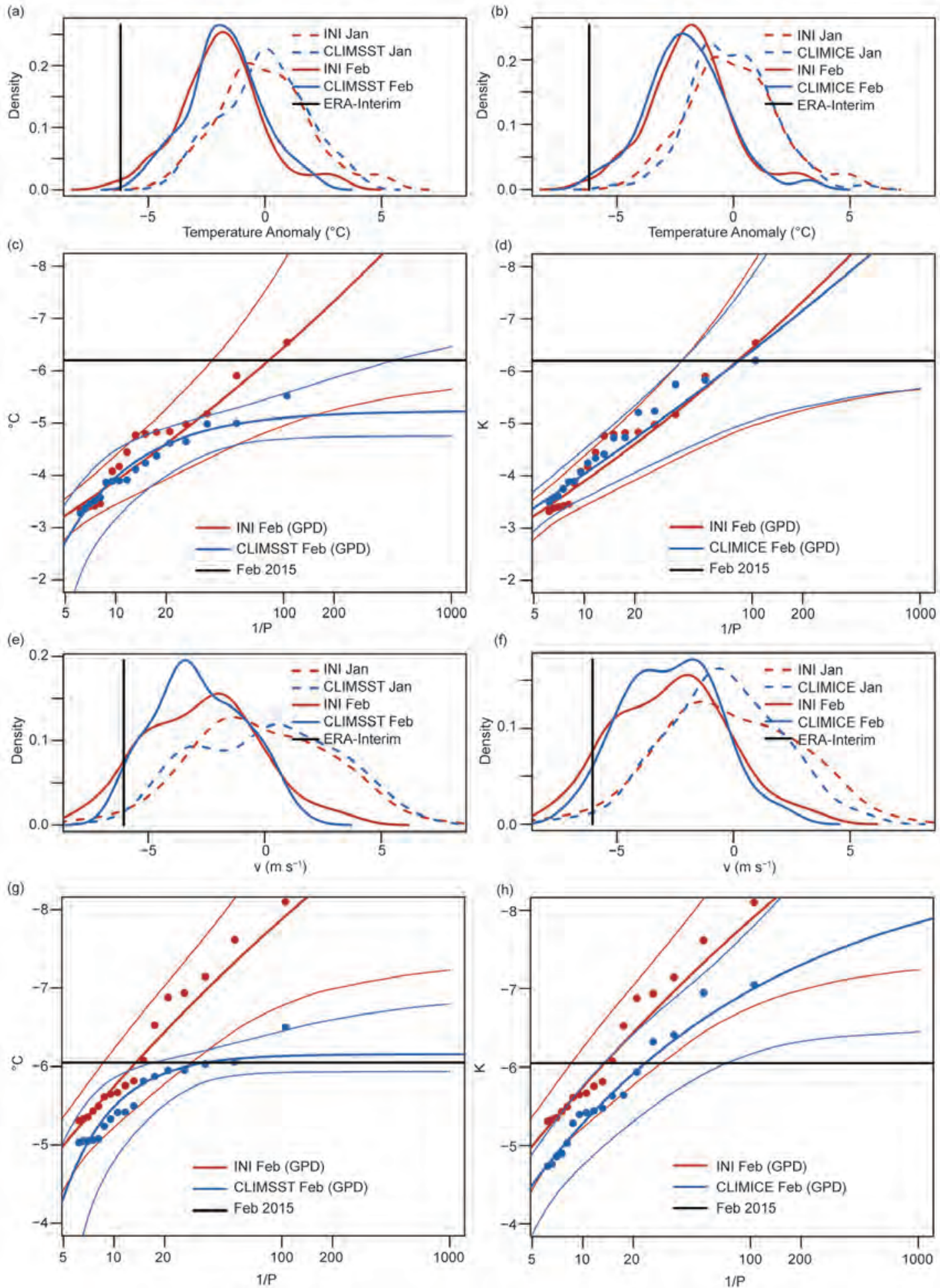

FIG. 8.2. (a)-(d) Simulated Feb 2015 2-m temperature anomalies $\left({ }^{\circ} \mathrm{C}\right)$ and (e)-(h) anomalies of the jet index $\left(\mathrm{m} \mathrm{s}^{-1}\right)$ with respect to the model climatology when starting the predictions in Jan (dashed) and in Feb (continuous). (a),(b) and (e),(f) compare the PDFs of the simulations with observed conditions of SST and SIC to the one using climatological conditions CLIMSST (a),(e) and CLIMICE (b),(f) using kernel smoothed densities. The black line denotes the observed anomaly. (c),(d) and (g),(h) show a peak over threshold analysis of the ensemble tails comprising of a GPD for the Feb predictions. The lines show the central estimate with the 5\%-95\% confidence interval obtained by resampling the ensemble data with replacement. 
advection of colder Arctic temperatures (compared to INI) due to larger ice coverage (Sun et al. 2016). The observed event represents a rare case, particularly for the temperature anomaly, and a generalized Pareto distribution (GPD) retaining 20\% of ensemble data is used to estimate the event probability for predictions starting in February (Figs. 8.2c,d and g,h) and January (Supplemental Fig. S8.4). The return period of the temperature anomaly in the conditioned predictions (starting in February) is 100 years and around 1000 years in the unconditioned predictions (starting in January), consistent with the return time estimated from the observations as described in the introduction.

Changes in event probabilities (intercept with the black line, Fig. 8.2) reveal lower probabilities in CLIMSST for both temperature and the jet index and lower probabilities for CLIMICE for the jet index compared to INI. For the temperature anomaly, sea ice conditions seem not to have played a role. The uncertainty ranges (determined by resampling) are overall large (95\% confidence bounds, thin lines). Differences in probabilities are qualitatively consistent with predictions starting in January. Overall we find that SST and SIC have increased the probability of establishing a meandering flow approximately by a factor 10 (January predictions, Supplemental Figs. $\mathrm{S} 8.4 \mathrm{e}, \mathrm{f}$ ) and doubled the probability that the flow maintained its wavy structure (February predictions, Figs. $8.2 \mathrm{~g}, \mathrm{~h}$ ). The temperature anomaly would have been extremely unlikely if anomalous SSTs would not have persisted in February (Fig. 8.2c), yet the cold anomaly represents an extreme case without preconditioning the flow (Supplemental Figs. S8.4ad), regardless of the surface boundary forcing.

As a summary we conclude that reduced Arctic sea ice, which is linked to anthropogenic activity, and anomalous SSTs, mainly a consequence of natural variability, did not drive the core of the event, but they may have both contributed in establishing and sustaining the anomalous meander of the jet stream, and hence, could contribute in the near future to enlarge the probability of such extreme cold spells in the region.

ACKNOWLEDGEMENTS. This work was funded by the EU projects EUCLEIA (607085), SPECS (308378), and PRIMAVERA (641727). The authors are supported by the following fellowships: Bellprat (ESA Living planet, VERITAS-CCI), Massonnet and Fučkar (Juan de la Cierva), García-Serrano (Marie Currie, DPETNA, 655339), Guemas (Ramón y Cajal)
The author thankfully acknowledges the computer resources, technical expertise, and assistance provided by the Red Española de Supercomputación. We further thank constructive comments from Martin Hoerling and three anonymous reviewers.

\section{REFERENCES}

Barnes, E. A., 2013: Revisiting the evidence linking Arctic amplification to extreme weather in midlatitudes. Geophys. Res. Lett., 40, 4734-4739, doi:10.1002/grl.50880.

Bellprat, O., and F. Doblas-Reyes, 2016: Attribution of extreme weather and climate events overestimated by unreliable climate simulations. Geophys. Res. Lett., 43, 2158-2164, doi:10.1002/2015GL067189.

Bindoff, N. L., and Coauthors, 2013: Detection and attribution of climate change: from global to regional. Climate Change 2013: The Physical Science Basis, T. Stocker et al., Eds., Cambridge University Press, 867-952.

Buizza, R., and T. N. Palmer, 1995: The singular-vector structure of the atmospheric global circulation. J. Atmos. Sci., 52, 1434-1456.

Cohen, J., J. A. Screen, J. C. Furtado, M. Barlow, D. Whittleston, D. Coumou, and J. Jones, 2014: Recent Arctic amplification and extreme mid-latitude weather. Nat. Geosci., 7, 627-637, doi:10.1038 Ingeo2234.

Dee, D. P., and Coauthors, 2011: The ERA-Interim reanalysis: Configuration and performance of the data assimilation system. Quart. J. Roy. Meteor. Soc., 137, 553-597.

Deser, C., and M. L. Blackmon, 1995: On the relationship between tropical and North Pacific sea-surface temperature variations. J. Climate, 8, 1677-1680.

Diaz, H. F., and R. G. Quayle, 1978: The 1976-77 winter in the contiguous United States in comparison with past records. Mon. Wea. Rev., 106, 1393-1421.

Francis, J. A., and S. J. Vavrus, 2012: Evidence linking Arctic amplification to extreme weather in mid-latitudes. Geophys. Res. Lett., 39, L06801, doi:10.1029/2012GL051000.

Hartmann, D. L., 2015: Pacific sea surface temperature and the winter of 2014. Geophys. Res. Lett., 42, 18941902, doi:10.1002/2015GL063083.

Kim, B.-M., S.-W. Son, S.-K. Min, J.-H. Jeong, S.-J. Kim, X. Zhang, and J.-H. Yoon, 2014: Weakening of the stratospheric polar vortex by Arctic sea-ice loss. Nat. Comm., 5, 4646, doi:10.1038/ncomms5646. 
Kug, J.-S., J.-H. Jeong, Y.-S. Jang, B.-M. Kim, C. K. Folland, S.-K. Min, and S.-W. Son, 2015: Two distinct influences of Arctic warming on cold winters over North America and East Asia. Nat. Geosci., 8, 759762, doi:10.1038/ngeo2517.

NOAA/CPC (National Weather Service, Climate Prediction Center), cited 2016: Monthly mean NAO index since January 1950. [Available online at www .cpc.ncep.noaa.gov/products/precip/CWlink/pna /nao.shtml.]

Overland, J., J. A. Francis, R. Hall, E. Hanna, S.J. Kim, and T. Vihma, 2015: The melting Arctic and midlatitude weather patterns: Are they connected? J. Climate, 28, 7917-7932, doi:10.1175 /JCLI-D-14-00822.1.

Sun, L., J. Perlwitz, and M. Hoerling, 2016: What caused the recent "Warm Arctic, Cold Continents" trend pattern in winter temperatures? Geophys. Res. Lett., 43, 5345-5352, doi:10.1002/2016GL069024.

Tebaldi, C., D. Adams-Smith, and A. Kenward, 2013: Warming winters U.S. temperature trends. Climate Central Special Report, 15 pp. [Available online at www.climatecentral.org/wgts/warming-winters /WarmingWinters.pdf.]

van Oldenborgh, G. J., R. Haarsma, H. De Vries, and M. R. Allen, 2015: Cold extremes in North America vs. mild weather in Europe: The winter of 2013-14 in the context of a warming world. Bull. Amer. Meteor. Soc., 96, 707-714, doi:10.1175/BAMS-D-14-00036.1. 


\title{
9. THE 2015 EXTREME DROUGHT IN WESTERN CANADA
}

\author{
Kit Szeto, Xuebin Zhang, Robert Edward White, and Julian Brimelow
}

Analysis results indicate that the 2015 extreme drought in western Canada was likely an outcome of anthropogenically influenced warm spring conditions and naturally forced dry weather from May to July.

Introduction. Although drought is common over western Canada (Bonsal et al. 2011), the drought that affected the area during the spring and summer of 2015 (Fig. 9.1a) was unusual in terms of its severity, extent, and impacts. British Columbia (B.C.) and Alberta were the most severely affected provinces. Vast areas in southern B.C. were assigned the highest possible (Level-4) drought rating by the B.C. government, several extreme-low streamflow advisories, and extreme wildfire risk ratings. Stringent water restrictions were in place by the end of June (AFCC 2016). In Alberta, conditions were even drier, and the Alberta government declared the province an Agricultural Disaster Area by early August. The extreme dry and warm conditions also created one of the most active and longest wildfire seasons for western Canada, and some rivers ran at their lowest recorded flows since measurements began 80 to 100 years ago (CMOS 2016). The extreme heat and dryness the region experienced in 2015 have raised concerns as to whether or not anthropogenic climate change (ACC) has increased the risk of extreme droughts in the area; this is the question we attempt to address in this paper.

Hydrometeorological conditions. Because the drought affected a vast area that includes regions characterized by different climate conditions, this study focuses on southern B.C., among the worst-affected regions. Three critical factors need to exist for severe drought to occur in southern B.C.: 1) low snowpack near the end of winter, 2) dry spring (May-June), and 3) dry summer (July-August) conditions (BCMOE 2016). The winter preceding the drought was characterized by near-normal precipitation. Apart from the

AFFILIATIONS: SZETO, ZHANG, AND WHITE-Environment and Climate Change Canada, Downsview, Ontario, Canada; Brimelow-Environment and Climate Change Canada, Edmonton, Alberta, Canada

DOI:10.II75/BAMS-D-16-0147.I

A supplement to this article is available online (10.1175 /BAMS-D-16-0147.2) extremely low snowpack that was observed in southwestern B.C. throughout the winter, near-normal to slightly below-normal snowpacks were present near the end of winter across most of the province (BCRFC 2015a). However, due to anomalously warm temperatures in March and April (MA; Fig. 9.2a), record low snow water equivalent (SWE) was observed over most of southern B.C. by 1 May (BCRFC 2015b). A persistent upper ridge off the west coast of North America (Fig. 9.1b) resulted in extraordinary warm and dry conditions from May through July (MJJ; Fig. 9.1c). The low SWE was compounded by the extreme dry conditions to create one of the worst droughts in the region. Time series of region-averaged standardized precipitation and evapotranspiration index (SPEI; Vicente-Serrano et al. 2010) for MJJ shows that the value for 2015 was the second lowest for the 1950-2015 period (Fig.9.1d), reflecting the significant surface moisture deficit in the area.

Methods. Attribution for the 2015 event is carried out using CMIP5 results (Taylor et al. 2012). It is wellknown that coarse-grid climate models have very limited skills in simulating precipitation or SWE at regional scales. The preceding discussion suggests that it is justifiable to simplify the attribution analysis by limiting the drivers to the warm MA temperature $\left(T_{34}\right)$ that caused the enhanced and earlier than normal melt and subsequent low summer runoff, and the hot and dry MJJ weather that aggravated the conditions during the growing season. In addition, the intensity of the upper ridge, which is physically linked to the variability of both precipitation $(P)$ and temperature $(T)$ during MJJ, is used as proxy for both variables.

It is evident from the point correlation map of region-averaged MJJ $P$ with geopotential heights $(Z)$ at $500 \mathrm{hPa}$ (Fig. 9.1e) that dry (wet) conditions are related to positive (negative) upper-level height anomalies off the west coast. A parameter $(H)$ is formulated to quantify the intensity of the upper-level ridge (see 
(a)
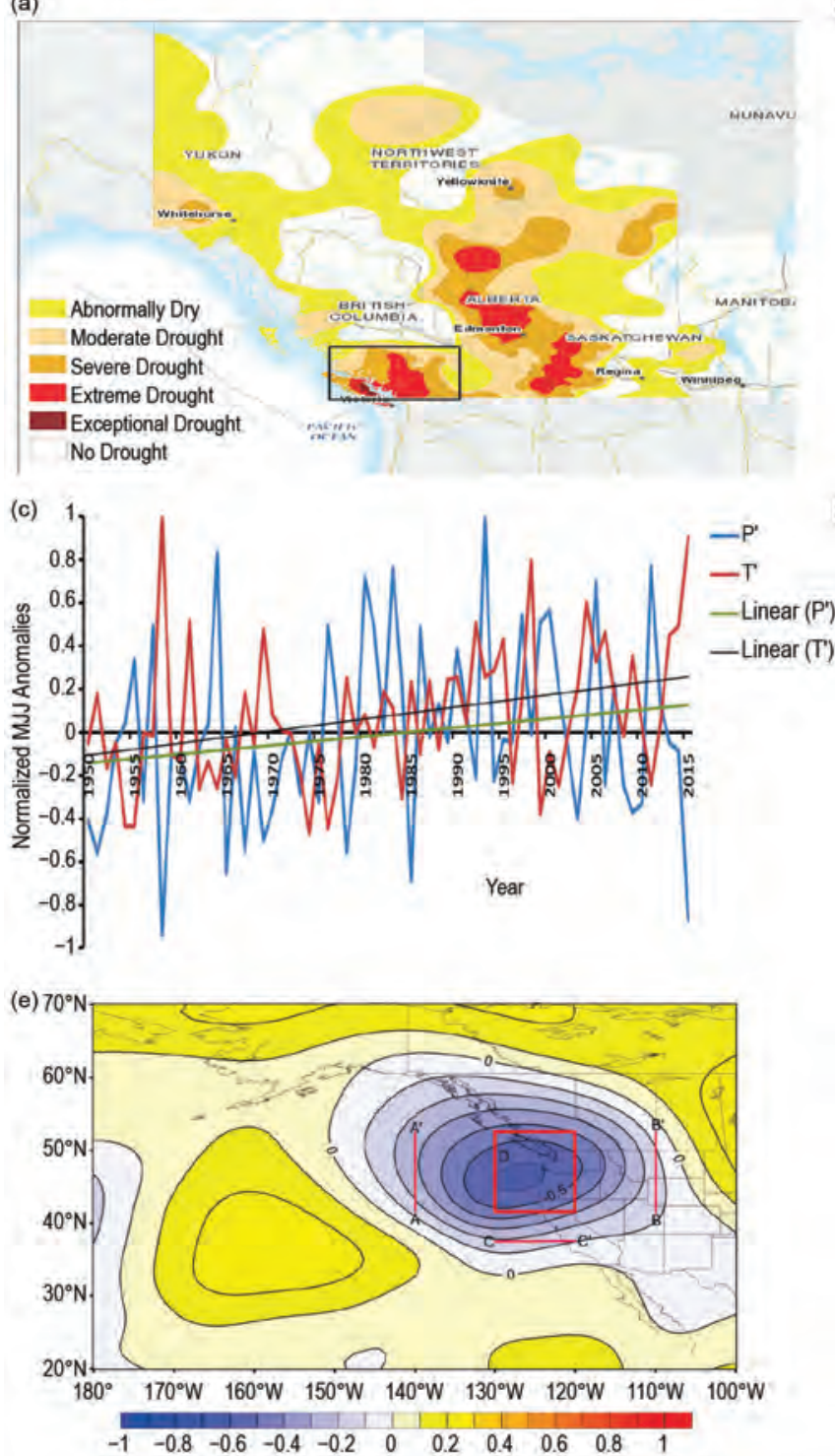

(b)
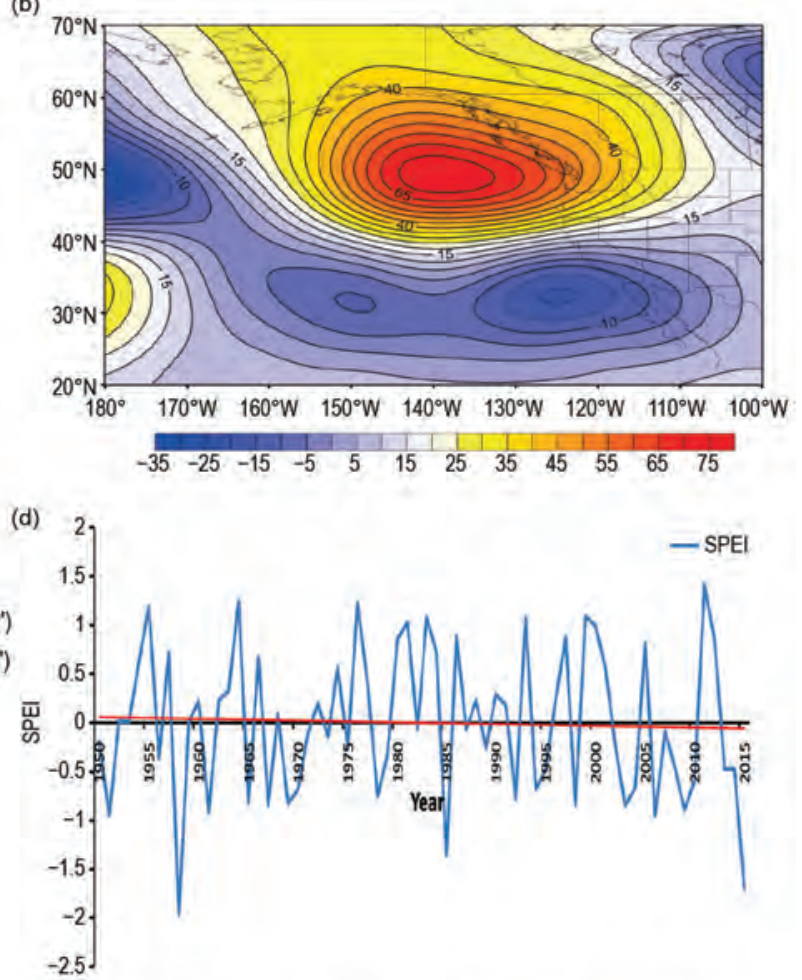

(f)

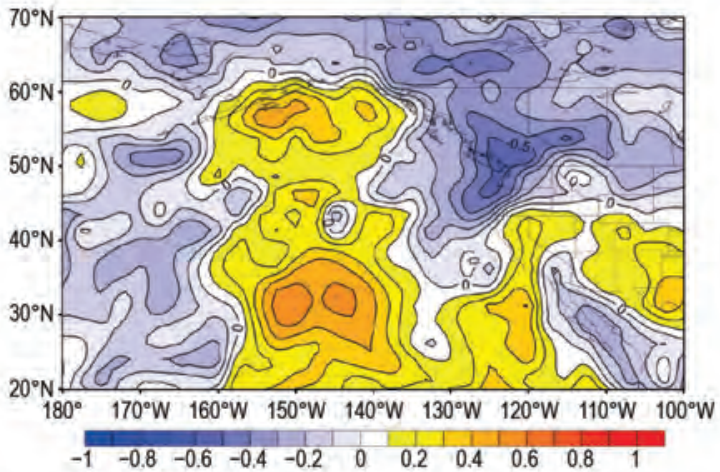

Fig. 9.I. (a) Jul 2015 drought conditions over western Canada (adapted from AAFC 2016). The rectangle over southern B.C. shows the study area where spatial averages of parameters are calculated. (b) MJJ height anomalies at $500 \mathrm{hPa}$ from NCEP reanalysis (Kalnay et al. 1996). (c) 1950-20I5 time series of normalized area-average MJJ precipitation and temperature anomalies computed from Environment and Climate Change Canada's homogenized CANGRD monthly dataset (Vincent et al. 2015). (d) Time series (blue) and linear trend (red) of area-average MJJ SPEI obtained from the SPEI Global Drought Monitor (http://sac.csic.es/spei/map/maps .html). (e) Map of correlations between the P' time series in (b) and MJJ NCEP height at $500 \mathrm{hPa}$. Also shown are the region $D$ and cross-sections used in the computation of $H$ with Eq. (I). (f) Map of correlations between the time series of $\mathrm{H}$ computed from NCEP reanalysis with MJJ GPCP precipitation (Adler et al. 20I2).

the online supplemental information for details):

$$
H=3\left\langle Z^{\prime}\right\rangle_{D}-\left\langle Z^{\prime}\right\rangle_{A A^{\prime}}-\left\langle Z^{\prime}\right\rangle_{B B^{\prime}}-\left\langle Z^{\prime}\right\rangle_{C C^{\prime}}
$$

where the anomalies are relative to the 1971-2000 climatology. Locations of the region D and transects used in the calculation of $H$ are shown in Fig. 9.1e. $H$ exhibits statistically significant correlations with precipitation over western Canada in general
(Fig. 9.1f). Contemporaneous correlations between detrended $H$ and $P, T$, and SPEI averaged over southern B.C. are $-0.68,0.74$, and -0.76 , respectively. Time series of $H$ computed from reanalysis data (Fig. 9.2c) shows that years of extreme positive values of $H$ (e.g., above the 95th percentile- $H c=60 \mathrm{~m}$ ) also correspond well with extreme dry and warm years. In particular, both the driest and hottest MJJ and largest $H$ occurred in 1958, and the value for 2015 is the third 
largest over the period. The other two high $H$ years (1969 and 1992) were also exceptionally warm and dry, but the conditions improved in July, resulting in less extreme seasonal averages.

To determine how greenhouse gas (GHG) forcing influences $T_{34}$ and the $H$-index, we compare the trends and other statistics of these variables as computed from observed or reanalysis data and ensembles of CMIP5 historical simulations with natural (NAT) or all (ALL) forcings. The list of 19 CMIP5 models used in the analysis is given in the online supplemental information. The change in likelihood of extreme droughts in southern B.C. from GHG forcing is assessed by evaluating how the exceedance probabilities for these variables differ between the ALL and NAT ensembles. This is achieved by calculating the fraction of attributable risk (FAR; Allen 2003), as detailed in the supplemental information.

Results. We first investigate if ACC has increased the risk of reduced snowpacks at the end of winter. There is no detectable trend of December-March precipitation in either the observations or CMIP5 results (not shown). There are, however, significant warming trends for $T_{34}$ in both the observed and CMIP5-ALL ensemble-mean data, but not for the NAT runs (Fig. 9.2a). No significant increasing trend is evident in the ensemble maximum $T_{34}$ for either ALL or NAT. The best estimate (median) FAR calculated by using thresholds corresponding to the 96th percentiles of (a)

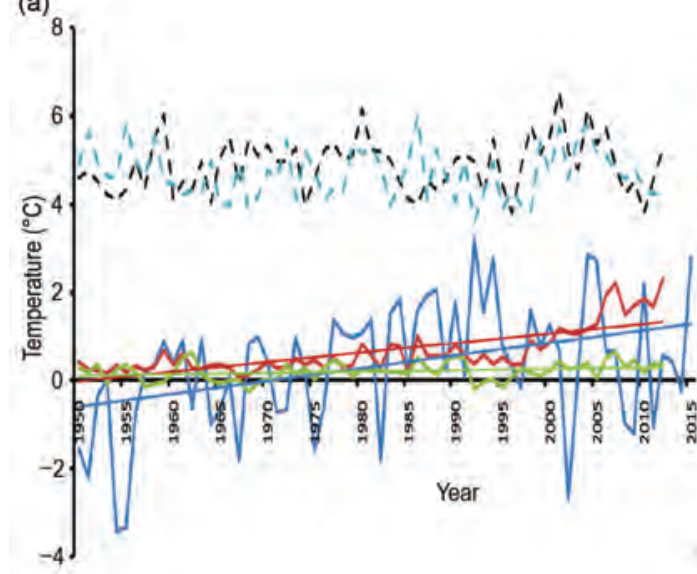

(c)

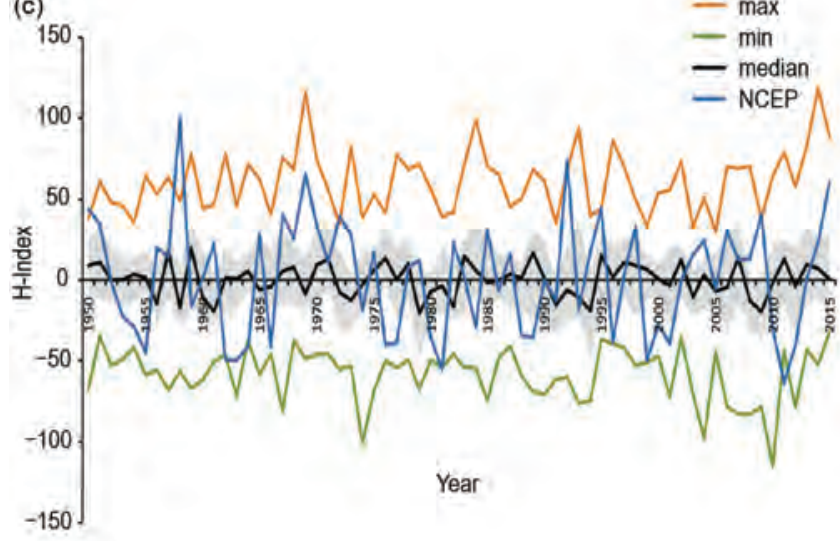

(b)

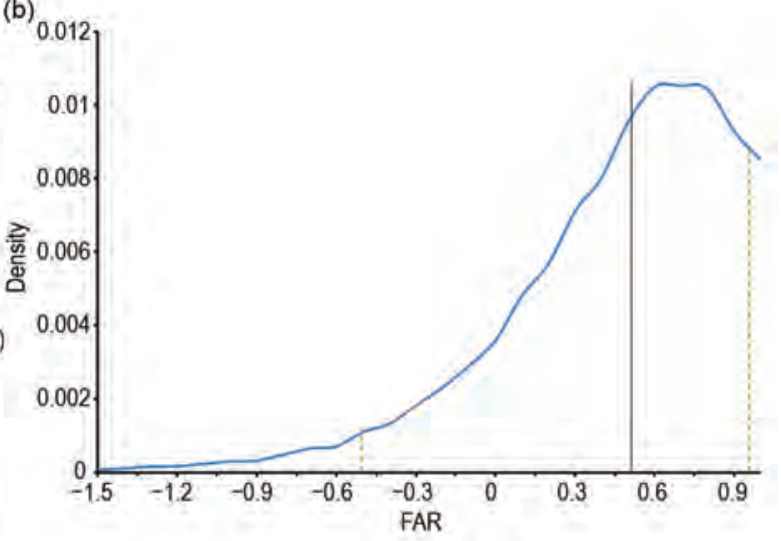

(d)

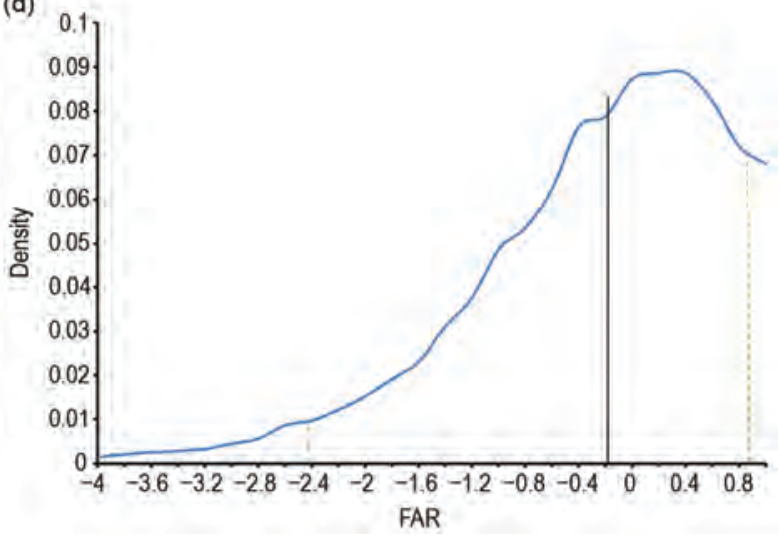

FIG. 9.2 (a) Time series of MA temperatures ( $\left.T_{34}\right)$ computed from CANGRD (blue) dataset and the ensemble mean $\mathrm{T}_{34}$ for experiments ALL (red) and NAT (green), along with linear trends for the corresponding series. Also shown are the time series of ensemble maximum for ALL (dashed black) and NAT (blue dashed). (b) Empirical distribution of FAR computed with thresholds set as the 96 th percentiles of $T_{34}$ from the individual ALL runs. (c) 1950-20I5 time series of the MJJ $H$-index computed from NCEP reanalysis (blue) and the ensemble minimum (green), median (black), and maximum (orange) of $\boldsymbol{H}$ for experiment ALL. Gray shading indicates the range between the 25th and 75th percentiles. The CMIP5 historical simulations end at 2005 and ensemble statistics for $\boldsymbol{H}$ from 2006 to 2015 are computed from the RCP4.5 projection results. (d) As in (b) but for the MJJ $H$-index and computed with thresholds set as the 96th percentiles of $H$ from the ALL runs. 
T34 in ALL runs (i.e., the same percentile for the $T_{34}$ observed for 2015) is about 0.49 (Fig. 9.2b). This suggests that external forcing (mainly anthropogenic forcing) may have doubled the risk for the occurrence of the recent extreme high $T_{34}$ that resulted in the early snowmelt, as evidenced by the early peak flows in the streamflow data (BCRFC 2015b). We note, however, that the FAR estimate has a large spread.

How ACC might have affected the MJJ conditions is examined next. Figure 9.1c shows that both $T$ and $P$ increased between 1950 and 2015. Given that there is no trend in the area-average SPEI (Fig. 9.1d), it is likely that the effects of increasing $P$ on surface water balance could have been offset by the increase in evapotranspiration due to the warming temperatures during this time. Regardless of whether the increases in $T$ and $P$ were the result of ACC, the results suggest they currently do not have detectable influence on surface water balance in MJJ and thus drought risk in the region.

Next we assess whether GHG forcing has affected the upper ridge that creates the meteorological conditions (i.e., low $P$ and high $T$ ) that are critical for the development of extreme drought. The bounds of $H$ computed from either the ALL or NAT ensembles are comparable to those exhibited in the $H$-index derived from the NCEP reanalysis, suggesting that the "observed" variability of $H$ was reproduced by the models in these two experiments. No significant trend (at 5\% level) is detected for either the NCEP $H$ or ensemble statistics (median, extrema, etc.) for the two CMIP5 experiments (Fig. 9.2c; results are not shown for NAT), suggesting that GHG forcing has not produced detectable change in the intensity of the west coast upper ridge and the attendant increase in the risk of drought in the area.

Lastly, we examine if ACC has increased the risk of extreme $H$ that are associated with extreme droughts. Results show that the exceedance probability for extreme $H$ in ALL runs is similar to and perhaps somewhat smaller than that in NAT runs (Fig. 9.2d), suggesting that GHG forcing has not resulted in detectable increase in the risk of extremely high $H$, and consequently the occurrence of intense stationary upper ridge and associated extreme warm and dry conditions. Similar results are also obtained for a parallel analysis that was carried out by constructing $H$ based on the $Z$ ' composited over the three driest MJJ during the 1950-2015 period.

Concluding remarks. The multifaceted characteristics and forcings of droughts render attribution analysis of their causes a challenging task, particularly for a region where both cold- and warm-season processes are critical for drought development. Results from this study indicate that ACC likely played a role in causing the warm late-winter temperatures and the associated reduction in snowpack that set the stage for the 2015 drought. On the other hand, there is no detectable evidence that GHG forcing influenced the intensity or the likelihood of occurrence for the strong and persistent upper-air ridge off the west coast that brought the record heat and dryness in MJJ, which escalated the drought to an extreme event. The results thus suggest that the extreme drought was likely an outcome of anthropogenic effect that has increased the occurrence of extreme warm spring temperatures and natural climate variability that caused the persistent upper ridge. The climate of western Canada is known to be influenced strongly by key Pacific climate variability modes on sub-seasonal to multidecadal time scales (Gan et al. 2007). For instance, the developing intense 2015-16 El Niño could have contributed to the extreme summer conditions. However, the question of whether or not El Niño played a role does not alter the conclusion that the extreme MJJ conditions were mainly a result of natural variability. Lastly, it is noteworthy that analysis of CMIP5 projections suggests that both late-winter warming and the west coast upper ridge could be enhanced in response to GHG forcing during the latter part of this century. As such, effects of changes in warm-season precipitation and temperature on the surface water budget might not offset each other, or may even reinforce each other in the future. The collective effects of these projected changes on future extreme droughts in western Canada are being investigated and the results will be reported elsewhere.

ACKNOWLEDGEMENTS. We thank the three anonymous reviewers and Dr. James Kossin for helpful comments. This research is supported by Environment and Climate Change Canada and the Changing Cold Regions Network (CCRN) which is sponsored by the Natural Sciences and Engineering Research Council of Canada (NSERC). 


\section{REFERENCES}

AAFC, 2016: 2015 Annual review of agroclimate conditions across Canada. Agriculture and AgriFood Canada , 23 pp. [Available online at www .agr.gc.ca/resources/prod/doc/pdf/agroclimate _ar_2015-en.pdf.]

Adler, R. F., G. Gu, and G. Huffman, 2012: Estimating climatological bias errors for the Global Precipitation Climatology Project (GPCP). J. Appl. Meteor. Climatol., 51, 84-99, doi:10.1175/JAMC-D-11-052.1.

Allen, M., 2003: Liability for climate change. Nature, 421, 891-892, doi:10.1038/421891a.

BCMOE, 2016: British Columbia drought response plan. B.C. Ministry of Environment, 38 pp. [Available online at http://www2.gov.bc.ca/assets/gov /environment/air-land-water/water/drought-info /drought-response-plan-update-june-2015.pdf.]

BCRFC, 2015a: Water supply and snow survey bulletin: March 1, 2015. British Columbia River Forecast Centre [Available online at http://bcrfc.env.gov .bc.ca/bulletins/watersupply/archive.htm.]

_- 2015b: Water supply and snow survey bulletin: May 1, 2015. British Columbia River Forecast Centre [Available online at http://bcrfc.env.gov.bc.ca /bulletins/watersupply/archive.htm.

Bonsal, B. R., E. Wheaton, A. C. Chipanshi, C. A. Lin, D. J. Sauchyn, and L. Wen, 2011: Drought research in Canada: A review. Atmos.-Ocean, 49, 303-319, doi: 10.1080/07055900.2011.555103.

CMOS, 2016: Canada's top ten weather stories for 2015. Canadian Meteorological and Oceanographic Society. [Available online at www.cmos.ca/site/top _ten?a=2015.]

Gan, T., A. Gobena, and Q. Wang, 2007: Precipitation of southwestern Canada: Wavelet, scaling, multifractal analysis and teleconnection to climate anomalies. J. Geophys. Res., 112, D10110, doi:10.1029/2006JD007157.

Kalnay, E., and Coauthors, 1996: The NCEP/NCAR 40Year Reanalysis Project. Bull. Amer. Meteor. Soc., 77, 437-470.

Taylor, K. E., R. J. Stouffer, and G. A. Meehl, 2012: An overview of CMIP5 and the experiment design. Bull. Amer. Meteor. Soc., 93, 485-498, doi:10.1175/BAMS -D-11-00094.1.

Vicente-Serrano, S. M., S. Beguería, and J. I. LópezMoreno, 2010: A multiscalar drought index sensitive to global warming: The standardized precipitation evapotranspiration index. J. Climate, 23, 1696-1718, doi:10.1175/2009JCLI2909.1.
Vincent, L.A., X. Zhang, R. D. Brown, Y. Feng, E. Mekis, E. J. Milewska, H. Wan, and X. L. Wang, 2015: Observed trends in Canada's climate and influence of low-frequency variability modes. J. Climate, 28, 4545-4560. doi:10.1175 /JCLI-D-14-00697.1. 


\title{
10. HUMAN CONTRIBUTION TO THE RECORD SUNSHINE OF WINTER 20I4/I5 IN THE UNITED KINGDOM
}

\author{
Nikolaos Christidis, Mark McCarthy, Andrew Ciavarella, and Peter A. Stott
}

Extreme winter sunshine in the United Kingdom, as observed in the record high 20I4/I5 season, has become more than 1.5 times more likely to occur under the influence of anthropogenic forcings.

Observational data of sunshine duration since 1930 from the Met Office National Climate Information Centre (NCIC; Perry and Hollis 2005) reveal that winter 2014/15 was the sunniest in the United Kingdom (Fig. 10.1a). The common perception of drab British winters is seemingly challenged by the increasing trend of $2.4 \pm 0.7$ sunshine hrs decade ${ }^{-1}$ (mean \pm standard deviation) during 1930-2015 (Fig. 10.1a). With winters in the region projected to become warmer and wetter in a changing climate (van Oldenborgh et al. 2013), increasing sunshine would suggest longer sunny spells between heavier rainfall events. Brighter winters may also enhance solar energy production. Annual sunshine over western Europe was found to follow periods of dimming in the 1960-80s and brightening thereafter, while large positive seasonal trends are particularly evident in winter (Sanchez-Lorenzo et al. 2008). Contrary to the changes in Europe, a sunshine decline in recent decades has been observed in parts of the world where aerosol concentrations have been increasing, such as China and the Indian subcontinent (Wang et al. 2012; Liao et al. 2015; Niroula et al. 2015).

We attempt to formally establish the role of the overall anthropogenic forcing on the climate based on ensembles of simulations with and without anthropogenic effects produced with an atmospheric model. This well-established methodology (Pall et al. 2011; Christidis et al. 2013) provides distributions of climatic variables in the actual (ALL forcings) and natural (NAT) climate, constructed with the two ensembles. Probabilities $\mathrm{P}_{1}$ and $\mathrm{P}_{0}$ of a threshold exceedance computed with the ALL and NAT simulations help assess the anthropogenic effect in terms of the fraction of attributable risk (FAR; Allen

AfFiliations: Christidis, McCarthy, Ciavarella, and StotTMet Office Hadley Centre, Exeter, United Kingdom

DOI:I0.1175/BAMS-D-I6-0143.I

A supplement to this article is available online (10.1175

/BAMS-D-16-0143.2)
2003), defined as $1-\left(\mathrm{P}_{0} / \mathrm{P}_{1}\right)$. FAR values close to unity indicate prominent human influence on the event. Changes in the return time of extreme events (estimated from inverse probabilities) can also be examined.

As models do not provide a sunshine duration diagnostic, we employ the downward solar (SW) flux at the surface as a proxy (Fig. 10.1a). Observed winter sunshine hours and solar radiation averaged over the United Kingdom have a correlation of 0.9 over the common observational period, though individual years may differ in sign of anomaly (e.g., 2010). Cloud cover (correlation coefficient 0.3 for inverse variable estimated from observations) would be less suitable in our analysis, as it also incorporates a nighttime component. SW winter flux in $2014 / 15$ is a joint record together with $2007 / 08$, though flux observations cover a considerably shorter period than sunshine.

We employed the Hadley Centre event attribution system (Christidis et al. 2013), built on the HadGEM3-A model, to generate the ALL and NAT simulations. A major upgrade of the model was recently undertaken within the EUCLEIA project (http://eucleia.eu/). As a result, our system now features the highest resolution model used in attribution studies, with 85 vertical levels and about $60-\mathrm{km}$ horizontal resolution. Ensembles of 15 simulations were produced for both the ALL and NAT experiments, which cover the period 1960-2013. Observed sea surface temperatures (SSTs) and sea ice data (Rayner et al. 2003) were used as boundary conditions in the ALL simulations. An estimate of the anthropogenic warming in the SSTs obtained from atmosphere-ocean coupled models (Stone 2013) was subtracted from the SST observations in the NAT simulations and the sea ice was adjusted accordingly (Christidis et al. 2013). Figure 10.1b depicts the modeled time series of the SW winter flux anomaly relative to 1961-90 corresponding to the ensemble 
(a)
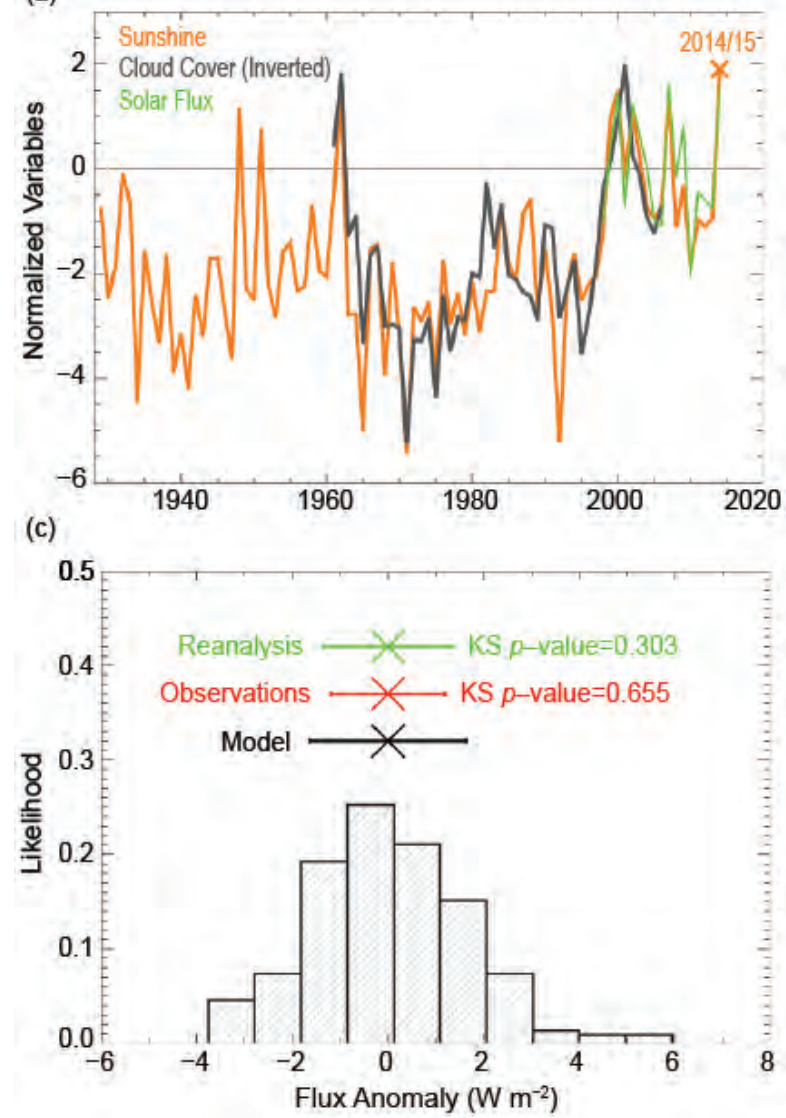

(b)

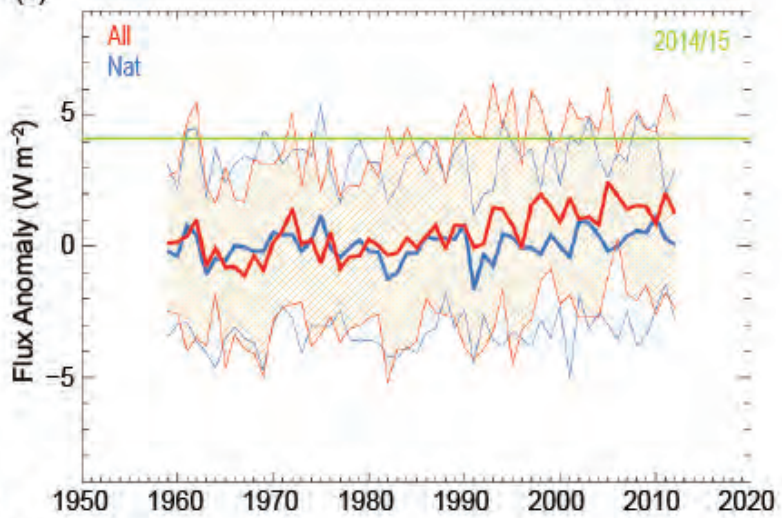

(d)

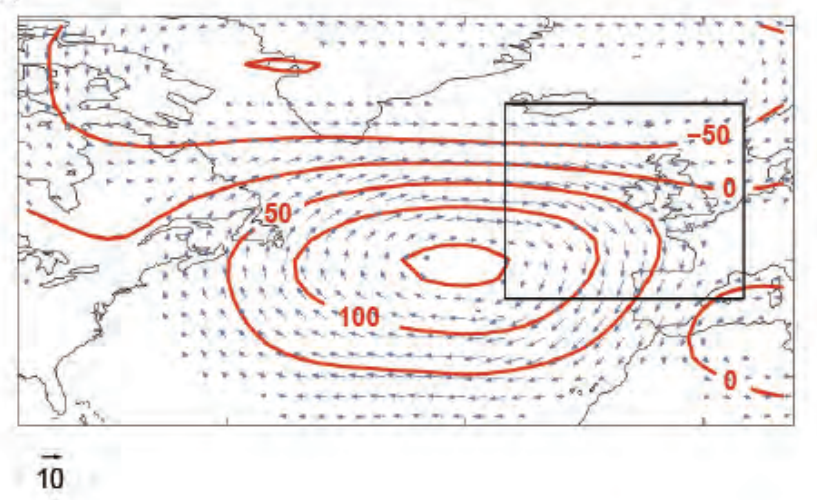

FiG. IO.I. (a) U.K. winter sunshine (orange), inverted cloud cover (gray), and solar flux (green) time series constructed with NCIC observations and normalized relative to the common observational period. (b) Time series of winter flux anomalies relative to 196I-90 from the ALL (red) and NAT (blue) experiments. The thick lines correspond to the ensemble mean, and the thin lines mark the \pm 2 standard deviation range. The 20I4/15 anomaly estimate is shown in green. (c) Modeled flux anomalies in recent winters (histogram) and the \pm I standard deviation range from different datasets (whiskers). KS tests examine whether the modeled data are significantly different from the other datasets. (d) Winter mean geopotential height (red) and wind (blue arrows) anomalies relative to $1961-90$ at $500 \mathrm{hPa}$ constructed with reanalysis data.

mean of the two experiments, together with their \pm 2 standard deviation (SD) range. An increase relative to the natural world becomes evident after the 1990s. The 2014/15 flux was 1.55 times above the mean during the observational period (1998-2012), which corresponds to an anomaly estimate of $4.1 \mathrm{~W} \mathrm{~m}^{-2}$ (green line in Fig. 10.1b). This estimate is subsequently used as a threshold to calculate the probabilities of extreme events $\mathrm{P}_{1}$ and $\mathrm{P}_{0}$.

Modeled fluxes for the actual climate are evaluated against NCIC observations and data from the NCEPNCAR reanalysis (Kalnay et al. 1996). We select the common winters in the three datasets and using anomalies relative to the common period mean, we conduct two-sided Kolmogorov-Smirnov (KS) tests that show no significant difference between the simulated fluxes and the reanalysis or observational data ( $\mathrm{P}$ values greater than 0.1; Fig. 10.1c). The good agreement remains when the model is evaluated over a longer period against the reanalysis (which includes more years than the observations).

Apart from the role of anthropogenic climate change, the possible contribution from the atmospheric flow in winter 2014/15 to the extreme sunshine will also be considered in our study (Fig. 10.1d). Synoptic conditions are often crucial to the occurrence of extremes (Wallace et al. 2015; Deser et al. 2012). For example, a persistent southwesterly flow over the United Kingdom was a key factor to the extreme rainfall in the winter before the one examined in this study (Christidis and Stott 2015). Figure 10.1d illustrates a predominantly zonal westerly flow in winter 2014/15 (also seen in the surface pressure pattern and consistent with the observed positive phase of the North Atlantic Oscillation), which transports moist air over the United Kingdom and would not 
generally be expected to provide favorable conditions for sunshine. The warming ocean seen in SST observations would also not favor extreme sunshine, as it increases the amount of water vapor in the atmosphere. The observed 2014/15 winter mean SST over the wider U.K. region is close to its mean value after 1980 when the sunshine increases and is therefore unlikely to have influenced the event.

Results. We first estimate the return time corresponding to the 2014/15 solar flux anomaly and investigate how it has changed in the present climate relative to the natural world, irrespective of the atmospheric circulation (i.e., under any synoptic conditions). We use the winters of the most recent simulated decade (2004-13) as a proxy of the present climate (i.e., 150 seasons for each experiment) and construct distributions of the solar flux anomaly with and without human influence. Estimates of $\mathrm{P}_{1}$ and $\mathrm{P}_{0}$ are then obtained from the two distributions using the generalized Pareto distribution, while uncertainties are derived with a Monte Carlo bootstrap procedure (Christidis et al. 2013). In that way, we construct the return time (inverse probability) distributions shown in Fig. 10.2a. The results indicate that anthropogenic forcings lead to a marked decrease in the return time from 48 to 14 years (best estimates, defined as the 50 th percentile of the distributions). The distribution of the FAR is shown in Fig 10.2b. The best estimate of the FAR is 0.72 , suggesting that human influence increases the chances of extreme events by a factor of 3.6 (5\%-95\% uncertainty range: 1.6-17.2). We also examine how the chances have changed in consecutive decades since the 1960s (Fig. 10.2c). The return time decreases from over a century in the mid-1960s to about 15 years after the mid-1990s and remains well below the NAT estimates in the last 20 years.

To assess the effect of the atmospheric circulation, we adopt the approach of Christidis and Stott (2015), whereby we partition the simulated winters between those that resemble the reference flow pattern (Fig. 10.1d) and those that do not. The grouping is based on the correlation coefficient over the wider U.K. region marked by the box in Fig. 10.1d. To separate the circulation effect from that of anthropogenic forcings, we only use the NAT simulations, which yield a total of 810 winters, 197 of which belong to the high-correlation group with correlation coefficients above 0.6 . The mean flow of the highly correlated seasons resembles the reanalysis pattern, whereas the mean of winters with low correlations displays a weak easterly flow (see online supplemental material).
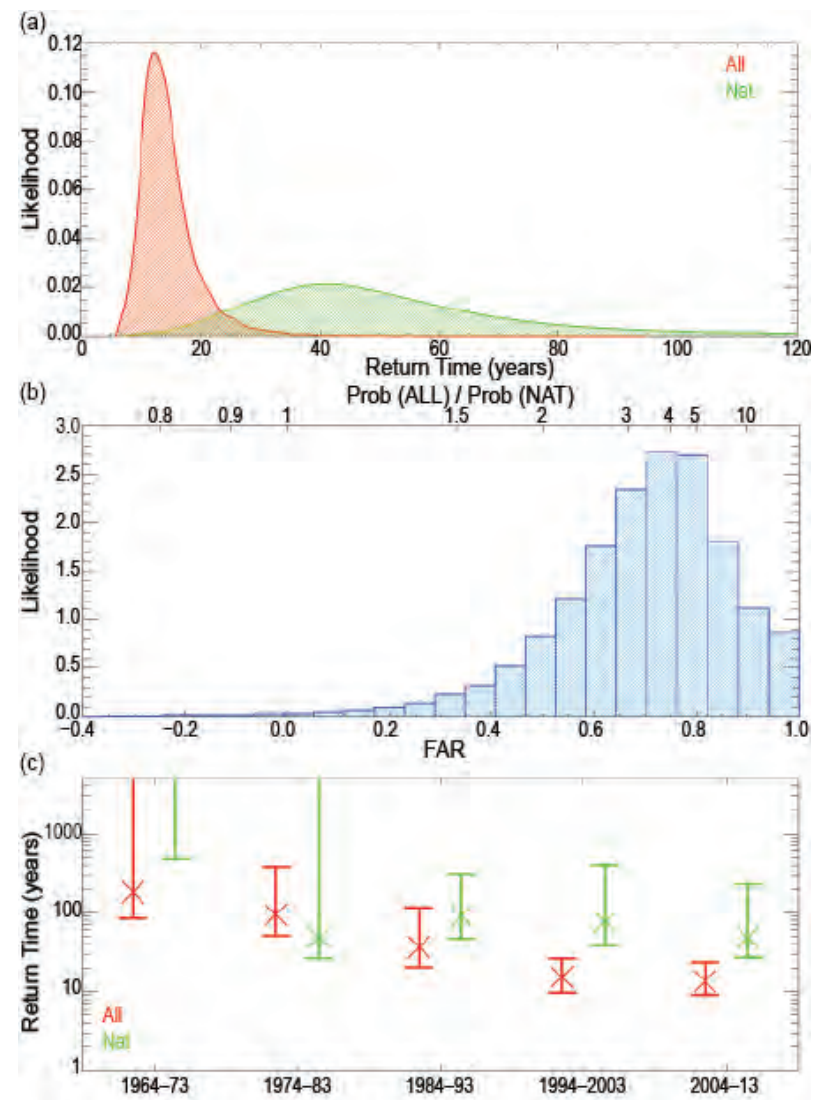

FIG. 10.2. (a) Normalized distributions of the return time of an extreme winter sunshine event in the United Kingdom, defined as an exceedance of the 2014/15 solar flux anomaly. The distributions were constructed with (red) and without (green) anthropogenic climate change. (b) Normalized FAR distribution measuring how much human influence changes the likelihood of an extreme winter sunshine event. The change in probability is shown on the top $x$ axis. (c) Change in the return time of extreme events with (red) and without (green) anthropogenic climate change in consecutive decades. The best estimate (50th percentile) is represented by the cross, and the 5\%-95\% uncertainty range is marked by the whiskers.

The latter is associated with colder and drier continental air over the United Kingdom, which is more conducive to sunny conditions. Indeed, we find that winters with low-pattern correlations are about 14 times more likely to break the 2014/15 flux record (5\%-95\% uncertainty range: 3.7 to $\left.>10^{3}\right)$. Our findings are not too sensitive to the choice of the correlation coefficient used to discriminate between seasons (see online supplemental material).

Conclusions. Evidence of human influence on winter sunshine extremes in the United Kingdom is shown here, consistent with an observed increasing trend in 
sunshine hours in recent decades. This trend together with internal variability appear to have been key drivers of the 2014/15 record, which occurred within a meteorological context not typical of sunny conditions. Changes in aerosol emissions constitute the component of the anthropogenic forcing most likely to affect sunshine (Sanchez-Romero et al. 2014). Unlike winter, NCIC observations do not show a notable trend in summer sunshine, when one might expect the direct effect from reduced aerosol concentrations to be larger due to the decreased cloud amount. The discrepancy might be a result of the indirect effect linked to changes in cloud properties that could be stronger in winter, though this needs to be further investigated in future work.

ACKNOWLEDGEMENTS. This work was supported by the Joint BEIS/Defra Met Office Hadley Centre Climate Programme (GA01101) and the EUCLEIA project funded by the European Union's Seventh Framework Programme [FP7/2007-2013] under Grant Agreement No. 607085.

\section{REFERENCES}

Allen, M. R., 2003: Liability for climate change. Nature, 421, 892.

Christidis, N., and P. A. Stott, 2015: Extreme rainfall in the United Kingdom during winter 2013/2014: The role of atmospheric circulation and climate change [in "Explaining Extremes of 2014 from a Climate Perspective”]. Bull. Amer. Meteor. Soc., 96 (12), S46S50, doi:10.1175/BAMS-D-15-00094.1.

,,-- A. Scaife, A. Arribas, G. S. Jones, D. Copsey, J. R. Knight, and W. J. Tennant, 2013: A new HadGEM3-A based system for attribution of weather and climate-related extreme events. J. Climate, 26, 2756-2783, doi:10.1175/JCLI-D-12-00169.1.

Deser, C., R. Knutti, S. Solomon, and A. S. Phillips, 2012: Communication of the role of natural variability in future North American Climate. Nat. Climate Change, 2, 775-779, doi:10.1038/nclimate1562.

Kalnay, E., and Coauthors, 1996: The NCEP/NCAR 40year reanalysis project. Bull. Amer. Meteor. Soc., 77, 437-470.

Liao, W., X. Wang, Q. Fan, S. Zhou, M. Chang, Z. Wang, Y. Wang, and Q. Tu, 2015: Long-term atmospheric visibility, sunshine duration and precipitation trends in South China. Atmos. Environ., 107, 204-2016, doi:10.1016/j.atmosenv.2015.02.015.
Niroula, N., K. Kobayashi, and J. Xu, 2015: Sunshine duration is declining in Nepal across the period from 1987 to 2010. J. Agric. Meteor., 71, 15-23, doi:10.2480/agrmet.D-14-00025.

Pall, P., T. Aina, D. A. Stone, P. A. Stott, T. Nozawa, A. G. J. Hilberts, D. Lohmann, and M. R. Allen, 2011: Anthropogenic greenhouse gas contribution to flood risk in England and Wales in autumn 2000. Nature, 470, 382-385, doi:10.1038/nature09762.

Perry, M., and D. Hollis, 2005: The generation of monthly gridded datasets for a range of climatic variables over the UK. Int. J. Climatol., 25, 10411054, doi:10.1002/joc.1161.

Rayner, N. A., D. E. Parker, E. B. Horton, C. K. Folland, L. V. Alexander, D. P. Rowell, E. C. Kent, and A. Kaplan, 2003: Global analyses of sea surface temperature, sea ice, and night marine air temperature since the late nineteenth century. J. Geophys. Res., 108, 4407, doi:10.1029/2002JD002670.

Sanchez-Lorenzo, A., J. Calbó, and J. Martin-Vide, 2008: Spatial and temporal trends in sunshine duration over western Europe (1938-2004). J. Climate, 21, 6089-6098, doi:10.1175/2008JCLI2442.1.

Sanchez-Romero, A., A. Sanchez-Lorenzo, J. Calbó, J. A. González, and C. Azorin-Molina, 2014: The signal of aerosol-induced changes in sunshine duration records: A review of the evidence. J. Geophys. Res. Atmos., 119, 4657-4673, doi:10.1002/2013JD021393.

Stone, D., 2013: Boundary conditions for the C20C Detection and Attribution Project: The All-Hist/ est1 and Nat-Hist/CMIP5-est1 scenarios. Lawrence Berkeley National Laboratory, 18 pp. [Available online at http://portal.nersc.gov/c20c /input_data/C20C-DandA_dSSTs_All-Hist-est1 _Nat-Hist-CMIP5-est1.pdf.]

Van Oldenborgh, G. J., M. Collins, J. Arblaster, J. H. Christensen, J. Marotzke, S. B. Power, M. Rummukainen, and T. Zhou, 2103: Annex I: Atlas of global and regional climate projections. Climate Change 2013: The Physical Basis, T. F. Stocker et al., Eds., Cambridge University Press, 1311-1393.

Wallace, J. M., C. Deser, B. V. Smoliak, and A. S. Philips, 2015: Attribution of climate change in the presence of internal variability. Climate Change: Multidecadal and Beyond, C.-P. Chang et al., Eds., World Scientific, 1-29.

Wang, Y., Y. Yang, N. Zhao, C. Liu, and Q. Wang, 2012: The magnitude of the effect of air pollution on sunshine hours in China. J. Geophys. Res., 117, D00V14, doi:10.1029/2011JD016753. 


\title{
II. THE ROLE OF ANTHROPOGENIC WARMING IN 2015 CENTRAL EUROPEAN HEAT WAVES
}

\author{
Sebastian Sippel, Friederike E. L. Otto, Milan Flach, and Geert Jan van Oldenborgh
}

\author{
Station-based observations and bias-corrected model simulations show that the frequency of \\ short-term heat waves in central Europe has increased, albeit quantitative estimates of risk ratios \\ differ considerably between methods.
}

Summer 2015 in Europe. The summer 2015 in Europe was highly unusual, as persistent heat and dryness prevailed in large parts of the continent. In central and eastern Europe, a combination of record-low seasonal rainfall (Orth et al. 2016) and record-high monthly July/August temperatures were observed over an area stretching from France to western Russia (Supplemental Fig. S11.1). The anomalous temperatures were caused by a sequence of four intense heat waves that struck the region from the end of June to early September (e.g., Fig. 11.1a). It is precisely the few-day heat that causes problems with human health, especially when combined with high humidity (McGregor et al. 2010). We analyze seasonal maxima of 3-day mean temperature ( $\mathrm{Tair}_{3 \mathrm{~d} \text {, max }}$ ) and seasonal maxima of 3-day daily maximum wet bulb temperature $\left(\right.$ WBTX $\left._{3 \mathrm{~d} \text {, max }}\right)$, a measure of human thermal discomfort that combines temperature and humidity and is a proxy for heat stress on the human body (Fischer and Knutti 2013; Sherwood and Huber 2010).

The series of heat waves began with a strongly meandering jet stream, that is summertime "omegablocking" (Dole et al. 2011), and the advection of very warm subtropical air into central and western Europe (Supplemental Fig. S11.1). Later in the season, the jet stream was displaced to the north, so that stable high-pressure systems could prevail over central and eastern Europe bringing heat there. The first heat wave in early July was hence most pronounced in western parts of the continent, while south-central and east-central Europe experienced the highest

AFFILIATIONS: SIPPEL-Max Planck Institute for Biogeochemistry, Jena, Germany; OTTO-Environmental Change Institute, University of Oxford, Oxford, United Kingdom; FLACH-Max Planck Institute for Biogeochemistry, Jena, Germany; van OldenBorgh-Weather and Climate Modeling, Koninklijk Nederlands Meteorologisch Instituut, De Bilt, Netherlands

DOI:I0.1175/BAMS-D-16-0150.I

A supplement to this article is available online (10.1I75 /BAMS-D-16-0150.2) temperatures in the subsequent heat waves later in the season (Fig. 11.1b).

Anomalies in the hottest 3-day mean temperature reached up to $+6^{\circ} \mathrm{C}$ relative to climatology (Figs. $11.1 \mathrm{c}, \mathrm{d})$, and temperature records were broken, including nationwide records (Kitzingen, Germany: $40.3^{\circ} \mathrm{C}$; https://weather.com/news/climate/news/europe-heat-wave-poland-germany-czech-august-2015), various station records stretching from France to the Balkan countries and southern Sweden (www .meteofrance.fr/actualites/26913226-episode -de-tres-fortes-chaleurs-en-france), nighttime temperatures (Vienna, Austria: $26.9^{\circ} \mathrm{C}$ ), record 3-day mean temperatures across central Europe (Fig. 11.1e), and inland water temperatures (e.g., Lake Constance). Europe experienced the hottest August ever recorded (NOAA 2016), and the entire summer season ranked third after the unusual summers of persistent heat in 2003 and 2010 with hotspots in France and western Russia, respectively (Barriopedro et al. 2011; Stott et al. 2004). This extraordinary sequence of events raises the question to what extent human-induced climate change played a role in short-term heat waves beyond natural climate variability.

A potential anthropogenic contribution to the summer 2015 heat events had already been investigated in near-real time (www.climatecentral.org /europe-2015-heatwave-climate-change), and in the present paper we build upon and substantiate the previous analysis. We investigate two diagnostics (Tair $_{3 \mathrm{~d}, \max }$ and WBTX $\mathrm{Wd,max}$ ) at four locations in longterm station-based observational records and in a large ensemble of consistently bias-corrected regional climate model simulations.

Methods and Data. First, we analyze long-term observational data (115 years of data for each station) from the ECA\&D dataset (Klein Tank et al. 2002) of four central and eastern European stations that 
(a)
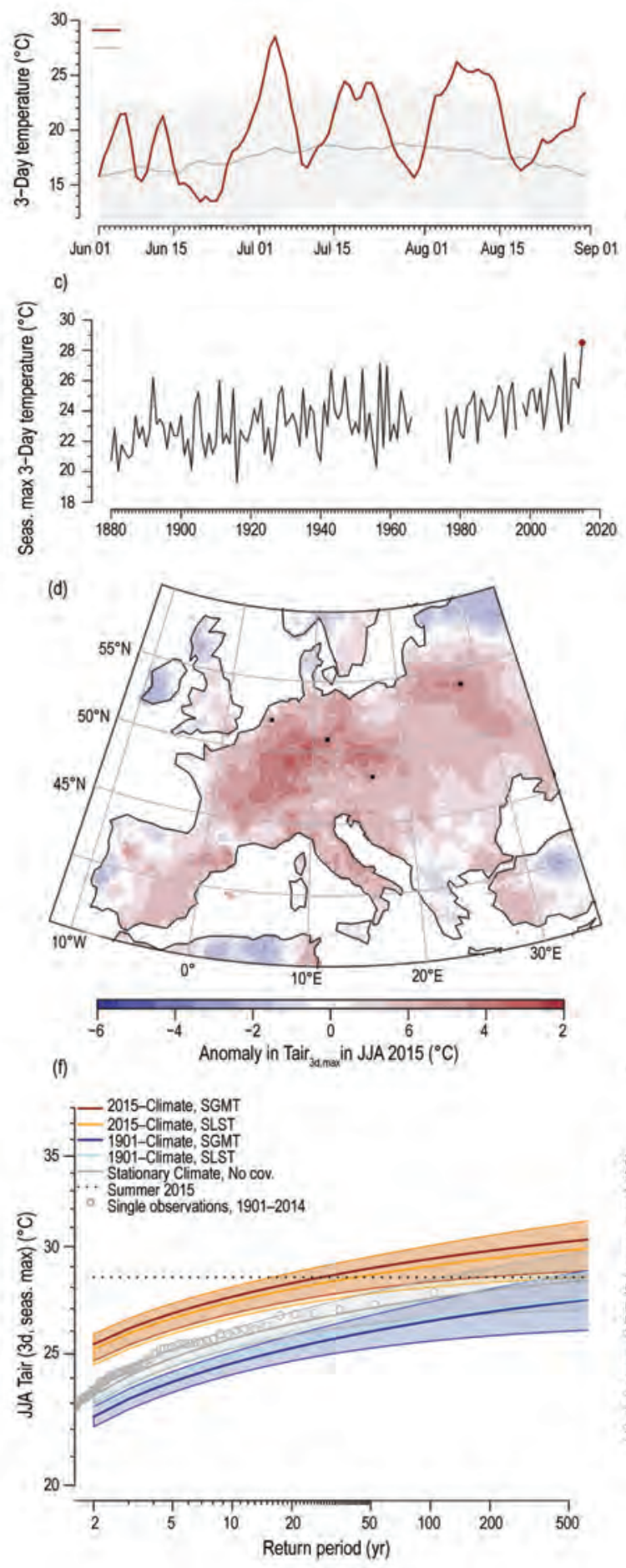

(b)

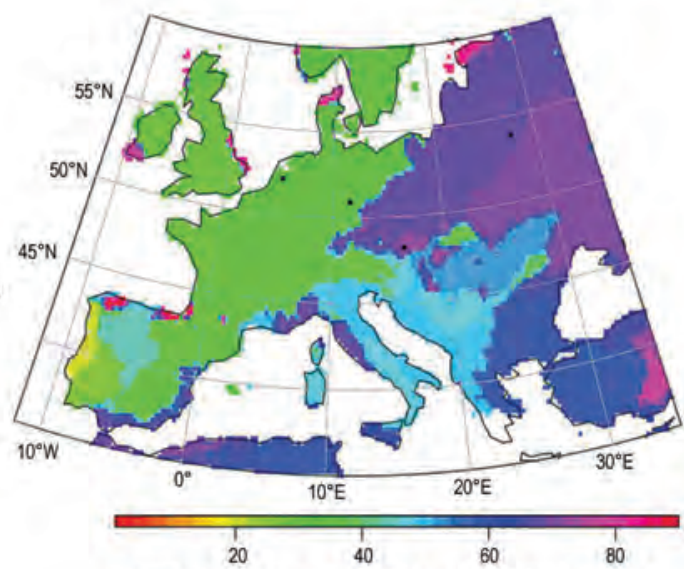

Day of seasonal heat record, JJA 2015 (days after 6 Jan 2015)

(e)
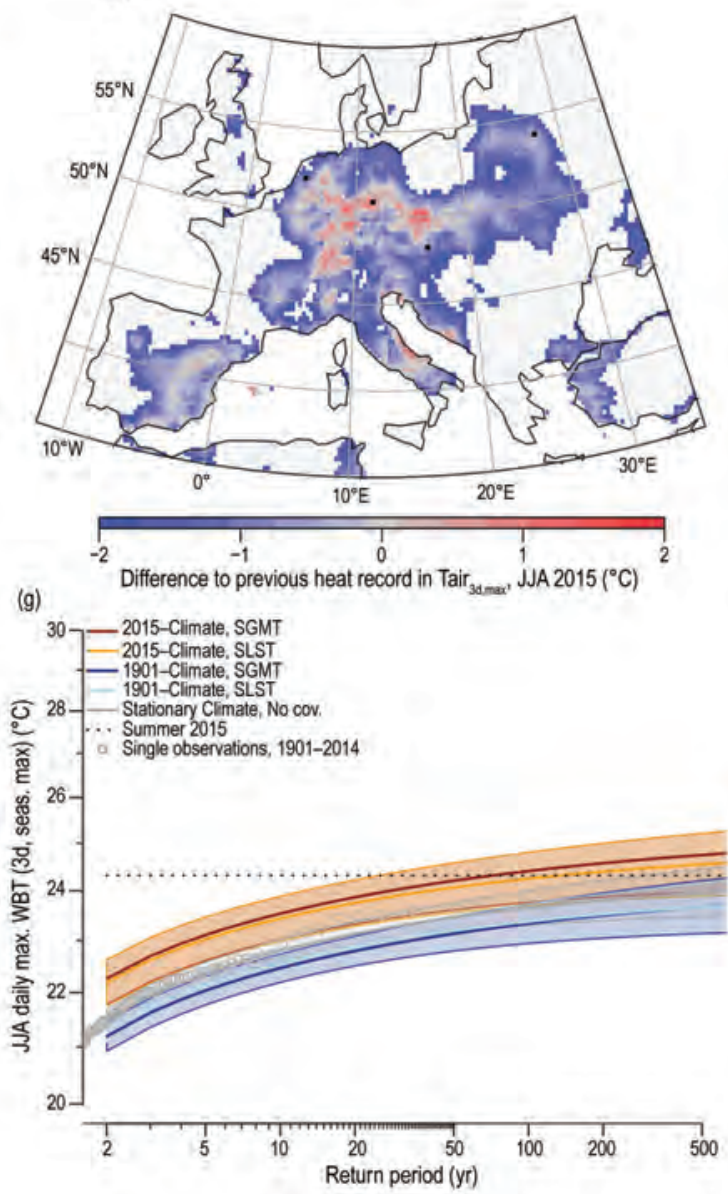

Fig. II.I. (a) Time series of 3-daily mean temperatures in summer 2015 at the Jena site (gray shading denotes $\pm 2-\sigma$ deviations relative to long-term interannual variability). (b) Day of seasonal temperature record in summer 2015. (c) Time series of seasonal maximum of 3-day mean temperatures ( (air $_{3 d, \max }$ ) at the Jena site (summer 2015 is marked by a red dot). (d) Anomalies in Tair $_{3 \mathrm{~d}, \max }$ over Europe in summer 2015 relative to 198I-2010. (e) Difference to previous heat records (1950-2014) in Tair3d, max in the EOBS dataset. Positive differences indicate a new heat record in JJA 2015. (f),(g) Return time plots of GEV fits for Tair $_{3 \mathrm{~d}, \max }$ and WBTX ${ }_{3 \mathrm{~d}, \max }$, respectively, at the Jena site. Red (orange) lines indicate the fit for 2015 climate, dark-blue (light-blue) lines indicate the fit for $190 \mathrm{I}$ climate for a smoothed global mean temperature covariate (smoothed local summer temperature covariate). 
were affected by the heat waves in summer 2015 (Table 11.1), using data from 1901 onward. For each station, annual time series of Tair $_{3 \mathrm{~d} \text {, max }}$ and WBTX $\mathrm{Wd}_{3 \mathrm{~d}}$ $\max _{\text {max }}$ are calculated for July-August. $\mathrm{WBTX}_{3 \mathrm{~d} \text {, max }}$ is derived from daily maximum air temperature and vapor pressure (computed from relative humidity and daily mean temperature; www.srh.noaa.gov /epz/?n=wxcalc_rh) using an iterative procedure based on the psychrometric equation (Sullivan and Sanders 1974). Subsequently, generalized extreme value (GEV) statistical models are fitted to the data (Coles 2001) excluding the year 2015, using two different assumptions about changes in climate:

1) A "local" station-based covariate to the location parameter of the GEV (21-year smoothed local summer temperatures, SLST) as a proxy for any changes to local climate;

2) A "global" covariate to the location parameter (21-year smoothed global mean temperatures, SGMT) as a proxy for anthropogenic influence on climate (van Oldenborgh et al. 2012).

To avoid overfitting the relatively low number of data points, no dependence in the scale or shape parameter is assumed. Probability ratios (PR) based on the GEV as a metric to quantify human-induced change in the odds of extreme events $\left(\mathrm{PR}=\mathrm{p}_{\mathrm{ANT}} / \mathrm{p}_{\mathrm{NAT}}\right.$; Fischer and Knutti 2015) were obtained by calculating the probability of an event as warm or warmer than the observed 2015-event in a 2015-climate $\left(\mathrm{p}_{\mathrm{ANT}}\right)$, and in 1901 as a proxy for preindustrial climate.

Second, a model ensemble-based assessment using the global general circulation model HadAM3P $\left(1.875^{\circ} \times 1.25^{\circ} \times 15-\mathrm{min}\right.$ resolution $)$ and a dynamically downscaled regional variant (HadRM3P, $0.44^{\circ} \times$ $0.44^{\circ} \times 5$-min resolution) is conducted to complement the empirical analysis (see Massey et al. 2015 for all details regarding the model setup). Initial condition ensembles are generated for an anthropogenic scenario (ANT, $n=2286$ ), in which the model is driven by observed (2015) sea surface temperatures (SSTs) and anthropogenic forcings in atmosphere-only mode for 1 year at a time (starting 1 December; Massey et al. 2015); and a natural scenario (NAT, $\mathrm{n}=4414$ ) with all anthropogenic forcings (i.e., greenhouse gases, aerosols, halocarbons, and ozone) set to preindustrial levels and 11 different estimates of natural SSTs (Schaller et al. 2014). For each of the four locations (centered over a $1^{\circ} \times 1^{\circ}$ grid cell), a resampling bias correction strategy based on an observational constraint is applied to the model ensemble (Sippel et al. 2016) because the raw model output is notoriously too hot and dry (Black et al. 2015; Massey et al. 2015), severely compromising attribution statements (Supplemental Fig. S11.2). The seasonal maximum 21-day average temperature from the E-OBS dataset (Haylock et al. 2008) is used as a resampling

Table II.I. Location of meteorological stations and probability ratios estimated from observed and simulated data. Very large PR with a lower bound (5\% confidence interval) exceeding 10 are reported

as $>10$. PR from the model output are given as 5 th to 95 th percentile of 100 bootstrapped replicates $(n=1000)$. A PR range exceeding one would be significant at $95 \%$ confidence under a one-sided test. PR for the original model simulations (i.e., non-bias corrected) are indicated for comparison only. *The observed De Bilt series contains a well-known inhomogeneity in 1950, so the homogenized series from KNMI was used instead. **Humidity data was not available for Vienna and Minsk in the ECA\&D dataset for the year 2015.

\begin{tabular}{|c|c|c|c|c|}
\hline Station & De Bilt* & Jena & Minsk & Vienna \\
\hline Country & Netherlands & Germany & Belarus & Austria \\
\hline Location & $52^{\circ} 06^{\prime} \mathrm{N}, 5^{\circ} \mathrm{II} \mathrm{I}^{\prime} \mathrm{E}$ & $50^{\circ} 55.5^{\prime} \mathrm{N}, 11^{\circ} 35^{\prime} \mathrm{E}$ & $53^{\circ} 52^{\prime} \mathrm{N}, 27^{\circ} 32^{\prime} \mathrm{E}$ & $48^{\circ} 14^{\prime} \mathrm{N}, 16^{\circ} 2 \mathrm{I}^{\prime} \mathrm{E}$ \\
\hline Tair $_{3 d, \max , 2015}\left({ }^{\circ} \mathbf{C}\right)$ & 25.2 & 28.5 & 27.3 & 29.1 \\
\hline $\mathrm{PR}_{\text {HadRM3P, BC-anom }}$ & $1.2-1.4$ & I.1-2.5 & I.7-2.5 & $1.8-2.9$ \\
\hline $\mathrm{PR}_{\text {HadRM3P, BC-anom, obs. trend }}$ & $4.7-7.5$ & $4.1-8.7$ & $3.4-5.2$ & $>10$ \\
\hline $\mathrm{PR}_{\text {EOBS, GEV-GMT }}$ & $>10$ & $>10$ & $>10$ & $>10$ \\
\hline $\mathbf{W B T}_{3 \mathrm{~d}, \max }\left(2015,{ }^{\circ} \mathrm{C}\right)$ & 22.9 & 24.3 & $\mathrm{n} / \mathrm{a}^{* *}$ & $\mathrm{n} / \mathrm{a}^{* *}$ \\
\hline $\mathrm{PR}_{\text {HadRM3P, BC-anom }}$ & $1.3-1.8$ & $1.5-3.1$ & $\mathrm{n} / \mathrm{a}^{* *}$ & $\mathrm{n} / \mathrm{a}^{* *}$ \\
\hline $\mathrm{PR}_{\mathrm{HadRM} 3 \mathrm{P}, \mathrm{BC} \text {-anom, obs. trend }}$ & $>10$ & $2.7-7.7$ & $\mathrm{n} / \mathrm{a}^{* *}$ & $\mathrm{n} / \mathrm{a}^{* *}$ \\
\hline $\mathrm{PR}_{\text {EOBS, GEV-GMT }}$ & $>10$ & $>8.6$ & $\mathrm{n} / \mathrm{a}^{* *}$ & $\mathrm{n} / \mathrm{a}^{* *}$ \\
\hline
\end{tabular}


constraint, and a percentile-based transfer function is calibrated for each station separately on the 1986-2010 climatology using an identical model setup (Massey et al. 2015). Subsequently, both natural and anthropogenic simulations are resampled using the derived relationship (Sippel et al. 2016). In contrast to widely used methods like quantile-quantile mapping, resampling retains the full multivariate structure and physical consistency of the model output but reduces the available ensemble size and chooses colder and wetter ensemble members, therefore alleviating the hot and dry bias (Sippel et al. 2016). In the context of event attribution, it is applied for the first time in this paper (Figs. 11.2a-d; see next section). To avoid potential mean biases due to station location, the mean of the resampled ensemble is adjusted to the station mean (Supplemental Figs. S11.2c,d). Results are demonstrated exemplarily for one station (Jena), and probability ratios are reported for all stations. tions. The 21-day resampling constraint considerably improves the representation of short-term heat waves by avoiding physically implausible simulations (Figs. $11.2 \mathrm{a}-\mathrm{d}$ ) and improving the simulated variability of heat waves (Supplemental Figs. S11.2c,d). The correlation structure between the temperature constraint and short-term heat stress $\left(\mathrm{WBTX}_{3 \mathrm{~d} \text {, max }}\right)$ in the observations is reproduced in the resampled model ensemble but not in the original model ensemble (Figs. 11.2a,c). This indicates that robust attribution statements for impact-related, and thus multivariate quantities (such as $\mathrm{WBTX}_{3 \mathrm{~d} \text {, max }}$ ), require a physically consistent bias correction of model output.

Consistent with the observations, the model-based assessment shows a shift in the return periods toward more frequent and more pronounced summer heat stress (Fig. 11.2b) in all locations (Table 11.1) and both bias-corrected and original simulations. The probability ratios derived from the bias-corrected
Results and Discussion. The statistical analysis of estimated return times of Tair $_{3 \mathrm{~d} \text {, max }}$ reveals that 2015-like heat events occur in present day climate approximately every 27 years in Jena with the onesided $5 \%$ lower confidence bound at 16 years (Fig. 11.1). Including both the local and global climate change covariates into the GEV fit demonstrates a profound increase in return times of those types of events relative to earlier years for both Tair $_{3 \mathrm{~d}}$, ${ }_{\max }$ and $\mathrm{WBTX}_{3 \mathrm{~d} \text {, max }}$ in Jena (Figs. 11.1f,g) and all other locations with probability ratios typically exceeding a value of 10 (Table 11.1). The intensity of heat waves increases by about $3^{\circ} \mathrm{C}$ in Tair $_{3 d, \text { max }}$ but only $1.1^{\circ} \mathrm{C}$ in WBTX $_{3 \mathrm{~d} \text {, max }}$ (Figs. 11.1f,g). In spite of this difference, the increase in the probability ratio is similar.

A similar analysis is conducted in a very large ensemble of model simula- (a)
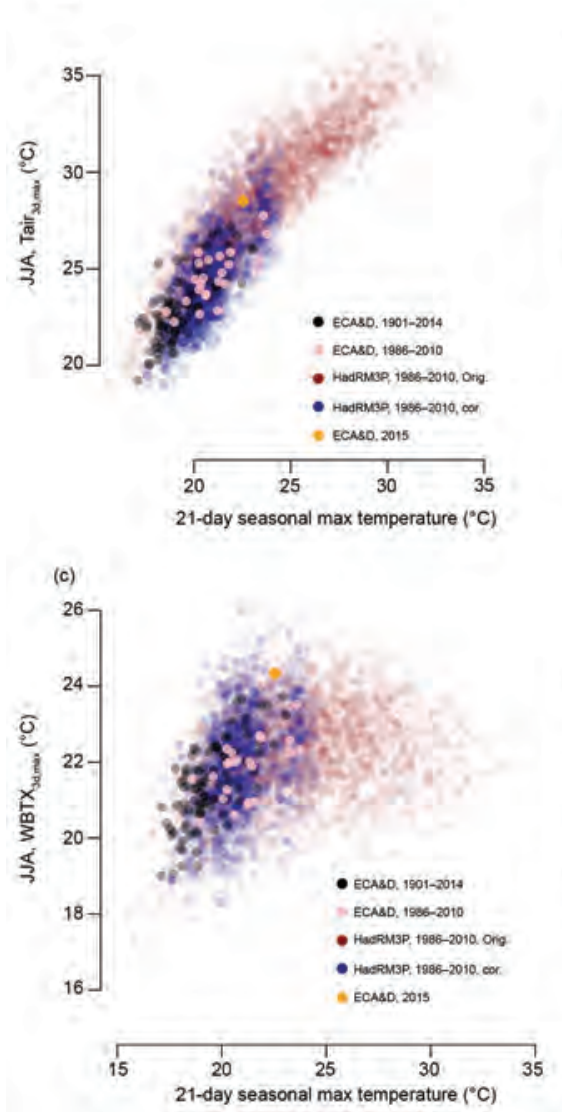

FIG. II.2. (a),(c) Correlation between 2I-day seasonal maximum temperature (observational constraint for resampling bias correction) and impact-related quantities ( Tair $_{3 \mathrm{~d}, \max }$ and $\mathrm{WBTX}_{3 \mathrm{~d}, \max }$, respectively). Pink dots correspond to 1986-2010, the period used for calibration of the bias correction resampling function. (b),(d) Return time plots for original and bias-corrected model output

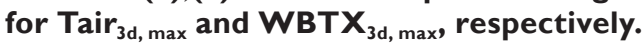


model ensembles range from 1.1 to $2.9\left(\right.$ Tair $\left._{3 \mathrm{~d}, \max }\right)$ for the four locations $\left(\mathrm{PR}=1.3-3.1\right.$ for $\mathrm{WBTX}_{3 \mathrm{~d} \text {, max }}$ in Jena and De Bilt), depending on the magnitude of the 2015 event, the model-simulated warming, and interannual variability. These estimates are thus lower than those estimated from the observations but can be largely explained by method- and datarelated differences. For instance, the statistical method assumes that the trend is caused fully by anthropogenic factors, while the model analysis is based on a "real counterfactual" scenario but tends to underestimate warming trends in temperature extremes in Europe (Min et al. 2013). The mean observed change across all locations between 2015 and 1901 of $3.1^{\circ} \mathrm{C}\left(\right.$ Tair $\left._{3 \mathrm{~d}, \max }\right)$ and $2.2^{\circ} \mathrm{C}\left(\mathrm{WBTX}_{3 \mathrm{~d} \text {, }}\right.$ max $)$ is much larger than the original $\left(+1.1^{\circ} \mathrm{C}\right.$ in Tair $_{3 \mathrm{~d} \text {, }}$ ${ }_{\max }$ and $+0.5^{\circ} \mathrm{C}$ in $\left.\mathrm{WBTX}_{3 \mathrm{~d}, \max }\right)$ and bias corrected $\left(+0.9^{\circ} \mathrm{C}\right.$ in Tair $_{3 \mathrm{~d}, \text { max }}$ and $+0.5^{\circ} \mathrm{C}$ in $\left.\mathrm{WBTX}_{3 \mathrm{~d} \text {, max }}\right)$ model simulations. Hence, replacing the model-simulated warming by the observed change between 1901 and 2015 causes roughly a tripling of probability ratios for the bias-corrected simulations at all locations (e.g., 3.4-8.7 for Tair $_{3 \mathrm{~d}, \max }$ and 2.7 to exceeding 10 for $\mathrm{WBTX}_{3 \mathrm{~d} \text {, max }}$; cf., Table 11.1). Furthermore, uncertainties due to event selection (Christiansen 2015), dependence on the spatial and temporal scale (Angélil et al. 2014), high nonlinearity in attribution metrics such as the probability ratio (Supplemental Fig. S11.2), and a slightly higher variability on submonthly time scales in the model simulations than in the observations despite bias correction further contribute to model-data discrepancies and variability in the presented estimates of the probability ratios.

Conclusion. In conclusion, the multimethod analysis applied in this paper provides consistent evidence that human-induced climate change has contributed to the increase in the frequency and intensity of short-term heat waves and heat stress such as the central and eastern Europe 2015 event.

However, quantitative estimates of the risk ratio at local scales can differ widely depending on the exact methodologies applied, thus highlighting large method- and data-related uncertainties. In this study, due to the large discrepancy between observed and modeled trends in temperature extremes, the modelestimated probability ratios are lower than those estimated from the observations.

ACKNOWLEDGEMENTS. The work of Sippel and Flach was funded by the European Commission
Horizon 2020 BACI (Towards a Biosphere Atmosphere Change Index) Project (Grant 640176).

\section{REFERENCES}

Angélil, O., D. A. Stone, M. Tadross, F. Tummon, M. Wehner, and R. Knutti, 2014: Attribution of extreme weather to anthropogenic greenhouse gas emissions: Sensitivity to spatial and temporal scales. Geophys. Res. Lett., 41,2150-2155, doi:10.1002/2014GL059234.

Barriopedro, D., E. M. Fischer, J. Luterbacher, R. Trigo, and R. García-Herrera, 2011: The hot summer of 2010: Redrawing the temperature record map of Europe. Science, 332, 220-224, doi:10.1126 /science.1201224.

Black, M. T., D. J. Karoly, and A. D. King, 2015: The contribution of anthropogenic forcing to the Adelaide and Melbourne, Australia, heat waves of January 2014 [in "Explaining Extreme Events of 2014 from a Climate Perspective"]. Bull. Amer. Meteor. Soc., 96 (12), S145-S148.

Christiansen, B., 2015: The role of the selection problem and non-Gaussianity in attribution of single events to climate change. J. Climate, 28, 9873-9891, doi:10.1175/JCLI-D-15-0318.1.

Coles, S., 2001: An Introduction to Statistical Modeling of Extreme Values. Springer, 209 pp.

Dole, R., and Coauthors, 2011: Was there a basis for anticipating the 2010 Russian heat wave? Geophys. Res. Lett., 38, L06702, doi:10.1029/2010GL046582.

Fischer, E. M., and R. Knutti, 2013: Robust projections of combined humidity and temperature extremes. Nat. Climate Change, 3, 126-130, doi:10.1038 /nclimate1682.

—, and — 2015: Anthropogenic contribution to global occurrence of heavy-precipitation and hightemperature extremes. Nat. Climate Change, 5, 560564, doi:10.1038/nclimate2617.

Haylock, M. R., N. Hofstra, A. M. G. Klein Tank, E. J. Klok, P. D. Jones, and M. New, 2008: A European daily high-resolution gridded data set of surface temperature and precipitation for 1950-2006. J. Geophys. Res., 113, D20119, doi:10.1029/2008JD10201.

Klein Tank, A. M. G., and Coauthors, 2002: Daily dataset of 20th-century surface air temperature and precipitation series for the European Climate Assessment. Int. J. Climatol., 22, 1441-1453, doi:10.1002 /joc.773. 
Massey, N., and Coauthors, 2015: weather@ homedevelopment and validation of a very large ensemble modelling system for probabilistic event attribution. Quart. J. Roy. Meteor. Soc., 141, 1528-1545, doi:10.1002/qj.2455.

McGregor, G., P. Bessemoulin, K. Ebi, and B. Menne, Eds., 2010: Heat waves and health: Guidance on warning system development. WMO 1142, $114 \mathrm{pp}$. [Available online at www.who.int/globalchange /publications/heatwaves-health-guidance/en/.]

Min, E., W. Hazeleger, G. J. van Oldenborgh, and A. Sterl, 2013: Evaluation of trends in high temperature extremes in north-western Europe in regional climate models. Environ. Res. Lett., 8, 014011, doi:10.1088/1748-9326/8/1/014011.

NOAA, cited 2016: Climate at a glance: Global time series. [Available online at www.ncdc.noaa.gov/cag /time-series/global/europe/land/3/8/1912-2015.]

Orth, R., J. Zscheischler, and S. I. Seneviratne, 2016: Record dry summer in 2015 challenges precipitation projections in Central Europe. Sci. Rep., 6, 28334, doi:10.1038/srep28334.

Schaller, N., F. E. L. Otto, G. J. van Oldenborgh, N. R. Massey, S. Sparrow, and M. R. Allen, 2014: The heavy precipitation event of May-June 2013 in the upper Danube and Elbe basins [in "Explaining Extreme Events of 2013 from a Climate Perspective"]. Bull. Amer. Meteor. Soc., 95 (9), S69-S72.

Sherwood, S. C., and M. Huber, 2010: An adaptability limit to climate change due to heat stress. Proc. Natl. Acad. Sci. USA, 107, 9552-9555, doi:10.1073 /pnas.0913352107.

Sippel, S., and Coauthors, 2016: A novel bias correction methodology for climate impact simulations. Earth Syst. Dyn., 7, 71-88, doi:10.5194/esd-7-71-2016.

Stott, P. A., D. A. Stone, and M. R. Allen, 2004: Human contribution to the European heatwave of 2003. Nature, 432, 610-614, doi:10.1038/nature03089.

Sullivan, J., and L. D. Sanders, 1974: Method for obtaining wet-bulb temperatures by modifying the psychometric formula. NOAA Tech. Memo. EDS BOMAP-11, 8 pp. [Available online at http://docs .lib.noaa.gov/noaa_documents/NESDIS/TM_EDS /TM_EDS_BOMAP/TM_EDS_BOMAP_11.pdf.]

Van Oldenborgh, G. J., A. Van Urk, and M. Allen, 2012: The absence of a role of climate change in the 2011 Thailand floods [in "Explaing Extreme Events of 2011 from a Climate Perspective"]. Bull. Amer. Meteor. Soc., 93, 1047-1049. 


\title{
12. THE 20I5 EUROPEAN HEAT WAVE
}

\author{
Buwen Dong, Rowan Sutton, Len Shaffrey, and Laura Wilcox
}

A heat wave swept across central Europe in summer 2015. Model experiments suggest that anthropogenic forcings were a major factor in setting the conditions for the development of the 2015 heat wave.

Observations. An extreme summer heat wave set temperature records across Europe during June and July. On 1 July, London experienced its hottest July maximum temperature on record: $36.7^{\circ} \mathrm{C}$. Paris recorded its second hottest day ever on 2 July, with a high temperature of $39.7^{\circ} \mathrm{C}$, and Berlin experienced its highest temperature on record, $37.9^{\circ} \mathrm{C}$, on 4 July (BBC News 1 July 2015; Liberto 2015). Averaged over central Europe (Fig. 12.1a), the seasonal mean (June-August) surface air temperature (SAT) anomaly was $2.40^{\circ} \mathrm{C}$ above the $1964-93$ mean: 3.65 standard deviations of the interannual variability. This magnitude of warming is comparable with previous hot summers in Europe, such as 2003 (e.g., Schaer et al. 2004; Christidis et al. 2015) and 2010 (e.g., Barriopedro et al. 2011; Otto et al. 2012) when summer mean SAT anomalies over the same region were $2.38^{\circ} \mathrm{C}$ and $2.42^{\circ} \mathrm{C}$ (3.63 and 3.68 standard deviations), respectively. In addition to the very hot mean SAT, records over central Europe were set for some temperature extremes: the annual hottest day temperature (TXx), seasonal mean daily maximum temperature (Tmax), and diurnal temperature range (DTR) were $4.04^{\circ}, 3.04^{\circ}$, and $1.53^{\circ} \mathrm{C}$ above the $1964-93$ mean. The 2015 summer extreme hot temperature occurred in the context of a decade of summer warming and increases in hot temperature extremes, and in fact, 2015 was the driest and the second hottest summer in recent decades (Figs. 12.1a,b).

The observed spatial patterns of 2015 anomalies in SAT and temperature extremes, relative to the 1964-93 mean, indicate coherent positive anomalies over central Europe, but weak negative anomalies over northern Europe (Figs. 12.1c-h). These temperature anomalies are associated with an

AFFILIATIONS: DONG, SUTTON, ShafFRey, AND WILCOXNational Centre for Atmospheric Science, Department of Meteorology, University of Reading, Reading, United Kingdom

DOI:I0.II75/BAMS-D-16-0140.I

A supplement to this article is available online ( 10.1175 /BAMS-D-16-0140.2) anomalous anticyclonic circulation (not shown) and reduced precipitation over central Europe and a weak increase over northern Europe (Supplemental Figs. S12.1b,g). Importantly, the magnitude of changes in Tmax and TXx is about twice that in seasonal mean daily minimum temperature (Tmin) and the annual hottest night temperature ( $\mathrm{TNx}$ ), suggesting an important role of land-atmosphere-cloud feedbacks associated with the precipitation deficit over central Europe in summer. This results in a reduction of evaporation and cloud cover associated with soil drying, enhancing Tmax and TXx more than Tmin and TNx through increased daytime downward shortwave radiation and decreased daytime upward latent heat flux (Vautard et al. 2007; Fischer and Schär 2010; Mueller and Seneviratne 2012; Boé and Terray 2014; Miralles et al. 2014; Perkins 2015; Dong et al. 2016). Precipitation anomalies in the winter and spring seasons before summer 2015 were much smaller than in summer over central Europe (not shown). This implies the land-atmosphere-cloud feedback on the 2015 European heat wave was mainly through simultaneous precipitation deficit rather than a presummer deficit over central Europe.

What caused these anomalous summer conditions over central Europe in 2015? Relative to the 1964-93, warm sea surface temperatures (SSTs) were present in many regions (Fig. 12.1i), with a prominent warm anomaly $\left(>1.2^{\circ} \mathrm{C}\right)$ in the tropical Pacific during the developing phase of the exceptionally strong 2015/16 El Niño (WMO 2016). There were also SST anomalies along the Gulf Stream extension in the North Atlantic with a cooling to the north and warming to the south. Associated with this feature is an enhanced meridional SST gradient along the Gulf Stream extension. This might have favored a northward shift of the North Atlantic summer storm track (e.g., Ogawa et al. 2012; Dong et al. 2013a and 2013b; Duchez et al. 2016), which would result in reduced precipitation in summer 2015 over central Europe (Supplemental Fig. S12.1g). The large warming in the 
(a) 4

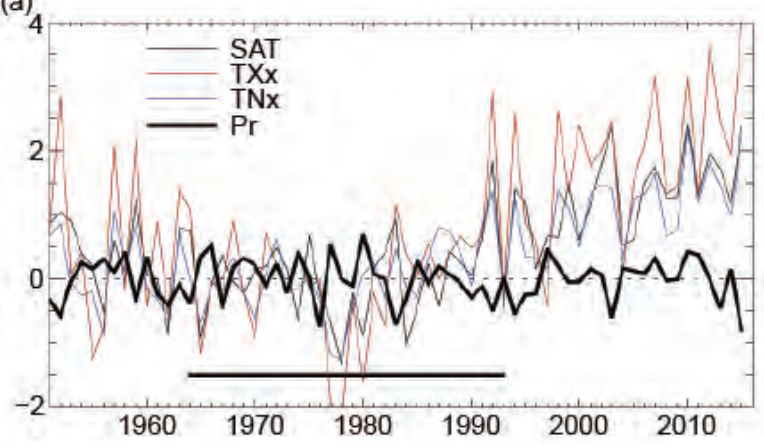

(c)

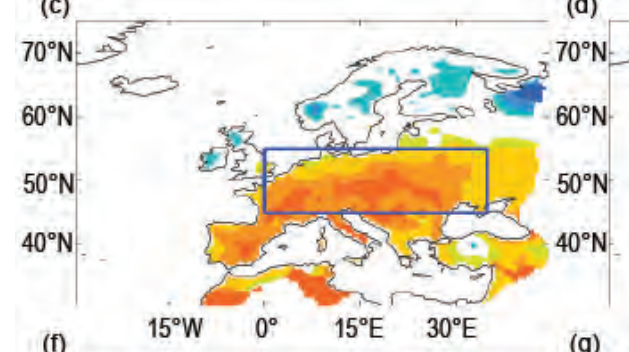

(b)

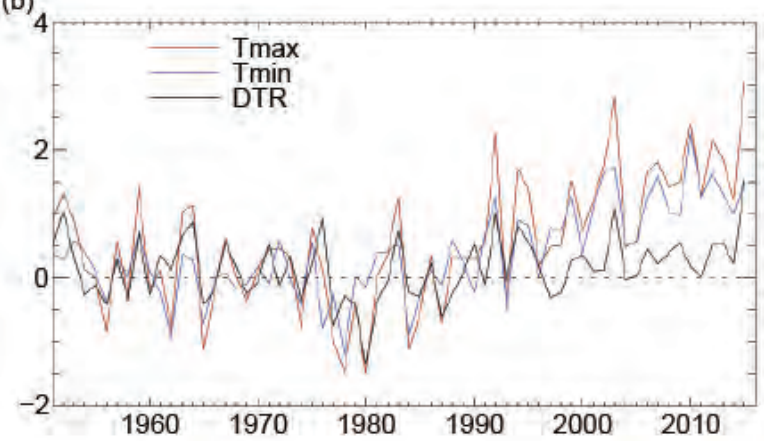

(e)
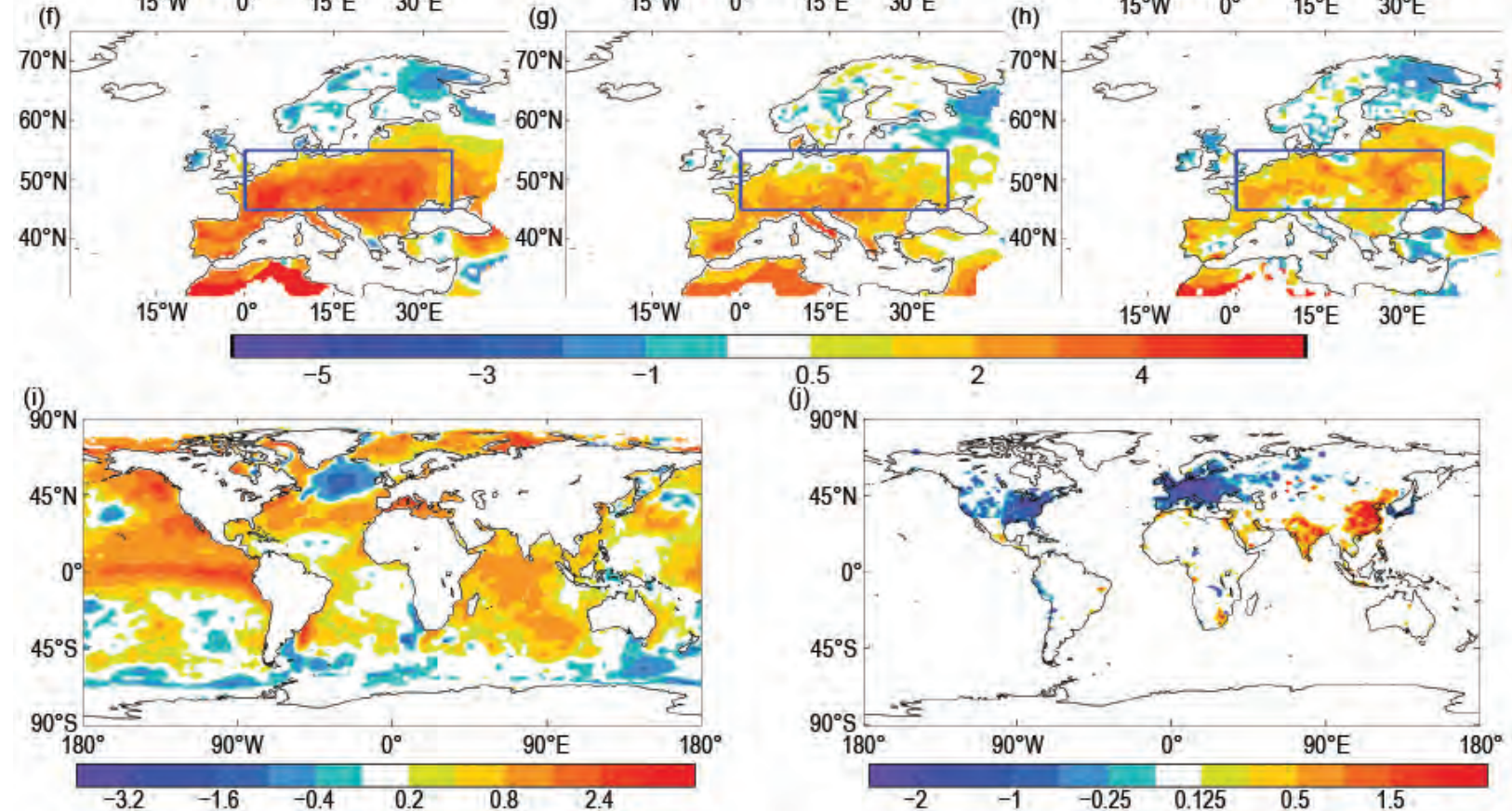

FIG. I2.I. (a),(b) Time series and (c)-(h) spatial patterns of summer or annual anomalies relative to $1964-93$ [black bar in (a)] climatology. (a),(b) Time series averaged over central Europe $\left[45^{\circ}-55^{\circ} \mathrm{N}, 0^{\circ}-35^{\circ} \mathrm{E}\right.$, land only, blue box in (c)-(h)]. (c)-(h) Spatial patterns of 2015 anomalies in summer mean SAT, TXx, TNx, summer mean Tmax, Tmin, and DTR from the gridded E-OBS dataset (version I2.0; Haylock et al. 2008). (i) Spatial patterns of 2015 summer SST anomalies relative to 1964-93. (j) Changes in annual mean sulphur dioxide emissions ( $g$ $\mathrm{m}^{-2} \mathrm{yr}^{-1}$ ) in 2015 relative to $1964-93$. The units are ${ }^{\circ} \mathrm{C}$ for temperatures and $\mathrm{mm}^{-1} \mathrm{yy}^{-1}$ for precipitation (Pr).

Arctic might also be a factor for the 2015 summer heat wave (Coumou et al. 2015).

Climate model experiments. Relative to 1964-93, there were significant increases in greenhouse gas (GHG) concentrations (e.g., WMO 2015) and also significant changes in anthropogenic aerosol (AA) precursor emissions with reductions from Europe and North America and increases from Asia (Fig. 12.1j; Lamarque et al. 2010 and 2011). A set of climate model experiments has been carried out to identify the relative roles of changes in SST/sea ice extent (SIE) and 
anthropogenic forcings (GHG and AA) in shaping the 2015 European summer heat wave. In this study, we do not address the anthropogenic contribution to SST/SIE changes, but rather consider these changes as an independent forcing factor. We use the atmosphere configuration of the Met Office Hadley Centre Global Environment Model version 3 (HadGEM3-A; Hewitt et al. 2011), with a resolution of $1.875^{\circ}$ longitude by $1.25^{\circ}$ latitude and 85 vertical levels. The CONTROL experiment is performed for the period 1964-93. Two other experiments, 2015ALL and 2015SST, are performed for the period November 2014 to October 2015 , use 2015 SST/SIE boundary conditions, but they differ in the specification of GHG and AA forcings (Table 12.1). All experiments are 27 years long, with only the last 25 years used for analysis (as an ensemble of 25 one-year members).

The CONTROL experiment reproduces both the mean and interannual variability of summer SAT over central Europe, despite the fact that there is no interannual variability in SST/SIE, GHG, and AA (Supplemental Fig. S12.1a). However, there are biases in the simulated seasonal mean precipitation and some temperature extremes in CONTROL (Supplemental Figs. S12.1b-e). Precipitation is overestimated by 0.23 $\mathrm{mm}$ day $^{-1}$ ( $10 \%$ larger than observations), Tmax is underestimated by $1.5^{\circ} \mathrm{C}$, and Tmin is overestimated by $1.5^{\circ} \mathrm{C}$. As a result, seasonal mean SAT is similar to observations, but DTR is underestimated by about $3.0^{\circ} \mathrm{C}$ in CONTROL (a common bias in AGCMs and RGCMs; e.g., Kysely and Plavcova 2012; Cattiaux et al. 2015). The underestimation of Tmax, TXx, and DTR, and overestimation of Tmin and TNx (not shown) imply that the cloud cover over the region in the model might be overestimated, as suggested by the overestimation of area-averaged precipitation. Despite the mean biases in the temperature extremes, their interannual variability in the CONTROL experiment is in broad agreement with observations (Supplemental Figs. S12.1a-e).

In response to all forcing changes (2015ALL), the area-averaged summer warming over central Europe is $1.6^{\circ} \mathrm{C}$, compared to $2.4^{\circ} \mathrm{C}$ in observations (Fig. 12.2a). This implies that about $2 / 3$ of the observed summer warming might have been anticipated as a mean response to SST/SIE and anthropogenic forcing changes. Spatial patterns of changes in SAT and temperature extremes show some differences to observed changes (Figs. 12.1, and 12.2) with the large temperature changes in the model displaced eastward to eastern Europe. The model mean response shows warming and an increase in temperature extremes over both central and northern Europe (Figs. 12.2c-h), but does not capture the observed precipitation reduction over central Europe (not shown). Therefore, it is likely that the model is not capturing cloud and land surface feedbacks induced by precipitation changes, and thus underestimates the observed surface warming and changes in Tmax and TXx over central Europe by about $1 / 3$, while simulated changes in Tmin and TNx are similar in magnitude to observations (Fig. 12.2a). The SST/SIE changes have a relatively weak effect on SAT and hot extremes but lead to a considerable increase in Tmin and TNx, likely related in part to water vapor feedback because increased water vapor in the atmosphere enhances the downward longwave radiation, which has a large impact on night temperatures (Dai et al. 1999; Dong et al. 2016). Quantitatively, SST/SIE changes explain $22.5 \%$ of the area-averaged central European warming signal in the model, with the remaining $77.5 \%$ explained by GHG and AA changes with an assumption that the responses to different forcings add linearly (Fig. 12.2b), indicating a dominant role for the direct impact of anthropogenic

Table I2.I. Summary of numerical experiments.

\begin{tabular}{|c|l|}
\hline Experiments & Boundary conditions \\
\hline CONTROL & $\begin{array}{l}\text { Forced with monthly mean climatological sea surface temperature (SST) and sea ice extent (SIE) aver- } \\
\text { aged over the period of } 1964 \text { to } 1993 \text { using HadISST data (Rayner et al. 2003), with greenhouse gas } \\
\text { (GHG) concentrations averaged over the same period, and anthropogenic aerosol (AA) precursor } \\
\text { emissions averaged over the period of } 1970 \text { to } 1993 \text { (Lamarque et al. 20I0). }\end{array}$ \\
\hline 20I5ALL & $\begin{array}{l}\text { Forced with monthly mean SST and SIE from November 20I4 to October 20I5 using HadISST data, } \\
\text { with GHG concentrations in 20I4 (WMO 20I5), and AA precursor emissions for 20I5 from RCP4.5 } \\
\text { scenario (Lamarque et al. 20II). }\end{array}$ \\
\hline 20I5SST & As 20I5ALL, but with GHG concentrations and AA precursor emissions the same as in CONTROL. \\
\hline
\end{tabular}


(a)

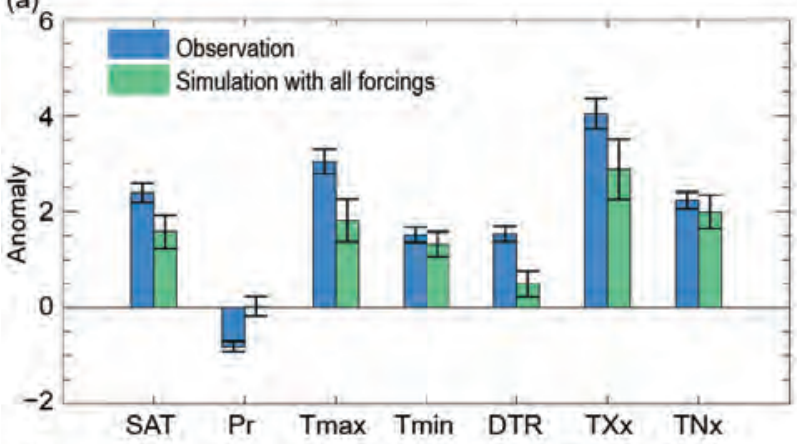

(c)

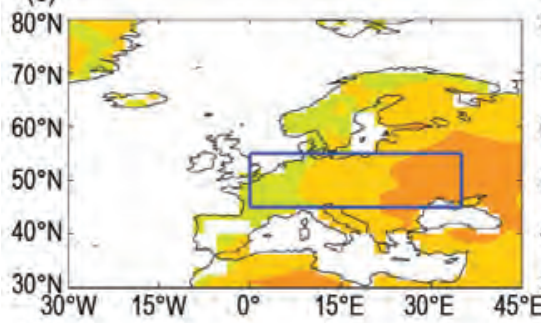

(f)
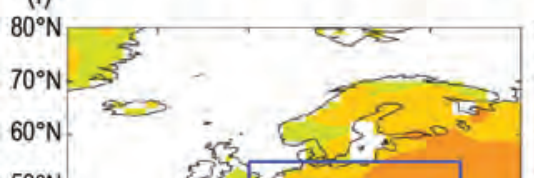

$50^{\circ} \mathrm{N}$

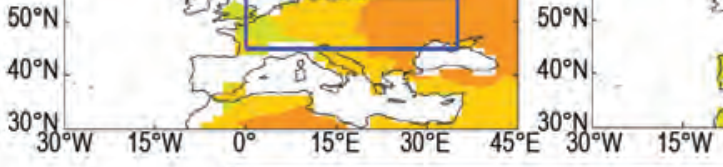

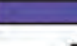

$-8$ (d)

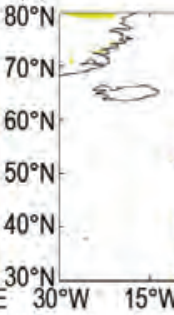

(g)

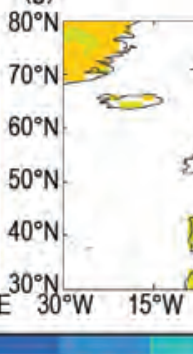

(b)

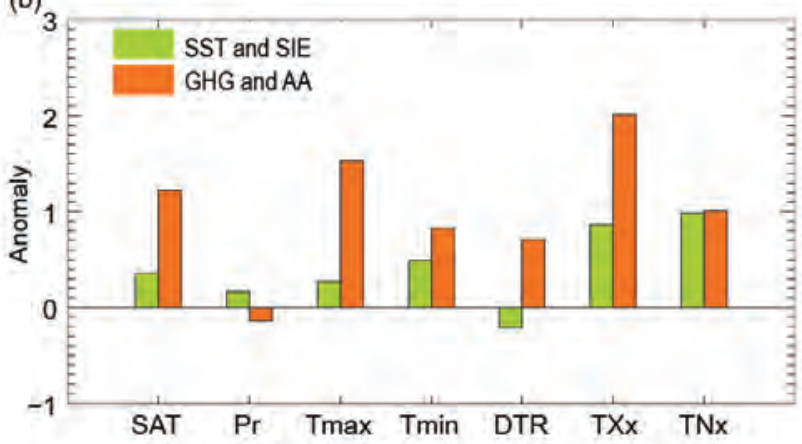

(e)
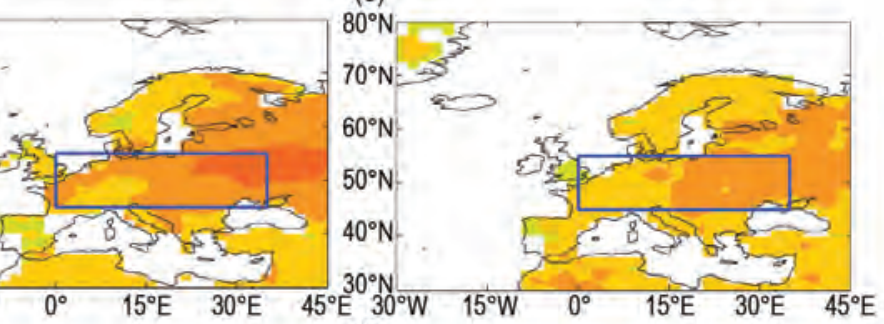

(h)

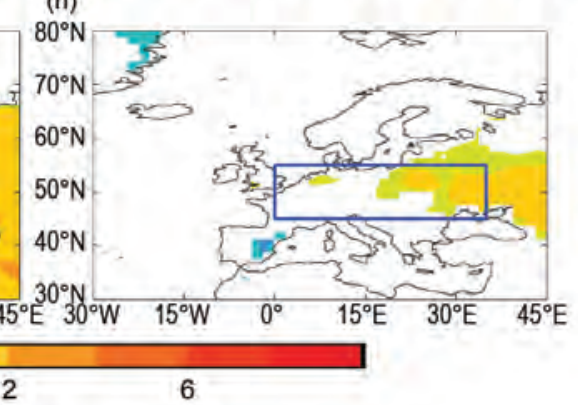

Fig. 12.2. (a) Observed and simulated 2015 anomalies for SAT, $\operatorname{Pr}\left(\mathbf{m m}\right.$ day-1$\left.^{-1}\right)$, Tmax, Tmin, DTR, TXx, and TNx averaged over central Europe (land only) in response to changes in all forcings (2015ALL-CONTROL). Colored bars indicate central estimates and whiskers show the $90 \%$ confidence intervals based on a two-tailed Student's t-test. (b) Model responses to different forcings. SST and SIE: Response to changes in SST/SIE (20I5SST-CONTROL); GHG and AA: Response to changes in anthropogenic forcings (2015ALL-20I5SST). (c)-(h) Spatial patterns of changes in temperature and temperature extremes (SAT, TXx, TNx, Tmax, Tmin, and DTR) in response to all forcings (2015ALL-CONTROL). Only changes that are statistically significant at the $90 \%$ confidence level are plotted in (c)-(h). The unit is ${ }^{\circ} \mathrm{C}$.

forcings in changes of summer SAT and temperature extremes in the model mean response (Fig. 12.2b; Supplemental Fig. S12.2).

The various model experiments exhibit substantial internal variability in simulated precipitation and temperature extremes (Supplemental Fig. S12.1). One particular year in 2015ALL exhibits a decrease (relative to CONTROL) of the area-averaged precipitation that is as large as the observed anomaly (Supplemental Fig. S12.1b). The magnitudes, relative to CONTROL, of the area-averaged summer SAT and temperature extremes in this driest year are very close to the observed anomalies (Supplemental Fig. S12.1f). Furthermore, the spatial patterns of simulated changes in SAT and precipitation also show good agreement with the observed patterns despite the eastward extension of large temperature anomalies in the simulation (Supplemental Figs. S12.1h,i). Interestingly, there are no such years in either the CONTROL or 2015SST simulation. This suggests that changes in SST/SIE and anthropogenic forcings set preconditions for an extremely dry year, such as summer 2015, to occur in the model simulation. The inability of the model to reproduce observed precipitation anomalies in the mean response, and the good agreement of changes in one particular year with observed anomalies in response to changes in all forcings, suggests that internal atmospheric variability might have played a significant role for the reduction in precipitation, and hence the severity of the 2015 European summer heat 
wave. Specifically, our simulations suggest internal variability contributed about $1 / 3$ of the observed summer warming and increases in hot temperature extremes over central Europe, in line with attributions of the severity of the 2010 Russian heat wave (e.g., Dole et al. 2011; Otto et al. 2012). However, it is important to recognize that the quantitative partitioning of causes is potentially sensitive to model biases, such as the mean wet bias discussed earlier.

Conclusions. Summer 2015 was marked by hot and dry conditions over central Europe and significant increases in temperature extremes. Model experiments indicate that high temperatures were caused by a combination of forced responses and internal atmospheric variability. Model simulations suggest that changes in SST/SIE and anthropogenic forcings explain about $2 / 3\left(1.6^{\circ} \mathrm{C}\right)$ of the observed warming $\left(2.4^{\circ} \mathrm{C}\right)$ and changes in hot temperature extremes over central Europe relative to 1964-93. Interestingly, when comparing 2015SST with 2015ALL simulations, the results indicate that the impact of anthropogenic forcings plays the dominant role. About $1 / 3\left(0.8^{\circ} \mathrm{C}\right)$ of the observed summer mean warming and changes in hot extremes is not explained by the model mean response and consequently may have resulted from internal variability, principally through physical processes associated with precipitation deficits. Thus, our results indicate that anthropogenic forcings set the conditions for the development of the 2015 heat wave in central Europe, but that internal variability was an important factor in explaining its extreme character.

ACKNOWLEDGEMENTS. This work was supported by EUCLEIA project funded by the European Union's Seventh Framework Programme [FP7/2007-2013] under Grant Agreement No. 607085 and by the U.K.-China Research and Innovation Partnership Fund through the Met Office Climate Science for Service Partnership China (CSSP China) as part of the Newton Fund. Authors are supported by the U.K. National Centre for Atmospheric Science-Climate at the University of Reading. HadISST and E-OBS gridded datasets are available from www.metoffice.gov.uk/hadobs/ and www.ecad.eu /download/ensembles/ensembles.php.

\section{REFERENCES}

Barriopedro, D., E. M. Fischer, J. Lutenbacher, R. M. Trigo, and R. Garcia-Herrera, 2011: The hot summer of 2010: Redrawing the temperature record map of Europe. Science, 332, 220-224.

BBC News, 2015: Hottest July day ever recorded in UK. BBC, 1 July 2015. [Available online at www.bbc .co.uk/news/uk-england-33324881.]

Boé, J., and L. Terray, 2014: Land-sea contrast, soilatmosphere and cloud-temperature interactions: interplays and roles in future summer European climate change. Climate Dyn., 42, 683-699.

Cattiaux, J., H. Douville, R. Schoetter, S. Parey, and P. Yiou, 2015: Projected increase in diurnal and interdiurnal variations of European summer temperatures. Geophys. Res. Lett., 42, 899-907, doi:10.1002/2014GL062531.

Christidis, N., G. S. Jones, and P. A. Stott, 2015: Dramatically increasing chance of extremely hot summers since the 2003 European heatwave. Nat. Climate Change, 5, 46-50.

Coumou, D., J. Lehmann, and J. Beckmann, 2015: The weakening summer circulation in the Northern Hemisphere mid-latitudes. Science, 348, 324-327.

Dai, A., K. E. Trenberth, and T.R. Karl, 1999: Effects of clouds, soil moisture, precipitation, and water vapor on diurnal temperature range. J. Climate, 12, 2451-2473.

Dole, R., and Coauthors, 2011: Was there a basis for anticipating the 2010 Russian heat wave? Geophys. Res. Lett., 38, L06702, doi:10.1029/2010GL046582.

Dong, B., R. T. Sutton, T. Woollings, and K. Hodges, 2013a: Variability of the North Atlantic summer stormtrack: Mechanisms and impacts. Environ. Res. Lett., 8, 034037, doi:10.1088/1748-9326/8/3/034037.

Dong, B.-W., R. T. Sutton, and T. Woollings, 2013b: The extreme European summer 2012 [in "Explaining Extreme Events of 2012 from a Climate Perspective”]. Bull. Amer. Meteor. Soc., 94 (9), S28-S32.

Dong, B.-W., R. T. Sutton, and L. Shaffrey, 2016: Understanding the rapid summer warming and changes in temperature extremes since the mid1990s over Western Europe. Climate Dyn., open access, doi:10.1007/s00382-016-3158-8.

Duchez, A., and Coauthors, 2016: Drivers of exceptionally cold North Atlantic Ocean temperatures and their link to the 2015 European heat wave. Environ. Res. Lett., 11, 074004, doi:10.1088/1748-9326/11/7/074004. 
Fischer, E. M., and C. Schär, 2010: Consistent geographical patterns of changes in high-impact European heatwaves. Nat. Geosci., 3, 398-403, doi:10.1038/ngeo866.

Haylock, M. R., N. Hofstra, A. M. G. Klein Tank, E. J. Klok, P. D. Jones, and M. New, 2008: A European daily high-resolution gridded dataset of surface temperature and precipitation for 1950-2006. J. Geophys. Res., 113, D20119, doi:10.1029/2008JD010201.

Hewitt, H. T., D. Copsey, I. D. Culverwell, C. M. Harris, R. S. R. Hill, A. B. Keen, A. J. McLaren, and E. C. Hunke, 2011: Design and implementation of the infrastructure of HadGEM3: The next-generation Met Office climate modelling system. Geosci. Model Dev., 4, 223-253, doi:10.5194/gmd-4-223-2011.

Kysely, J., and E. Plavcova, 2012: Biases in the diurnal temperature range in Central Europe in an ensemble of regional climate models and their possible causes. Climate Dyn., 39, 1275-1286, doi:10.1007/s00382 -011-1200-4.

Lamarque, J.-F., and Coauthors, 2010: Historical (1850-2000) gridded anthropogenic and biomass burning emissions of reactive gases and aerosols: Methodology and application. Atmos. Chem. Phys., 10, 7017-7039, doi:10.5194/acp-10-7017-2010.

Lamarque, J.-F., and Coauthors, 2011: Global and regional evolution of short-lived radiatively-active gases and aerosols in the Representative Concentration Pathways. Climatic Change, 109, 191-212, doi:10.1007/s10584-011-0155-0.

Liberto, T. D., 2015: Summer heat wave arrives in Europe. Climate.gov, 14 July 2015. [Available online at www.climate.gov/news-features/event-tracker /summer-heat-wave-arrives-europe.]

Miralles, D. G., A. J. Teuling, C. C. van Heerwaarden, and J. V. G. de Arellano, 2014: Mega-heatwave temperatures due to combined soil desiccation and atmospheric heat accumulation. Nat. Geosci., 7, 345-349.

Mueller, B., and S. I. Seneviratne, 2012: Hot days induced by precipitation deficits at the global scale. Proc. Natl. Acad. Sci. USA, 109, 12 398-12 403.

Ogawa, F., H. Nakamura, K. Nishii, T. Miyasaka, and A. Kuwano-Yoshida, 2012: Dependence of the climatological axial latitudes of the tropospheric westerlies and storm tracks on the latitude of an extratropical oceanic front. Geophys. Res. Lett., 39, L05804, doi:10.1029/2011GL049922.
Otto, F. E. L., N. Massey, G. J. van Oldenborgh, R. G. Jones, and M. R. Allen, 2012: Reconciling two approaches to attribution of the 2010 Russian heat wave. Geophys. Res. Lett., 39, L04702, doi:10.1029/2011GL050422.

Perkins, S.E., 2015: A review on the scientific understanding of heatwaves-Their measurement, driving mechanisms, and changes at the global scale. Atmos. Res., 164, 242-267, doi:10.1016/j.atmosres.2015.05.014.

Rayner, N. A., D. E. Parker, E. B. Horton, C. K. Folland, L. V. Alexander, D. P. Rowell, E. C. Kent, and A. Kaplan, 2003: Global analyses of sea surface temperature, sea ice, and night marine air temperature since the late nineteenth century. J. Geophys. Res., 108, 4407, doi:10.1029/2002JD002670.

Schaer, C., P. L. Vidale, D. Luethi, C. Frei, C. Haeberli, M. A. Liniger and C. Appenzeller, 2004: The role of increasing temperature variability in European summer heatwaves. Nature, 427, 332-336.

Vautard, R., and Coauthors, 2007: Summertime European heat and drought waves induced by wintertime Mediterranean rainfall deficit. Geophys. Res. Lett., 34, L07711, doi:10.1029/2006GL028001.

WMO, 2015: The state of greenhouse gases in the atmosphere based on global observations through 2014. WMO Greenhouse Gas Bulletin, No. 11, 4 pp. [Available online at www.wmo.int/pages/prog/arep /gaw/ghg/GHGbulletin.html.]

WMO, 2016: Exceptionally strong El Niño has passed its peak, but impacts continue. WMO Press Release 3, 18 February 2016. [Available online at www .wmo.int/media/content/exceptionally-strong -el-ni\%C3\%B1o-has-passed-its-peak-impacts -continue.] 


\title{
13. THE LATE ONSET OF THE 2015 WET SEASON IN NIGERIA
}

\author{
Kamoru A. Lawal, Abayomi A. Abatan, Oliver Angélil, Eniola Olaniyan, Victoria H. Olusoji, \\ Philip G. Oguntunde, Benjamin Lamptey, Babatunde J. Abiodun, Hideo Shiogama, \\ Michael F. Wehner, and Dáithí A. Stone
}

\begin{abstract}
We find no evidence that the delayed onset of the wet season over Nigeria during April-May 2015 was made more likely by anthropogenic influences or anomalous sea surface temperatures.
\end{abstract}

Introduction. Nigeria experienced a delay in the onset of the wet season in 2015. Annually, the wet season in Nigeria starts with the steady advancement of the intertropical discontinuity [ITD-represented in this study by the average latitudinal position of $15^{\circ} \mathrm{C}$ dewpoint temperature contour line between longitude $2^{\circ}-15^{\circ} \mathrm{E}$ (www.cpc.ncep.noaa.gov/products /international/itf/itcz.shtml; Eldridge 1957; Buckle 1996; Pospichal et al. 2010; Fig. 13.1a)] from the south to the north (Nicholson and Grist 2003; Omotosho and Abiodun 2007; Omotosho 2008). The season usually begins around March or April in the southern parts $\left(4^{\circ}-8^{\circ} \mathrm{N}\right)$ of the country, commencing almost one-and-a-half months later in the northern parts $\left(8^{\circ} \mathrm{N}\right.$ northward: Ati et al. 2002; Oguntunde et al. 2014). In 2015, however, the northward progression of the onset of rainfall exhibited some anomalous behavior. In April, the ITD did not advance substantially from March, being more than $2^{\circ}$ south of its usual latitudinal position and also about $1^{\circ}$ south of the 10th percentile of its southernmost latitudinal position based on the 1981-2010 climatological period (Fig. 13.1a). Consequently, almost the entire country experienced April rains that were $40 \%$ below normal (Fig. 13.1b). The situation improved in the month of May when the southern and central regions

\begin{abstract}
AFFILIATIONS: LAWAL- Nigerian Meteorological Agency, Lagos, Nigeria; ABATAN_Department of Geological and Atmospheric Sciences, lowa State University, Ames, lowa; ANGÉLIL-University of New South Wales, Sydney, Australia; OlaniYan, OlusojI-Nigerian Meteorological Agency, Abuja, Nigeria; Oguntunde-Federal University of Technology, Akure, Nigeria; LAMPTEY-African Centre of Meteorological Application for Development, Niamey, Niger; ABIODUN-Department of Environmental and Geographical Sciences, University of Cape Town, Cape Town, South Africa; SHIOGAMA-National Institute for Environmental Studies, Tsukuba, Japan; WeHner, StONELawrence Berkeley National Laboratory, Berkeley, California DOI:I0.1175/BAMS-D-|6-0131.I
\end{abstract}

A supplement to this article is available online (10.1175 /BAMS-D-|6-0I3I.2) experienced almost normal rainfalls (i.e., $\pm 20 \%$ ), but areas north of $10^{\circ} \mathrm{N}$ still experienced more than $40 \%$ rainfall deficits (Fig. 13.1c). Normal rainfall amounts arrived in the northern regions in June, even though the ITD remained about $2^{\circ}$ south of its climatological latitudinal positions from April to July (Fig. 13.1a). According to reports from farmers (e.g., Daily Post [Nigeria], 21 June 2015; Okojie 2015) and personal conversations with some stakeholders, there were widespread crop failures resulting from continuous irregular rainfall (Agbo et al. 2015). Consequently, socio-economic activities, food production, and water resources were negatively affected during the year because the rainfall and growing seasons started much later than expected. Although the economic implications of the delay in the onset of the 2015 wet season have not been quantified at the time of this report, the nation witnessed abrupt increases in the prices of food commodities, thereby affecting food security (www.foodsecurityportal.org/nigeria /indicators; Agbo et al. 2015).

With the growing confidence of users in climate models (which are used for planning in order to mitigate the threat of climate variability and change; Abiodun et al. 2012; Olaniyan et al. 2015), a number of questions arise: Can simulations of current generation atmosphere-land climate models capture the late onsets such as occurred in 2015 in Nigeria? What is the role of anomalous sea surface temperatures (SSTs), as well as anthropogenic interference in the climate system (or non-anthropogenic interference) in altering the chance of the 2015 late onset of the rainy season over Nigeria?

Data. In this study, we use daily rainfall and dewpoint observations from a network of more than 50 meteorological stations of the Nigerian Meteorological Agency (NiMet; www.nimet.gov.ng). We also analyze simulations conducted with the CAM5.1 
(a)
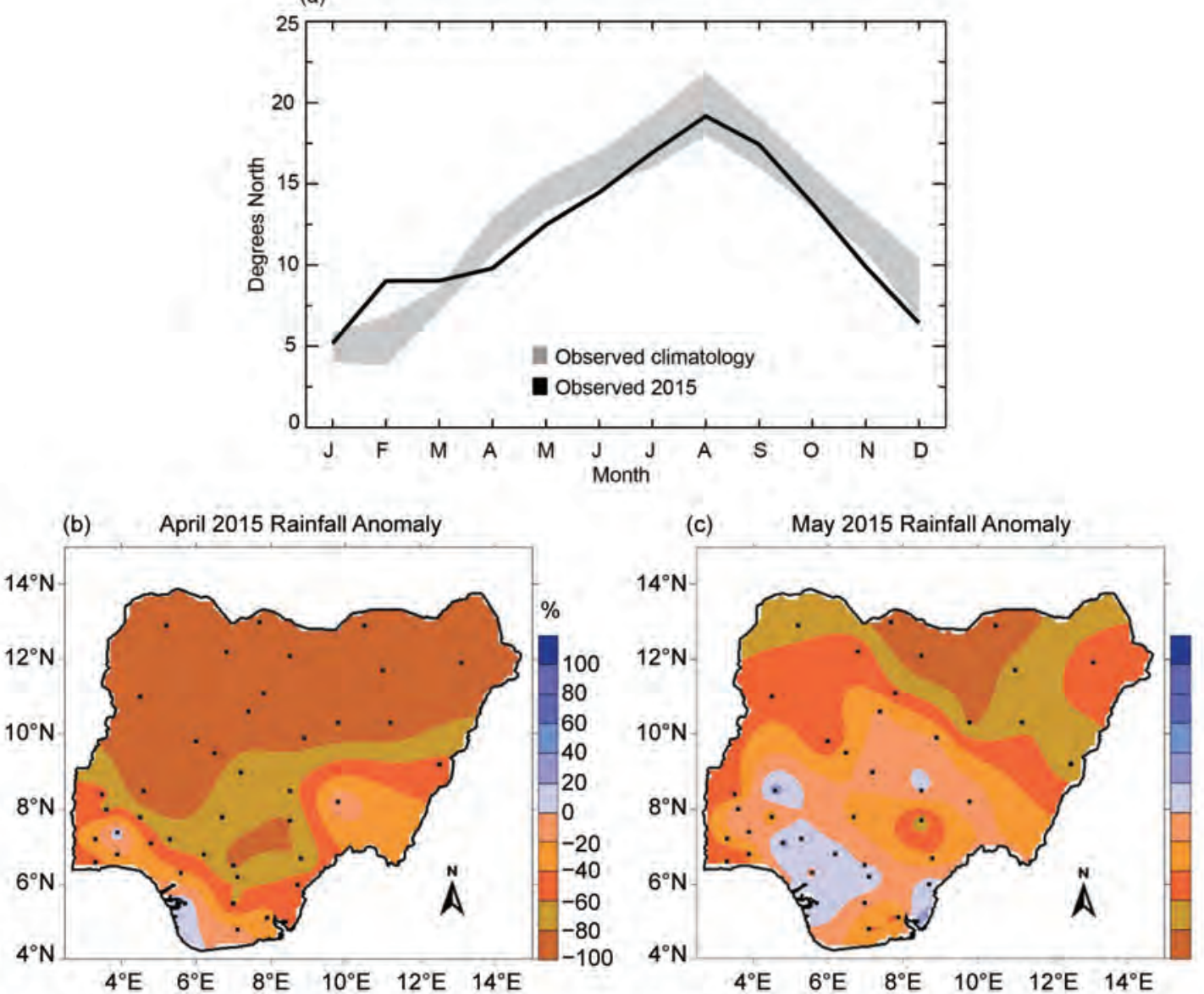

(d) April 2015 Observed SST Anomaly
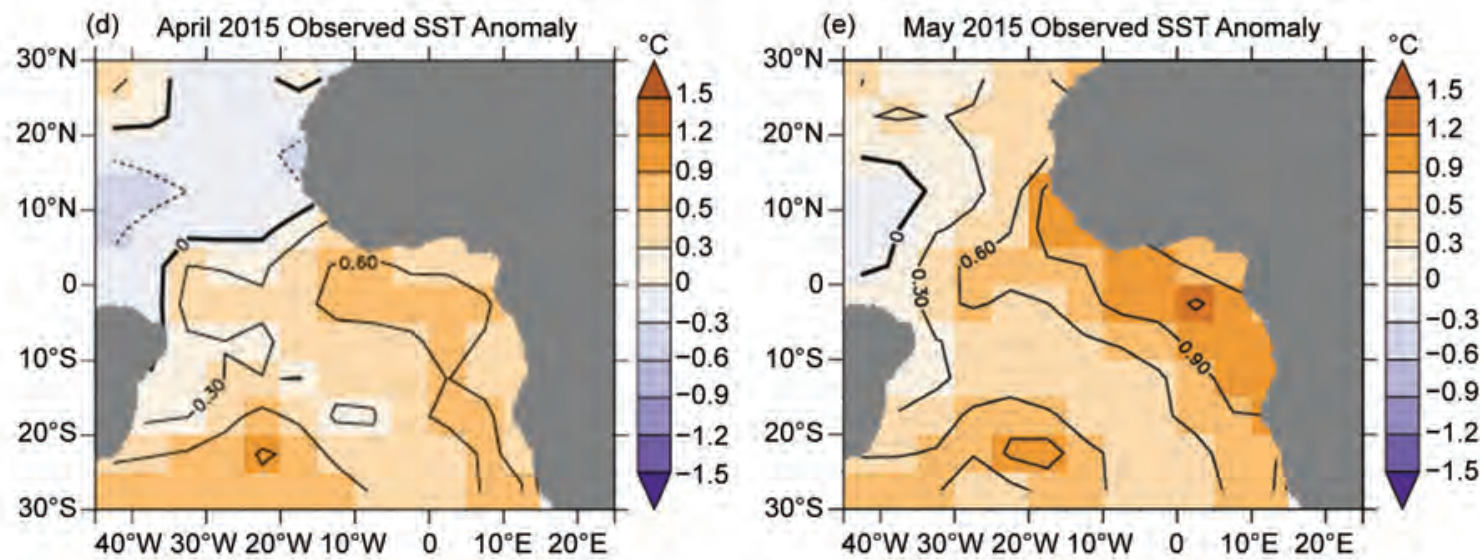

FIG.I3.I. (a) Observed mean monthly climatological and 2015 latitudinal positions of ITD over Nigeria; the gray shade represents the 10th-90th percentile range of the latitudinal positions of the ITD during the 198I-2010 period. Rainfall anomalies (\%) over Nigeria in (b) Apr and (c) May 20I5; the dots represent the location of all the synoptic meteorological stations used in the study while the brown colors indicate rainfall deficit. SST anomalies (shade and contour; ${ }^{\circ} \mathrm{C}$ ) over the Atlantic Ocean in (d) Apr and (e) May 2015.

(Neale et al. 2012) and MIROC5 (Watanabe et al. 2010) atmosphere-land climate models. CAM5.1 is run at $\sim 1.0^{\circ}$ spatial resolution, while MIROC5 is at $\sim 1.5^{\circ}$. Both models are run under the experimental protocol of the $\mathrm{C} 20 \mathrm{C}+$ Detection and Attribution Project (http://portal.nersc.gov/c20c; Stone 2013), with 99 and 100 simulations, respectively, run under observed (All-Hist) radiative, ocean surface, and 
land use/cover boundary conditions, and another 98 and 100 simulations, respectively, run under what those boundary conditions might have been in the absence of anthropogenic interference (Nat-Hist) (Angélil et al. 2016; Shiogama et al. 2013 and 2014). Nat-Hist anthropogenic forcings are set to circa year 1850 values, while observed ocean temperatures and sea ice are cooled by spatially- and time-varying amount based on atmosphere-ocean models in the CMIP5 archive (Stone and Pall 2016, unpublished manuscript). In addition to substantial algorithmic differences, there are some distinctions in the setup between the models: MIROC 5 uses prescribed aerosol precursor emissions, while CAM5.1 uses prescribed aerosol burdens, relevant here as simulated precipitation over West Africa can be sensitive to the regional aerosol forcing (Tompkins et al. 2005; Rosenfeld et al. 2008 and 2014). In addition, MIROC5 uses year1850 land cover for the Nat-Hist simulations, while CAM5.1 uses present-day land cover; land cover/use change is understood to have significant effects on rainfall and atmospheric variables such as midtropospheric wind speed, daily extreme temperatures, specific humidity, evapo-transpiration, etc., over Nigeria (Abiodun et al. 2008; Dirmeyer et al. 2010; Christidis et al. 2013). Given that monitoring of seasonal climate and the impacts of its variability over Nigeria is based on precipitation, we focus on April and May precipitation here. Anomalies are calculated from the 1981-2010 precipitation climatology for all data sources. Furthermore, ITD are calculated from the dewpoint observations obtained from NiMet data archive and from output of the CAM5.1 and MIROC5 simulations. Relative to the observed climatology, both models tend to have a northward bias in the ITD during the first half of the year, including the onset period, with the CAM5.1 ITD advancing a bit faster than observed during the onset season (Figs. 13.2a,b). Beyond this bias, the positions of the ITD in both models closely follow the observed climatological positions throughout the year, and the range of year-to-year variability is comparable to the observed range. Lawal (2015) found that CAM5.1 is capable of representing the dominant circulation processes during the wet season.

Results. The results from both models suggest that anthropogenic influences may have moderately (CAM5.1) or slightly (MIROC5) decreased the chance for low April rainfall and not altered the chances for low May rains (Table 13.1). The confidence intervals about these estimates however, are large, and the pos- sible difference in April drought frequencies could have resulted from random sampling. The estimates of the risk ratio (the ratio of the probabilities in 2015 between the All-Hist and Nat-Hist ensembles of being drier than the 10th percentile of the All-Hist simulations during the 1981-2010 periods) are less than 1.0 in April while the estimates are close to 1.0 in May (Table 13.1). In addition, the simulations suggest little spatial structure in the influence of anthropogenic emissions on the chance of low April-May 2015 precipitation (Figs. 13.2c-f); low risk ratios in the northern regions in April are not robust due to the low rainfall usually experienced there.

While anthropogenic influence may not have substantially affected the chance of the late onset, the influence of the naturally occurring anomalies in SSTs may be different. Figures 13.1d,e show that the observed SSTs (www.esrl.noaa.gov/psd/data /gridded/data.kaplan_sst.html; Kaplan et al. 1998;) over the Gulf of Guinea were warmer than normal during April-May 2015. Under these warmer-thannormal SST conditions, it should have been possible to advect sufficient moisture to support precipitation (Zheng et al. 1999; Odekunle and Eludoyin 2008). It would also be expected that the moisture laden southwesterly trade winds would have become more energized, buoyant, and capable of dynamically pushing the ITD deeply into the northern end of the country, thereby resulting in above-normal rainfall both at the coastal and inland parts of the country (Omotosho and Abiodun 2007). However, both models suggest that anomalous SSTs had little effect on the chance of low May 2015 precipitation while they indicate that anomalous SSTs might in fact have decreased the chance of low April 2015 precipitation over the country relative to amounts experienced during the previous eight years (risk ratio $-\mathrm{P}_{\text {All-Hist }} / \mathrm{P}_{2007-2014}$, with the 2007-14 period used because of the availability of 100 -member ensembles with both models; Table 13.1) and, in a statistically significant manner for CAM5.1, relative to the 1981-2010 climatology (not shown). This is consistent with the shift in ITD position in CAM5.1's All-Hist 2015 simulations relative to the 1981-2010 climatology (Fig. 13.2a).

The results for soil moisture are similar to those of SSTs (not shown). Both models suggest that both the anthropogenic emissions and anomalous SSTs decreased the chance of dry soil (upper $10 \mathrm{~cm}$ ) in May 2015, but they are also consistent with no influence. This suggests little effect of temperature on Nigerian soil moisture in a warming climate. Three possible explanations for this are: firstly, if it has not yet rained, 
(a)

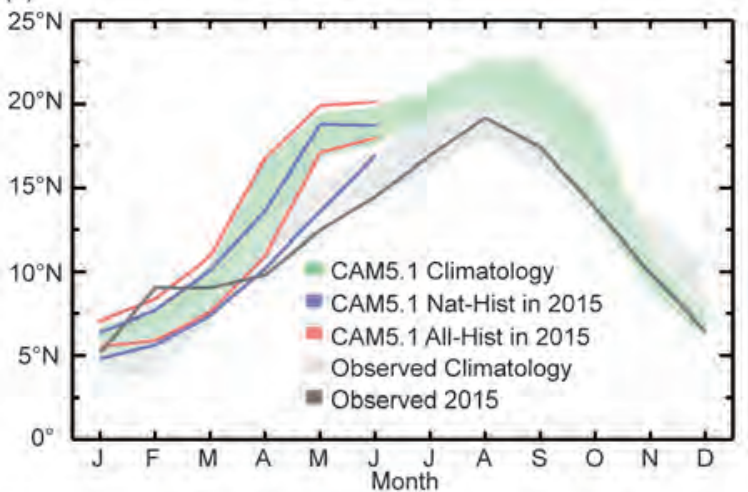

(c)

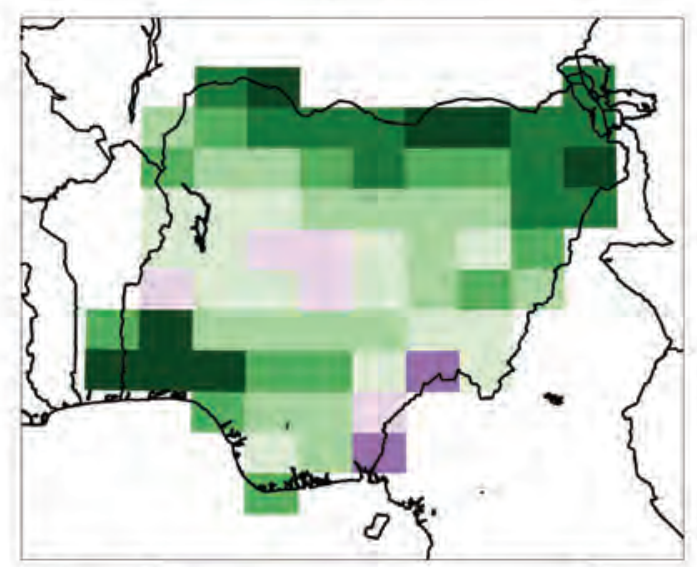

(e)

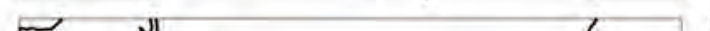

(b)

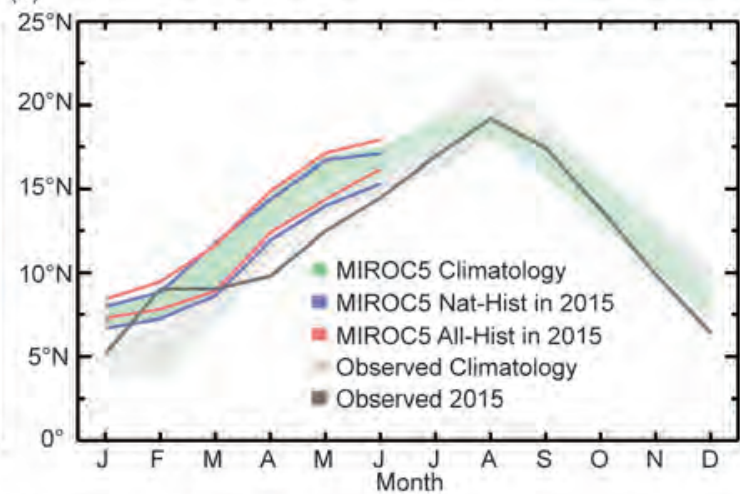

(d)

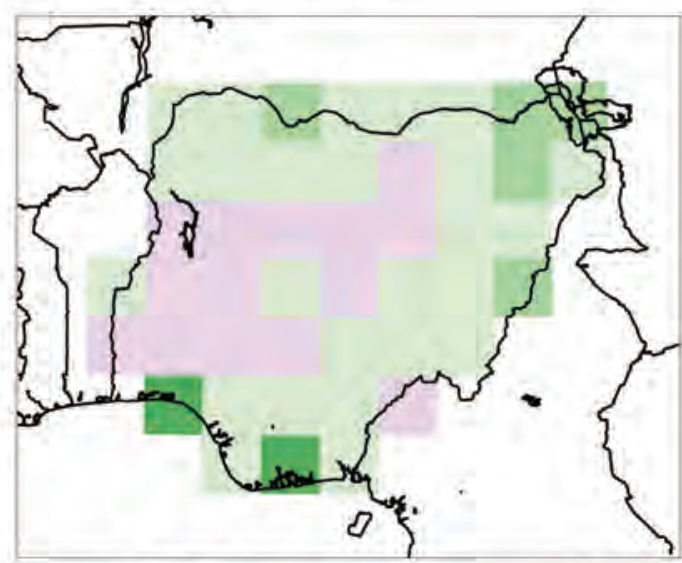

(f)

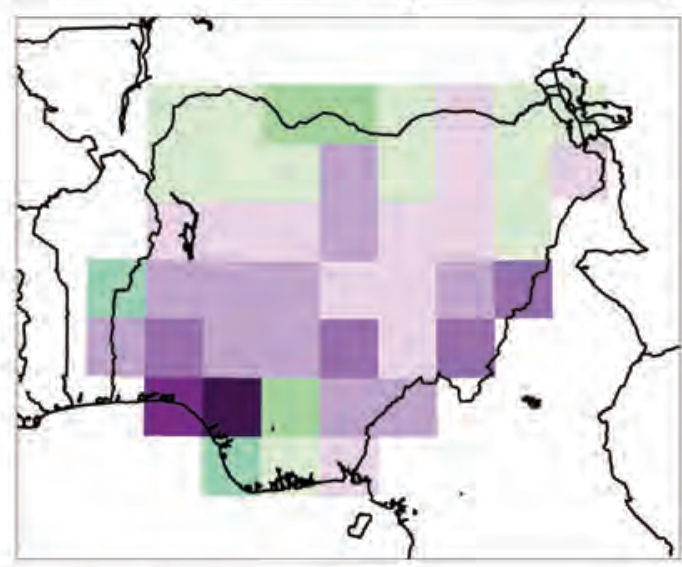

0.25

0.5

2

4

FIG. 13.2. Annual cycle of the ITD as simulated by (a) CAM5.I and (b) MIROC5. The I0th-90th percentile range of the 2015 All-Hist and Nat-Hist simulations are denoted by pairs of lines, with turquoise shade denoting the range from the 50 CAM5.I and 10 MIROC5 simulations covering the I98I-20I0 climatological period; observed values are reproduced from Fig. I3. Ia. (c),(f) The spatial structures of the risk ratio due to anthropogenic emissions for falling below the 10th percentile of 198I-2010 simulated precipitation climatology in Apr and May 2015 over Nigeria from (c),(e) CAM5.I; (d),(f) MIROC5. Green colors indicate that the chance of a dry month has decreased due to emissions.

then there is no moisture to evaporate from the soil; secondly, if the rains have arrived, then the air is too moist to support evaporation, so there is no warm- ing effect on evaporation during these months; and lastly, the anthropogenic signal may be smaller than the internal variability of the soil moisture, that is, 
Table I3.I. Probability ( $P x)$ of being below the I0th percentile of precipitation over the I98I2010 period in the All-Hist and Nat-Hist ensembles, and the risk ratios for the anthropogenic influence (PALL-Hist/PNat-Hist) and for the influence of anomalous SSTs with respect to the previous 8 years (PALL-Hist/P2007-2014) for exceeding that threshold in Apr and May 2015 over Nigeria.

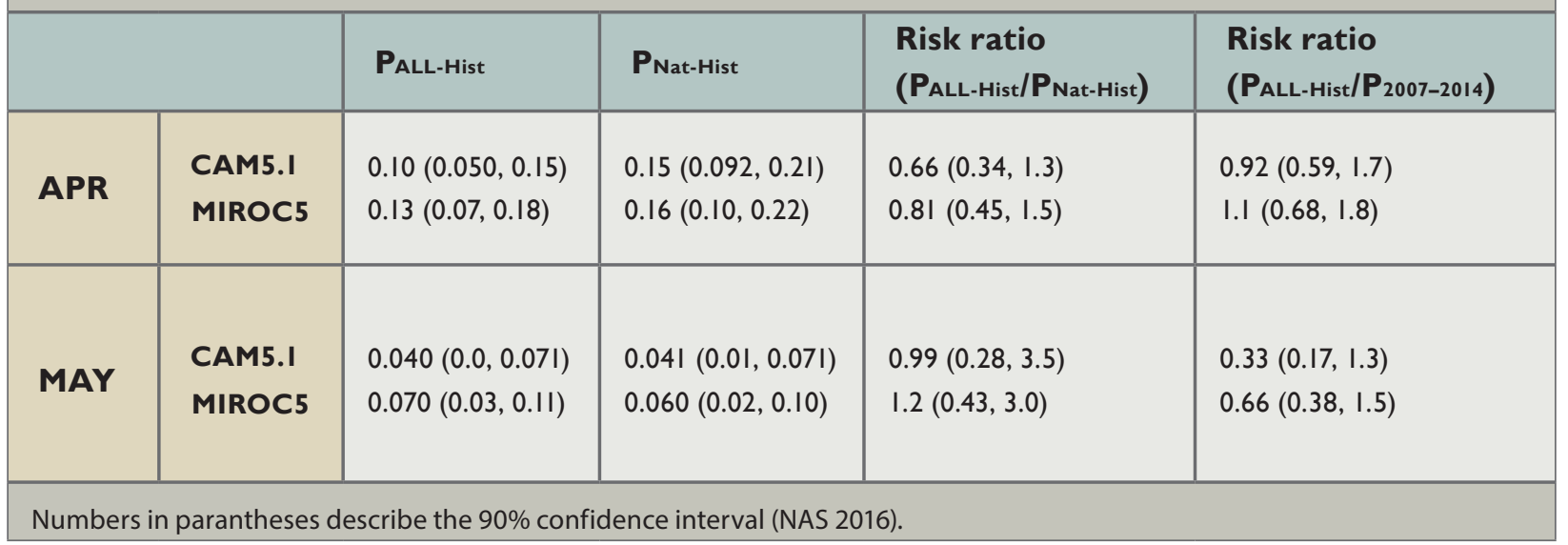

low signal-to-noise ratio. This contradicts the notion that mean warming dominates the impact of anthropogenic emissions on every extreme weather event (Trenberth et al. 2015).

Summary. The results from the climate models examined indicate that there is little or no evidence of anthropogenic emissions or anomalous SSTs on the delay in the onset of the 2015 wet season in Nigeria. In as much as the models do suggest an influence, the effect was, in fact, to make the late onset less likely and thus truly a fluke. The implication is that rainfall deficits observed over Nigeria during the April-May 2015 onset period were the results of unforced internal variability of the tropical atmosphere (see analyses in Supplemental Materials).

ACKNOWLEDGEMENTS. We appreciate the primary editor and other anonymous reviewers for their helpful comments and suggestions. We also thank NiMet, Japanese Research Community, and Lawrence Berkeley National Laboratory that provided observations and simulations datasets used in this study. Stone and Wehner were supported by the Regional and Global Climate Modeling Program (contract number DE-AC02- 05CH11231); Abatan by the U.S. National Science Foundation (grant number AGS-1243030); and Shiogama by the Program for Risk Information on Climate Change.

\section{REFERENCES}

Abiodun, B. J., J. S. Pal, E. A. Afiesimama, W. J. Gutowski, and A. Adedoyin, 2008: Simulation of West African monsoon using RegCM3 Part II: Impacts of deforestation and desertification. Theor. Appl. Climatol., 93, 245-261, doi:10.1007/s00704 -007-0333-1.

Abiodun, B. J., K. A. Lawal, A. T. Salami, A. A. Abatan, 2012: Potential influences of global warming on future climate and extreme events in Nigeria. Reg. Environ. Change, 13, 477-491, doi:10.1007/s10113 -012-0381-7.

Agbo, A. D., V. A. Yusuf, and A. Acholo, 2015: Nigeria: Poor harvest looms as irregular rainfall continues. All Africa for Daily Trust, 23 July 2015. [Available online at http://allafrica.com/stories/201507231260. html.]

Angélil, O., D. Stone, M. Wehner, C. J. Paciorek, H. Krishnan, and W. Collins, 2016: An independent assessment of anthropogenic attribution statements for recent extreme weather. J. Climate, in press, doi:10.1175/JCLI-D-16-0077.1.

Ati, O. F., C. J. Stigter, and E. O. Oladipo, 2002: A comparison of methods to determine the onset of growing season in Northern Nigeria. Int. J. Climatol., 22, 731-742, doi:10.1002/joc.712.

Bai, P., W. Gan, and L. Shi, 2011: Bayesian confidence interval for the risk ratio in a correlated $2 \times 2$ table with structural zero. J. Appl. Stat., 38, 2805-2817, doi:10.1080/02664763.2011.570318. 
Buckle, C., 1996: Weather and Climate in Africa. Addison-Wesley Longman, $312 \mathrm{pp}$.

Christidis, N., P. A. Stott, G. C. Hegerl, and R. A. Betts, 2013: The role of land use change in the recent warming of daily extreme temperatures. Geophys. Res. Lett., 40, 589-594, doi:10.1002/grl.50159.

Dirmeyer, P. A., D. Niyogi, N. de Noblet-Ducoudré, R. E. Dickinson, and P. K. Snyder, 2010: Impacts of land use change on climate. Int. J. Climatol., 30, 1905-1907, doi:10.1002/joc.2157.

Eldridge, R. H., 1957: A synoptic study of West African disturbance lines. Quart. J. Roy. Meteor. Soc., 83, 303-314.

Kaplan, A., M. Cane, Y. Kushnir, A. Clement, M. Blumenthal, and B. Rajagopalan, 1998: Analyses of global sea surface temperature 1856-1991. J. Geophys. Res., 103 (C9), 18567-18589.

Lawal, K. A., 2015: Understanding the variability and predictability of seasonal climates over West and Southern Africa using climate models. PhD thesis, Faculty of Science, University of Cape Town, Cape Town, South Africa. [Available online at https:// open.uct.ac.za/handle/11427/16556.]

Kuonen D., 2006: Studentized bootstrap confidence intervals based on M-estimates. J. Appl. Stat., 32, 443-460, doi:10.1080/02664760500079340.

NAS, 2016: Attribution of Extreme Weather Events in the Context of Climate Change. National Academies Press, 186 pp., doi:10.17226/21852.

Nicholson, S. E., and J. P. Grist, 2003: The seasonal evolution of the atmospheric circulation over West Africa and equatorial Africa. J. Climate, 16, 1013-1030.

Neale, R. B., and Coauthors, 2012: Description of the NCAR Community Atmosphere Model (CAM 5.0). NCAR Tech. Note, NCAR/TN-486+STR, 274 pp. [Available online at www.cesm.ucar.edu/models /cesm1.0/cam/docs/description/cam5_desc.pdf.]

Odekunle, T. O., and A. O. Eludoyin, 2008: Sea surface temperature patterns in the Gulf of Guinea: Their implications for the spatio-temporal variability of precipitation in West Africa. Int. J. Climatol., 28, 1507-1517, doi:10.1002/joc.1656.

Oguntunde, P. G., G. Lischeid, B. J. Abiodun, and O. Dietrich, 2014: Analysis of spatial and temporal patterns in onset, cessation and length of growing season in Nigeria. Agric. For. Meteor., 194, 77-87, doi:10.1016/j.agrformet.2014.03.017.
Okojie, J., 2015: Climate change threatens food production in Nigeria. Business Day, 5 August 2015. [Available online at http://businessdayonline.com /climate-change-threatens-food-production-in -nigeria/.]

Olaniyan, E., E. Afiesimama, F. Oni, and K. A. Lawal, 2015: Simulating the daily evolution of West African monsoon using high resolution regional COSMOmodel: A case study of the first half of 2015 over Nigeria. J. Climatol. Wea. Forecasting, 3, 142, doi:10.4172/2332-2594.1000142.

Omotosho, J. B., 2008: Pre-rainy season moisture build-up and storm precipitation delivery in the West Africa Sahel. Int. J. Climatol., 28, 937-946, doi:10.1002/joc.1548.

—_, and B. J. Abiodun, 2007: A numerical study of moisture build-up and rainfall over West Africa. Meteor. Appl., 14, 209-225, doi:10.1002/met.11.

Pospichal, B., D. Bou Karam, S. Crewell, C. Flamant, A. Hünerbein, O. Bock, and F. Saïd, 2010: Diurnal cycle of the intertropical discontinuity over West Africa analysed by remote sensing and mesoscale modelling. Quart. J. Roy. Meteor. Soc., 136 (Suppl. 1), 92-106, doi:10.1002/qj.435.

Rosenfeld, D., U. Lohmann, G. B. Raga, C. D. O’Dowd, M. Kulmala, S. Fuzzi, A. Reissell, and M. O. Andreae, 2008: Flood or drought: How do aerosols affect precipitation? Science, 321, 1309-1313, doi:10.1126 /science.1160606.

— , and Coauthors, 2014: Global observations of aerosol-cloud-precipitation-climate interactions. Rev. Geophys., 52, 750-808, doi:10.1002/2013RG000441.

Shiogama, H., M. Watanabe, Y. Imada, M. Mori, M. Ishii, and M. Kimoto, 2013: An event attribution of the 2010 drought in the South Amazon region using the MIROC5 model. Atmos. Sci. Lett., 14, 170-175, doi:10.1002/asl2.435.

$-, \ldots,-, \ldots$, Y. Kamae, M. Ishii, and M. Kimoto, 2014: Attribution of the June-July 2013 heat wave in the southwestern United States. SOLA, 10, 122-126, doi:10.2151/sola.2014-025.

Stone, D., 2013: Boundary conditions for the C20C Detection and Attribution Project: The All-Hist lest1 and Nat-Hist/CMIP5-est1 scenarios. Lawrence Berkeley National Laboratory, 18 pp. [Available online at http://portal.nersc.gov/c20c /input_data/C20C-DandA_dSSTs_All-Hist-est1 _Nat-Hist-CMIP5-est1.pdf.] 
Tompkins, A. M., C. Cardinali, J.-J. Morcrette, and M. Rodwell, 2005: Influence of aerosol climatology on forecasts of the African Easterly Jet. Geophys. Res. Lett., 32, L10801, doi:10.1029/2004GL022189.

Trenberth, K. E., J. T. Fasullo, and T. G. Shepherd, 2015: Attribution of climate extreme events. Nat. Climate Change, 5, 725-730, doi:10.1038/nclimate2657.

Watanabe, M., and Coauthors, 2010: Improved climate simulation by MIROC5: Mean states, variability, and climate sensitivity. J. Climate, 23, 6312-6335, doi:10.1175/2010JCLI3679.1.

Zheng, X., E. A. B. Eltahir, and K. A. Emanuel, 1999: A mechanism relating tropical Atlantic Spring sea surface temperature and West African rainfall. Quart. J. Roy. Meteor. Soc., 125, 1129-1163. 


\title{
14. HUMAN INFLUENCES ON HEAT-RELATED HEALTH INDICATORS DURING THE 2015 EGYPTIAN HEAT WAVE
}

\author{
Daniel Mitchell
}

A combined modeling and observational assessment of the 2015 heat wave in Egypt found that human discomfort increased due to anthropogenic climate change.

Introduction. In August 2015, northeast Africa and the Middle East experienced a heat wave that caused high levels of human discomfort, even for countries particularly adapted to extreme heat. Reports suggest that more than 90 people died throughout Egypt, with the majority being elderly (Al Jazeera, 17 August 2015). In and around Cairo, many of the deaths were blamed on overpopulation and cramped living conditions, notably including prisons and psychiatric centers, a problem that is not necessarily restricted to the developing world (Huffington Post, 15 August 2015; Holt 2015). The local health ministry reported that persistently high humidity was at least partially to blame. In the previous year (2014), the region experienced an unprecedented drought (Bergaoui et al. 2015; Barlow and Hoell 2015), and combined with political tensions, the recent heat wave could enhance unrest in the region (Schleussner et al. 2016).

While direct attribution of climate change on mortality is possible (Mitchell et al. 2016a), the required observed mortality data are not easily obtained in this specific region. As such, the attribution study is performed on the wet bulb globe temperature (WBGT), a proxy for human discomfort. Note that Mitchell et al. (2016a) used a different heat stress metric, apparent temperature, because this could be used directly with the health impact assessment (HIA) model they employed. As this study does not use a HIA model, the WBGT is chosen so the study can be contrasted with a recent climate predictions study (Pal and Eltahir 2015). A comparison of the two different heat stress metrics is given in Willett and Sherwood (2012).

AFFILIATIONS: MITCHELL-Environmental Change Institute, Oxford University, Oxford, England

DOI:I0.II75/BAMS-D-16-0132.I

A supplement to this article is available online $(10.1175$

/BAMS-D-16-0132.2)
Methods. The WBGT is estimated using the following equation (Fischer and Knutti 2012):

$$
\mathrm{WBGT}=0.567 \mathrm{~T}+0.393 e+3.94
$$

The water vapor pressure, $e=f(T, R H)$, can be approximated using a derivation of the Magnus formula (Sonntag 1990; Sippel and Otto 2014), where the terms $T$ and $R H$ are temperature and relative humidity, respectively, and are available from model output and from the Met Office Integrated Data Archive System (MIDAS; Met Office 2012) station data. This study focuses on Egypt as a whole, but a subanalysis is also performed for Cairo (the most populated city in Egypt). A map of the station locations is given in Fig. 14.1a with Cairo marked in red.

Event attribution is performed using the weather@ home framework, which comprises a global atmosphere-only driving model (HadAM3P; Massey et al. 2015) and a 50-km regional model covering northern Africa and the Middle East (the setup is identical to Bergaoui et al. 2015). Approximately 2000 simulations of 2015 are run using perturbed initial conditions (actual scenario) and compared with 2000 simulations estimating a naturalized version of 2015 (natural scenario). The natural simulations employ solar and volcanic forcings fixed at 2015 levels with all other forcings set to preindustrial values. However, the actual scenarios employ all forcings at 2015 levels, which include the aforementioned natural forcings as well as greenhouse gases, aerosols, and land use. The model is spun up for 2 years before 2015 to equilibrate long-memory processes in the Earth-atmosphere system. The natural scenario simulations include 10 estimates of possible natural sea surface temperatures (SSTs), which are estimated using coupled oceanatmosphere models (Schaller et al. 2016). The model simulations are interpolated to each of the different station locations.

Results. The observed WBGT over Egypt (i.e., the average of all stations) is shown by the black line 
(a)

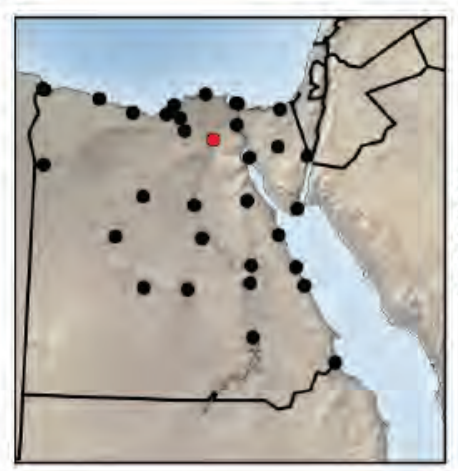

(d) (b)

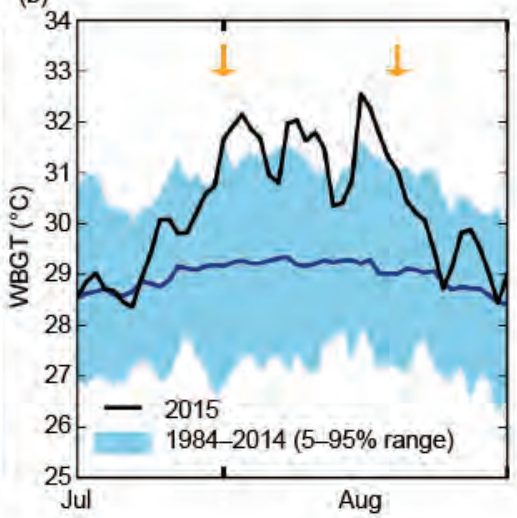

(c)

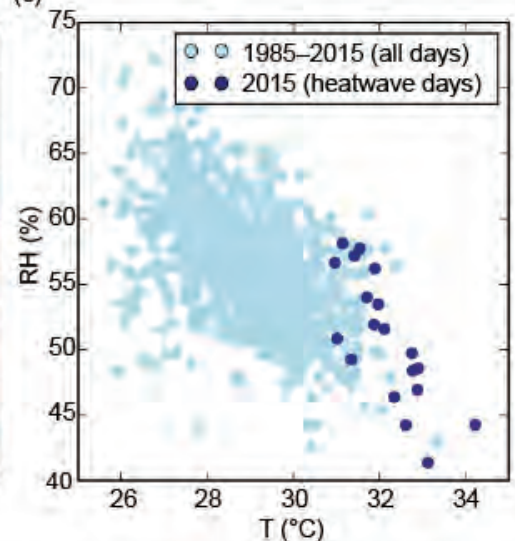

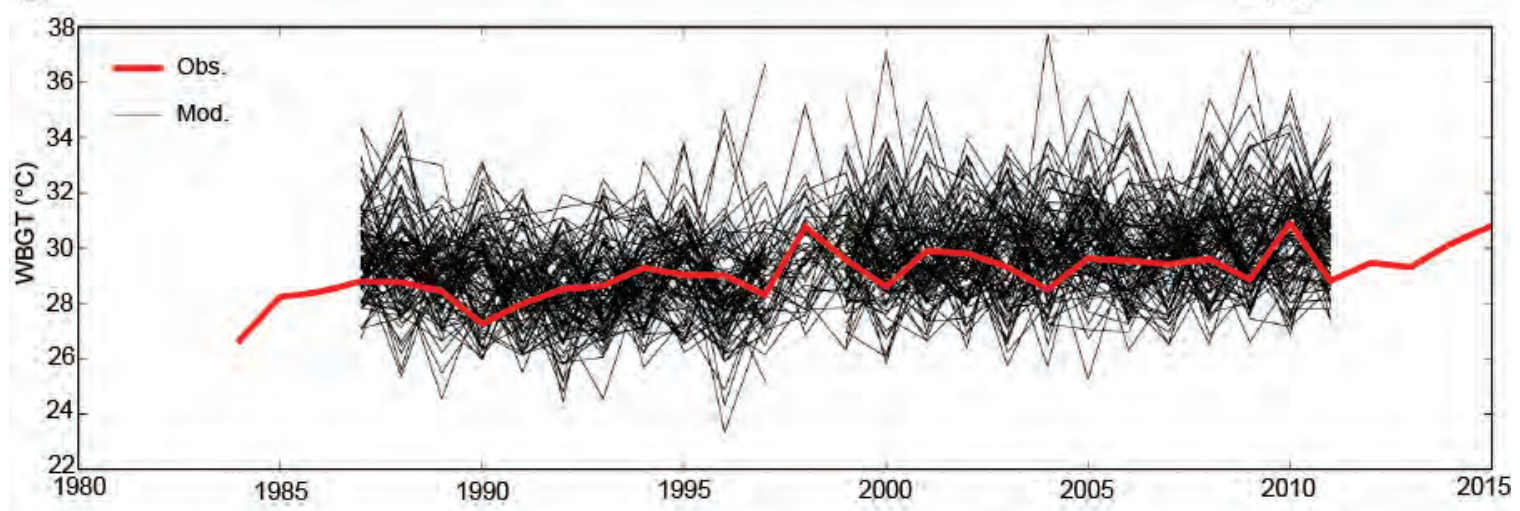

FIG. I4.I. (a) Station locations over Egypt from MIDAS. The red station marks Cairo International Airport. (b) The observed WBGT cycle over Egypt through I5 Jul to 3I Aug. The black line shows 20I5; the light blue region is the 5\%-95\% range covering 1984-20 I4; and the dark blue line is the climatology. Orange arrows mark the beginning and start of the heat wave (see text). (c) A scatter plot of observed Aug daily temperatures against relative humidity levels (light blue) for all days over the 1984-2015 period, and (dark blue) the days during the 2015 heat wave (first 19 days of Aug). (d) Aug averaged WBGT for (red) observations and (black) individual ensemble members of HadAM3P.

of Fig. 14.1b for 2015. The WBGT in August was a maximum for 2015 and was greater than the 5-95 percentile range of previous years (1984-2014; blue region). Here, the heat wave is defined as starting when the 5-95 percentile in WBGT is exceeded for at least 5 days and ends when the WBGT drops below the 5-95 percentile without exceeding it in the subsequent 5 days. The heat wave event is marked with orange arrows on Fig. 14.1b. While the primary reason for the high WBGT is the high temperatures over this period, the high relative humidity levels (for the given temperature levels) were also important. Around half of the heat wave days had this combination with the other half having approximately average relative humidity levels for the respective temperature levels (Fig. 14.1c).

A reasonable hypothesis would be that this event was made more likely due to human-induced climate change because the observed August WBGT has a significant positive trend over Egypt (Fig. 14.1d, red line). To test this, model simulations of the 2015 climate over the region are employed. The modeled bias in WBGT is first examined using 100 ensemble members spanning 1987-2012 (Fig. 14.1c, black lines). This period is chosen because it is the length of time that the required observed SST forcing data are available for the model simulations. The multiensemble mean of the simulations shows a similar trend in WBGT to observations, as can be seen in Fig. 14.1d.

Compared with the observed data, the model performs remarkably well for mean climate with the bias in WBGT over this period being $0.007^{\circ} \mathrm{C}$. However, larger biases are observed in the mean temperatures with the model being $1.88^{\circ} \mathrm{C}$ too warm; and for relative humidity, the model is $\sim 8 \%$ too dry. Therefore, the well-simulated mean WBGT in the model is partially due to compensating errors from the temperature and relative humidity being biased in opposing directions (as relevant for heat stress). The variance of daily temperature and WBGT are 


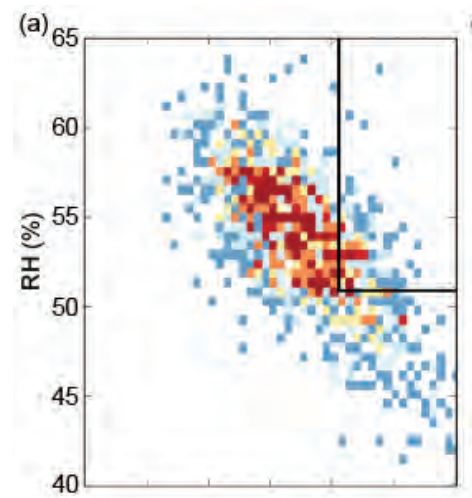

(b)
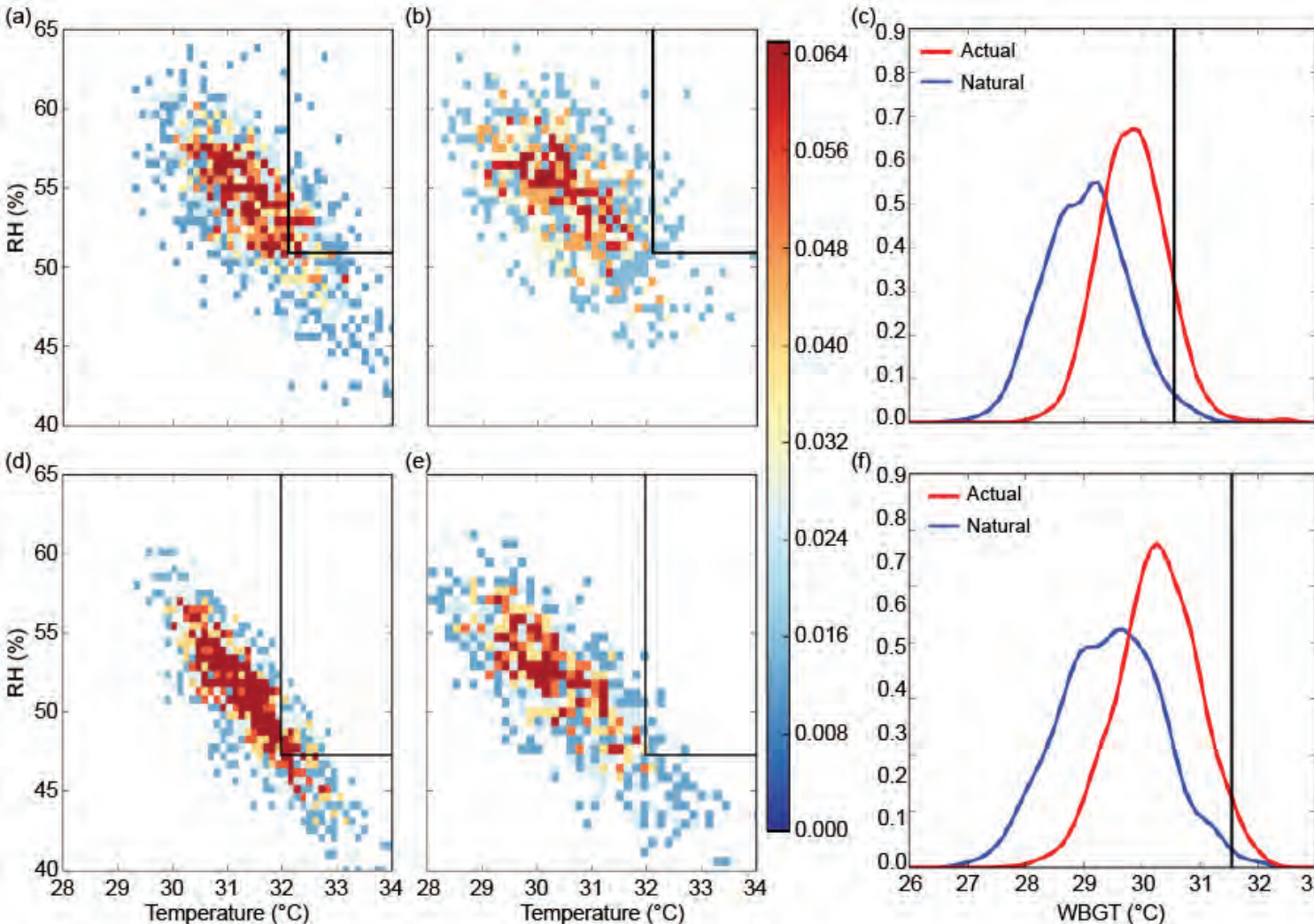

(e)
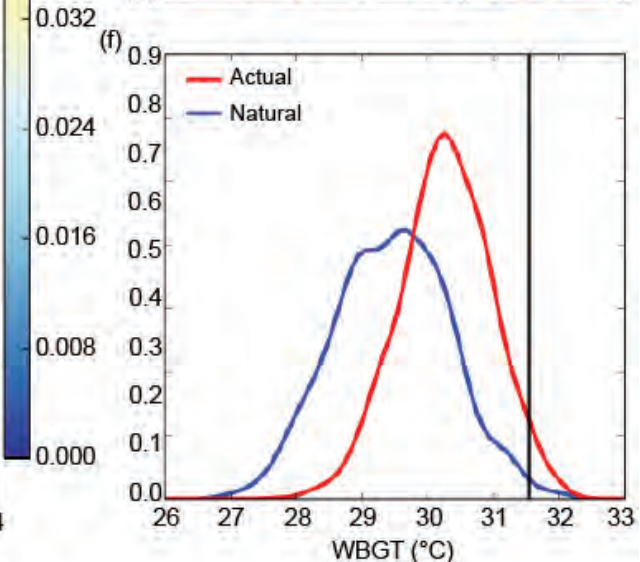

FIG. 14.2. Two-dimensional histograms of 19-day average relative humidity and temperature during Aug for (a),(d) the actual simulations and (b),(e) the natural simulations. (c),(f) One-dimension PDFs of the WBGT for (red) actual and (blue) natural simulations. (a)-(c) For Egypt; (d)-(f) for Cairo. Black lines show the observed value of the variable in question averaged over the first 19 days in Aug 2015. All plots are expressed as a density (i.e., they integrate to I).

also well reproduced (not shown) although there are large low biases in the variance of modeled-relative humidity $\left(\sigma_{\mathrm{obs}} / \sigma_{\bmod }=1.89\right)$.

Before the event is assessed, the monthly mean and daily variability about the mean for temperature, relative humidity, and WBGT are corrected to match observations at each station location. For temperature, this has been performed in Hempel et al. (2013). Applying their procedure to relative humidity and WBGT also proves to be an adequate bias correction, perhaps, unsurprisingly, as both variables evolve in a similar fashion to temperature. (Note that calculating WBGT from the bias-corrected variables yields almost identical results as calculating WBGT from the raw variables and then bias-correcting. In this assessment, the latter method is used.)

To understand the 19-day event (e.g., Fig. 14.1b) more completely, the coevolution of temperature and relative humidity is contrasted with WBGT. Figure 14.2 shows the $2 \mathrm{D}$ histograms of modeled, 19-day averaged, relative humidity, and temperature over Egypt for the actual scenario (Fig. 14.2a) and the natural scenario (Fig. 14.2b). Figures 14.2d,e show the same but for Cairo only. The black lines show the observed thresholds during the event, and hence model data that fall to the upper-right of these thresholds are more extreme than the observed event. It is clear that more model data exceed the observed threshold in the actual scenario than in the natural. This is true for Egypt as a whole, and specifically for Cairo, and confirms the hypothesis that human-induced climate change has made this event more likely.

Performing the same comparison on the WBGT (Figs. 14.2c,f for Egypt and Cairo, respectively) supports this conclusion. To quantify the level of anthropogenic contribution to the event, the fraction of attributable risk (FAR) is used. This is defined, as in Allen (2003) as $1-\left(\mathrm{P}_{\mathrm{Nat}} / \mathrm{P}_{\mathrm{Act}}\right)$, where $\mathrm{P}_{\mathrm{Nat}}$ is the probability of exceeding the event in the natural scenario, and $\mathrm{P}_{\mathrm{Act}}$ is the probability of exceeding the event in the actual scenario.

Over Egypt and Cairo, the FAR values (with 2 sigma errors) in WBGT are calculated as $0.69( \pm 0.17)$ and $0.67( \pm 0.07)$, respectively. (Note that if a shorter 
averaging period is used, such as 7-day averages, the FAR values are similar for Egypt as a whole, although decrease for Cairo.) While the heat wave center of action was in the south of Egypt (e.g., Haaretz 2015), Cairo (in the north) experienced slightly higher temperatures due to the urban heat island effect (e.g., Heaviside et al. 2015). Luckily, like Cairo, most of Egypt's population resides in the north, with 9 out of 10 of the largest cities (by population) being located there. Had the heat wave been more focused over the north, the death toll could have been far higher.

Conclusions and discussions. In this study, an analysis of heat stress was undertaken for the 2015 Egyptian heat wave. It was found that over Egypt the event was made $69 \%( \pm 17 \%)$ more likely due to anthropogenic climate change, and this was a similar value of $67 \%$ ( \pm $7 \%)$ when only Cairo was considered. The principal driver of human discomfort was high temperature, but relatively high humidity levels for those given temperatures also played a role for around half of the heat wave. It is noted that the daily variance of relative humidity is bias-low in this region. This is especially relevant for the developing regions of the world, as an increased exceedance of critical thresholds (such as the temperature at which the human body can still transfer heat to the surrounding) will be among the most important impacts felt for society under climate change (Pal and Eltahir 2015). This is especially true for high-mitigation scenarios, such as those presented in the 2015 Paris Agreement, because impacts on society will be largely felt through changes in extremes (Mitchell et al. 2016b).

While assessing human health under climate change is of particular importance in this region, it also presents unique challenges. This analysis focuses only on a physical heat stress measure of human discomfort and does not take into account social aspects (e.g., Klinenberg 2002). To do this, a full epidemiological analysis is needed in the first instance (as in Mitchell et al. 2016a). However, while in the context of Africa, meteorological data over Egypt are surprisingly abundant, reliable, and freely available, epidemiological data (such as all-cause mortality) are not. Nevertheless, this study represents a step in understanding health impacts of climate change in the region, and it is hoped that this study and others like it will prompt local governments to make national-level health data more widely available to the outside community.
ACKNOWLEDGEMENTS. Mitchell is funded under the ACE Africa project. I would like to thank all of the volunteers who have donated their computing time to climateprediction.net and weather@home. Also, thanks to the Oxford e-Research Centre and Met Office Hadley Centre PRECIS teams for their technical and scientific support in the development and application of weather@home.

\section{REFERENCES}

Allen, M., 2003: Liability for climate change. Nature, 421, 891-892.

Barlow, M., and A. Hoell, 2015: Drought in the Middle East and central-southwest Asia during winter 2013/14 [in "Explaining Extreme Events of 2014 from a Climate Perspective"]. Bull. Amer. Meteor. Soc., 96 (12), S71-S76, doi:10.1175/BAMS-D-15-00127.1.

Bergaoui, K., D. Mitchell, R. Zaaboul, R. McDonnell, F. Otto, and M. Allen, 2015: The contribution of humaninduced climate change to the drought of 2014 in the southern Levant region [in "Explaining Extreme Events of 2014 from a Climate Perspective"]. Bull. Amer. Meteor. Soc., 96 (12), S66-S70, doi:10.1175 /BAMS-D-15-00129.1.

Fischer, E. M., and R. Knutti, 2012: Robust projections of combined humidity and temperature extremes. Nat. Climate Change, 3, 126-130, doi:10.1038 /nclimate1682.

Haaretz, 2015: Death toll in Egypt heatwave rises to 106. Haaretz [online], 18 August 2015. [Available online at www.haaretz.com/middle-east-news/1.671762.]

Heaviside, C., X.-M. Cai, and S. Vardoulakis, 2015: The effects of horizontal advection on the urban heat island in Birmingham and the West Midlands, United Kingdom during a heatwave. Quart. J. Roy. Meteor. Soc., 141, 1429-1441, doi:10.1002/qj.2452.

Hempel, S., K. Frieler, L. Warszawski, J. Schewe, and F. Piontek, 2013: A trend-preserving bias correctionthe ISI-MIP approach. Earth Syst. Dyn., 4, 219-236, doi:10.5194/esd-4-219-2013.

Holt, D. W. E., 2015: Heat in US Prisons and Jails: Corrections and the Challenge of Climate Change. Sabin Center for Climate Change Law, Columbia Law School, 134 pp. [Available online at https:// web.law.columbia.edu/sites/default/files/microsites /climate-change/holt_-_heat_in_us_prisons_and _jails.pdf.]

Klinenberg, E., 2002: Heat Wave: A Social Autopsy of Disaster in Chicago. University of Chicago Press, 328 pp. 
Massey, N., and Coauthors, 2015: weather@home-development and validation of a very large ensemble modelling system for probabilistic event attribution. Quart. J. Roy. Meteor. Soc., 141, 1528-1545, doi:10.1002/qj.2455.

Met Office, 2012: Met Office Integrated Data Archive System (MIDAS) Land and Marine Surface Stations Data (1853-current). NCAS British Atmospheric Data Centre, cited 2016. [Available online at http:// catalogue.ceda.ac.uk/uuid/220a65615218d5c9cc9e4 785a3234bd0.]

Mitchell, D., and Coauthors, 2016a: Attributing human mortality during extreme heat waves to anthropogenic climate change. Environ. Res. Lett. , 11, 074006, doi:10.1088/1748-9326/11/7/074006.

— , R. James, P. M. Forster, R. A. Betts, H. Shioga$\mathrm{ma}$, and M. Allen, 2016b: Realizing the impacts of a $1.5^{\circ} \mathrm{C}$ warmer world. Nat. Climate Change, 6, 735737, doi:10.1038/nclimate3055.

Pal, J. S., and E. A. B. Eltahir, 2015: Future temperature in southwest Asia projected to exceed a threshold for human adaptability. Nat. Climate Change, 6 , 197-200, doi:10.1038/nclimate2833.

Schaller, N., and Coauthors, 2016: Human influence on climate in the 2014 southern England winter floods and their impacts. Nat. Climate Change, 6, 627-634, doi:10.1038/nclimate2927.

Schleussner, C. F., J. F. Donges, R. V. Donner, and H. J. Schellnhuber, 2016: Armed-conflict risks enhanced by climate-related disasters in ethnically fractionalized countries. Proc. Natl. Acad. Sci. USA, 113, 9216-9221, doi:10.1073/pnas.1601611113.

Sippel, S., and F. E. L. Otto, 2014: Beyond climatological extremes - assessing how the odds of hydrometeorological extreme events in South-East Europe change in a warming climate. Climatic Change, 125, 381-398, doi:10.1007/s10584-014-1153-9.

Sonntag, D., 1990: Important new values of the physical constants of 1986, vapor pressure formulations based on the ITS-90, and psychrometer formulae. $Z$. Meteorol., 70, 340-344.

Willett, K. M., and S. Sherwood, 2012: Exceedance of heat index thresholds for 15 regions under a warming climate using the wet-bulb globe temperature. Int. J. Climatol., 32, 161-177, doi:10.1002/joc.2257. 


\title{
15. ASSESSING THE CONTRIBUTIONS OF LOCAL AND EAST PACIFIC WARMING TO THE 2015 DROUGHTS IN ETHIOPIA AND SOUTHERN AFRICA
}

\author{
Chris Funk, laura Harrison, Shraddhanand Shukla, Andrew Hoell, Diriba Korecha, \\ Tamuka Magadzire, Gregory Husak, and Gideon Galu
}

Anthropogenic warming contributed to the 2015 Ethiopian and southern African droughts by increasing EI Niño SSTs and local air temperatures, causing reduced rainfall and runoff, and contributing to severe food insecurity.

Introduction. In northern Ethiopia $\left(7^{\circ}-14^{\circ} \mathrm{N}, 36.5^{\circ}-\right.$ $40.5^{\circ} \mathrm{E}, \mathrm{NE}$ ) during June-September (JJAS) of 2015 and in southern Africa $\left(13.5^{\circ}-27^{\circ} \mathrm{S}, 26.5^{\circ}-36^{\circ} \mathrm{E}\right.$, SA) during December-February (DJF) of 2015/16, main growing seasons rains were extremely poor. In Ethiopia, Climate Hazards Group Infrared Precipitation with Stations (CHIRPS) (Funk et al. 2015c) and Centennial Trends (Funk et al. 2015b) data indicated one of the worst droughts in more than 50 years (FEWSNET 2015). More than ten million people currently require humanitarian relief (FEWSNET 2016a). SA rains were also extremely poor (FEWSNET 2016b); in Mozambique and Malawi, February maize prices were more than twice the five-year average, and in Zimbabwe the president has declared a national disaster in view of the El Niño-induced poor rains and the escalating food insecurity situation.

$\mathrm{NE}$ has been experiencing long-term rainfall declines (Funk et al. 2008; Funk et al. 2005; Jury and Funk 2013; Viste et al. 2012; Williams et al. 2012). The eastern Ethiopian highlands have exhibited recurrent soil moisture and runoff deficits since the 1990s (Funk et al. 2015c). NE rains in 2015 were the driest on record, but station data density prior to 1950 is very sparse for Ethiopia (Funk et al. 2015b). SA rainfall does not exhibit a decline, but the 2015-16 drought was severe. The impact of ENSO on Ethiopian rainfall is well documented (Fig. S15.1; Camberlin 1997; Degefu 1987; Diro et al. 2011; Gissila et al. 2004; Korecha

\footnotetext{
AFFILIATIONS: FUNK-U.S. Geological Survey and University of California Santa Barbara, Santa Barbara, California; HARRISON, Shukla, Korecha, Magadzire, Husak, and Galu-University of California Santa Barbara, Santa Barbara, California; HOELLNOAA/Earth System Research Laboratory Physical Sciences Division, Boulder, Colorado

DOI:I0.II75/BAMS-D-16-0167.I
}

A supplement to this article is available online ( 10.1175 /BAMS-D-16-0167.2) and Barnston 2007; Korecha and Sorteberg 2013; Segele and Lamb 2005): the warm phase of ENSO is associated with suppressed rains during the main wet season (JJAS) over north and central Ethiopia. There have also been numerous papers documenting a negative teleconnection between El Niño and SA rainfall (Supplemental Fig. S15.1; Hoell et al. 2015; Jury et al. 1994; Lindesay 1988; Misra 2003; Nicholson and Entekhabi 1986; Nicholson and Kim 1997; Reason et al. 2000; Rocha and Simmonds 1997).

Is Anthropogenic Climate Change Causing More Extreme El Niños? Our attribution approach is similar to our 2014 study (Funk et al. 2015a) examining boreal spring rainfall deficits in Kenya and southeastern Ethiopia. We first assess changes in Niño-3.4 SST extremes based on climate change simulations and then interpret these results using empirical relationships between Niño-3.4 SSTs and regional rainfall and air temperatures. Figures 15.1a,b examine JJAS and DJF Niño-3.4 SSTs (Huang et al. 2015) from observations (blue/red bars) and a multimodel climate change ensemble (red lines and blue shading; SST simulations from 19 model combinations and 34 simulations; 2006-15 simulation values were based on the RCP8.5 experiment; for details see https:// climexp.knmi.nl) based on simulations from 1861 through 2100. For each of the 34 simulations, for each year, the top six Niño-3.4 SST events from the surrounding 30 years typified El Niño. The heavy red lines depict the ensemble average of these values for each year. The thin red lines identify the $80 \%$ confidence interval associated with the ensemble spread. The climate change distribution agrees reasonably well with the observed increasing strength of moderate-strong Niño-3.4 events. The simulations predict increasingly extreme Niño-3.4 events, and 

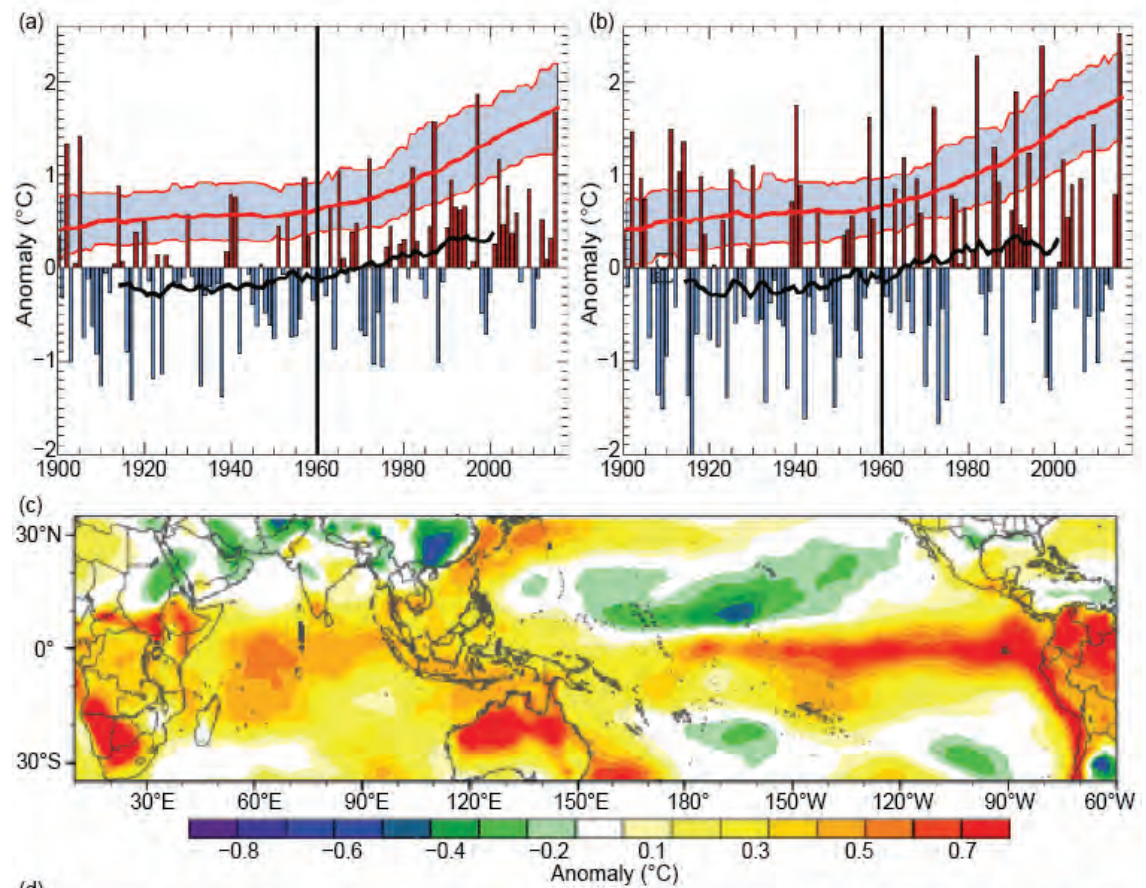

(d)
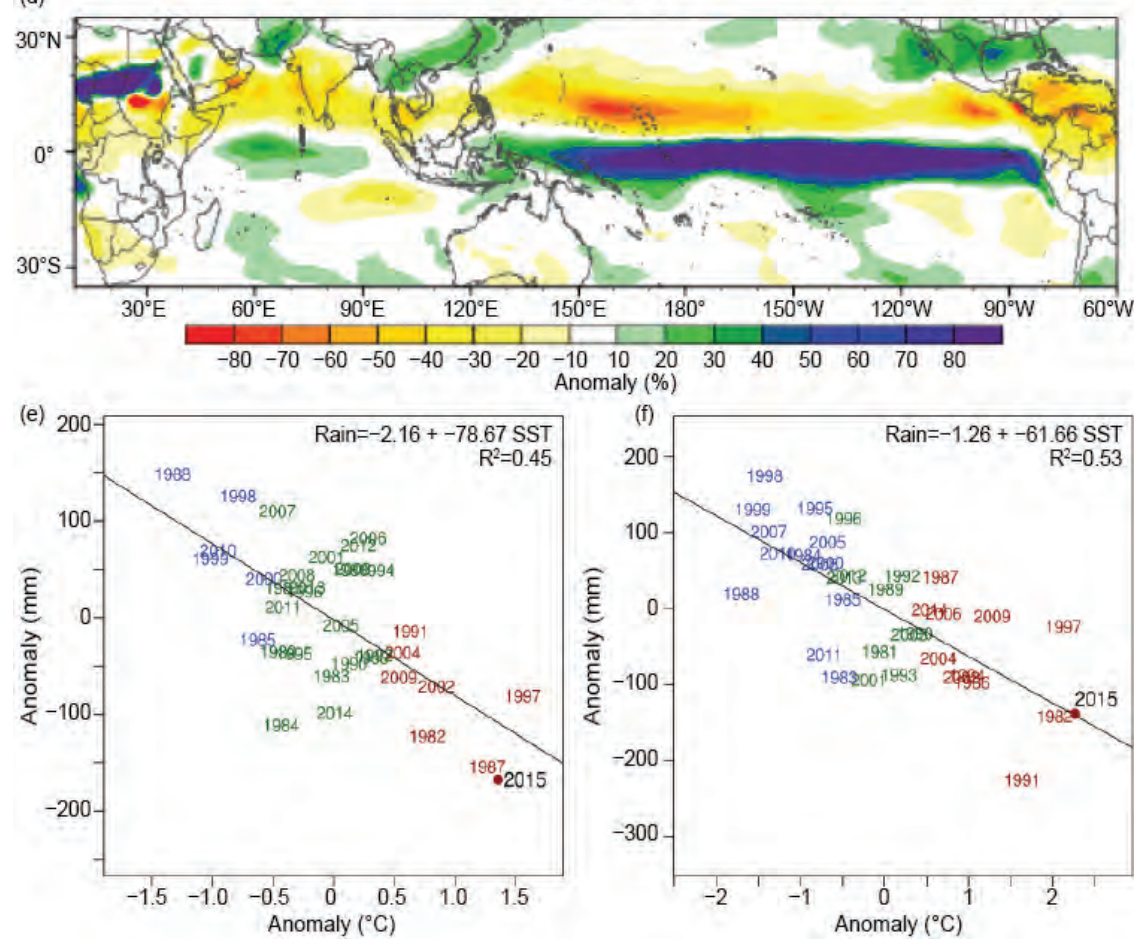

FIG. I5.I. (a),(b) Observed Niño-3.4 SST anomalies (bars) along with associated 30-yr means (thick black line). SST simulations are from 19 model combinations and 34 simulations; 2006-15 simulation values were based on the RCP8.5 experiment (for details see https://climexp.knmi.nl). Thick and thin red lines show running 30-yr climate change ensemble EI Niño SSTs (see www.esrl.noaa.gov/psd/repository/alias/facts). (c),(d) Changes in the DJF Geophysical Fluid Dynamics Laboratory Atmospheric Model version 3 nearsurface air temperatures and precipitation during 1980-20I5 EI Niño events versus 1920-79 EI Niño events. Results based on the 17-member ensemble mean. (e),(f) Scatterplots between Niño-3.4 SST and observed NE and SA rainfall anomalies. this is what we see in the SST observations (Supplemental Figs. S15.1a,b): increasingly intense El Niño events.

To estimate radiatively forced changes in ENSO maxima, we subtracted the average 1946-75 ensemble sea surface temperatures over the Niño3.4 region (temporal center point marked with the black vertical lines in Figs. 15.1a,b) from the 2000-29 Niño-3.4 values (the last point on the thick red line). For DJF and JJAS, this gives us an estimated change of $+1.2^{\circ} \mathrm{C}$. Using the $80 \%$ confidence intervals for 2015-16 and repeating this calculation lets us establish a range of values $\Delta \mathrm{T}_{\mathrm{DJF}}=+1.2^{\circ}$ $\pm 0.5^{\circ} \mathrm{C}$ and $\Delta \mathrm{T}_{\mathrm{JJAS}}=+1.1^{\circ} \pm$ $0.5^{\circ} \mathrm{C}$.

We next examine three atmospheric GCM simulation ensembles, drawn from the Earth Systems Research Laboratory Facility for Climate Assessments (FACTS; see www .esrl.noaa.gov/psd/repository /alias/facts). Using FACTS, we examined differences between 1980-2015 and 1920-79 moderate-to-strong El Niños, using atmospheric General Circulation Model (AGCM) simulations. Figures 15.1c,d show results for a single model for DJF. Supplemental Fig. S15.2 shows similar results for all three models for both seasons. Over the tropical $\mathrm{Pa}-$ cific and Indian Oceans (Fig. 15.1c), recent El Niños have been associated with much warmer conditions $\left(>+0.8^{\circ} \mathrm{C}\right)$, consistent with Figs. 15.1a,b, but have also been potentially influenced by natural decadal variability (Wittenberg 2009). Accompanying the warming is a very large $(70 \%+)$ 
(a)

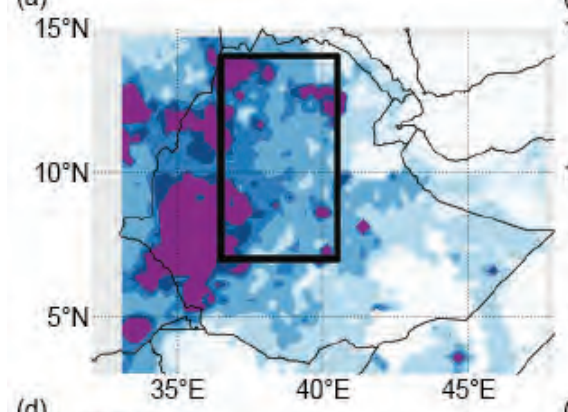

(d)

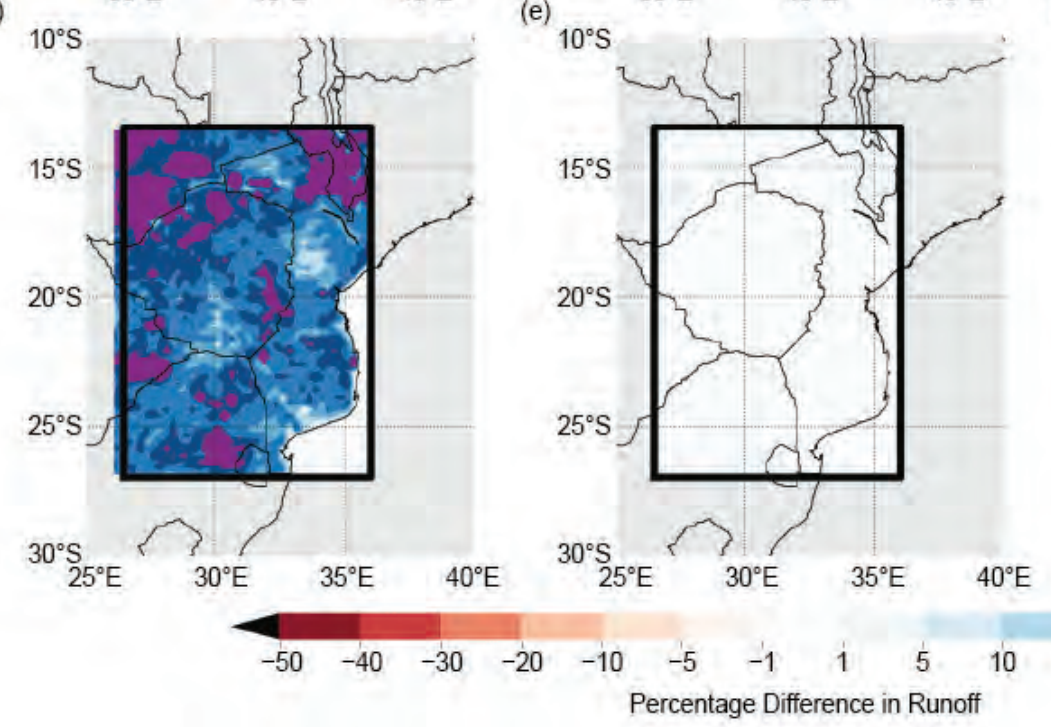

(b)

$15^{\circ} \mathrm{N}$

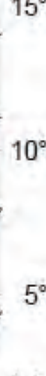

$5^{\circ} \mathrm{N}$

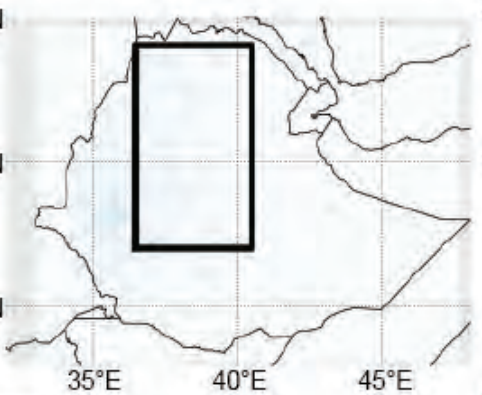

$10^{\circ} \mathrm{S}$

(f)

(c)

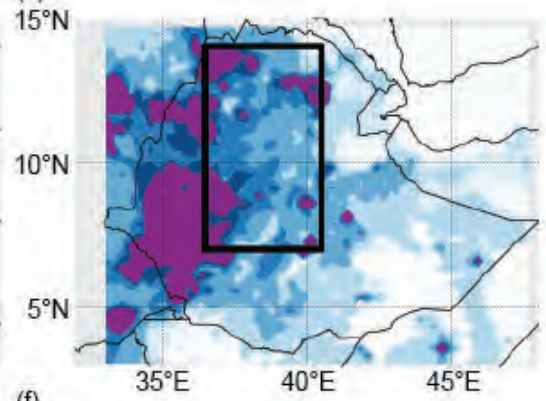

(f) $10^{\circ} \mathrm{S}$

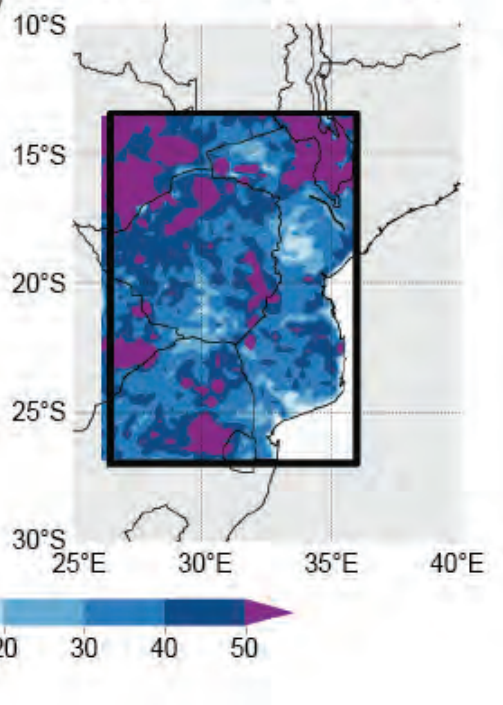

Fig. 15.2. Hydrologic sensitivity experiment results for runoff. (a),(d) The influence of anthropogenic rainfall reductions. (b),(e) The influence of local air temperature increases. (c),(f) Combines the effects of low rainfall and warm air temperatures. (a)-(c) NE experiments. (d)-(f) SA experiments. Each panel shows the change in runoff, in comparison with observed conditions, when rainfall and air temperatures are increased and/or cooled.

increase in eastern Pacific rainfall (Fig. 15.1d), one measure of the strength of ENSO (Chiodi and Harrison 2010; Chiodi and Harrison 2015; Curtis and Adler 2000). The magnitude of El Niño precipitation increases over the eastern Pacific would strongly influence El Niño's atmospheric forcing strength, and we find a precipitation decline (Fig. 15.1d) over southern Africa that is broadly consistent with our empirical analysis. Results from two other models and JJAS are similar (Supplemental Fig. S15.2).

Estimating Rainfall and Air Temperature Changes due to El Niño. Figures 15.1e,f show regressions between NE/SA rainfall and Niño-3.4 SSTs. Our study regions were chosen based on historical teleconnections (Supplemental Figs. S15.1e,f) and the pattern of the 2015-16 deficits. In Ethiopia and southern Africa, Niño-3.4 SSTs explained $45 \%$ and $53 \%$ of the $1981-82$ to $2015-16$ rainfall variance, respectively. While rainfall performance varied substantially during strong El Niños (the 1997-98 response was relatively modest in both regions), the observations suggest that a $1^{\circ} \mathrm{C}$ increase in El Niño-3.4 SSTs produces a $79 \mathrm{~mm}$ and $62 \mathrm{~mm}$ decrease in NE and SA rainfall, respectively. These regressions slopes suggest that without anthropogenic Niño-3.4 warming, NE and SA rainfall would have been approximately $16 \%$ and $24 \%$ greater, respectively.

ENSO teleconnections and warming trends were used to estimate anthropogenic air temperature changes of $+0.9^{\circ} \mathrm{C}$ (Supplemental Material). Using the lower bounds of Niño-3.4 SST change $\left(\mathrm{T}_{\mathrm{JJAS}}=0.6^{\circ} \mathrm{C}\right.$, $\mathrm{T}_{\mathrm{DJF}}=0.7^{\circ} \mathrm{C}$ ) gives estimates of a $9 \%$ and $14 \%$ rainfall change and a $0.8^{\circ} \mathrm{C}$ and $0.7^{\circ} \mathrm{C} \mathrm{JJAS/DJF}$ air temperature change in $\mathrm{NE}$ and $\mathrm{SA}$, respectively.

Contrapositive Hydrologic Experiment. We performed four hydrologic experiments using the variable infiltration capacity (VIC) model. In these experiments, we drove the VIC model with (i) 
observed weather forcings, (ii) weather forcing in which we increased NE/SA precipitation by $16 \%$ and $24 \%$, (iii) weather forcings with air temperatures cooled by $+0.9^{\circ} \mathrm{C} /+0.9^{\circ} \mathrm{C} \mathrm{NE} / \mathrm{SA}$, and (iv) weather forcings with both (i) and (ii) changes. Figure 15.2 shows results for experiments (ii)-(iv), expressed as anomalies from (i). Our contrapositive NE runoff changes, in our region of interest, for (ii)-(iv) were: $+35 \%,+1 \%,+37 \%$; for SA (ii)-(iv) changes were: $+48 \%$, $+1 \%,+49 \%$. Clearly, anthropogenic disruptions in precipitation, associated with the large increases in ENSO SST (Figs. 15.1a,b), provided the dominant contribution. As was the case for 2014 (Funk et al. 2015a), we find that a $\sim 1^{\circ} \mathrm{C}$ warming over the tropical Pacific can have a much greater impact than a $\sim 1^{\circ} \mathrm{C}$ warming in local air temperatures.

Conclusions. Anthropogenic warming contributed substantially to the very warm 2015/16 El Niño SSTs, and this anthropogenic contribution likely reduced NE and SA rainfall by approximately $16 \%$ and $24 \%$. The associated simulated runoff reductions were much larger, $35 \%$ and $48 \%$, respectively. $\mathrm{A} \sim 1^{\circ} \mathrm{C}$ warming over the tropical Pacific appears associated with a large $(>70 \%)$ increase in El Niño diabatic forcing (Fig. 15.1f), and modest ( 20\%) precipitation reductions over NE/SA. These "modest" rainfall reductions, acting to accentuate natural El Niño impacts, have contributed to substantial food crises.

Recent El Niños appear to be more intense (Supplemental Fig. S15.2). During El Niños, warmer IndoPacific SSTs, and associated rainfall changes, may be more influential than the direct impacts of local increases in air temperatures. The contrast between Figs. 15.2a,b and 15.2d,e tell us that, based on these hydrologic simulations, nonlocal warming in the tropical Pacific had a much stronger drought impact than did relatively small local air temperature impacts. We feel this result is quite important, possibly indicating that a major mode of "climate change" may be associated with more extreme tropical SST and SST gradients. "Global warming" expressed as local increases in air temperatures may have less dramatic impacts. Assessments (Brown et al. 2015) of local temperature impacts on crop yields suggest relatively small yield reductions per degree of warming ( $2 \%$ per ${ }^{\circ} \mathrm{C}$ ). A degree of warming in Niño-3.4 SSTs, concomitant with a warm ENSO event, can have larger impacts due to teleconnected precipitation declines.

Because runoff forms a relatively small fraction of the hydrologic balance, the influence of rainfall deficits can be amplified, potentially leading to severe hydropower shortages (Davison 2015; Onishi 2016) and even severe drinking water deficits (Gauette 2016). These crises are just one aspect of the widespread food insecurity related to the extreme 2015/16 El Niño (Fig. 15.1), which is thought to have contributed to the severe food insecurity of 60 million people "primarily in the most vulnerable regions of southern Africa, East Africa, Central America, and the Pacific Islands" (OCHA 2016). If La Niña conditions follow, extreme warming in the western Pacific may lead to dry conditions over equatorial East Africa (Funk et al. 2015a; Funk et al. 2014; Shukla et al. 2014), exacerbating food insecurity conditions.

ACKNOWLEDGEMENTS. This research was supported by the US Geological Survey's Land Change Science program, the USAID Famine Early Warning Systems Network, and NASA SERVIR grant NNX16AM02G. Production of the rainfall data were supported by the USGS Earth Resources Observations and Science Center (http://earlywarning.usgs.gov /fews/datadownloads/Global/CHIRPS2.0). We would like to thank the Royal Netherlands Meteorological Institute for providing the CMIP5 simulations (https://climexp.knmi.nl) and the Earth System Research Laboratory Physical Sciences Division www.esrl.noaa.gov/) for providing the observed temperature and simulated precipitation fields.

\section{REFERENCES}

Brown, M., and Coauthors, 2015: Climate Change, Global Food Security, and the U.S. Food System. U.S. Department of Agriculture/U.S. Global Change Research Program, 146 pp., doi:10.7930/J0862DC7.

Camberlin, P., 1997: Rainfall anomalies in the source region of the Nile and their connection with the Indian summer monsoon. J. Climate, 10, 1380-1392.

Chiodi, A. M., and D. E. Harrison, 2010: Characterizing warm-ENSO variability in the equatorial $\mathrm{Pa}$ cific: An OLR perspective. J. Climate, 23, 2428-2439, doi:10.1175/2009JCLI3030.1.

—, and —-, 2015: Global seasonal precipitation anomalies robustly associated with El Niño and La Niña events-An OLR perspective. J. Climate, 28, 6133-6159, doi:10.1175/JCLI-D-14-00387.1.

Curtis, S., and R. Adler, 2000: ENSO indices based on patterns of satellite-derived precipitation. J. Climate, 13, 2786-2793. 
Davison, W., 2015: Ethiopia sees nationwide power cuts while drought dries dams. Bloomberg News [online], 1 December 2015. [Available online at www.bloomberg.com/news/articles/2015-12-01/ethiopia-sees -nationwide-power-cuts-while-drought-dries -dams.]

Degefu, W., 1987: Some aspects of meteorological drought in Ethiopia. Drought and Hunger in Africa: Denying Famine a Future, M. H. Glanz, Ed., Cambridge University Press, 23-36.

Diro, G., D. I. F. Grimes, and E. Black, 2011: Teleconnections between Ethiopian summer rainfall and sea surface temperature: Part II. Seasonal forecasting. Climate Dyn., 37, 121-131, doi:10.1007/s00382 -010-0896-x.

FEWS NET, 2015: Illustrating the extent and severity of the 2015 drought, 7 pp.

—, 2016a: Food Security Outlook, Ethiopia: Largescale food security emergency projected for 2016, 19 pp.

— , 2016b: Southern Africa Special Report: Illustrating the extent and severity of the 2015-2016 drought, $8 \mathrm{pp}$.

Funk, C., and Coauthors, 2005: Recent drought tendencies in Ethiopia and equatorial-subtropical eastern Africa. Vulnerability to Food Insecurity: Factor Identification and Characterization Rep. 01/2005, 12 pp. [Available online at http://pdf.usaid.gov/pdf _docs/PNADH997.pdf.]

— M. M. Dettinger, J. C. Michaelsen, J. P. Verdin, M. E. Brown, M. Barlow, and A. Hoell, 2008: Warming of the Indian Ocean threatens eastern and southern African food security but could be mitigated by agricultural development. Proc. Natl. Acad. Sci. USA, 105, 11081-11086, doi:10.1073/pnas.0708196105.

—, A. Hoell, S. Shukla, I. Bladé, B. Liebmann, J. B. Roberts, and G. Husak, 2014: Predicting East African spring droughts using Pacific and Indian Ocean sea surface temperature indices. Hydrol. Earth Syst. Sci., 18, 4965-4978, doi:10.5194/hess-18-4965-2014.

_-, S. Shukla, A. Hoell, and B. Livneh, 2015a: Assessing the contributions of East African and west Pacific warming to the 2014 boreal spring East African drought [in "Explaining Extreme Events of 2014 from a Climate Perspective"]. Bull. Amer. Meteor. Soc., 96 (12), S77-S81.

— , S. E. Nicholson, M. Landsfeld, D. Klotter, P. Peterson, and L. Harrison, 2015b: The Centennial Trends Greater Horn of Africa precipitation dataset. Sci. Data, 2, 150050, doi:10.1038/sdata.2015.50.
— , and Coauthors, 2015c: The climate hazards infrared precipitation with stations-A new environmental record for monitoring extremes. Sci. Data, 2, 150066, doi:10.1038/sdata.2015.66.

Gauette, N., 2016: U.S. dispatches emergency aid for Ethiopian drought. CNN Politics, CNN [online], 3 March 2016. [Available online at www.cnn .com/2016/03/03/politics/ethiopia-us-disaster -assistance-drought/index.html.]

Gissila, T., E. Black, D. Grimes, and J. Slingo, 2004: Seasonal forecasting of the Ethiopian summer rains. Int. J. Climatol., 24, 1345-1358, doi:10.1002/joc.1078. Hoell, A., C. Funk, T. Magadzire, J. Zinke, and G. Husak, 2015: El Niño-Southern Oscillation diversity and southern Africa teleconnections during austral summer. Climate Dyn., 45, 1583-1599, doi:10.1007 /s00382-014-2414-z.

Huang, B., and Coauthors, 2015:Extended reconstructed sea surface temperature version 4 (ERSST. v4). Part I: Upgrades and intercomparisons. J. Climate, 28, 911-930, doi:10.1175/JCLI-D-14-00006.1.

Jury, M. R., and C. Funk, 2013: Climatic trends over Ethiopia: Regional signals and drivers. Int. J. Climatol., 33, 1924-1935, doi:10.1002/joc.3560.

— C. Mc Queen, and K. Levey, 1994: SOI and QBO signals in the African region. Theor. Appl. Climatol., 50, 103-115.

Korecha, D., and A. G. Barnston, 2007: predictability of June-September rainfall in Ethiopia. Mon. Wea. Rev., 135, 628-650, doi:10.1175/MWR3304.1.

— , and A. Sorteberg, 2013: Validation of operational seasonal rainfall forecast in Ethiopia. Water Resour. Res., 49, 7681-7697, doi:10.1002/2013WR013760.

Lindesay, J., 1988: South African rainfall, the Southern Oscillation and a Southern Hemisphere semiannual cycle. Int. J. Climatol., 8, 17-30, doi:10.1002 /joc.3370080103.

Misra, V., 2003: The influence of Pacific SST variability on the precipitation over Southern Africa. J. Climate, 16, 2408-2418, doi:10.1175/2785.1.

Nicholson, S. E., and M. D. Entekhabi, 1986: The quasiperiodic behavior of rainfall variability in Africa and its relationship to the Southern Oscillation. Arch. Meteor. Geophys. Bioclimatol., Ser. A, 34, 311-348.

—, and J. Kim, 1997: The relationship of the El Nino-Southern oscillation to African rainfall. Int. J. Climatol., 17, 117-135. 
OCHA, 2016: El Nino: Overview of impact, projected humanitarian needs and response. U.N. Office for the Coordination of Humanitarian Affairs, 20 pp. [Available online at https://docs.unocha .org/sites/dms/Documents/OCHA_ElNino _Overview_13Apr2016.pdf.]

Onishi, N., 2016: Climate change hits hard in Zambia, an African success story. New York Times [online], 12 April 2016. [Available online at www.nytimes .com/2016/04/13/world/africa/zambia-drought -climate-change-economy.html?_r=0.]

Reason, C., R. Allan, J. Lindesay, and T. Ansell, 2000: ENSO and climatic signals across the Indian Ocean basin in the global context: Part I, Interannual composite patterns. Int. J. Climatol., 20, 1285-1327.

Rocha, A., and I. Simmonds, 1997: Interannual variability of south-eastern African summer rainfall. Part I: Relationships with air-sea interaction processes. Int. J. Climatol., 17, 235-265.

Segele, Z. T., and P. J. Lamb, 2005: Characterization and variability of Kiremt rainy season over Ethiopia. Meteor. Atmos. Phys., 89, 153-180, doi:10.1007 /s00703-005-0127-x.

Shukla, S., C. Funk, and A. Hoell, 2014: Using constructed analogs to improve the skill of MarchApril-May precipitation forecasts in equatorial East Africa. Environ. Res. Lett., 9, 094009, doi:10.1088/1748-9326/9/9/094009.

Viste, E., D. Korecha, and A. Sorteberg, 2012: Recent drought and precipitation tendencies in Ethiopia. Theor. Appl. Climatol., 112, 535-551, doi:10.1007 /s00704-012-0746-3.

Williams, A. P., and Coauthors, 2012: Recent summer precipitation trends in the Greater Horn of Africa and the emerging role of Indian Ocean sea surface temperature. Climate Dyn., 39, 2307-2328, doi:10.1007/s00382-011-1222-y.

Wittenberg, A. T., 2009: Are historical records sufficient to constrain ENSO simulations? Geophys. Res. Lett., 36, L12702, doi:10.1029/2009GL038710. 


\title{
16. THE DEADLY COMBINATION OF HEAT AND HUMIDITY IN INDIA AND PAKISTAN IN SUMMER 2015
}

\author{
Michael Wehner, Dáithí Stone, Hari Krishnan, Krishna AchutaRao, and Federico Castillo
}

We find that the deadly heat waves in India and Pakistan in 2015 were exacerbated by anthropogenic climate change. Although the impacts of both events were severe, the events themselves were not connected to each other.

Observations and Impacts. Andhra Pradesh, Telangana, and other southeastern Indian states suffered a deadly heat wave in late May and early June of 2015. Daily high temperatures exceeded $45^{\circ} \mathrm{C}$ in many places throughout India for several days in a row. In late June and early July, just a few weeks later, Pakistan also suffered from a deadly heat wave with similar daily high temperatures. Although the Pakistani heat wave occurred very soon after the Indian heat wave, they were distinct meteorological events. Ratnam et al. (2016) classify heat waves over India into two types, those that occur over north-central India and those that occur over coastal eastern India. The study finds that the former tend to be associated with anomalous blocking over the North Atlantic Ocean. Heat waves over coastal eastern India were found to be associated with westerly anomalies over the Indian landmass, thereby reducing the land-sea breeze along the coastal regions. Hence the Loo, a strong afternoon overland wind, brought hot and dry conditions to India (Fig. 16.1a). By late June, the Indian monsoon was well developed, curtailing these winds and terminating the heat wave (see www .tropmet.res.in/ lip/Publication/Scientific-Reports /RR-185.pdf). In Pakistan by this time, winds were onshore (Fig. 16.1b), and the unusually hot conditions were also unusually humid. The high numbers of deaths in both events are attributed not only to the weather conditions but also to institutional failures. Hospitals were overwhelmed with patients suffering from heat-related symptoms and at some point had to turn away patients (Salim et al. 2015). It is difficult to be precise about the ultimate number of fatalities

AFFILIATIONS: WeHNER, STONE, AND KRISHNAN-Lawrence Berkeley National Laboratory, Berkeley, California; ACHUTARAOIndian Institute of Technology Delhi, Hauz Khas, New Delhi, India; CASTILLO-University of California at Berkeley, Berkeley, California DOI:I0.II75/BAMS-D-16-0145.I

A supplement to this article is available online $(10.1175$ /BAMS-D-16-0145.2) associated with these heat waves, but upwards of 2500 excess deaths are estimated to have occurred in the Indian heat wave (Ratnam et al. 2016) and at least 700 alone in the Pakistani megacity of Karachi (Masood et al. 2015) with many more throughout the country.

To further characterize these heat waves, we have analyzed 1973-2015 subdaily (hourly and 3-hourly) temperature and heat index (Steadman 1979a,b) calculated from the HadISD v1.0.4.2015p quality controlled weather station dataset (Dunn et al. 2012). Heat index, one of several methods to measure the combined effect of temperature and humidity on human health, is a bicubic function of both variables intended to fit a model of a fully clothed adult (see Supplemental Material for its definition). Figures $16.1 \mathrm{c}, \mathrm{d}$ show the daily maximum instantaneous heat index (thick red lines) and the temperature (thick black lines) associated with it during the heat waves in Hyderabad (in the Indian state of Telangana, WMO station number 431280) and Karachi (the largest city in Pakistan, WMO station number 417800). The pentadal averages of these daily maxima are shown with thin lines. Climatological averages over 1974-2014 are shown with horizontal dotted lines for May in Hyderabad and June in Karachi to show the events' relative severity. In Hyderabad, the daily maximum heat index was about $2^{\circ}-4^{\circ} \mathrm{C}$ higher than temperature during the heat wave. In Karachi, this difference was about $7^{\circ}-12^{\circ} \mathrm{C}$, reflecting a much higher relative humidity. The first column of Table 16.1 shows representative values of temperature and heat index during the most severe periods of the 2015 heat waves drawn from Figs. 16.1c,d.

Figures $16.2 \mathrm{a}, \mathrm{b}$ are scatterplots of relative humidity against temperature at the time of the daily maximum heat index value over the observational record of 1973-2015. Colored dots show the official U.S. NOAA advisory heat index levels of caution, extreme caution, danger, and extreme danger. In such hot climates, the 1974-2014 average daily maxi- 
(a)

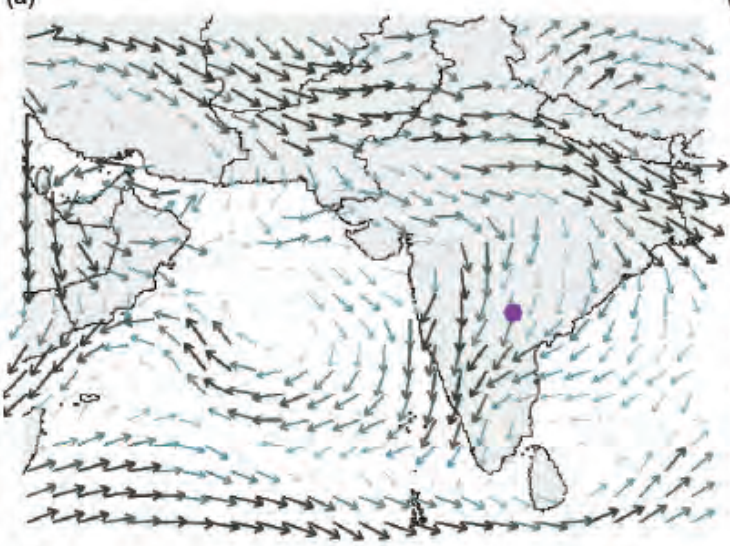

(c)

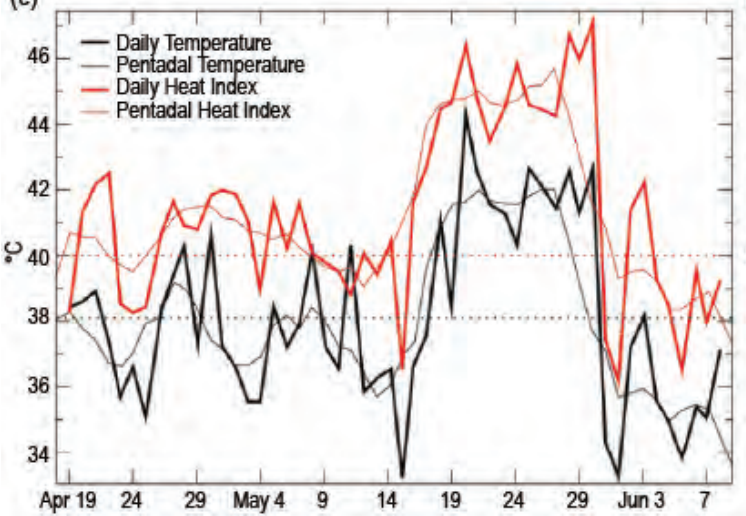

(b)

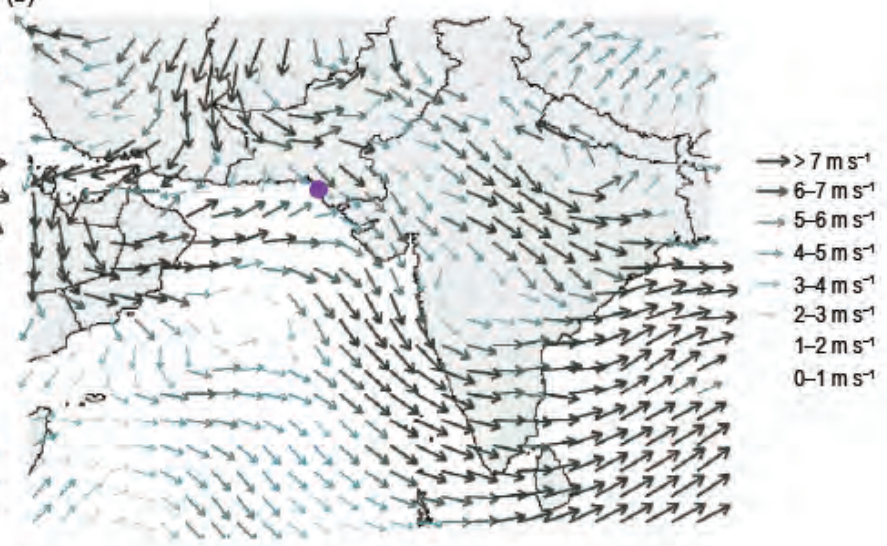

(d)

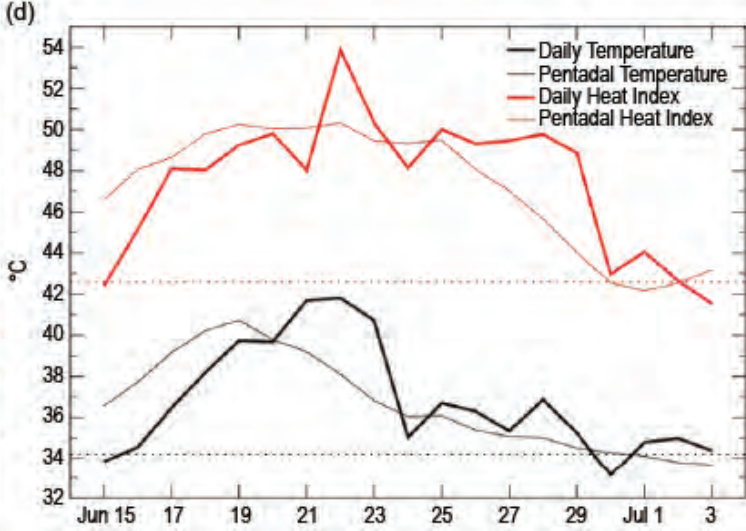

FIG.I6.I. (a),(b) Afternoon $700 \mathrm{hPa}$ wind vectors and speed from the ERA-Interim reanalysis on (a) 29 May 2015 (Indian heat wave) and (b) same on 30 Jun 2015 (Pakistani heat wave). The purple dots indicate the location of the weather stations used in this study. (c),(d) Daily maximum heat index values and associated temperatures during (c) the Indian heat wave and (d) same for the Pakistani heat wave. Dotted horizontal lines are I974-20 I4 climatological averages for the month of the occurrence of the peak in the heat waves.

mum heat index (indicated by the large black dot) is well within the advisory levels revealing that these U.S.-based statements were not developed for these regions. More widely applicable measures of the threat of severe heat wave to human health are not available (Wehner et al. 2016). Rare and dangerous events are along the upper-right edge of this two-dimensional distribution, which are not necessarily the highest temperatures. The 2015 heat waves are represented by asterisks. These figures reveal stark differences in both the heat waves and climatologies of the two cities. In Hyderabad, the 2015 heat wave was among the highest temperatures ever experienced but relative humidity was low, around 20\%. In Karachi, the 2015 heat wave was hot but not near record levels. However, because relative humidity was high (35\%-70\%), the daily maximum heat indices were among the highest ever experienced. These combinations of temperature and relative humidity were rare events as is evident by the proximity of the asterisks to the edge of the distribution in Fig. 16.2b.
Analysis of possible human influence. The annual maxima of the pentadal average of the daily maximum heat indices and associated temperatures exhibit increasing trends for both stations (thin red lines in Supplemental Figs. S16.1a,b). To account for this, we use a nonstationary peaks over threshold extreme value methodology (Coles 2001) to fit a generalized Pareto distribution in order to estimate timedependent return periods for high daily and pentadal values. To incorporate the effect of anthropogenic climate change, we used a time varying estimate of $\mathrm{CO}_{2}$ (see www.esrl.noaa.gov/gmd/ccgg/trends/) as the covariate in the Pareto distribution using a 95th percentile threshold and a 3 -week declustering. Using the event magnitudes in the first column of Table 16.1, we find a strong time dependence of the temperature and heat index return periods (Supplemental Figs. S16.1c,d) for the pentadal values. Very little time dependence in the return periods for the daily values for the Karachi station over the duration of the observational record is found, consistent with the 
Table 16.I. Estimates of observed daily maximum heat index and temperature $\left({ }^{\circ} \mathrm{C}\right)$, its return period (years), the corresponding quantile bias corrected return value in simulations of the actual world, and similar simulated quantities of a counterfactual world, human-induced risk ratio and return value changes. Bias corrections of the simulated actual distributions are made at the quantile corresponding to the observed return period. The magnitudes of the quantile bias corrections are the differences between values in the column labeled "Simulated Actual RV" and "Observed Value."

\begin{tabular}{|c|c|c|c|c|c|c|c|c|}
\hline & & $\begin{array}{l}\text { Observed } \\
\text { Value } \\
\left({ }^{\circ} \mathrm{C}\right)\end{array}$ & $\begin{array}{c}\text { Observed } \\
\text { RP } \\
\text { (years) }\end{array}$ & $\begin{array}{c}\text { Simulated } \\
\text { Actual } \\
\operatorname{RV}\left({ }^{\circ} \mathrm{C}\right)\end{array}$ & $\begin{array}{l}\text { Simulated } \\
\text { Counter- } \\
\text { factual } \\
\text { RP(years) }\end{array}$ & $\begin{array}{l}\text { Simulated } \\
\text { Counter- } \\
\text { factual } \\
\operatorname{RV}\left({ }^{\circ} \mathrm{C}\right)\end{array}$ & $\begin{array}{l}\text { Simulated } \\
\text { Risk Ratio }\end{array}$ & $\begin{array}{c}\text { Simulated } \\
\quad \Delta \mathbf{R V}\end{array}$ \\
\hline \multicolumn{9}{|c|}{ Heat Index } \\
\hline Hyderabad & daily & 46.9 & 1.9 & 42.5 & 23.6 & 40.7 & 12.1 & 1.7 \\
\hline Hyderabad & pentad & 45.7 & 2.8 & 42.0 & 92.3 & 40.3 & 32.8 & 1.7 \\
\hline Karachi & daily & 53.5 & 4.0 & 49.3 & 31.1 & 46.9 & 7.7 & 2.4 \\
\hline Karachi & pentad & 50.4 & 43.9 & 49.1 & $>>1000$ & 46.6 & $>1000$ & 2.5 \\
\hline \multicolumn{9}{|c|}{ Temperature } \\
\hline Hyderabad & daily & 44.0 & 2.7 & 43.4 & 9.6 & 42.5 & 3.6 & 1.0 \\
\hline Hyderabad & pentad & 41.8 & 1.8 & 41.7 & 3.3 & 40.8 & 1.9 & 0.9 \\
\hline Karachi & daily & 41.9 & 2.1 & 43.0 & 2.7 & 42.5 & 1.3 & 0.5 \\
\hline Karachi & pentad & 40.7 & 5.9 & 42.8 & 9.4 & 42.3 & 1.6 & 0.5 \\
\hline
\end{tabular}

absence of a significant trend in the extrema of daily maxima for that station (thick lines in Supplemental Fig. S16.2b). Return periods of high temperature and head index in Hyderabad exhibit strong time dependence for both the daily and pentadal values, also consistent with relative magnitude of the trends and variations of Supplemental Fig. S16.1a. The 2015 values of return periods corresponding to estimated event magnitudes are shown in the second numeric column of Table 16.1. Because the $\mathrm{CO}_{2}$ covariate is clearly dependent on human activities, there is a statistically significant relationship between human influence and the heat index. However, because the statistical model does not consider that unforced natural variations may be coincidental with increases in atmospheric $\mathrm{CO}_{2}$, this statistical significance does not necessarily mean that an anthropogenic response has been detected by this analysis alone.

To more rigorously estimate a possible human influence, we utilize simulations drawn from the C20C+ Detection and Attribution Subproject (Folland et al. 2014). Temperature and relative humidity were extracted from the grid points nearest to the Hyderabad and Karachi airport weather stations from two 98-member ensemble simulations of the Community Atmospheric Model (CAM5.1) at a resolution of approximately $100 \mathrm{~km}$ (Risser et al. 2016, unpublished manuscript, available online at https:// arxiv.org/abs/1606.08908). Simulations from 1996-
2015 driven by observed sea surface temperatures and sea ice distributions represent the "world that was," referred to here as "actual." A counterfactual "world that might have been" set of simulations represents the climate system had humans not altered the composition of the atmosphere (Folland et al. 2014). In this case, an estimate of the human-induced changes to the sea surface temperature and sea ice distribution obtained from the CMIP5 models is removed from the lower boundary conditions and atmospheric trace gas and aerosol concentrations set to preindustrial values (Stone 2013). Comparison of model grid points to individual weather stations is performed with caution. Hyderabad Airport is located in the countryside well outside of the metropolitan area, and thus should be representative of temperature variations occurring on spatial scales resolved by the climate model. Karachi Airport is, however, located within the metropolitan area, and Karachi itself is a coastal city, so the climate model may not be properly resolving urban and coastal microclimate phenomena that are influencing weather at the airport. However, the pair of ensemble simulations use the same changes in land use and cover, so differences are predominantly a result of changes in atmospheric composition and ocean state rather than in the urban heat island. The model was determined to be fit for purpose by the tests outlined in Angélil et al. (2016a). Angélil et al. 2016b conclude that CAM5.1's estimates of the 
(a)

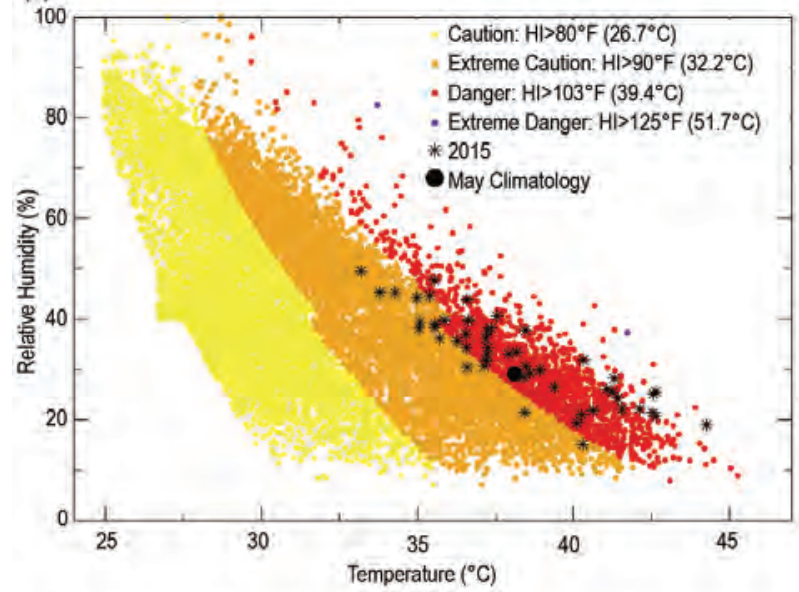

(c)

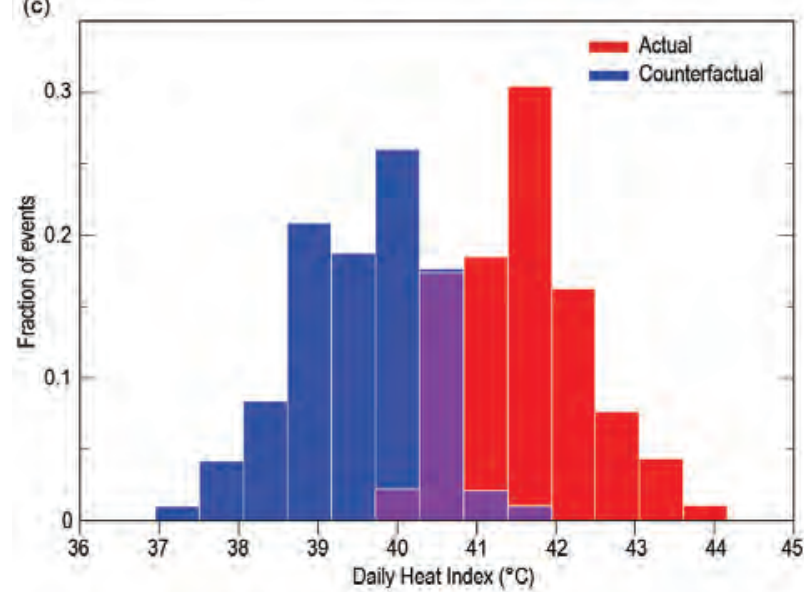

(b)

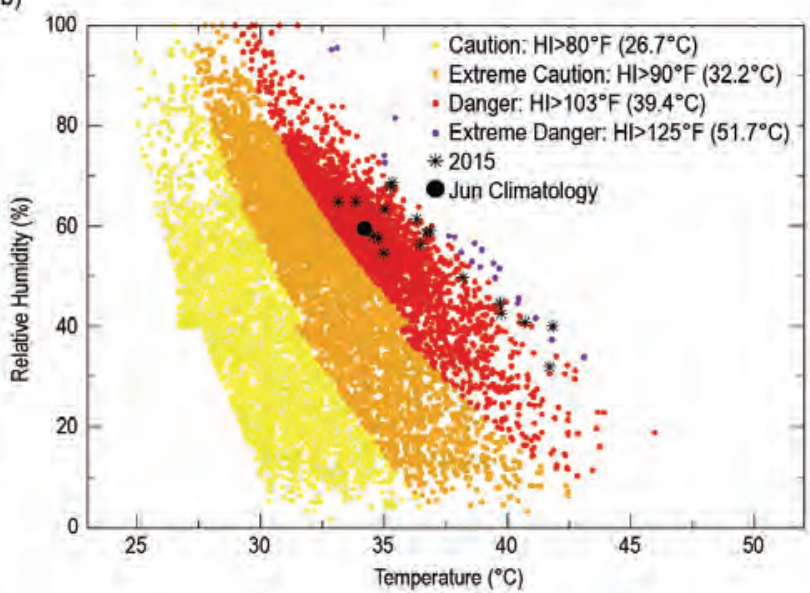

(d)

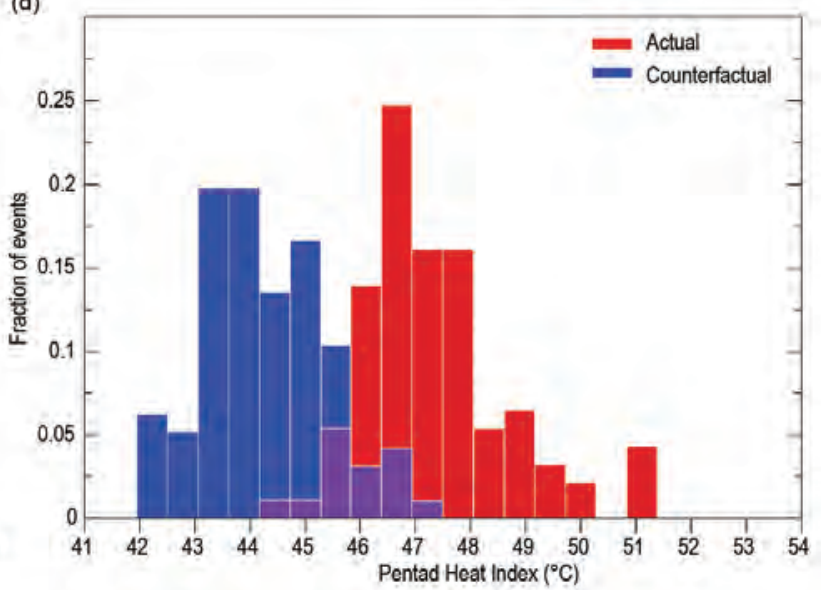

FIG. 16.2. (a),(b) Scatterplots of observed temperature and relative humidity from 1973-2015 at the time of the daily maximum heat index at (a) Hyderabad, India, and (b) Karachi, Pakistan. The 2015 heat wave days are shown by the asterisks. Other observations are colored according to NOAA heat index advisory levels. The large black dots are the May/Jun climatological averages. (c),(d) Histograms of uncorrected maximum pentadal average of daily maximum heat index for the counterfactual (blue) and actual (red) simulations, (c) May 20I5, Hyderabad and (d) Jun 20I5, Karachi.

1-in-1-year and 1-in-10-year anomalous thresholds for hot days over India/Pakistan are all consistent with estimates from current reanalysis products. Figures $16.2 \mathrm{c}$,d show histograms approximating the simulations' distribution of the pentadal average of the daily maximum heat index for the counterfactual world (blue) and actual world (red) during the month of the two heat waves' peak intensity and reveal a pronounced shift toward higher values caused by the changes in forcing due to anthropogenic activities. Corresponding histograms for the daily maximum heat index and for both measures of extreme temperature are shown in Supplemental Fig. S16.2. For both locations, the models' response in extreme temperature is less than in heat index but the profound difference in the daily and pentadal Karachi observational extremes revealed by changes in return period (Supplemental Figs. S16.1c,d) are not readily apparent in the simulations.

Utilizing the quantile bias correction method of Jeon et al. (2015), we estimate the changes in return period for corrected daily and pentadal values of peak temperature and heat index for both heat waves. This is used to define the "risk ratio," the ratio of the probabilities of reaching the corrected model estimates of the observed event in the factual and counterfactual simulations or, more simply, the inverse of the ratio of the corresponding return periods. Shown in Table 16.1, we find a substantial human increase in the risk ratio of heat index for both the Indian and Pakistani heat waves. The heat index risk ratio is substantially larger for pentadal values than it is for daily values. This is particularly relevant to assessing human-induced changes in the heat wave-related risk 
to human health and mortality, as is it is the longterm exposure to high heat that is most dangerous. Changes in simulated return values corresponding to the estimated observed return time are also shown in the last column of Table 16.1, revealing large humaninduced changes in the magnitude of heat waves of a fixed rarity for both cities.

We note that the climate model simulation (not shown) does not exhibit as large a trend in the estimated return periods of temperature and heat index as some of the HadISD observational products. However, the sampling uncertainty of the observations, represented by the error bars in Supplemental Figs. S16.1c,d, is large and the model is not necessarily inconsistent with the observations in this regard. Sampling uncertainty is much lower in the model because of the size of the ensemble dampens the inherent natural variability. In the simulations, the human signal is larger for the heat index than for temperature over both the daily and pentadal extremal measures at both locations (Table 16.1). We also find that for heat index, the human influence is greater on the pentadal scales than on the daily scales but that it is about the same for temperature at both locations. The time dependence of the Karachi observations could also be described this way, although there is essentially no trend in the daily extrema (Supplemental Figs. S16.1b,d). The time dependence of the Hyderabad observations is also similar except for the large change in the daily temperature (Supplemental Figs. S16.1a,c).

Jeon et al. (2015) demonstrated that risk ratio estimates for heat waves could be relatively insensitive to uncertainty in observed event magnitude. Hence, the principal uncertainties in the estimates of risk ratio and return value changes for heat wave occurrence in Table 16.1 stem from the use of a single climate model as well as the single estimate of counterfactual ocean state rather than observational uncertainty.

Conclusion. The deadly heat waves of 2015 in India and Pakistan were distinct meteorological events without obvious connection despite the proximity in location and time. We find a substantial human-induced increase ( $800 \%$ to $>100000 \%)$ in the likelihood of the observed heat indices. Alternatively, we also find a human-induced increase $\left(\sim 2^{\circ} \mathrm{C}\right)$ in the heat indices of nonindustrial events of equivalent rarity to that estimated in 2015 (Table 16.1). This anthropogenic influence is found to be higher for pentadal than for daily measures of heat wave severity, with potential implications for human health and mortality because of their dependence on heat wave duration.
ACKNOWLEDGEMENT. Wehner's and Stone's contributions to this work are supported by the Regional and Global Climate Modeling Program of the Office of Biological and Environmental Research in the Department of Energy Office of Science under contract number DE-AC02-05CH11231. Castillo's contribution is supported by the National Science Foundation grant No. 000237060 under the Earth System Model (EaSM2) program.

This document was prepared as an account of work sponsored by the U.S. government. While this document is believed to contain correct information, neither the U.S. government nor any agency thereof, nor the regents of the University of California, nor any of their employees, makes any warranty, express or implied, or assumes any legal responsibility for the accuracy, completeness, or usefulness of any information, apparatus, product, or process disclosed, or represents that its use would not infringe privately owned rights. Reference herein to any specific commercial product, process, or service by its trade name, trademark, manufacturer, or otherwise, does not necessarily constitute or imply its endorsement, recommendation, or favoring by the U.S. government or any agency thereof, or the regents of the University of California. The views and opinions of authors expressed herein do not necessarily state or reflect those of the U.S. government or any agency thereof or the regents of the University of California.

\section{REFERENCES}

Angélil, O., and Coauthors, 2016a: Comparing regional precipitation and temperature extremes in climate model and reanalysis products. Wea. Climate Extremes, 13, 35-42, doi:10.1016/j.wace.2016.07.001.

- D. Stone, M. Wehner, C. J. Paciorek, H. Krishnan, and W. Collins, 2016b: An independent assessment of anthropogenic attribution statements for recent extreme weather events. J. Climate, in press, doi:10.1175/JCLI-D-16-0077.1.

Coles, S., 2001: An Introduction to Statistical Modeling of Extreme Values. Springer Verlag, 208 pp.

Dunn, R. J. H., K. M. Willett, P. W. Thorne, E. V. Woolley, I. Durre, A. Dai, D. E. Parker, R. S. Vose, 2012: HadiSD: A quality controlled global synoptic report database for selected variables at long-term stations from 1973-2011. Climate Past, 8, 1649-1679, doi:10.5194/cp-8-1649-2012. 
Folland, C., D. Stone, C. Frederiksen, D. Karoly and J. Kinter, 2014: The International CLIVAR Climate of the 20th Century Plus (C20C+) Project: Report of the sixth workshop. CLIVAR Exchanges No. 65, 19, 57-59.

Jeon, S., C. J. Paciorek, and M. F. Wehner, 2016: Quantile-based bias correction and uncertainty quantification of extreme event attribution statements. Wea. Climate Extremes, 12, 24-32, doi:10.1016/j .wace.2016.02.001.

Masood, I., Z. Majid, S. Sohail, A. Zia, and S. Raza, 2015: The deadly heat wave of Pakistan, June 2015. Int. J. Occup. Environ. Med., 6, 247-248.

Ratnam, J. V., S. K. Behera, S. B. Ratna, M. Rajeevan, and T. Yamagata, 2016: Anatomy of Indian heat waves. Sci. Rep. 6, 24395, doi:10.1038/srep24395.

Salim, A., A. Ahmed, N. Ashraf, and M. Ashar, 2015: Deadly heat wave in Karachi, July 2015: Negligence or mismanagement? Int. J. Occup. Environ. Med., 6, 249.

Steadman, R. G., 1979a: The assessment of sultriness. Part I: A temperature-humidity index based on human physiology and clothing science. J. Appl. Meteor., 18, 861-873.

— $1979 \mathrm{~b}$ : The assessment of sultriness. Part II: Effects of wind, extra radiation and barometric pressure on apparent temperature. J. Appl. Meteor., 18, 874-885.

Stone, D., 2013: Boundary conditions for the C20C Detection and Attribution Project: The All-Hist/ est1 and Nat-Hist/CMIP5-est1 scenarios. Lawrence Berkeley National Laboratory, $18 \mathrm{pp}$. [Available online at http://portal.nersc.gov/c20c /input_data/C20C-DandA_dSSTs_All-Hist-est1 _Nat-Hist-CMIP5-est1.pdf.]

Wehner, M., F. Castillo, and D. Stone, 2016: Extreme heat waves, health, and welfare in a changing climate. Oxford Research Encyclopedia, Natural Hazard Science, in press, doi:10.1093 /acrefore/9780199389407.013.58. 


\title{
17. THE HEAVY PRECIPITATION EVENT OF DECEMBER 2015 IN CHENNAI, INDIA
}

\author{
Geert Jan van Oldenborgh, Friederike E. L. Otto, Karsten Haustein, and Krishna AchutaRao
}

Extreme one-day rainfall caused widespread flooding in Chennai, India, in December 2015. No effect of global warming was detected, likely caused by aerosols counteracting greenhouse gases up to now.

Introduction. At the beginning of December 2015, the Indian state of Tamil Nadu experienced extensive flooding. November had been the second wettest month in Chennai $(1049 \mathrm{~mm})$ in more than 100 years, but the main floods were caused by one day of extreme precipitation on 1 December. The commercial center, Chennai (formerly known as Madras), reported 24-hr precipitation from $0830 \mathrm{LT}$ ranging from 77 to $494 \mathrm{~mm}$ at 18 stations, with a citywide-average of $286 \mathrm{~mm}$ (Fig. 17.1a). The city was declared a disaster area on 2 December after many areas, including the airport, were flooded. Although in the satellite-based CMORPH analysis the largest precipitation amounts were recorded south of Chennai (Fig. 17.1b), we concentrate our analysis on this city because the impact was largest here. Damages were estimated to be as high as $\$ 3$ billion (U.S. dollars; Wall Street Journal, 11 December 2015).

This part of India has its main rainy season during the northeast monsoon (Srinivasan and Ramamurthy 1973; Yadav 2013) in October-December. Sea surface temperature (SST) in the Bay of Bengal typically exceeds the threshold for deep convection throughout the year. Weak vertical shear during May and October-December (months prior to and immediately following the southwest monsoon) makes conditions ideal for tropical storms and cyclones that make landfall on the southeastern coast of India. The extreme rainfall events have sizes of $O(100) \mathrm{km}$.

SST in the northern and western Bay of Bengal has hardly increased over the last 35 years, in contrast to most of the rest of the world (Fig. 17.1c). This is likely because of increased air pollution in the region, the

AFFILIATIONS: VAN OLDENBORGH-Royal Dutch Meteorological Institute, De Bilt, Netherlands; Otto AND HaustelNEnvironmental Change Institute, University of Oxford, Oxford, United Kingdom; ACHUTARAO-Indian Institute of Technology Delhi, New Delhi, India.

DOI:I0.II75/BAMS-D-16-0129.I "brown cloud," that blocks more sunlight counteracting the warming due to greenhouse gases, especially in premonsoon maximum temperatures (Padma Kumari et al. 2007; Wild 2012). The CMIP5 historical greenhouse gas (GHG) experiments without aerosols indeed indicate a larger trend in the Bay of Bengal (sea points in $\left.10^{\circ}-25^{\circ} \mathrm{N}, 80^{\circ}-90^{\circ} \mathrm{E}\right), 1.6^{\circ} \mathrm{C}(100 \mathrm{yr})^{-1}$ over October-December from 1970 to 2005, than the historical experiments, $1.3^{\circ} \mathrm{C}(100 \mathrm{yr})^{-1}$. This is still higher than the observed trend of $0.8^{\circ} \mathrm{C}(100 \mathrm{yr})^{-1}$. In line with this, SST anomalies were lower than elsewhere in the Indian Ocean in November-December 2015, although there was a warmer patch just off the coast of Chennai with $0.6^{\circ}-0.8^{\circ} \mathrm{C}$ anomalies (Fig. 17.1d). El Niño was also very strong these months.

Observational analysis. We analyze two datasets of daily station precipitation in the region. The public GHCN-D dataset (Menne et al. 2016) has 50 stations with at least 40 years of data in the area $10^{\circ}-15^{\circ} \mathrm{N}$, $79.5^{\circ}-81^{\circ} \mathrm{E}$ for a total of 3504 station-years. These coastal stations have similar climatologies of the wettest day of the year (RX1day). However, all but two of the series end in 1970. The India Meteorological Department (IMD) provided us with 19 nonpublic series with mean RX1day $>90 \mathrm{~mm}$ from the region for 1969-2013. Five of these did not have more than one or two years of valid data. One station had zeroes all through the wet season in a few years and was also discarded. Seven stations had monthly mean totals in 2001-04 that were about a factor of 10 smaller than satellite data; these years were deleted. A few very high precipitation amounts $(\geq 500 \mathrm{~mm})$ were on dry or moderately rainy days at other stations or in the satellite record and did not show up in flood records, so they were removed (displaced decimal points are common). After this quality-control procedure, 407 station years with at least $80 \%$ valid data in OctoberDecember remained. Both datasets were analyzed 
(a)
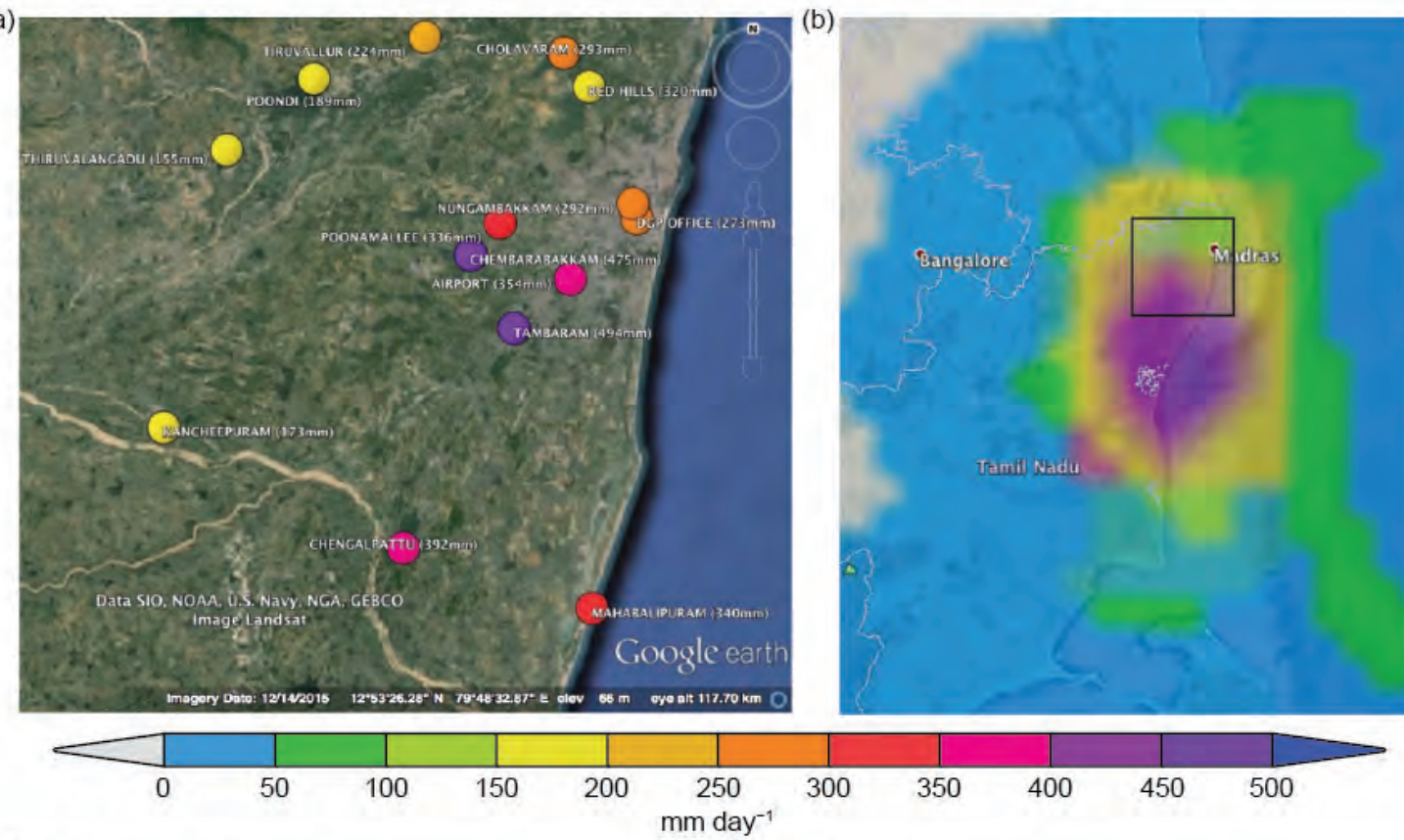

(c)

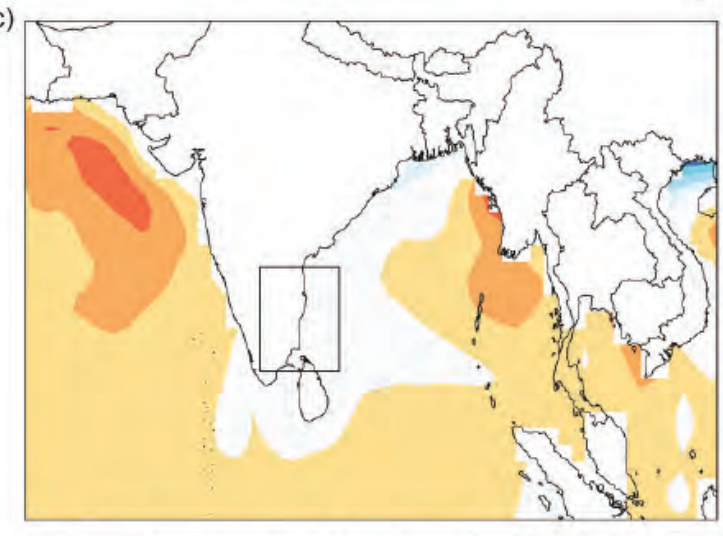

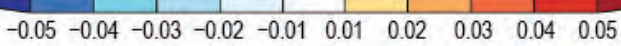

$\mathrm{K} \mathrm{yr}^{-1}$ (b)

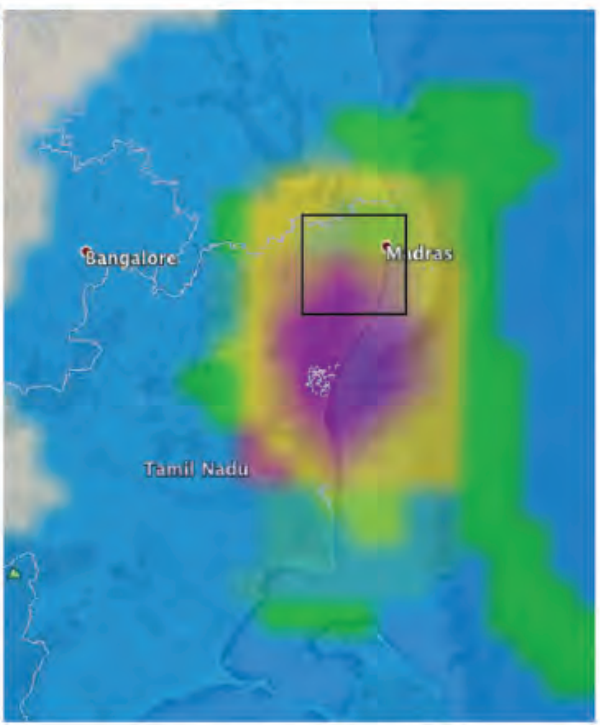

(d)

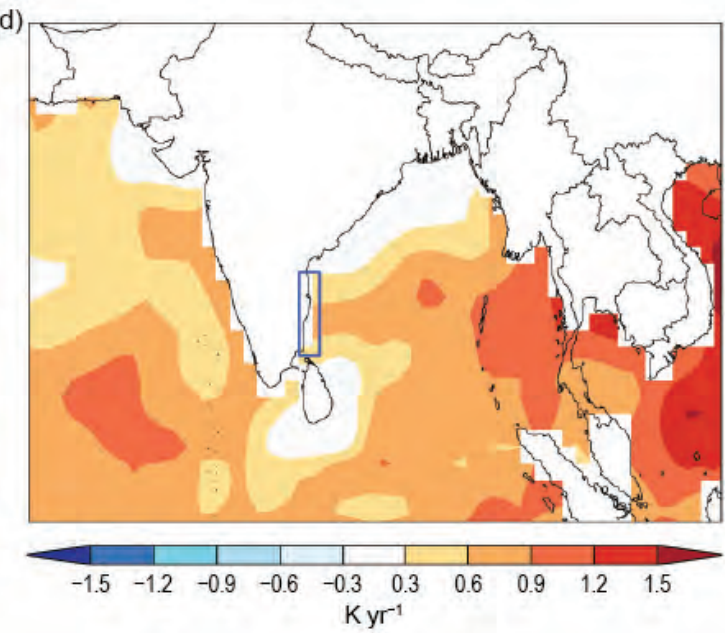

Fig. 17.I. (a) Rain gauge observations from 0830 LT of I Dec 2015 to 0830 LT of 2 Dec 2015 (mm day-1). The city of Chennai is visible in gray around the stations Nungambakkan and DGP Office in the city center. (b) Analyzed precipitation on 0000-2400 UTC I Dec 2015 (mm day-1; CMORPH, Joyce et al. 2004), the box indicates the region of panel (a). (c) Observed SST trend $\left({ }^{\circ} \mathrm{C}_{\mathrm{yr}^{-1}}\right)$ over the Bay of Bengal 198I-20I5 (SST OI v2, Smith et al. 2008). The box indicates the region of panel (b). (d) Observed anomalies $\left({ }^{\circ} \mathrm{C}\right)$ in Nov-Dec 2015. The blue box denotes the region investigated, the land area in $10^{\circ}-15^{\circ} \mathrm{N}, 79.5^{\circ}-81^{\circ} \mathrm{E}$.

separately with a fit to a generalized extreme value (GEV) distribution that scales with time (cf. Vautard et al. 2015), or the (ERSSTv4) Niño-3.4 index, assuming all stations have identical rainfall distributions. The uncertainties were estimated using a nonparametric bootstrap that takes spatial correlations into account with a 2D moving-block procedure analogous to the $1 \mathrm{D}$ one for temporal autocorrelations.

Both datasets show that the $494 \mathrm{~mm}$ observed in the Tambaram suburb is a rare event, with return times of 600-2500 years (95\% confidence interval; GHCN-D, assuming a stationary climate) and 300-4000 years (IMD; current climate, red lines in Fig. 17.2a) respectively. This means that the odds of receiving such extreme precipitation at a givenstation are less than $0.2 \%$ each year. The chance of such an amount occurring at any station in the region is higher. The rainfall in this area has around 5 degrees of freedom, so the return time for such a high amount in any rain gauge is five times lower. In fact, there is one 
(a) Oct-Dec Daily Stations Precipitation 1969-2013 (95\% Cl)
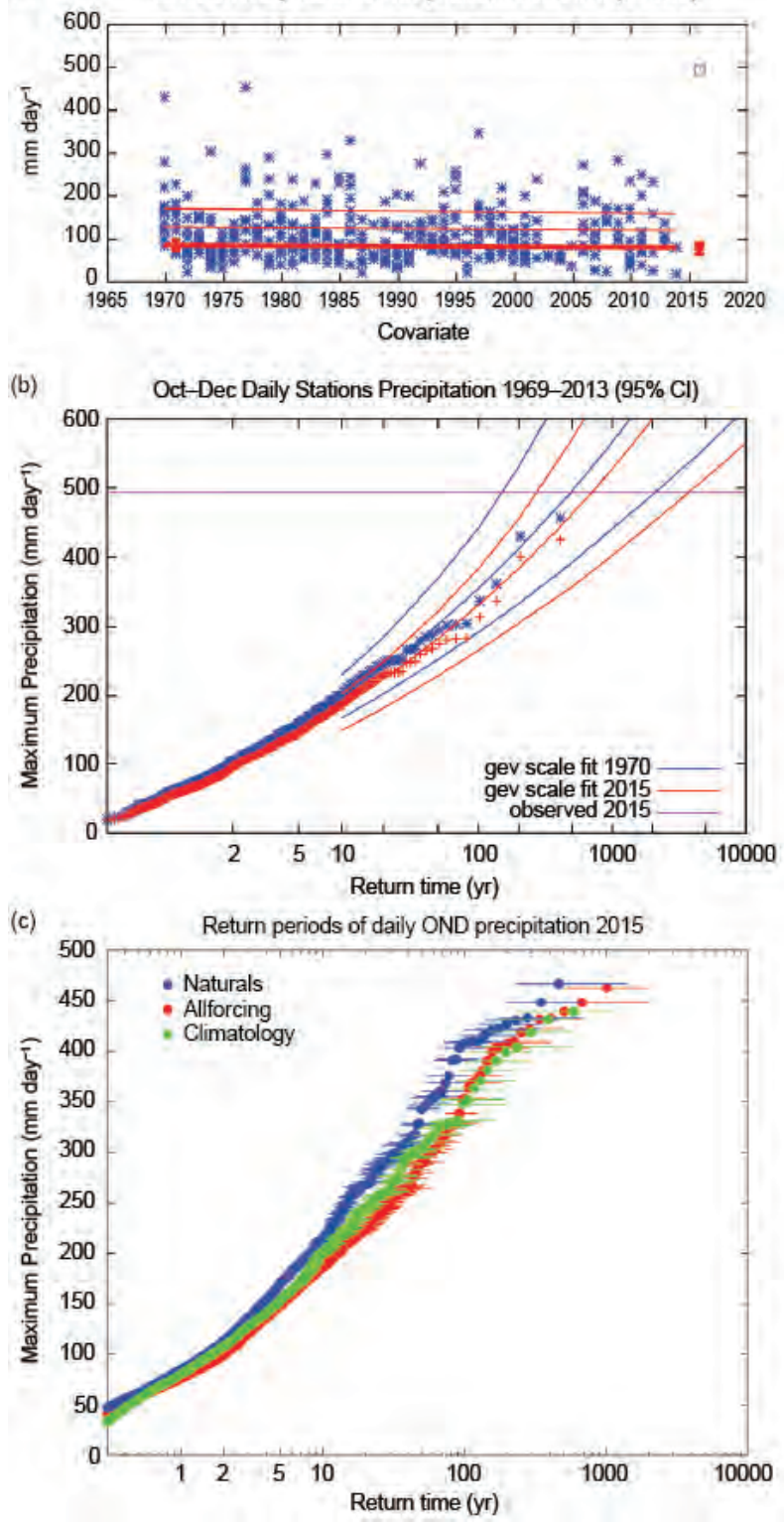

FIG. 17.2. (a) Maximum precipitation in Oct-Dec at 19 stations from 1969 to 2014 with a GEV fit in which the position parameter (thick red line) and scale parameter (difference between red lines) depend exponentially on time with their ratio constant. (b) Return time plot of these data with the GEV fit for 1970 (blue) and for 2015 (red) and 95\% uncertainties, the observations are also shown twice, shifted up (blue) and down (red) with the fitted trend. (c) Return times of maximum land grid box precipitation in the region $10^{\circ}-15^{\circ} \mathrm{N}, 77^{\circ}-82^{\circ} \mathrm{E}$ in the SST-forced regional model in the 2015 SST forced ensemble (red), the 2015 counterfactual world without anthropogenic emissions (blue) and the 1985-2014 climatology (green).

event in the GHCN-D dataset with higher precipitation: $500 \mathrm{~mm}$ at Vedaranayam on 18 November 1918.
The GHCN-D dataset (mainly up to 1970) shows no trend, whereas the IMD dataset shows a nonsignificant negative trend starting in 1969, see Figs. 17.2a,b. We conclude that there is no observational evidence for a positive trend. The $95 \%$ range is a factor $0.14-2.2$ increase in probability since 1970. A similar analysis using the Niño-3.4 index as covariate rather than time shows that there is a slight increase during El Niño, which is not significant at $p<0.1$ (one-sided). Total November-December precipitation is very weakly correlated with the Niño-3.4 index $(r$ $=0.18$, correlations reach $r>0.4$ further south along the coast). There is a stronger connection between mean precipitation and SST in the Bay of Bengal $\left(10^{\circ}-25^{\circ} \mathrm{N}, 80^{\circ}-95^{\circ} \mathrm{E}, r=0.30\right)$, which supports our hypothesis that the lack of trend in this area over the last 40 years is responsible for the lack of trend in extreme precipitation.

Global coupled climate models. We analyzed the rainfall extremes in a relatively high-resolution ensemble of model runs, 16 historical/RCP 8.5 experiments using the EC-Earth 2.3 model (Hazeleger et al. 2010) at T159, about $150-\mathrm{km}$ resolution. This model shows a strong positive trend in SST over the Bay of Bengal of about $0.2^{\circ} \mathrm{C}\left(10 \mathrm{yr}^{-1}\right)$ over $1975-2015$, which contradicts the observed trend. We therefore do not consider its modeled increase in the probability of high RX1day by a factor $1.6-6(95 \% \mathrm{CI})$.

The CMIP5 ensemble contains many models with a hard upper boundary of rainfall in the grid box corresponding to Chennai, in contrast to the observed probability distribution function (PDF; Fig. 17.2b), hence we could not use it either.

Regional climate model. We furthermore analyze the rainfall extremes in the regional atmosphere-only general circulation model HadRM3P, used in the weather@home distributed computing framework (Massey et al. 2015). The regional model over the CORDEX South Asian region (Giorgi et al. 2009) was employed at a $0.44^{\circ} \times 0.44^{\circ}$ resolution with a 5 -min time step is driven by the Hadley Centre model HadAM3P at $1.875^{\circ} \times 1.25^{\circ} \times 15$-min resolution. The initial conditions of the global model are perturbed at the first of December 2014 of every 13-month simulation to derive a set of very large ensembles of possible weather in the region of interest. Three different ensembles are simulated:

1) Simulations of the 13 months from December 2014 to December 2015 driven by observed (2015) 
SSTs and greenhouse gas concentrations $(n=2900)$,

2) Simulations of the same time frame in a counterfactual simulation $(n=6960)$ under preindustrial greenhouse gas and aerosol forcing and natural SSTs constructed by subtracting 11 different estimates of the human-induced warming pattern from the 2015 observed SSTs (Schaller et al. 2016), and

3) Climatological simulations of the years 19852014 with observed forcings to evaluate the reliability of the model as well as estimating the influence of the 2015 SSTs on the likelihood of the rainfall extremes.

Quantile-quantile assessments of the modeled precipitation reveal a small overestimation of the absolute values of precipitation but good representation of the overall distribution. Pressure over the region of interest is consistently underestimated. Because the biases in the model seem to be mainly an offset and we are comparing the model with itself in terms of magnitudes, we refrain from applying a bias correction. The SST difference between actual and preindustrial situations in the Bay of Bengal is about $0.5^{\circ} \mathrm{C}$ (Schaller et al. 2016, their Supplemental Fig. S17.3), in line with the observed trend.

To derive results comparable to the statistical analysis of the 19 stations described previously, we analyze daily maximum grid box precipitation in the October to November period over the region $10^{\circ}-15^{\circ} \mathrm{N}, 77^{\circ}-82^{\circ} \mathrm{E}$.

Comparing the two ensemble simulations for 2015 (Fig. 17.2c), we find again a nonsignificant negative change in the likelihood of extreme precipitation events with a return time above 100 years due to anthropogenic emissions. Comparing the simulations of 2015 with an ensemble of simulations of daily extreme rainfall from 1985 to 2014 reveals a small positive influence of the observed SST patterns on the likelihood of extreme rainfall. The analysis does not allow us to estimate the influence of the observed El Niño, only the global SST patterns. Qualitatively, the results are robust under different possible ways of characterizing the event spatially and temporally, by excluding the westernmost parts of the region or analyzing monthly data.

Discussion and conclusions. The observational analysis found no signal for a positive trend in extreme oneday precipitation at the southeastern coast of India over 1900-70, nor over 1970-2014. Coupled models show more extreme one-day precipitation events from 1970-2015, but a large ensemble of SST-forced models again shows no increase in the probability of extreme one-day precipitation due to anthropogenic emissions. A plausible factor is the lack of increase in SST in the western Bay of Bengal over the last 40 years, which is not reproduced correctly by the coupled models but is more realistic in the SST-forced model. This precludes an attribution of the floods to anthropogenic factors, probably to a large extent due to the two main pollutants, greenhouse gases and aerosols, having opposing effects. Over land this opposition is discussed by Padma Kumari et al. (2007) and Wild (2012).

There is a small but clear increase in probability of extremes in the SST-forced regional model, associated with El Niño and other SST anomalies. In the observations, the ENSO signal is also present but not statistically significant.

ACKNOWLEDGEMENTS. The station rainfall data (since 1969) provided by IMD is acknowledged. We would like to thank all of the volunteers who have donated their computing time to weather@home, and our colleagues at the Oxford eResearch Centre and the Met Office Hadley Centre PRECIS team for their technical expertise and scientific support. GJvO was supported by the FP7 EUCLEIA project under Grant \#607085.

\section{REFERENCES}

Giorgi, F., C. Jones, and G. R. Asgar, 2009: Addressing climate information needs at the regional level: The CORDEX framework. WMO Bulletin, 58, 175183. [Available online at http://public.wmo.int/en /bulletin/addressing-climate-information-needs -regional-level-cordex-framework.]

Hazeleger, W., and Coauthors, 2010: EC-Earth: A seamless Earth-system prediction approach in action Bull. Amer. Meteor. Soc., 91, 1357-1363, doi:10.1175/2010BAMS2877.1.

Joyce, R. E., J. E. Janowiak, P. E. Arkin, and P. Xie, 2004: CMORPH: A method that produces global precipitation estimates from passive microwave and infrared data at high spatial and temporal resolution. J. Hydrometeorol., 5, 487-503, doi:10.1175/1525 -7541(2004)005<0487:CAMTPG>2.0.CO;2.

Massey, N., and Coauthors, 2015: weather@home development and validation of a very large ensemble modelling system for probabilistic event attribution. Quart. J. Roy. Meteor. Soc., 141, 1528-1545, doi:10.1002/qj.2455. 
Menne, M., and Coauthors, 2016: Global Historical Climatology Network - Daily (GHCN-Daily), Version 3.22, doi:10.7289/V5D21VHZ.

Padma Kumari, B., A. L. Londhe, S. Daniel, and D. B. Jadhav, 2007: Observational evidence of solar dimming: Offsetting surface warming over India. Geophys. Res. Lett., 34, L21810, doi:10.1029/2007GL031133.

Schaller, N., and Coauthors, 2016: The human influence on climate in the 2014 southern England winter floods and their impacts. Nat. Climate Change, 6, 627-634, doi:10.1038/nclimate2927.

Smith, T. M., R. W. Reynolds, T. C. Peterson, and J. Lawrimore, 2008: Improvements to NOAA's historical merged land-ocean surface temperature analysis (1880-2006). J. Climate, 21, 2283-2296, doi:10.1175/2007JCLI2100.1.

Srinivasan, V., and K. Ramamurthy, 1973: Forecasting Manual Part IV: Comprehensive articles on selected topics. 18.4 Northeast monsoon. FMU Report No IV-18.4, India Meteorological Department, 130 pp. [Available online at www.imdpune.gov.in/weather _forecasting/Forecasting_Mannuals/IMD_IV18.4.pdf.]

Vautard, R., and Coauthors, 2015: Extreme fall 2014 precipitations in the Cévennes mountain range [in "Explaining Extremes of 2014 from a Climate Perspective”]. Bull. Amer. Meteor. Soc., 96 (12), S56S60, doi:10.1175/BAMS-D-15-00088.1.

Wild, M., 2012: Enlightening global dimming and brightening. Bull. Amer. Meteor. Soc., 93, 27-37, doi:10.1175/BAMS-D-11-00074.1.

Yadav, R. K., 2013: Emerging role of Indian ocean on Indian northeast monsoon. Climate Dyn., 41, 105116, doi:10.1007/s00382-012-1637-0. 


\title{
I8. ATTRIBUTION OF EXTREME RAINFALL IN SOUTHEAST CHINA DURING MAY 2015
}

\author{
Claire Burke, Peter Stott, Ying Sun, and Andrew Ciavarella
}

Anthropogenic climate change increased the probability that a short-duration, intense rainfall event would occur in parts of southeast China. This type of event occurred in May 2015, causing serious flooding.

Introduction. The prerainy season in southern China usually starts in April with a rainbelt forming along the Indochina Peninsula. The rainbelt moves northward across eastern China throughout the rainy season, which generally lasts from May to August (Ding and Chan 2005). In 2015, the prerainy season began in early May, about a month later than normal. After the rainbelt was established, the rainfall was exceptionally heavy with the total precipitation in some southern provinces more than $50 \%$ greater than the 1971-2000 average (CMA 2016). The rain fell in a series of heavy storms, causing severe flooding in many cities with impacts that included loss of life.

We examine the change in the character of rainfall during May in terms of the number of consecutive days of rain, total rainfall over a period of $n$ days $(n-$ day totals), and rainfall intensity. Using these metrics, we estimate the regional change in probability of extreme precipitation due to anthropogenic climate forcing.

Data. We use model data from a pair of multidecadal ensemble experiments using the latest Met Office HadGEM3-A-based attribution system. Each ensemble comprises 15 members spanning the period 1960-2013, one set with both anthropogenic and natural forcings (ALL) and the other with natural only (NAT). The system is an upgrade to that used in a number of previous studies described by Christidis et al. (2013) to higher resolution (N216 L85, $0.56^{\circ} \mathrm{x}$ $0.83^{\circ}$ horizontally), the latest operational dynamical core (ENDGame; Wood and Stainforth 2010), and land surface model (JULES; Best et al. 2011), as well as an updated forcings set consistent with the CMIP5

AFFiliations: Burke, Stott, ANd Ciaverella-Met Office Hadley Centre, Exeter, United Kingdom; SuN-National Climate Center, China Meteorological Administration, Beijing, China DOI:I0.II75/BAMS-D-16-0I44.I

A supplement to this article is available online (10.1I75 /BAMS-D-16-0144.2) generation (Jones et al. 2011). Members differ from one another solely through the stochastic physics and share atmospheric initialization from ERA-40 at 0000 UTC 1 December 1959.

We use observed daily precipitation data for 19612015 provided by the Climate Data Center of China National Meteorological Information Center (NMIC). This dataset uses quality controlled data from 2419 stations and is the best daily dataset available for climate study in China. Yang and Li (2014) show that most of the daily precipitation series are homogeneous and lack pronounced discontinuities resulting from instrumental changes or station relocation.

Methods. We divide the flood-affected area of southeast China into 12 regions of $3^{\circ} \times 3^{\circ}$ areas with spatially coherent rainfall patterns and variability. Region locations and corresponding time series of total monthly rainfall for May are shown in Fig. 18.1. Monthly totals show no clear trends outside of interannual variability (see Supplemental Material for linear fits).There is also no clear separation of expected changes in monthly rainfall under anthropogenic and natural forcings. Given the large interannual variability of monthly totals and the nature of the floods in May 2015 being related to several large daily rainfall totals, we instead look at changes in intensity and duration of rainfall events.

For the month of May, we count the number of consecutive wet days (daily total rainfall $>=1 \mathrm{~mm}$ ) (n_days) and record the total rainfall during each $n$-day event (n_day_tot). We then calculate the mean intensity of rainfall in $\mathrm{mm}$ day $^{-1}$ for each event (intens). Using this metric, any given month can have several rainfall events.

For each $3^{\circ} \times 3^{\circ}$ region in southeast China, the mean of the observed station data and the mean of the grid cells for the model data are calculated for each day. This daily area-mean for each region is then used to calculate $n$ _days, $n \_$day_tot, and intens. We 
(a)

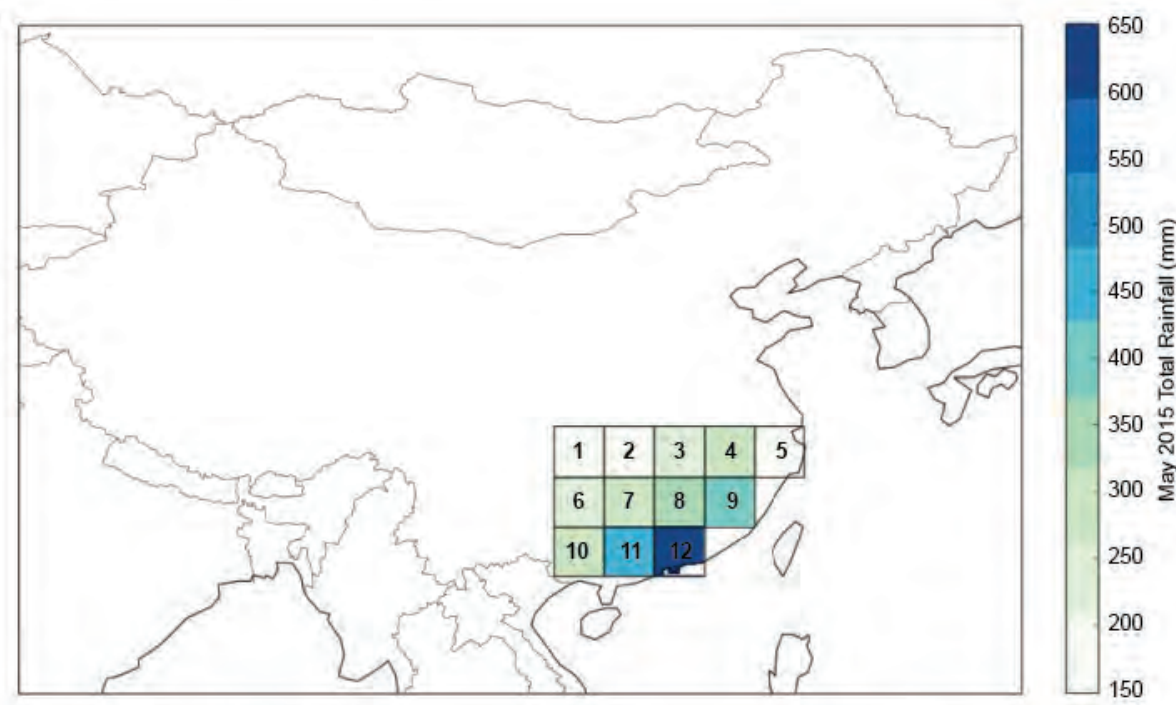

(b)

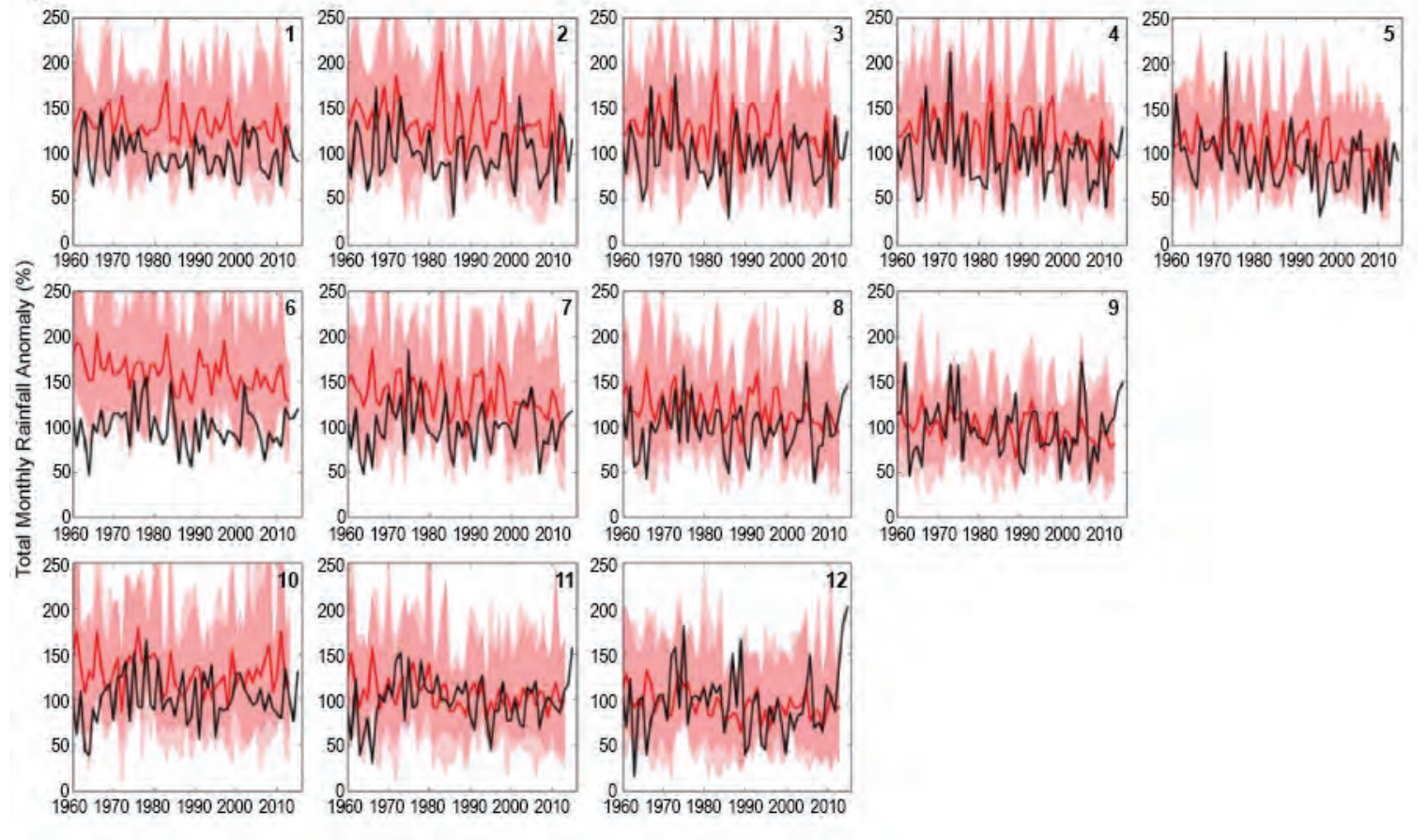

FIG. 18.I. (a) Regions of China examined in this study including total rainfall for May 2015. (b) Monthly total precipitation anomaly time series for regions I-12: observed totals (black lines), HadGEM3-A model mean (thick red lines), model ensemble 5th-95th percentile (dark red shading), and total model ensemble range (light red shading). Anomalies for both observations and models are with respect to 1961-90 climatology.

use all the available stations in each $3^{\circ} \times 3^{\circ}$ grid box, generally 40-60 stations, though the number of stations varies from year to year.

Model verification. We assess the capability of the models to represent daily rainfall characteristics and extremes by comparison of time series and rainfall intensity distributions between the model ensemble and the observations.
We plot observed and model time series total monthly rainfall for May, total number of rainy days, and maximum intens for each of 12 regions in Fig. 18.1 and Supplemental Fig. S18.1. The observed interannual variability of the time series clearly falls within the ensemble variability of HadGEM3-A, with the exception of region 6 , which we exclude from further analysis. Linear fits to the observed and modeled 
time series produce similar results albeit with low-fit significance (see Supplemental Material).

Supplemental Fig. S18.1 plots daily rainfall intensity distribution for the regions of southeast China. We perform a Kolmogrov-Smirnoff test (KS) for each region to determine how well the observed distribution of daily rainfall is reproduced by the ensemble mean - the results of this are indicated in the supplement. Nine of the 12 regions showed more than $95 \%$ likelihood of the observed and modeled distributions being drawn from the same population; an additional two regions showed $86 \%$. Region 10 showed only $72 \%$ likelihood and was excluded from further analysis.

The model can reproduce the mean and extremes of precipitation totals, intensities, number of rainy days in a month, and numbers of consecutive days of rain sufficiently well for the attribution study intended here.

Results. We select the top $10 \%$ of $n$ _day_tot rainfall to be defined as extreme events and examine the change in intens and $n_{-}$days over which this rain fell. The values for observed $n$ _days, $n_{-}$day_tot, and intens are shown in Supplemental Fig. S18.2 for all years including 2015. Following Christidis and Stott (2015), we take the most recent 15 years of model data (1999-2013) as representative of current climatology to produce probability distribution functions (PDF) for intens and $n_{-}$days. The PDF is calculated by fitting a gamma function to the normalized model histogram of the rainfall metric examined; we test the appropriateness of this fit in the supplement. PDFs allow the calculation of fraction of attributable risk (FAR; Allen 2003), defined as FAR $=1-(\mathrm{P}(\mathrm{NAT}) /$ $\mathrm{P}(\mathrm{ALL})$ ) for individual regions.

We calculate FAR for intensity of events greater than the May 2015 observed maximum, providing an estimate of the extent to which human influence has increased the risk of high-total-rainfall events with daily intensity as high as observed in May 2015. We also calculate FAR for the number of consecutive days of rain less than the maximum value observed for May 2015, providing an estimate of the extent to which human influence has increased the risk of having high-total-rainfall events with duration as short as in May 2015.

To calculate the error on FAR, we bootstrap resample (with replacement) the top $10 \%$ of $n_{\text {_day_tot }}$ for the all-forcings and natural-forcings models then refit the PDFs 1000 times for both intens and $n$ _days. The standard deviation of the FAR from the 1000 bootstrapped samples gives the error on FAR.
We exclude regions 6 and 10 from analysis (see model verification) and report results for the remaining 10 regions. We find positive FAR in 4 out of 10 and 9 out of 10 regions for intens and $n$ _days, respectively. The four regions for which intens showed positive FAR-7, 8, 11, and 12-are all spatially adjacent to each other; these and all the coastal regions show positive FAR for $n$ _days. The spatial contiguity of regions with positive FAR makes it more likely that these results are physically caused rather than a statistical fluke.

Three regions show positive FAR at $2 \sigma$ in one metric and $1 \sigma$ in the other; we focus our analysis on those. We find positive FAR at $2 \sigma$ confidence for increase in intens and $1 \sigma$ confidence for decrease in $n$ _days in regions 7 and 12 . We find positive FAR at $2 \sigma$ confidence for decrease in $n_{-}$days and $1 \sigma$ confidence for increase in intens for region 11 . We also find positive FAR for regions 8 and 9 at $1 \sigma$ confidence for $n$ _days. We present results for regions 7,11 , and 12 in Fig. 18.2. For the top $10 \%$ of $n_{-}$day_tot, we find anthropogenic climate change has increased the likelihood of intense rainfall, greater than or equal to that observed in May 2015, by $64 \% \pm 17 \%, 23 \% \pm$ $12 \%$, and $66 \% \pm 19 \%$ for regions 7,11 , and 12 , respectively. For the same regions, we find anthropogenic influence increases likelihood by $12 \% \pm 11 \%, 39 \% \pm$ $14 \%$, and $23 \% \pm 14 \%$, respectively, of a decrease in the number of consecutive days over which the rain fell with respect to the maximum number of consecutive days observed in May 2015.

Some studies show that the Pacific sea surface temperature anomaly (SSTA) is an important factor affecting the early rainy-season precipitation in southern China (e.g., Qiang and Yang 2013). We tested for the effect of El Niño on our results and find no obvious correlation between ENSO-3.4 index and any of the three indices we examine from May 2015.

Conclusion. During May 2015, large daily rainfall totals were recorded over much of southeast China. While no clear trends are seen in the monthly total rain for this region, we find that the character of the rainfall has changed, such that the same total amount of rain falls in shorter more intense storms. We have shown that for the month of May, anthropogenically forced climate change has increased the probability of this kind of intense, short-duration rainfall (as occurred in 2015) for some regions of southeast China. In the future, we might expect more occurrences of short, intense rainfall events in these regions, increasing the likelihood of flooding. 
(a)

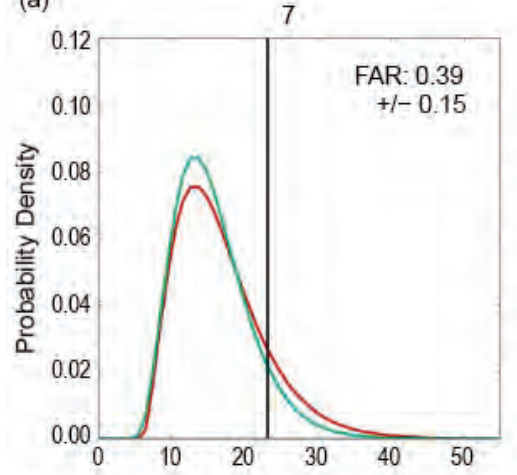

(b)

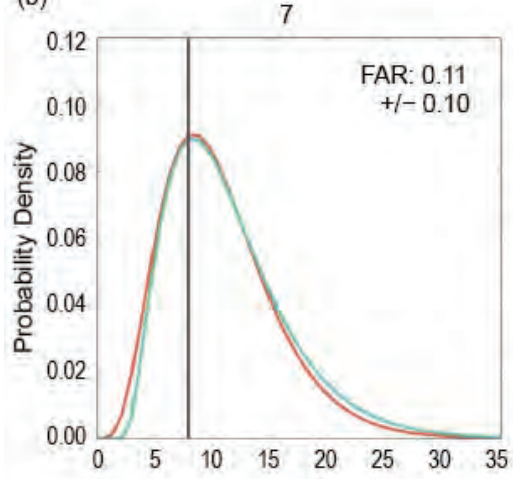

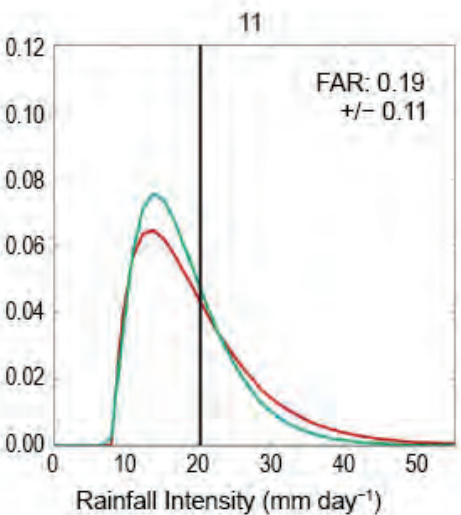
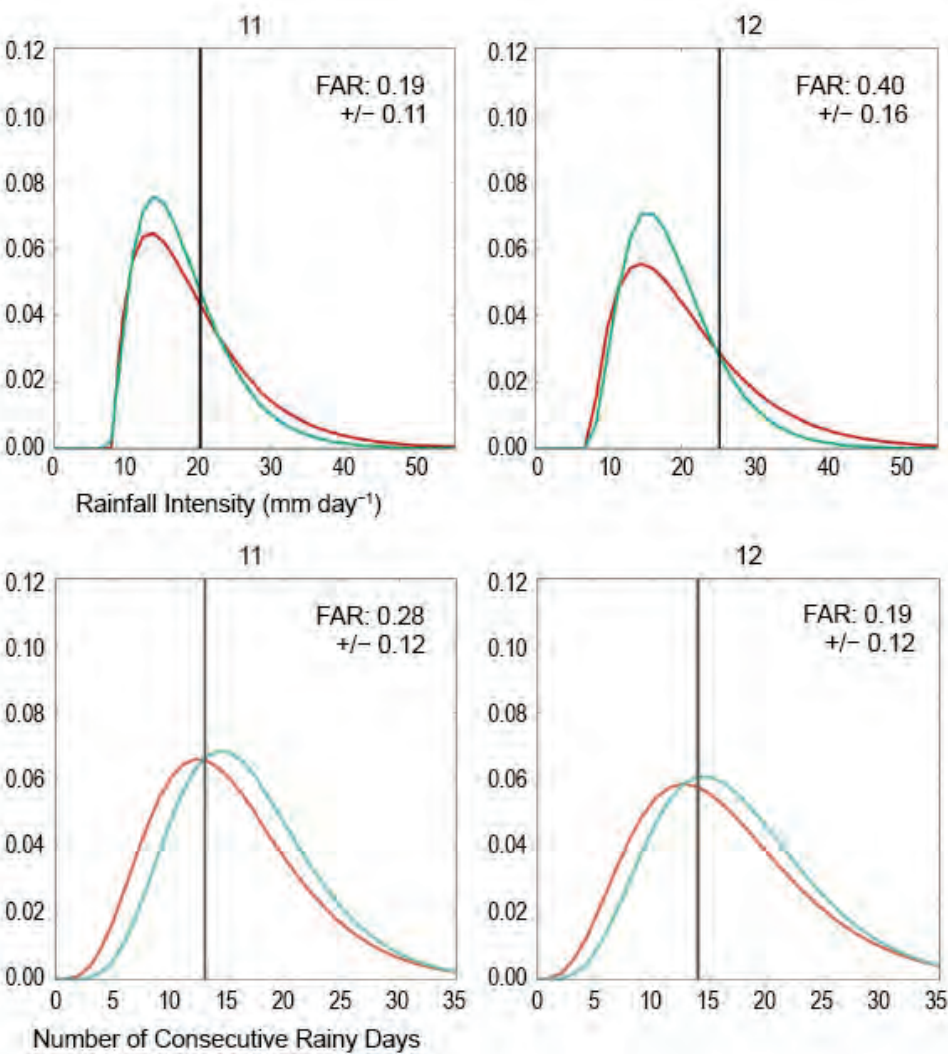

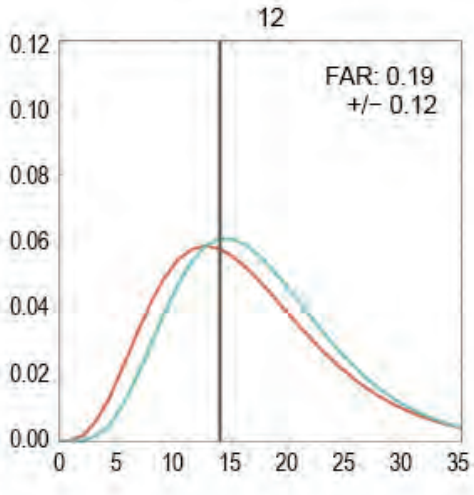

FIG. 18.2. (a) Probability distribution functions (PDFs) for the intensity of rainfall and (b) number of consecutive days of rain, where only the top $10 \%$ of rainfall total events (n_day_tot) defined by the observed 196I-90 climatology are selected. Red lines correspond to HadGEM3-A all forcings models (ALL); green is natural forcings only models (NAT); and black lines show the maximum value for May 20I5. FARs (FAR = I - (P(NAT) / P(ALL)) are indicated for each region. (a) FAR for intensity greater than the 2015 maximum value and (b) FAR for number of consecutive days of rain less than the 2015 maximum value. Only regions 7,11 , and 12 are shown.

ACKNOWLEDGEMENTS. This work and two of its contributors (Burke and Ciavarella) were supported by the UK-China Research and Innovation Partnership Fund through the Met Office Climate Science for Service Partnership (CSSP) China as part of the Newton Fund. This work was supported by the Joint DECC/Defra Met Office Hadley Centre Climate Programme (GA01101). Ying Sun is supported by China funding grants GYHY201406020 and 2012 CB417205.

\section{REFERENCES}

Allen, M., 2003: Liability for climate change. Nature, 421, 891-892, doi:10.1038/42189a.

Best, M. J., and Coauthors, 2011: The Joint UK Land Environment Simulator (JULES), model description - Part 1: Energy and water fluxes. Geosci. Model Dev., 4, 677-699, doi:10.5194/gmd-4-677-2011.

Christidis, N., P. A. Stott, A. A., Scaife, A. Arribas, G. S. Jones, D. Copset, J. R. Knight, and W. J. Tennant, 2013: A new HadGEM3-A-based system for attribution of weather-and climate-related extreme events. J. Climate, 26, 2756-2783, doi:10.1175 /JCLI-D-12-00169.1.

Christidis, N., and P. A. Stott, 2015: Extreme rainfall in the United Kingdom during winter 2013/14: The role of atmospheric circulation and climate change [in "Explaining Extreme Events of 2014 from a Climate Perspective"]. Bull. Amer. Meteor. Soc., 96 (12), S46S50, doi:10.1175/BAMS-D-15-00094.1. 
CMA, 2016: China Climate Bulletin 2015. China Meteorological Administration, 50 pp.

Davey, M. K., A. Brookshaw, and S. Ineson, 2014: The probability of the impact of ENSO on precipitation and near-surface temperature. Climate Risk Management, 1 (2014) 5-24, doi:10.1016/j.crm.2013.12.002.

Ding, Y. H., and J. C. L. Chan, 2005: The East Asian summer monsoon: An overview. Meteor. Atmos. Phys., 89, 117-142, doi:10.1007/s00703-005-0125-z.

Jones, C. D., and Coauthors, 2011: The HadGEM2-ES implementation of CMIP5 centennial simulations, Geosci. Model Dev., 4, 543-570, doi:10.5194/gmd-4 -543-2011.

Qiang, X. M., and X. Q. Yang, 2013: Relationship between the first rainy season precipitation anomaly in South China and the sea surface temperature anomaly in the Pacific (in Chinese). Chinese J. Geophys., 56 (8), 2583-2593.

Wood, L., and A. Stainforth., 2010: ENDGame Formulation v3. 01. Met Office paper.

Yang, S., and Q. Y. Li, 2014: Improvement in homogeneity analysis method and update of China precipitation data (in Chinese). Progressus Inquistitiones De Mutatione Climatis, 10 (4), 276 -281 . 


\title{
19. RECORD-BREAKING HEAT IN NORTHWEST CHINA IN JULY 20I5: ANALYSIS OF THE SEVERITY AND UNDERLYING CAUSES
}

\author{
Chiyuan Miao, Qiaohong Sun, Dongxian Kong, and Qingyun Duan
}

The record-breaking heat over northwest China in July 2015 was linked directly to atmospheric general circulation indices and anthropogenic forcing. The latter increased the risk of extreme heat by three-fold.

Introduction. In July 2015, northwest China experienced an unusually long and intense heat wave, especially in Xinjiang Autonomous Region (Fig. 19.1a). Maximum daily temperatures (TMX) exceeded $40^{\circ} \mathrm{C}$ on a record-breaking number of July days in 50 out of 88 counties in Xinjiang, and historical TMX records were broken in 28 counties. The highest TMX was $47.7^{\circ} \mathrm{C}$ in Turpan. This year also smashed the historical records of heat wave duration in 51 counties.

Our paper poses three questions: How extreme was the heat in Northwest China in July 2015 in a historical context? What factors led to the record-breaking heat? Did human-induced climate change increase the odds of abnormally high July heat in Xinjiang?

Data and methods. We collected the July TMX from National Meteorological Information Center (NMIC; http://data.cma.cn). The NMIC has conducted data quality control, including extreme value control, consistency check, and spatial consistency test (Liu and Li 2003). We used the data at the 53 stations with continuous July TMX records throughout the period of 1961-2015. We defined the extreme threshold as the 90th percentile of area-averaged July TMX between 1961 and 1990 (Mazdiyasni and AghaKouchak 2015). Heat wave duration was defined as the total number of days within July that TMX exceeded the threshold (Meehl and Tebaldi 2004).

Simulations from 10 global climate models (GCMs) from the Coupled Model Intercomparison

AFFILIATIONS: MIAO, SUn, KONG, AND DUAN-State Key Laboratory of Earth Surface Processes and Resource Ecology, College of Global Change and Earth System Science, Beijing Normal University, Beijing, China, and Joint Center for Global Change Studies, Beijing, China

DOI:I0.II75/BAMS-D-16-0142.I

A supplement to this article is available online (I0.1I75 /BAMS-D-16-0142.2)
Project Phase 5 of (CMIP5; Taylor et al. 2012) were used to assess the contribution of human influences on the observed July TMX (Supplemental Table S19.1 for the model list). The simulations driven by preindustrial control setting, natural forcing, all forcings, and anthropogenic greenhouse gases (GHG) forcing were assessed. As compared to the usual 2005, these 10 models extend the historical and natural simulations to 2012. However, we focused the GCM simulation analysis on the period 1961-2015 to enable comparison with observations. We used the TMX projection from the Representative Concentration Pathways 4.5 (RCP4.5) scenario to extend the time series of all forcings simulations through 2015, similar to Zhou et al. (2014) and Sun et al. (2014). For each GCM, only one member (rlilp1) run was employed in this study. We used several statistical techniques to assess the severity and causes of the extreme heat:

1) To estimate the univariate return period, we selected the generalized extreme value (GEV) distribution for parametric fitting. This allows more stable estimates of return periods for extreme events occurring in the upper tail of the distribution (Fig. 19.1b). We used the Kolmogorov-Smirnov (K-S) goodnessof-fit test to verify the distribution (Wilks 2006).

2) We focused on the concurrence of July mean TMX anomaly and the duration of the heatwave (Fig. 19.1c). To estimate the concurrent extreme return period, we used the concept of copulas designed to model the dependence between multiple variables (Nelsen 2007). We used the Akaike information criterion (AIC; Akaike 1974) to identify the Gumbel copula as the most appropriate: smaller AIC values indicate a more reliable joint distribution (Supplemental Table S19.2).

3) To evaluate the impact of external forcing, we estimated scaling factors using the regularized optimal fingerprinting (ROF) method (Ribes et al. 

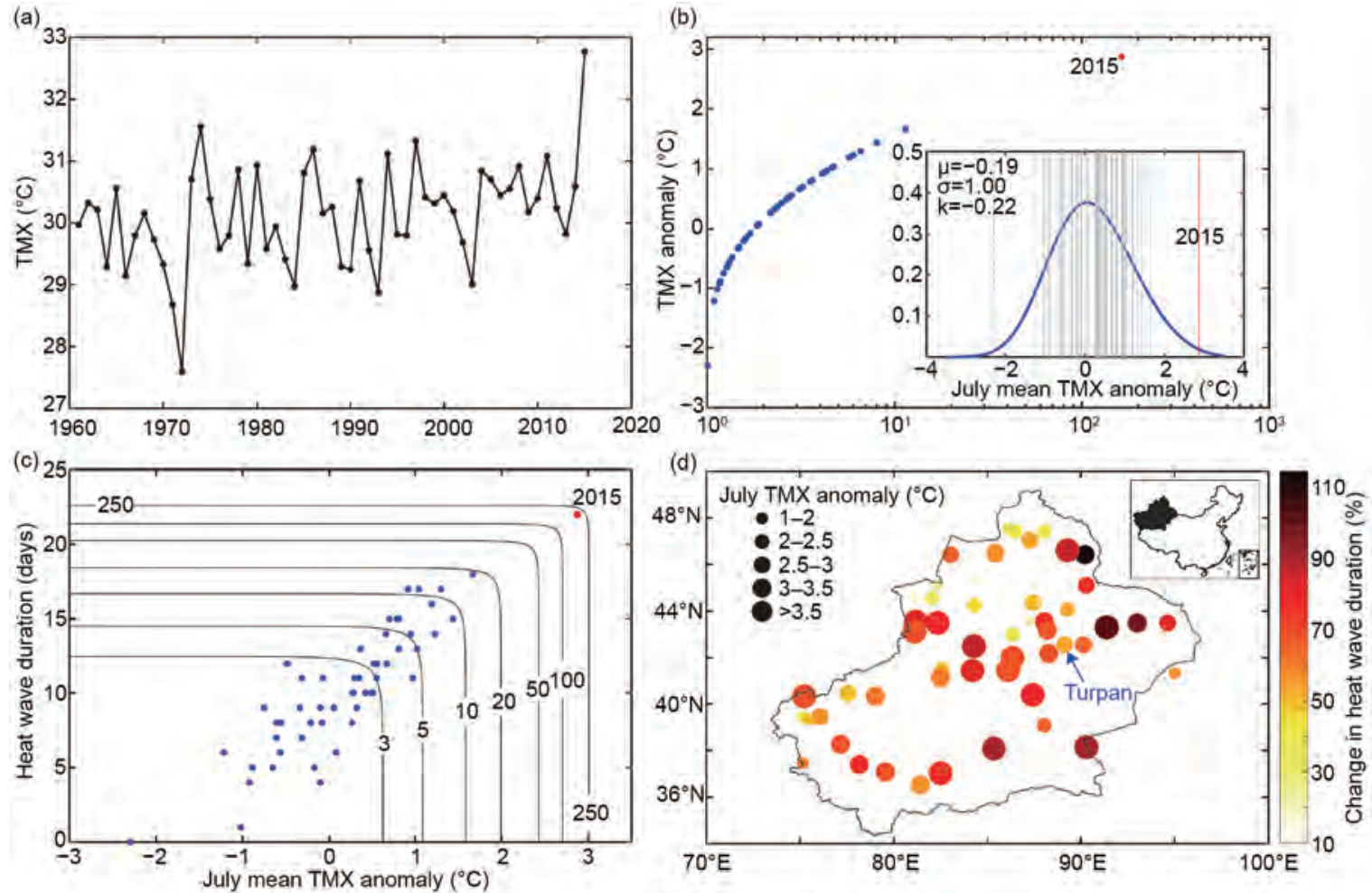

FIG. 19.I. (a) Time series of observed area-averaged Jul TMX over Xinjiang Autonomous Region, China, from 196I-2015. (b) Return period for Jul mean TMX. The univariate distribution was fit with a GEV function. Maximum likelihood estimates (MLEs) were used to obtain the location parameter $\mu$, scale parameter $\sigma$, and shape parameter $k$. (c) Return period for concurrent Jul mean TMXs and heat wave durations. The bivariate joint distribution was fit with the Gumbel copula function. The numbers on the contour lines indicate the compound return period. (d) Spatial distribution of changes in July mean TMX anomaly $\left({ }^{\circ} \mathrm{C}\right)$ and heat wave duration (\%), relative to the average for each individual station during the baseline of 196I-90.

2013). Two categories were assessed: anthropogenic variations in GHG and natural forcing (Fig. 19.2b). Uncertainty ranges (5-95\%) for the scaling factors were evaluated via Monte Carlo simulations. If the scaling factor for a forcing simulation was significantly greater than zero, then the influence of that forcing on the variable (i.e., July TMX) is detected (Zhang et al. 2013).

4) To analyze the attributable risk, we employed the conventional fraction of attributable risk (FAR $=$ $\left.1-P_{\text {nat }} / P_{\text {all }}\right)$ method (Stone and Allen 2005; Stott et al. 2015). We compared the probability of the observed 2015 July mean TMX anomaly occurring in the all forcing $\left(P_{\text {all }}\right)$ and natural forcing $\left(P_{\text {nat }}\right)$ simulations to ascertain the contribution of anthropogenic climate change. Bootstrapping (with replacement) was performed 1000 times per period to estimate the FAR uncertainty (Fig. 19.2c).

5) To test causality, we applied Granger causality analysis (GCA; Granger 1969). We examined the impact of the El Niño-Southern Oscillation (ENSO) on the monthly mean TMX during the period of 19612015 (Supplemental Fig. S19.1). The fundamental concept in GCA is that if the prediction of $X$ (monthly mean TMX) is improved by including $Y$ (here, the monthly ENSO index) as a predictor, then $Y$ is said to be Granger causal for $X$ (significance determined by $F$-test; $p<0.05$; Sun et al. 2016). In addition, a contour map for the South Asia high (SAH) was generated to explore its coincidence with the heat events.

Results. A. Observed 2015 July TMX in historical context. Figure 19.1a shows that the July mean TMX in 2015 $\left(32.76^{\circ} \mathrm{C}\right)$ was the highest during the past 55 years and was $2.87^{\circ} \mathrm{C}$ higher than the mean TMX during the baseline period (1961-90). The gray and red lines in the embedded figure in Fig. 19.1b correspond to July mean TMX anomaly during 1961-2014 and in 2015, respectively, relative to the baseline period. The K-S test shows that the GEV distribution was not rejected at $p<0.05$ level. The 2015 July heat was close to a 1-in-166-year event. Because only 55 years of observed 
(a)
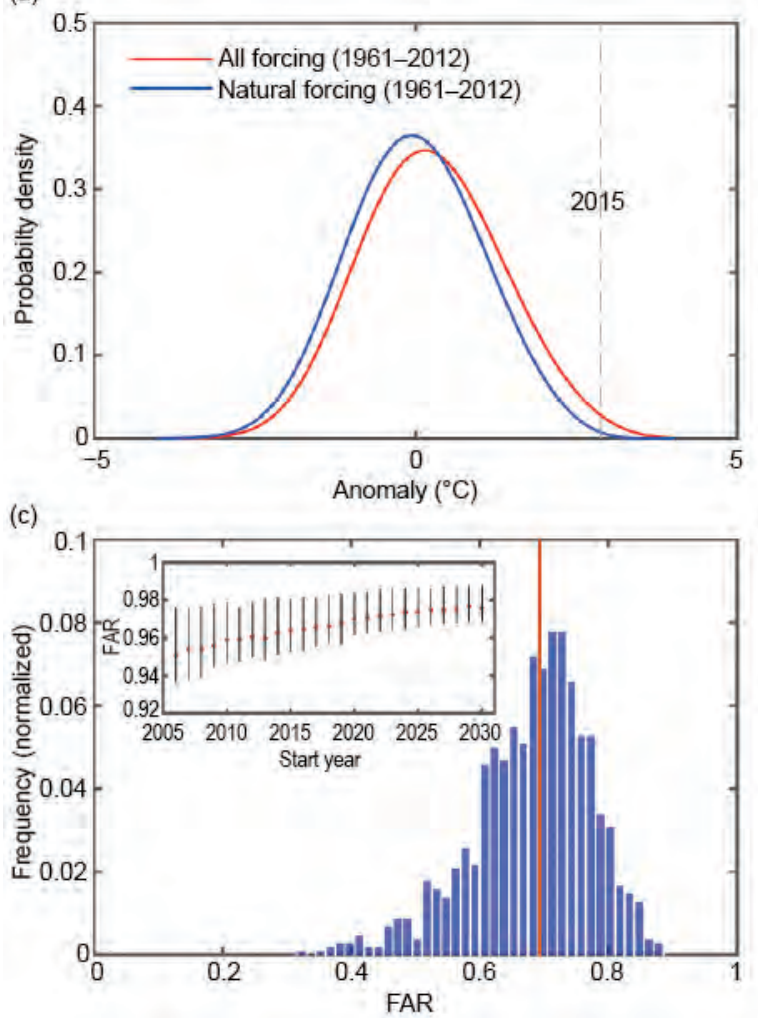

(b)

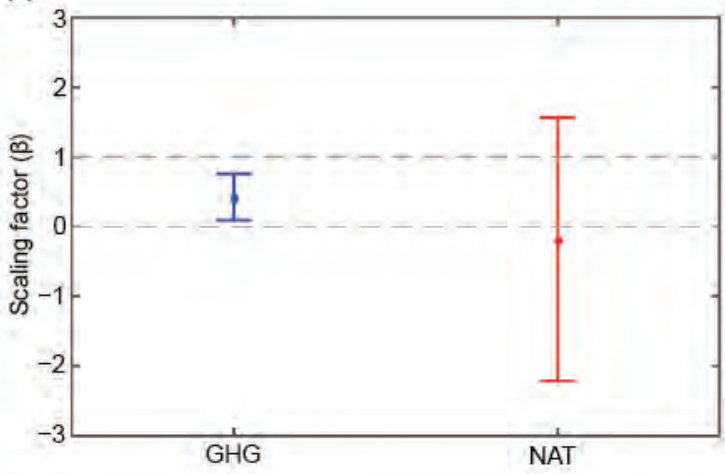

(d)

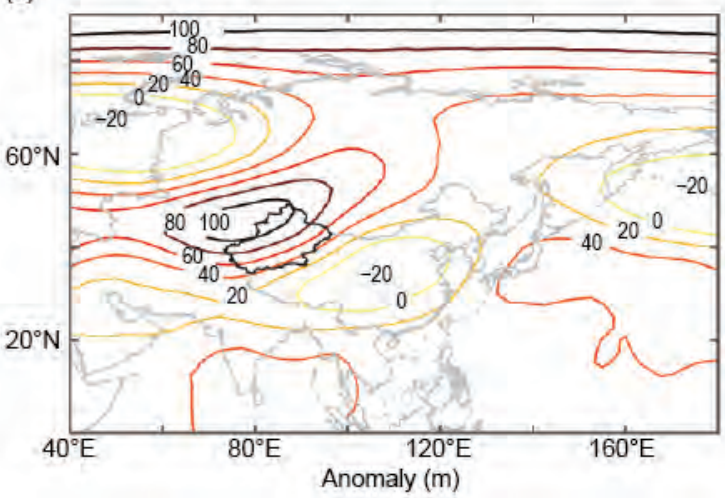

FIG. 19.2. (a) PDFs for Jul mean TMX anomaly (relative to 196I-90) for the all forcing (red) and natural forcing (blue) simulations; (b) Attribution analysis based on the TMX time series under different forcing conditions, (c) PDFs for estimated FAR focused on all forcing (196I-2015) and natural forcing (196I-20I2). The blue histogram was generated by bootstrap resampling; the red line is the median. The embedded figure shows estimated FAR results (median and 25th-75th percentiles) from the all forcing simulation for different 30-year periods against the natural forcing simulation for 196I-20I2. The $x$-axis indicates the starting year of the 30-year moving window. (d) The geopotential height anomaly field (m) for Jul 2015 at $100 \mathrm{hPa}$ (baseline period: 1980-2009) estimated with the NCEP-DOE Reanalysis 2 datasets.

data were used, the 166-year return period can be considered as a lower bound. The blue and red dots in Fig. 19.1c indicate the return periods for concurrent July mean TMX and heat wave duration during the period 1961-2014 and in 2015. The July 2015 concurrency was a 1-in-200-year event. We also found that the most severe changes from baseline in 2015 July mean TMX and heatwave duration were mainly in the middle and northeastern areas of Xinjiang. The heat wave duration was approximately double that of the baseline period (Fig. 19.1d).

Results. B. Analysis of the attributable risk. We compared the likelihood of the July mean TMX anomaly occurring in different CMIP5 experiments (Fig. 19.2a). When anthropogenic forcing was included, the probability density function (PDF) shifted to the right, indicating an increased likelihood of high temperatures. The scaling factor for the GHG-forcing simulation, estimated by the regularized optimal fingerprinting method, was 0.41 [ $90 \%$ confidence interval (CI): 0.09-0.76; Fig. 19.2b], suggesting that the changes in area-averaged July mean TMX were responsive to the anthropogenic greenhouse-gases forcing. It was estimated that all PDFs assumed a GEV distribution. When the 2015 July mean TMX anomaly $\left(2.87^{\circ} \mathrm{C}\right)$ was marked as the threshold, the equivalent FAR value was 0.68 (90\% CI: 0.51-0.81; Fig. $19.2 \mathrm{c}$ ), indicating that $68 \%$ of the risk of such event is attributed to anthropogenic climate change. This translates to about three-fold (90\% CI: 2.04-5.32) increase in the probability of 2015 July mean TMX anomaly occurring due to anthropogenic influence. The RCP4.5 experiments indicated that the risk from human-induced climate change increases with time, while uncertainty reduces with time (Fig. 19.2c, embedded figure). We also attempted to find other factors that contributed to the extremely high TMX 
in July 2015. The 2015 ENSO was one of the strongest since 1960. GCA showed that there was no significant ( $p=0.35$ ) causal relationship between area-averaged mean TMX and ENSO index (Supplemental Fig. S19.1a). However, for 10 stations in central Xinjiang, significant causal relationship $(p<0.05)$ was detected between TMX changes and ENSO (Supplemental Fig. S19.1b). The extreme heat events in July 2015 might be also related to the movement of the South Asia high (SAH), which is the most intense and persistent anticyclone system in the upper troposphere and lower stratosphere over southern Asia during boreal summer (Mason and Anderson 1963). Less precipitation and heat events usually occur in the region where the SAH moves in (Chen et al. 2011). According to the geopotential height anomaly field in July 2015 at 100 $\mathrm{hPa}$, the SAH center moved northward (Fig. 19.2d) and dominated the weather of the entire Xinjiang region, coinciding with the extreme heat events in northwest China.

Conclusions. Our analysis of July TMX records over the last 55 years indicates that the record-breaking heat observed over Northwest China in 2015 was at least a 1-in-166-year event. The return period increased to $\sim 200$ years if heat wave duration was also taken into account. CMIP5-based FAR analyses suggest that anthropogenic climate change increased the likelihood of such an extreme event by three-fold. The extreme heat event is related to the ENSO and SAH. This study is an important step toward a comprehensive understanding of the record-breaking 2015 heat in Xinjiang.

ACKNOWLEDGEMENTS. This research was supported by the National Natural Science Foundation of China (No. 41622101; No. 91547118), and the State Key Laboratory of Earth Surface Processes and Resource Ecology. We acknowledge the World Climate Research Programme's Working Group on Coupled Modeling, which is responsible for CMIP. We also express thanks to the National Meteorological Information Center of the China Meteorological Administration for archiving the observed climate data.

\section{REFERENCES}

Akaike, H., 1974: A new look to the statistical model identification. IEEE Trans. Autom. Control, 19, 716723.
Chen, L., S. G. Wang, K. Z. Shang, and D. B. Yang, 2011: Atmospheric circulation anomalies of largescale extreme high temperature events in northwest china. J. Desert Res., 31, 1052-1058.

Granger, C. W. J., 1969: Investigating causal relations by econometric models and cross-spectral methods. Econometrica, 37, 424-438.

Liu, X. M., and Q. X. Li, 2003: Research of the inhomogeneity test of climatological data series in China. Acta Meteor. Sin., 17, 492-502.

Mason R. B., and C. E. Anderson, 1963: The development and decay of the $100 \mathrm{mb}$ summertime anticyclone over southern Asia. Mon. Wea. Rev., 91, 3-12.

Mazdiyasni, O., and A. AghaKouchak, 2015: Substantial increase in concurrent droughts and heatwaves in the United States. Proc. Natl. Acad. Sci. USA, 112, 11484-11489, doi:10.1073/pnas.1422945112.

Meehl, G. A., and C. Tebaldi, 2004: More intense, more frequent, and longer lasting heat waves in the 21st century. Science, 305, 994-997.

Nelsen, R. B., 2007: An Introduction to Copulas. Springer, 269 pp.

Ribes, A., S. Planton, and L. Terray, 2013: Application of regularised optimal fingerprinting to attribution. Part I: Method, properties and idealised analysis. Climate Dyn., 41, 2817-2836, doi:10.1007/s00382 -013-1735-7.

Stone, D. A., and M. R. Allen, 2005: The end-to-end attribution problem: From emissions to impacts. Climatic Change, 71, 303-318, doi:10.1007/s10584 -005-6778-2.

Stott, P. A., 2015: Weather risks in a warming world. Nat. Climate Change, 5, 517-518, doi:10.1038 /nclimate2640.

Sun, Q., C. Miao, A. AghaKouchak, and Q. Duan, 2016: Century-scale causal relationships between global dry/wet conditions and the state of the Pacific and Atlantic Oceans. Geophys. Res. Lett., 43, 6528-6537, doi:10.1002/2016GL069628.

Sun, Y., X. Zhang, F. W. Zwiers, L. Song, H. Wan, T. Hu, H. Yin, and G. Ren, 2014: Rapid increase in the risk of extreme summer heat in Eastern China. Nat. Climate Change, 4, 1082-1085, doi:10.1038 Inclimate2410.

Taylor, K. E., R. J. Stouffer, and G. A. Meehl, 2012: An overview of CMIP5 and the experimental design. Bull. Amer. Meteor. Soc., 95, 485-498, doi:10.1175 /BAMS-D-00094.1.

Wilks, D. S., 2006: Statistical Methods in the Atmospheric Sciences. International Geophysics Series, Vol. 91, Elsevier Academic Press, 627 pp. 
Zhang, X. B., H. Wan, F. W. Zwiers, G. C. Hegerl, and S. K. Min, 2013: Attributing intensification of precipitation extremes to human influence. Geophys. Res. Lett., 40, 5252-5257, doi:10.1002/grl.51010.

Zhou, T. J., S. M. Ma, and L. W. Zou, 2014: Understanding a hot summer in central Eastern China: Summer 2013 in context of multimodel trend analysis [in "Explaining Extreme Events of 2013 from a Climate Perspective”]. Bull. Amer. Meteor. Soc., 95 (9), S54S57. 


\title{
20. HUMAN INFLUENCE ON THE 2015 EXTREME HIGH TEMPERATURE EVENTS IN WESTERN CHINA
}

\author{
Ying Sun, Lianchun Song, Hong Yin, Xuebin Zhang, Peter Stott, Botao Zhou, and Ting Hu
}

Human influence has very likely increased the probability of occurrence of the 2015 western China extreme summer temperature events by at least 3-fold and 42-fold for the highest daily maximum and minimum temperatures, respectively.

Introduction. The 2015 summer (June-August) was historically the hottest in western China (west of $105^{\circ} \mathrm{E}$ ), setting new records for the regionally averaged seasonal mean temperature, annual maxima of daily maximum (TXx), and daily minimum (TNx) temperatures. Many stations set new record high temperatures as well. During the period of 12 June-10 August, the daily high temperature above $38^{\circ} \mathrm{C}$ covered an area of about $753000 \mathrm{~km}^{2}$, with the highest temperature of $47.7^{\circ} \mathrm{C}$ recorded in Dongkan station $\left(42.83^{\circ} \mathrm{N}, 89.25^{\circ} \mathrm{E}\right)$ of Turpan. The long-lasting extreme high temperature events exerted serious impacts on agriculture and other sectors, resulting in severe heat damage for different crops such as corn, wheat, and fruit trees (CMA 2016).

Data and Methods. The observational data were extracted from the national dataset of homogenized daily temperatures for 1958-2015 with 492 stations in western China (see Fig. 20.1a for a map of station locations) available for the analyses. Even though the station density is poor in some areas, the available station observations represent the region reasonably well because extreme warm events are of fairly large spatial scale. These data were quality controlled and homogenized with RHtest (Xu et al. 2013) by the China National Meteorological Information Center. Two indices representing the hottest day and night temperatures in the summer season, TXx and TNx, were first calculated for individual stations. Regional mean values of TXx and TNx are then computed, with

AFFILIATIONS: Sun- National Climate Center, China Meteorological Administration, and Joint Center for Global Change Studies, Beijing, China; Song, YIN, ZHOU, AND HuNational Climate Center, China Meteorological Administration, Beijing, China; ZHANG - Climate Research Division, Environment and Climate Change Canada, Toronto, Ontario, Canada; StotTMet Office Hadley Centre, Exeter, United Kingdom

DOI:10.1175/BAMS-D-16-0158.I

A supplement to this article is available online (10.1175 /BAMS-D-16-0I58.2) consideration of uneven spatial distribution of the stations, by first averaging available station data within each $5^{\circ} \times 5^{\circ}$ grid box and then taking the averages of the available gridbox values within the region. Based on daily data from climate models participating in the Coupled Model Intercomparison Project Phase 5 (CMIP5; Taylor et al. 2012), the simulated TXx and TNx were used to estimate extreme temperature responses to external anthropogenic and natural forcing (ALL), natural forcing only (NAT), and the internal variability of the climate system. Model data are interpolated onto the same $5^{\circ} \times 5^{\circ}$ grids. Detailed information about observations, model data, and calculations are provided in the online supplemental material.

To estimate the influence of anthropogenic forcing (ANT) on the extreme events, our method involves three steps. 1) We first conduct a formal detection and attribution analysis for regional mean TXx and TNx values for 1958-2012 using an optimal fingerprinting method (Hegerl et al. 1997; Allen and Stott 2003) as implemented in Ribes et al. (2013). This is done by regressing the observations onto one or more modelsimulated responses to external forcings (ALL, ANT, and NAT). We obtain the scaling factors that scale the model-simulated responses to best match the observations. 2) We then multiply the model simulated responses to ALL and NAT with the relevant scaling factors to obtain the ALL and NAT reconstructions. 3) We finally estimate the probability of occurrence for an event as hot as the 2015 summer in the worlds with or without human influence, using a method described in Sun et al. (2014). The world without human influence is represented by adding preindustrial control simulations to the reconstructed 5-year average model responses to NAT forcing in 2007-12. The world with human influence is represented by adding preindustrial control simulations to the reconstructed 5 -year average model response to ALL forcing in 2013-17 that was estimated from simulations from 
(a)

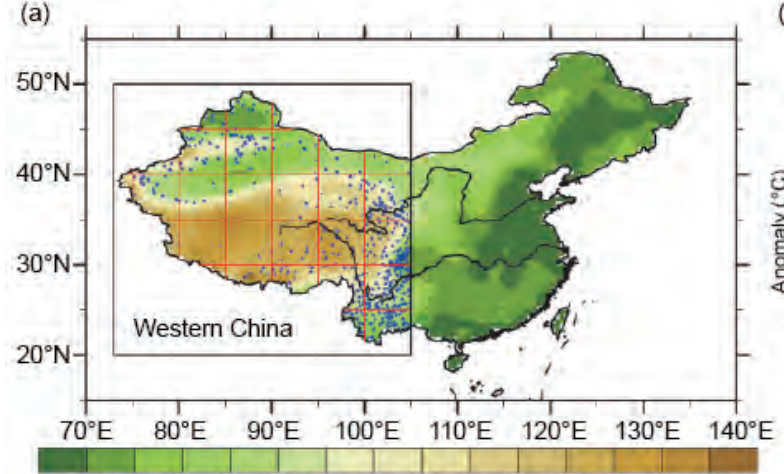

400800120016002000240028003200360040004400480052005600 (c)

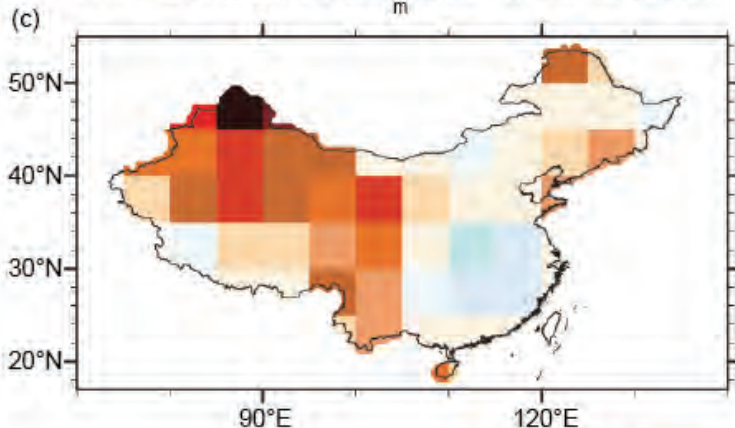

(b)

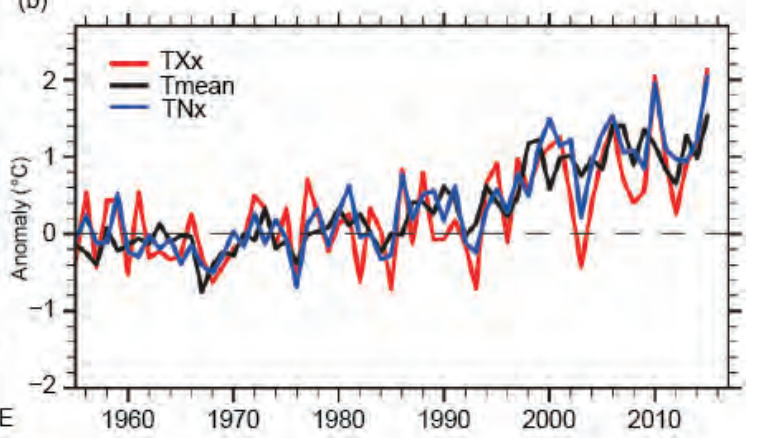

(d)

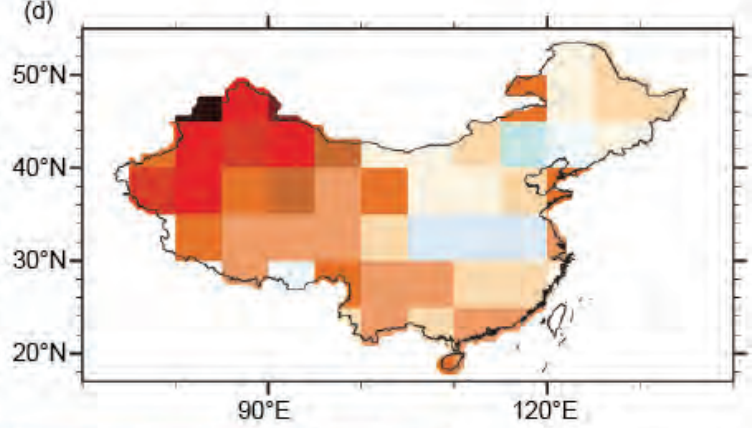

Fig. 20.I. (a) A map of China showing the locations of the observing stations (blue dots) used in the study. The colors show elevation (in meters). (b) Time series of summer mean temperature (black), the maximum daily maximum temperature TXx (red), and the maximum daily minimum temperature TNx (blue) anomalies over western China. (c) Spatial distribution of 2015 summer TXx, and (d) TNx anomalies relative to $1961-90$ average $\left({ }^{\circ} \mathrm{C}\right)$.

RCP 4.5 experiments. The percentage of years with temperatures at or above the 2015 summer temperature in the reconstructed series is considered as the probability for that event to occur in the worlds with or without human influence.

The fraction of attributable risk (FAR; Allen 2003; Stott et al. 2004) and its uncertainty range are estimated using a method described in Song et al. (2015). Because the effect of urbanization is not particularly strong in western China, it is not considered in this study.

Results. The regional averages of the 2015 summer (June-August) mean and the TXx and TNx in western China (west of $105^{\circ} \mathrm{E}$ ) were the highest on record beginning in 1958 , with $1.54^{\circ} \mathrm{C}, 2.14^{\circ} \mathrm{C}$, and $2.06^{\circ} \mathrm{C}$ above their respective 1961-90 averages (Fig. 20.1b). The long-term changes in the mean and the extreme temperatures are very similar, with the linear trends of $0.28^{\circ} \mathrm{C}(10 \mathrm{yr})^{-1}$ for mean temperature, $0.22^{\circ} \mathrm{C}(10$ $\mathrm{yr})^{-1}$ for TXx, and $0.30^{\circ} \mathrm{C}(10 \mathrm{yr})^{-1}$ for TNx during 1958-2012, respectively. Warming continued during the so-called global warming hiatus, consistent with the findings of Seneviratne et al. (2014).

Figures 20.1c,d show the maps of 2015 summer TXx and TNx anomalies in China, respectively. Both the maxima of daily maximum and daily minimum temperatures were very high in western China with positive anomalies almost everywhere in the region. In particular, the anomalies are generally larger than $3^{\circ} \mathrm{C}$ with the maximum above $5^{\circ} \mathrm{C}$ in the region north of $35^{\circ} \mathrm{N}$.

The 5-year mean time series shows that the evolutions of observed TXx and TNx are consistent with the model-simulated responses to ALL forcing but not with that to NAT forcing (Figs. 20.2a,b). Additionally, the $90 \%$ ranges of model-simulated $\mathrm{TNx}$ responses to ALL and NAT forcings do not overlap beyond the year 2000. The model-simulated response to NAT forcing shows small positive values near the end of the period, especially for TXx. This might be a reflection of underestimation of volcanic aerosols used in the CMIP5 simulations for the early twenty-first century as suggested by Santer et al. (2014). An implication is 

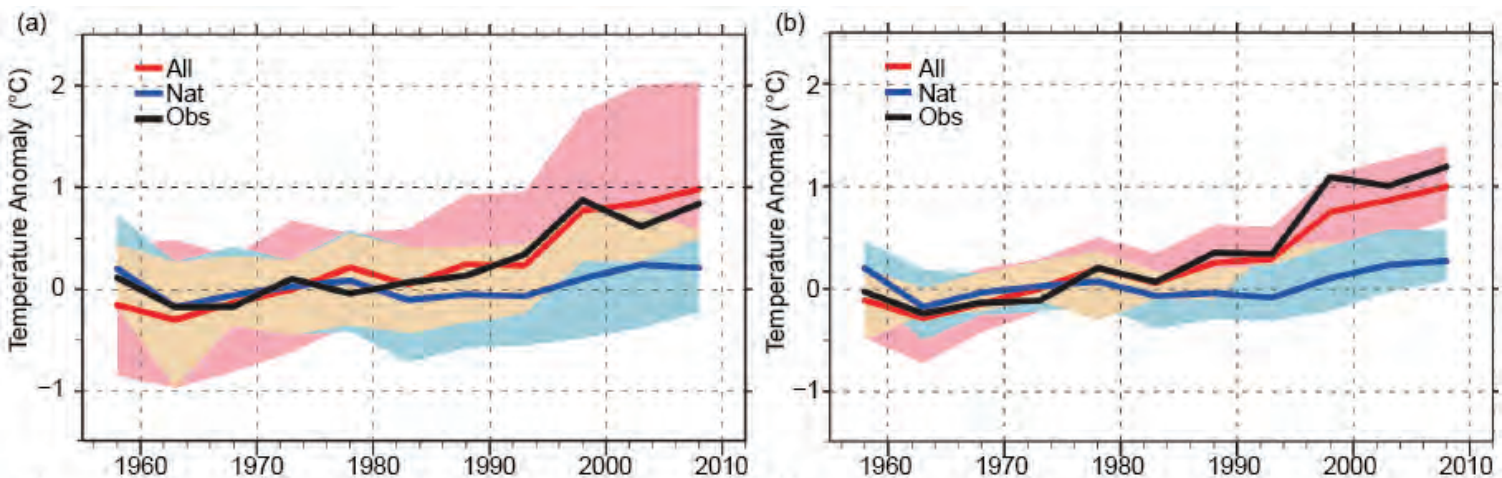

(c)

(d)
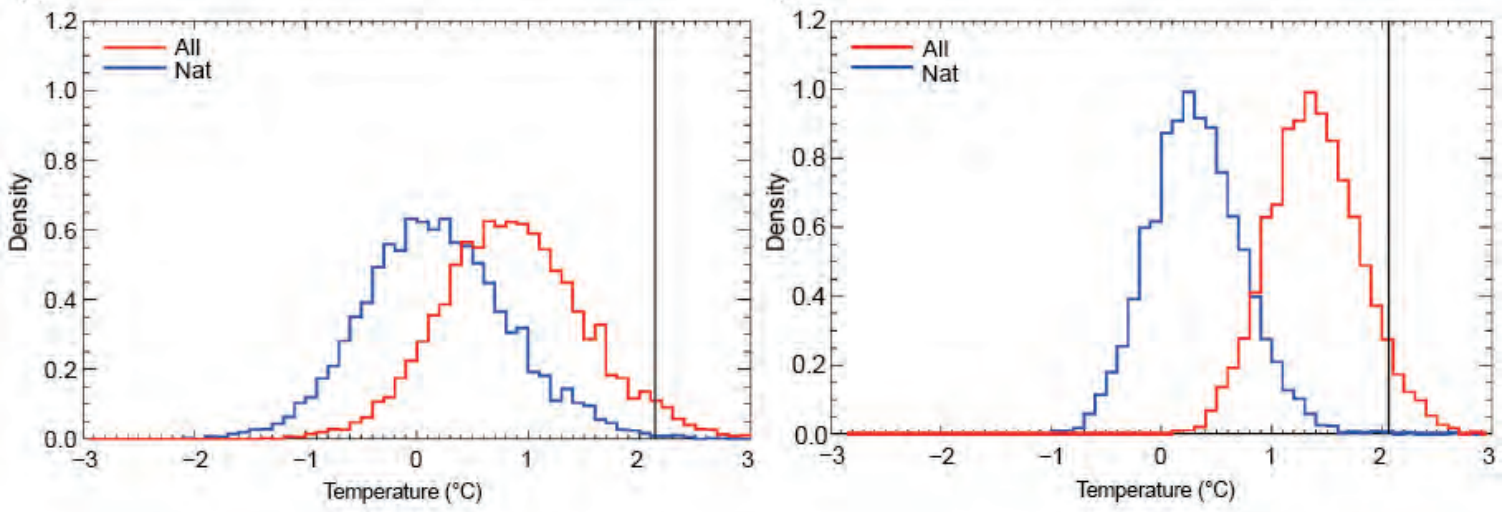

FIG. 20.2. Five-year mean nonoverlapping (a) TXx and (b) TNx anomalies ( ${ }^{\circ} \mathrm{C}$ ) from observations (black) and simulations of multimodel ensembles. The model ensemble averages are represented by red (ALL) and blue (NAT) lines. The blue and pink shadings show the $5 \%-95 \%$ ranges of the ALL and NAT simulations. (c) Probability histograms for the mean summer TXX and (d) TNx anomalies from the best estimates of NAT (blue) and ALL (red) forcing simulations in comparison with the observed values (OBS, vertical black line) in 2015.

that we might have underestimated human influence on the 2015 summer heat.

Our detection and attribution analyses were conducted on nonoverlapping 5-year mean series. We first regress the observations onto ALL and ALL-NAT (ANT) signals separately (one-signal analyses) and then onto ALL and NAT jointly (two-signal analyses). The one-signal analyses show that the ALL and ANT signals can be detected in the extreme temperatures, and there is no evidence to indicate, from residual consistency tests, that the model may have underestimated natural internal variability. The best estimates of scaling factors for ALL are 0.80 (90\% confidence level $0.46-1.14)$ and 1.20 (90\% confidence level 1.00-1.41) for TXx and TNx, consistent with earlier findings (e.g., Zwiers et al. 2011; Kim et al. 2015) for that general region yet over a much larger area.

The two-signal detection results indicate that the ANT signal can be separately detected from the NAT signal for both TXx and TNx, and that the NAT signal can be detected in TNx. The scaling factors for ANT and NAT are 0.78 (90\% confidence level $0.38-1.18$ ) and 0.89 (90\% confidence level $-0.16-1.95)$ for TXx and 1.21 (90\% confidence level 0.96-1.47) and 1.17 (90\% confidence level 0.48-1.87) for TNx, indicating the robustness of detectable human influence on the extreme temperatures. The residual consistency test shows that the model-simulated variability for TXx is consistent with the observed internal variability; however, the model-simulated TNx variability is larger than that of observations. These all suggest that the observed warming in the extreme temperatures are mainly attributable to anthropogenic external forcing rather than natural external forcing.

The 2015 summer TXx was $2.14^{\circ} \mathrm{C}$ higher than the 1961-90 average. The best estimate of temperature response to ALL forcing at the 2015 climate is $0.88^{\circ} \mathrm{C}$ (with a $90 \%$ range of $0.51^{\circ} \mathrm{C}-1.26^{\circ} \mathrm{C}$ ) above the $1961-90$ climatology. This suggests that $1.26^{\circ} \mathrm{C}$ of the TXx anomaly was due to natural internal variability. By calculating the percentage of years with TXx temperature anomalies at or above $2.14^{\circ} \mathrm{C}$ in the reconstructions with ALL forcing and with the NAT forcing, the hot 2015 TXx would be roughly a 
once-in-272-year event (with a 90\% range of 143-572 years) in the natural world, and that it became a oncein-28-year event (with a 90\% range of 12-94 years) under the climate appropriate for the anthropogenicforcing-induced world of 2015 . The probability of the event occurring has increased by almost 10 -fold due to human influence; there is more than a $90 \%$ chance for this increase to be at least 3-fold. The FAR (Stott et al. 2004) can thus be estimated as 0.90 (with a $90 \%$ range of 0.66-0.96).

The 2015 summer $\mathrm{TNx}$ was $2.06^{\circ} \mathrm{C}$ above its 1961-90 average. The best estimate of temperature response to ALL forcing at the 2015 climate is $1.40^{\circ} \mathrm{C}$ (with a $90 \%$ range $1.17^{\circ} \mathrm{C}-1.65^{\circ} \mathrm{C}$ ) above the $1961-90$ climatology. This suggests that $0.66^{\circ} \mathrm{C}$ of the $\mathrm{TNx}$ anomaly was due to natural internal variability. We estimate that the observed extreme warm temperature for 2015 would be a once-in-1430-year event (with a $90 \%$ range of 715-2860 years) in the NAT world, and that it became a once-in-16-year event (with a $90 \%$ range of 6-41 years) under the climate appropriate for the anthropogenic-forcing-induced world of 2015. The probability of the event occurring has increased by almost 89 -fold due to human influence; there is more than $90 \%$ chance for this increase to be at least 42 -fold. The FAR can thus be estimated as 0.99 (with a $90 \%$ range of $0.97-1.00$ ).

Conclusions. We have detected anthropogenic influence on the highest maximum (TXx) and minimum (TNx) temperatures in western China. We found that the record-breaking 2015 summer temperatures are the result of the combination of natural internal variability of the climate system and human emission of greenhouse gases. The natural internal variability may be associated with anomalous anticyclones on a range of time scales, the possible circulation features causing anomalously high temperatures in northwestern China and dryness in the Tibetan Plateau (Chen et al. 2011; Zhu et al. 2011).

We noted a much larger FAR for TNx than for TXx. This may come about for the following reason: the smaller variance in $\mathrm{TNx}$ would mean a larger change in the probability for a similar magnitude of temperature increase when compared with TXx. We also noted that the models may have slightly overestimated natural variability in the region. An implication of this is that our calculated changes in probability (and consequently the FAR) may be underestimated.
ACKNOWLEDGEMENTS. We appreciate comments by anonymous reviews as well as the editors. The work of Sun, Song, Yin, and Zhou is supported by China funding agencies through multiple grants: GYHY201406020, 2012CB417205, and 2012CB955900. Stott was supported by the UK-China Research and Innovation Partnership Fund through the Met Office Climate Science for Service Partnership (CSSP) China as part of the Newton Fund, the EUCLEIA project funded by the European Union's Seventh Framework Programme [FP7/2007-13] under Grant Agreement No. 607085, and by the Joint UK BEIS/Defra Met Office Hadley Centre Climate Programme (GA01101).

\section{REFERENCES}

Allen, M. R., 2003: Liability for climate change. Nature, 421, 891-892, doi:10.1038/421891a.

_ in optimal fingerprinting. Part I: Theory. Climate Dyn., 21, 477-491.

Chen, L., S.-G. Wang, K.-Z. Shang, and D-B. Yang, 2011: Atmospheric circulation anomalies of largescale extreme high temperature events in Northwest China. J. Desert Res., 31, 1052-1058.

CMA, 2016: China Climate Bulletin 2015. China Meteorological Administration, $50 \mathrm{pp}$.

Hegerl, G. C., and Coauthors, 1997: Multi-fingerprint detection and attribution of greenhouse-gas and aerosol-forced climate change. Climate Dyn., 13, 613-634.

Kim, Y.-H., S.-K. Min, X. Zhang, F. Zwiers, L. V. Alexander, M. G. Donat, and Y.-S. Tung, 2015: Attribution of extreme temperature changes during 1951-2010. Climate Dyn., 46, 1769-1782, doi:10.1007 /s00382-015-2674-2.

Ribes, A., S. Planton, and L. Terray, 2013: Application of regularised optimal fingerprinting to attribution. Part I: method, properties and idealised analysis. Climate Dyn., 41, 2817-2836, doi:10.1007/s00382 -013-1735-7.

Santer, B. D., and Coauthors, 2014: Volcanic contribution to decadal changes in tropospheric temperature. Nat. Geosci., 2, 185-189, doi:10.1038/ngeo2098. Seneviratne, S. I., M. G. Donat, B. Mueller, L. V. Alexander, 2014: No pause in the increase of hot temperature extremes. Nat. Climate Change, 4, 161163, doi:10.1038/nclimate2145. 
Song, L., Y. Sun, S. Dong, B. Zhou, P. A. Stott, and G. Ren, 2015: Role of anthropogenic forcing in 2014 hot spring in Northern China [in "Explaining Extreme Events of 2014 from a Climate Perspective"]. Bull. Amer. Meteor. Soc., 96 (12), S111-S115, doi:10.1175 /BAMS-D-15-00111.1.

Stott, P., D. A. Stone, and M. R. Allen, 2004: Human contribution to the European heatwave of 2003 . Nature, 432, 610-613.

Sun, Y., X. Zhang, F. W. Zwiers, L. Song, H. Wan, T. Hu, H. Yin, and G. Ren, 2014: Rapid increase in the risk of extreme summer heat in Eastern China. Nat. Climate Change, 4, 1082-1085, doi:10.1038 /nclimate2410.

Taylor, K. E., R. J. Stouffer, and G. A. Meehl, 2012: An overview of CMIP5 and the experiment design. Bull. Amer. Meteor. Soc., 93, 485-498, doi:10.1175/BAMS -D-11-00094.1.

$\mathrm{Xu}$, W.-H., Q. Li, X. L. Wang, S. Yang, L. Cao, and Y. Feng, 2013: Homogenization of Chinese daily surface air temperatures and analysis of trends in the extreme temperature indices. J. Geophys. Res. Atmos., 118, 9708-9720, doi:10.1002/jgrd.50791.

Zhu, X. H., O. Bothe, and K. Fraedrich, 2011: Summer atmospheric bridging between Europe and East Asia: Influences on drought and wetness on the Tibetan Plateau. Quat. Intl., 236, 151-157, doi:10.1016/j .quaint.2010.06.015.

Zwiers, F. W., X. B. Zhang, and Y. Feng, 2011: Anthropogenic influence on long return period daily temperature extremes at regional scales. J. Climate, 24, 296-307, doi:10.1175/2010JCLI3908.1. 


\title{
2I. A PERSISTENT JAPANESE HEAT WAVE IN EARLY AUGUST 2015: ROLES OF NATURAL VARIABILITY AND HUMAN-INDUCED WARMING
}

\author{
The persistent Japanese heat wave that occurred in early August 2015 was mainly attributed to \\ intraseasonal disturbances including tropical cyclones. Anthropogenic warming contributed to an increase \\ in the probability of occurrence.
}

\section{Chimaru Takahashi, Masahiro Watanabe, Hideo Shiogama, Yukiko Imada, and Masato Mori}

Introduction. A prolonged heat wave hit Japan in early August 2015. Daily maximum surface air temperature (SAT) exceeded $35^{\circ} \mathrm{C}$ for eight consecutive days and the 8-day mean anomaly was greater than $4^{\circ} \mathrm{C}$ at several observation sites, causing over 10000 people to suffer from heatstroke. This heat wave was particularly unusual because an ongoing extreme El Niño of 2015 was expected to lead to a cooler summer in Japan.

A primary cause of this heat wave was an intraseasonal tropical disturbance (Fig. 21.1). A tropical cyclone (TC), TC1513, was generated in the western North Pacific (WNP) during the convectively active phase of the intraseasonal oscillation (ISO) in the western Pacific (Fig. 21.1c and Supplemental Fig. S21.3c), followed by another TC (TC1514). Li and Zhou (2013) demonstrated that the two major components of the ISO, the 30-60 day Madden-Julian oscillation (MJO, Madden and Julian 1971) and the 10-20 day quasi-biweekly oscillation (QBWO, Chen and Sui 2010) can affect the genesis and intensity of TCs in the WNP during the summer. It appears that the TCs in this study likewise formed in association with the ISO.

The diabatic heating associated with the TCrelated precipitation induced a Rossby wave train, which is characterized by cyclonic circulation and anticyclonic circulation anomalies in the WNP and

AFFILIATIONS: TAKAHASHI AND WATANABE-Atmosphere and Ocean Research Institute, University of Tokyo, Chiba, Japan; SHIOGAMA-Center for Global Environmental Research, National Institute for Environmental Studies, Tsukuba, Japan; IMADA-Meteorological Research Institute, Tsukuba, Japan; MORIResearch Center for Advanced Science and Technology, University of Tokyo, Tokyo, Japan

DOI:10.II75/BAMS-D-16-0157.I

A supplement to this article is available online ( 10.1175 /BAMS-D-16-0157.2)
East Asia, respectively (Figs. 21.1b,d). This pattern is similar to the so-called Pacific-Japan (PJ) teleconnection pattern (Nitta 1987; Wakabayashi and Kawamura 2004) in July and August, accompanying a meridional tripolar pattern in precipitation, vorticity, and temperature anomalies (Supplemental Fig. S21.1a). Several studies have also reported that TCs can generate the PJ pattern over the WNP (Kawamura and Ogasawara 2006; Yamada and Kawamura 2007). In early August 2015, the positive PJ pattern gave rise to the abnormally persistent hot and dry days over Japan.

The El Niño conditions climatologically had a cooling impact on Japan in July-August (Supplemental Fig. S21.1a), yet the 2015 summer was still unexpectedly hot (Supplemental Fig. S21.1b). Anthropogenic warming can change the likelihood of specific extreme events, although the odds of an event occurring may vary from year to year depending on the regional sea surface temperature (SST) pattern (Christidis and Stott 2014). In this study, we investigate the possible influences of the intraseasonal variability, the 2015 strong El Niño, and anthropogenic warming on the Japanese heat wave in August 2015 using an atmospheric general circulation model (AGCM).

Methods. We performed four 100-member ensemble experiments using the Model for Interdisciplinary Research on Climate, version 5 (MIROC5), AGCM with a horizontal resolution of $150 \mathrm{~km}$ (Watanabe et al. 2010). Each of the four experiments used different initial conditions during January-October 2015: 1) ALL: Experiments designed to simulate the current observed world, forced by the observed historical SST and sea ice (SIC) derived from the HadISST dataset (Rayner et al. 2003) and historical anthropogenic and natural radiative forcing agents; 2) NAT1: Forced by natural forcing agents and historical SST and SIC 

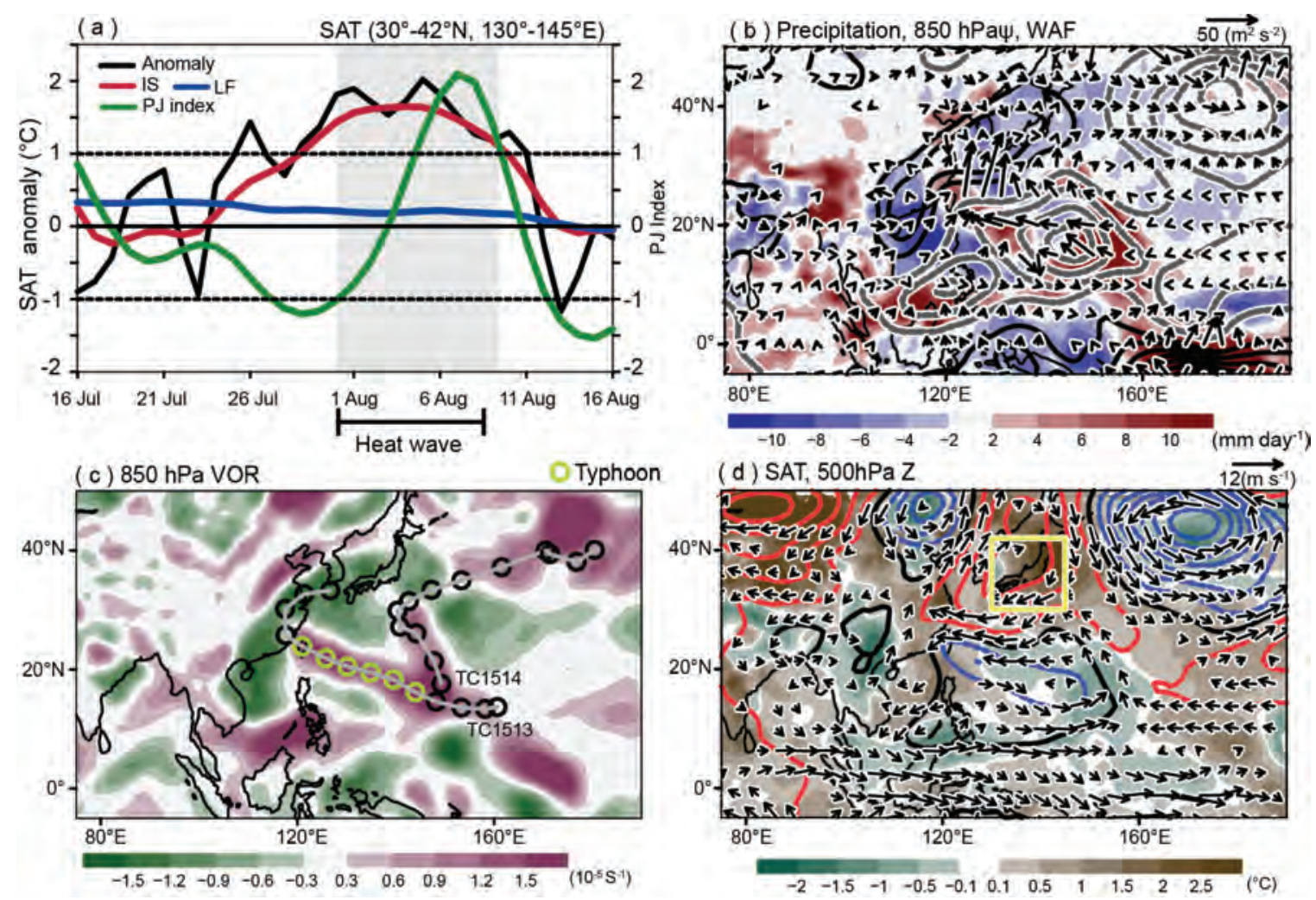

FIG. 2I.I. (a) Time series of observed SAT anomalies over Japan $\left(30^{\circ}-42^{\circ} \mathrm{N}, 130^{\circ}-145^{\circ} \mathrm{E}\right.$, land area only, daily anomaly in black, IS in red, and LF in blue) and normalized PJ index in green from 16 July to 16 Aug 2015. The shading indicates the analysis period (10-day from $31 \mathrm{Jul}$ to 9 Aug) including the heat wave event. (b)-(d) Observed patterns of the 10-day mean anomalies in (b) precipitation (shading), 850 -hPa stream function (contours, $10^{6} \mathrm{~m}^{2} \mathrm{~s}^{-1}$ interval), and $850-\mathrm{hPa}$ wave activity fluxes (vectors); (c) 850-hPa vorticity, on which 2 TC tracks (green and black circles) are superimposed; and (d) SAT (shading), 500-hPa geopotential height (contours, 10-m interval), and 500-hPa winds (vectors). The dashed contours indicate negative anomalies.

excluding anthropogenic forcings by subtracting the long-term 1870-2012 linear trends in SST from the HadISST dataset (Christidis and Stott 2014); 3) NAT2: Similar to NAT1, but forced by SST/SIC excluding anthropogenic forcings by subtracting SSTs estimated using the Coupled Model Intercomparison Project Phase 5 (CMIP5) attribution experiments (Stone 2013); 4) ALLnoENSO: Same as ALL but the SST anomaly that regressed onto the Niño-3.4 SST anomaly was removed in order to eliminate the influence of the extreme El Niño in 2015. The above experiments except for ALLnoENSO were designed by Shiogama et al. $(2013,2014)$ and updated from the previous runs (Imada et al. 2014). We also performed a 10-member long-term ALL experiment, called ALLLNG, for 1949-2014, to define the model climatology and evaluate the simulated interannual variability (Supplemental Fig. S21.2). We use the daily JRA-55 Reanalysis dataset (Onogi et al. 2007; Kobayashi et al. 2015) and Global Precipitation Climate Project (GPCP v1.2; Huffman et al. 2001). The TC data was obtained from the best-track of TC provided by the TokyoTyphoon Center, Japan Meteorological Agency.

We analyze daily anomalies of all related variables from the daily climatology for 1981-2010. Bandpass (10-60 day) and low pass (60 day) filters are applied to daily anomaly fields in order to extract the intraseasonal (IS) and low frequency (LF) components of natural variability. The IS component is mainly associated with the PJ pattern that links to TCs, and the LF part is related to seasonal variability including the influence of the 2015 El Niño. The SAT anomaly in Japan was largely dominated by the IS component in mid-July to mid-August (Fig. 21.1a). To examine the variability of the intraseasonal PJ pattern, the empirical orthogonal function (EOF) analysis is performed to intraseasonal $850-\mathrm{hPa}$ vorticity anomalies in the domain of $10^{\circ}-50^{\circ} \mathrm{N}, 110^{\circ}-170^{\circ} \mathrm{E}$ in July and August for 1981-2015 in the observation and for 2015 in the ALL ensemble. The intraseasonal PJ index is defined 
as the principal component associated with the leading EOF that accounts for $8.3 \%$ of the total variance in the observation. The observed intraseasonal PJ index exceeded 1 standard deviation $(\sigma)$ in the period of the heat wave in 2015 (Fig. 21.1a). We mainly analyze the 10-day period from 31 July to 9 August 2015 to cover the extreme heat event (Fig. 21.1a).

Results. The PJ pattern simulated in the ALL 100-member ensemble corresponds well with the observational pattern (Supplemental Figs. S21.3.a,b). A few ensemble members in ALL had SAT anomalies over Japan equal to or higher than the observation (extreme warm members) and well represent the positive PJ patterns induced by northwestward-propagating TC-like disturbance as in the observations (Supplemental Figs. S21.3d-f). Apart from the PJ pattern originating from TCs, an upper-tropospheric wave train also appears in the observation (Supplemental Fig. S21.3g). Ogasawara and Kawamura (2007) suggest that a combined effect of the PJ pattern and other teleconnection patterns propagating from the west may cause extraordinary summer weather. However, the extreme warm members in the ALL experiment do not exhibit a clear upper-level wave train (Supplemental Fig. S21.3h), suggesting that the PJ pattern played the key role in the occurrence of the 2015 extreme heat.

The simulated SAT anomalies $(T)$ are decomposed into IS $\left(T_{\mathrm{IS}}\right)$ and LF $\left(T_{\mathrm{LF}}\right)$ components for the 10-day period that includes the heat wave. The observed total and IS SAT anomalies are $1.7^{\circ} \mathrm{C}$ and $1.4^{\circ} \mathrm{C}$ averaged over Japan's land area $\left(30^{\circ}-42^{\circ} \mathrm{N}, 130^{\circ}-145^{\circ} \mathrm{E}\right)$, respectively, indicating that the IS component mostly explains the total SAT anomaly (Fig. 21.2a). The relative contributions of anthropogenic forcing and $\mathrm{El}$ Niño to the 2015 extreme heat wave are evaluated. The occurrence probability of an extreme warm event that exceeds or is equal to the observed SAT anomaly is estimated using the probability density function (PDFs) based on the assumption of a Gaussian distribution in each run. The best estimates (50th percentile) and uncertainties (the 5\%-95\% range) of the probabilities are estimated through random resampling. The best estimate in occurrence probability (the 5\%-95\% uncertainty range) of the 2015 extreme event is $2.8 \%$ $(1.2 \%-4.7 \%)$ for ALL, $1.8 \%(0.7 \%-3.4 \%)$ for NAT1, $1.6 \%(0.6 \%-2.8 \%)$ for NAT2, and $4.5 \%(2.2 \%-7.0 \%)$ for ALLnoENSO (Fig. 21.2c). The results suggest that the anthropogenic warming contributed to increase the probability of the 2015 heat wave by 1.5 to 1.7 times (5\%-95\% range: $0.6-5.0$ ), while the El Niño condition acted to counteract the anthropogenic warming effect and decrease the probability by 0.6 times (5\%-95\% range: $0.2-1.5$ ).

We also investigate why the low-frequency SAT in Japan during the 2015 heat wave unexpectedly exhibits positive anomalies (Fig. 21.1a) in spite of the strong El Niño year. The influences of anthropogenic forcing and El Niño on $T_{\mathrm{LF}}$ can be estimated from the difference between ALL and NAT ( $T_{\mathrm{GW}_{1}}$ and $T_{\mathrm{GW}_{2}}$ ), and ALL and ALLnoENSO ( $T_{\text {ENSO }}$ ), respectively (Fig. 21.2b). The ensemble mean of $T_{\mathrm{LF}}$ in ALL is approximately consistent with that in observation (Figs. 21.2a,d). The ensemble mean with $1 \sigma$ is $0.60^{\circ} \mathrm{C} \pm 0.42^{\circ} \mathrm{C}$ for $T_{\mathrm{GW} 1}, 0.44^{\circ} \mathrm{C} \pm 0.46^{\circ} \mathrm{C}$ for $T_{\mathrm{GW} 2}$, and $-0.24^{\circ} \mathrm{C} \pm 0.44^{\circ} \mathrm{C}$ for $T_{\text {ENSo. }}$ In observation, the SAT anomaly in Japan is $-0.19^{\circ} \mathrm{C} \pm 0.31^{\circ} \mathrm{C}$ for the warm phase of the ENSO, when Niño-3.4 SST anomaly is greater than $0.7 \sigma$ in July-August for 1958-2014. These results indicate that the $2015 \mathrm{El}$ Niño $\left(T_{\mathrm{ENSO}}\right)$ has a cooling impact on temperatures in Japan comparable to that of the climatology for other El Niño years and suggest that the impact of anthropogenic warming overcomes the cooling effect by the El Niño. However, an individual atmospheric response to SST variability in the tropics has large variation for the observation and the simulation. The best estimate (the 5\%-95\% range) of the probability exceeding the observed anomaly $\left(0.20^{\circ} \mathrm{C}\right)$ for $T_{\mathrm{LF}}$ by similar resampling is $48.6 \%(43.0 \%-54.7 \%)$ for ALL, 8.3\% (5.3\%-12.2\%) for NAT1, 18.3\% (13.7\%$22.8 \%)$ for NAT2, and $69.5 \%(64.7 \%-74.8 \%)$ for ALLnoENSO (Fig. 21.2d). This result also suggests that anthropogenic forcing caused a significant increase in the probability of a seasonally warm 2015 summer in Japan, while the El Niño decreased it.

As LF components are better captured by the ALL ensemble, we focused on the anthropogenic and El Niño contributions to $T_{\mathrm{LF}}$ over a wider region. In observations, positive $T_{\mathrm{LF}}$ anomalies over Japan are accompanied by anticyclonic circulation anomalies, which may be part of a wave train emanating from the subtropical WNP through the North Pacific to the west coast of North America that appears to be a seasonally generated positive PJ pattern (Fig. 21.2e). The changes in the atmospheric circulation owing to anthropogenic warming and El Niño, represented by $T_{\mathrm{GW} 2}$ and $T_{\mathrm{ENSO}}$, show a different structure (Figs. $21.2 \mathrm{~g}, \mathrm{~h}$ ). The change in atmospheric temperature as a result of anthropogenic global warming simulated by climate models shows strong warming over the polar region in the lower- to mid-troposphere (e.g., Simpson et al. 2014). This change indicates that the midlatitude 

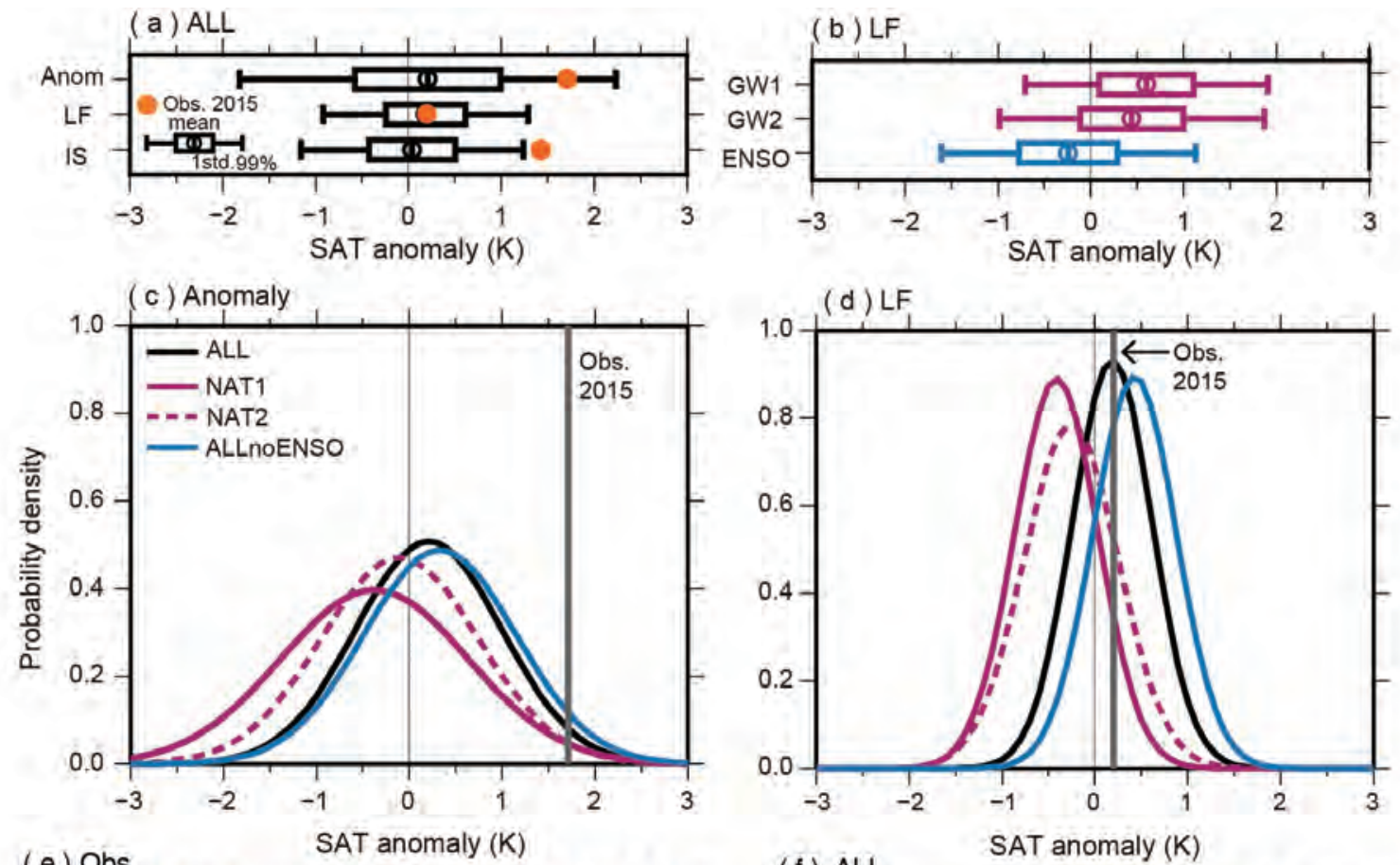

(e) Obs

(f) ALL

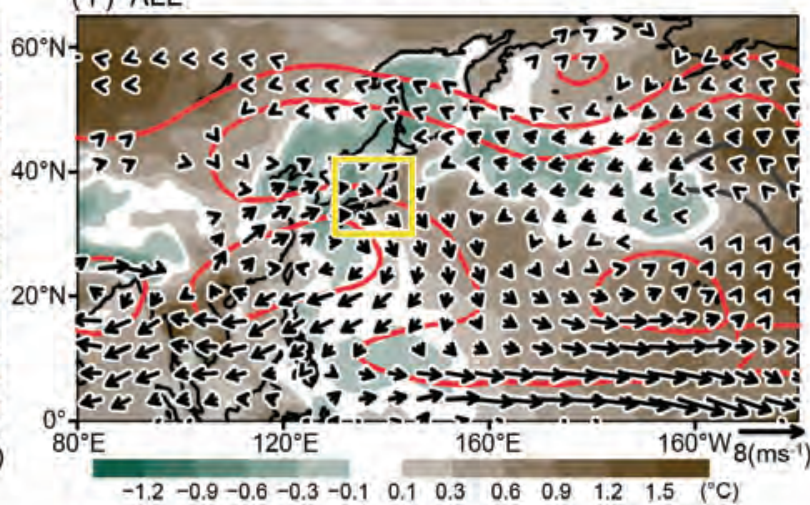

(h) ENSO (ALL-ALLnOENSO)

(g) GW2 (ALL-NAT2)
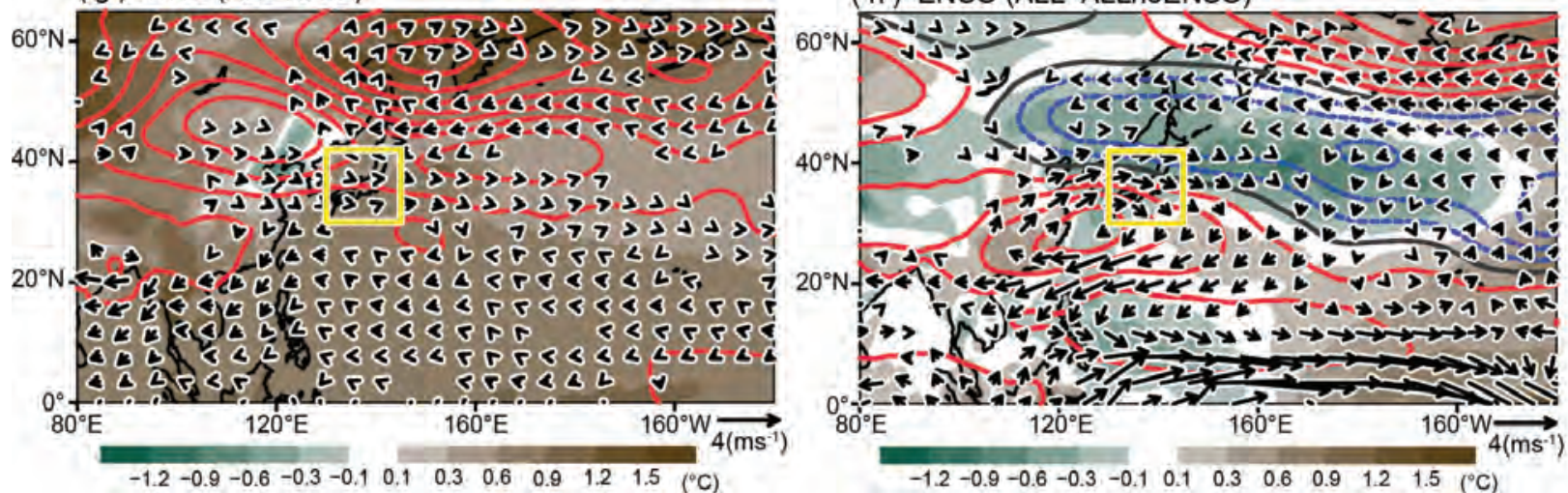

FIG. 2I.2. (a) Box-and-whisker plots of I0-day average SAT anomalies over the Japan land area [boxes in (e),(f)] in 2015 event. Daily anomalies, LF, and IS components in ALL are compared with observations (orange circles). (b) As in (a) but contributions of global warming and ENSO to LF in ALL. GWI, GW2, and ENSO represent the differences of SAT anomalies between ALL and NATI, NAT2, and ALLnoENSO, respectively. (c)-(d) PDFs of the 10-day averaged SAT over Japan for (c) daily anomalies and (d) LF components. (e)-(h) 10-day average LF SAT (shading), 500-hPa geopotential height [contours, $10-\mathrm{m}$ and $3-\mathrm{m}$ intervals with negative dashed in (e),(f) and (g),(h), respectively], and 850-hPa winds (vectors) anomalies for (e) Obs, (f) ALL, (g) GW2, and (h) ENSO. Anomalies in (f)-(h) represent the 100 -member ensemble means. 
circulation undergoes a poleward shift and thus the equator-to-pole temperature gradient decreases. The change in circulation patterns due to the anthropogenic effect $\left(T_{\mathrm{GW}_{2}}\right)$ likewise represents the midlatitude anticyclones with SAT and SST warming (Fig. 21.2g). On the other hand, the El Niño-induced teleconnection pattern in 2015 formed a wave train propagating from the tropical western Pacific northward and acts to decrease the seasonal SAT accompanied by the anomalous cyclonic circulation over Japan that links to a suppressed northward expansion of the climatological North Pacific high (Fig. 21.2h). The seasonal PJ pattern in summer tends to have negative correlations with El Niño-Southern Oscillation (ENSO) in the preceding boreal winter and with Indian Ocean temperature in the concurrent summer (Kubota et al. 2015). The 2015 El Niño-induced pattern (Fig. 21.2h) seems to be out of phase with the well-known PJ pattern (Wakabayashi and Kawamura 2004).

ENSO modifies the background state of tropical-subtropical ISO and thus significantly affects the degree of ISO modulation on TC formation in the WNP (Li et al. 2012). The El Niño in the summer 2015 provides the favorable background condition for the growth of tropical disturbances, including strengthened vorticity and monsoon trough within $5^{\circ}-20^{\circ} \mathrm{N}$ (Fig. 21.2h). We examined a possible influence of El Niño on the intraseasonal PJ teleconnection pattern and associated SAT in Japan for July-August 2015 (Supplemental Fig. S21.4). The result indicates that the extreme rainfall accompanied by intraseasonal variability is more enhanced east of the Philippines, which may in turn cause more warming in Japan through the PJ teleconnection due to extreme El Niño in 2015 (see online Supplemental Material). This work notes that an understanding of the interaction between tropical SST and the intraseasonal teleconnection is of importance for weather and climate prediction for East Asia. A follow-up study using atmosphere-ocean coupled GCMs is required to investigate any role of air-sea interaction in extraordinary weather and climate in Japan.

Conclusions. The persistent Japanese heat wave that occurred in early August of 2015 was mainly attributed to intraseasonal disturbances, including TCs. Yet, it is found that the anthropogenic warming increased the probability of occurrence of the event by 1.5 to 1.7 times. The contribution of human-induced warming to the 2015 heat wave would have been more pronounced if there had not been a concurrent extreme El Niño event because El Niño has a cooling effect in Japan.

ACKNOWLEDGEMENTS. This work was supported by Grant-in-Aid 24241009 and the Program for Risk Information on Climate Change (SOUSEI program) from the Ministry of Education, Culture, Sports, Science and Technology (MEXT), Japan.

\section{REFERENCES}

Chen, G., and C. -H. Sui, 2010: Characteristics and origin of quasi-biweekly oscillation over the western North Pacific during boreal summer. Geophys. Res. Lett., 115, D14113, doi:10.1029/2009JD013389.

Christidis, N., and P. A. Stott, 2014: Change in the odds of warm years and seasons due to anthropogenic influence on the climate. J. Climate, 27, 2607-2621, doi:10.1175/JCLI-D-13-00563.1.

Huffman, G. J., R. G. Adler, M. M. Morrissey, D. T. Bolvin, S. Curtis, R. Joyce, B. McGavock, and J. Susskind, 2001: Global precipitation at one-degree daily resolution from multi-satellite observations. J. Hydrometeor., 2, 36-50.

Imada, Y., H. Shiogama, M. Watanabe, M. Mori, M. Kimoto, and M. Ishii, 2014: The Contribution of anthropogenic forcing to the Japanese heat waves of 2013 [in "Explaining Extreme Events of 2013 from a Climate Perspective"]. Bull. Amer. Meteor. Soc., 95 (9), S52-S54.

Kawamura, R., and T. Ogasawara, 2006: On the role of typhoons in generating PJ teleconnection Pattern over the western North Pacific in late summer. SOLA, 2, 37-40, doi:10.2151/sola.2006-010.

Kobayashi, S., and Coauthors, 2015: The JRA-55 reanalysis: General specifications and basic characteristics. J. Meteor. Soc. Japan, 93, 5-48, doi:10.2151 /jmsj.2015-001.

Kubota, H., Y. Kosaka, and S.-P. Xie, 2015: A 117-year long index of the Pacific-Japan pattern with application to interdecadal variability. Int. J. Climatol., 36, 1575-1589, doi:10.1002/joc.4441.

Li, R. C., and W. Zhou, 2013: Modulation of western North Pacific tropical cyclone activity by the ISO. Part I: Genesis and intensity. J. Climate, 26, 29042918, doi:10.1175/JCLI-D-12-00210.1.

—, W. Zhou, J. C. K. Chan, and P. Huang, 2012: Asymmetric modulation of western North Pacific cyclogenesis by the Madden-Julian oscillation under ENSO conditions. J. Climate, 25, 5374-5385, doi:10.1175/JCLI-D-11-00337.1. 
Madden, R. A., and P. R. Julian, 1971: Detection of a 40-50 day oscillation in the zonal wind in the tropical Pacific. J. Atmos. Sci., 28, 702-208.

Nitta, T., 1987: Convective activities in the tropical western Pacific and their impact on the Northern Hemisphere summer circulation. J. Meteor. Soc. Japan, 65, 373-390.

Ogasawara, T., and R. Kawamura, 2007: Combined effects of teleconnection patterns on anomalous summer weather in Japan. J. Meteor. Soc. Japan, 85, 11-24, doi:10.2151/jmsj.85.11.

Onogi, K., and Coauthors, 2007: The JRA-25 reanalysis. J. Meteor. Soc. Japan, 85, 369-432, doi:10.2151 /jmsj.85.369.

Rayner, N. A., Parker, E. B. Horton, C. K. Folland, L. V. Alexander, D. P. Rowell, E. C. Kent, and A. Kaplan, 2003: Global analyses of sea surface temperature, sea ice, and night marine air temperature since the late nineteenth century. J. Geophys. Res., 108, 4407, doi:10.1029/2002JD002670.

Shiogama, H., M. Watanabe, Y. Imada, M. Mori, M. Ishii, and M. Kimoto, 2013: An event attribution of the 2010 drought in the south Amazon region using the MIROC model. Atmos. Sci. Lett., 14, 170-175, doi:10.1002/asl2.435.

,,,$--- \ldots$, Y. Kamae, M. Ishii, and M. Kimoto, 2014: Attribution of the June-July 2013 heat wave in the southwestern United States. SOLA, 10 , 122-126, doi:10.2151/sola.2014-025.

Simpson, I. R., T. A. Shaw, and R. Seager, 2014: A diagnosis of the seasonally and longitudinally varying midlatitude circulation response to global warming. J. Atmos. Sci., 71, 2489-2515, doi:10.1175/JAS -D-13-0325.1.

Stone, D., 2013: Boundary conditions for the C20C Detection and Attribution Project: The All-Hist/ est1 and Nat-Hist/CMIP5-est1 scenarios. Lawrence Berkeley National Laboratory, 18 pp. [Available online at http://portal.nersc.gov/c20c /input_data/C20C-DandA_dSSTs_All-Hist-est1 _Nat-Hist-CMIP5-est1.pdf.]

Wakabayashi, S., and R. Kawamura, 2004: Extraction of major teleconnection patterns possibly associated with the anomalous summer climate in Japan. J. Meteor. Soc. Japan, 82, 1577-1588.

Watanabe, M., and Coauthors, 2010: Improved climate simulation by MIROC5: Mean states, variability, and climate sensitivity. J. Climate, 23, 6312-6335, doi:10.1175/2010JCLI3679.1.
Yamada, K., and R. Kawamura, 2007: Dynamical link between typhoon activity and the PJ teleconnection pattern from early summer to autumn as revealed by the JRA-25 reanalysis. SOLA, 3, 65-68, doi:10.2151 /sola.2007-017. 


\title{
22. CLIMATE CHANGE AND EL NIÑO INCREASE LIKELIHOOD OF INDONESIAN HEAT AND DROUGHT
}

\author{
Andrew D. King, Geert Jan van Oldenborgh, and David J. Karoly
}

\begin{abstract}
El Niño and human-induced climate change have substantially increased the likelihood of rainfall deficits and high temperatures, respectively, in Indonesia such as those experienced in the drought conditions of July-October 2015.
\end{abstract}

Introduction. Indonesia experienced severe heat and drought throughout the dry season of 2015. The period July-October saw extreme precipitation deficits and record-breaking hot temperatures (Figs. 22.1a,b). The combination of heat and drought contributed to fires across much of the country, which were associated with fatalities and were likely the worst since 1997 (Huijnen et al. 2016). The fires had broader health impacts through increased prevalence of respiratory problems (Koplitz et al. 2016).

El Niño conditions in the central Pacific are strongly linked with seasonal precipitation deficits south of the equator in the dry season (Hendon 2003; Fig. 22.1c) and, to a lesser extent, warmer land temperatures (Harger 1995; Fig. 22.1d). Previous strong El Niño events, such as 1997, were associated with severe drought conditions in Indonesia. Anthropogenic influences may also have played a role in this event. The relative influences of El Niño-Southern Oscillation (ENSO) and human-induced climate change are investigated here.

Data and methods. To assess this current extreme event in the long-term context of a changing climate, it is desirable to have high-quality longterm observational time series. It is also preferable to have gridded observations, when comparing with climate model output, at a moderate resolution, especially over Indonesia where larger grid boxes contain both land and ocean. Unfortunately, in many regions of the developing world such data do not exist. The use of temperature and precipitation

AFFILIATIONS: KING AND KAROLY-ARC Centre of Excellence for Climate System Science, School of Earth Sciences, University of Melbourne, Melbourne, Victoria, Australia; VAN OLDENBORGHRoyal Netherlands Meteorological Institute (KNMI), De Bilt, Netherlands

DOI:I0.II75/BAMS-D-16-0164.I

A supplement to this article is available online ( 10.1175 /BAMS-D-16-0164.2) data from a range of observation-based datasets were investigated, and ERA-Interim (1979-2015; Dee et al. 2011) was selected for use in this analysis. Other longer-running reanalyses and analyses, such as ERA20C (Poli et al. 2016) and CRU-TS3.23 (Harris et al. 2014), were found to include inhomogeneities prior to the satellite era (1979 onwards). A long, relatively homogenous, precipitation series was obtained from the GPCC $1^{\circ}$ V7 analysis (1901-2015) extended by the V5 monitoring analysis (Schneider et al. 2015). Temperature and precipitation data were regridded onto a regular $2^{\circ}$ grid and averaged over land boxes within the region $0^{\circ}-11^{\circ} \mathrm{S}, 95^{\circ}-141^{\circ} \mathrm{E}$ for July-October (time series shown in Supplemental Fig. S22.1). There is agreement in temperature trends between ERA-Interim and limited observational data from the public Global Historical Climatology NetworkMonthly database (Lawrimore et al. 2011) available since 1979 (Supplemental Fig. S22.2). The trends and connection to El Niño were also investigated in observational data. It was impossible to find a temperature series longer than the ERA-Interim series, as the station density is low, variability is small, and coastal effects make interpolation to the interiors of large islands doubtful. For further details on our observational analysis, see the online Supplemental Material.

The Niño-3.4 index was calculated from HadISST (Rayner et al. 2003) for July-December. Values of the Niño-3.4 index more than $+0.83^{\circ} \mathrm{C}(1 \sigma)$ above zero in the observations were deemed to be El Niño seasons. Applying this threshold to the climate models results in selecting $10 \%$ of the seasons due to a tendency toward lower Niño-3.4 variability in most models.

Model data were extracted from the CMIP5 archive (Taylor et al. 2012) and evaluated for their performance in capturing observed temperature and precipitation variability. The model data processing followed the same regridding and subsequent masking as the reanalysis (the raw resolution of most 

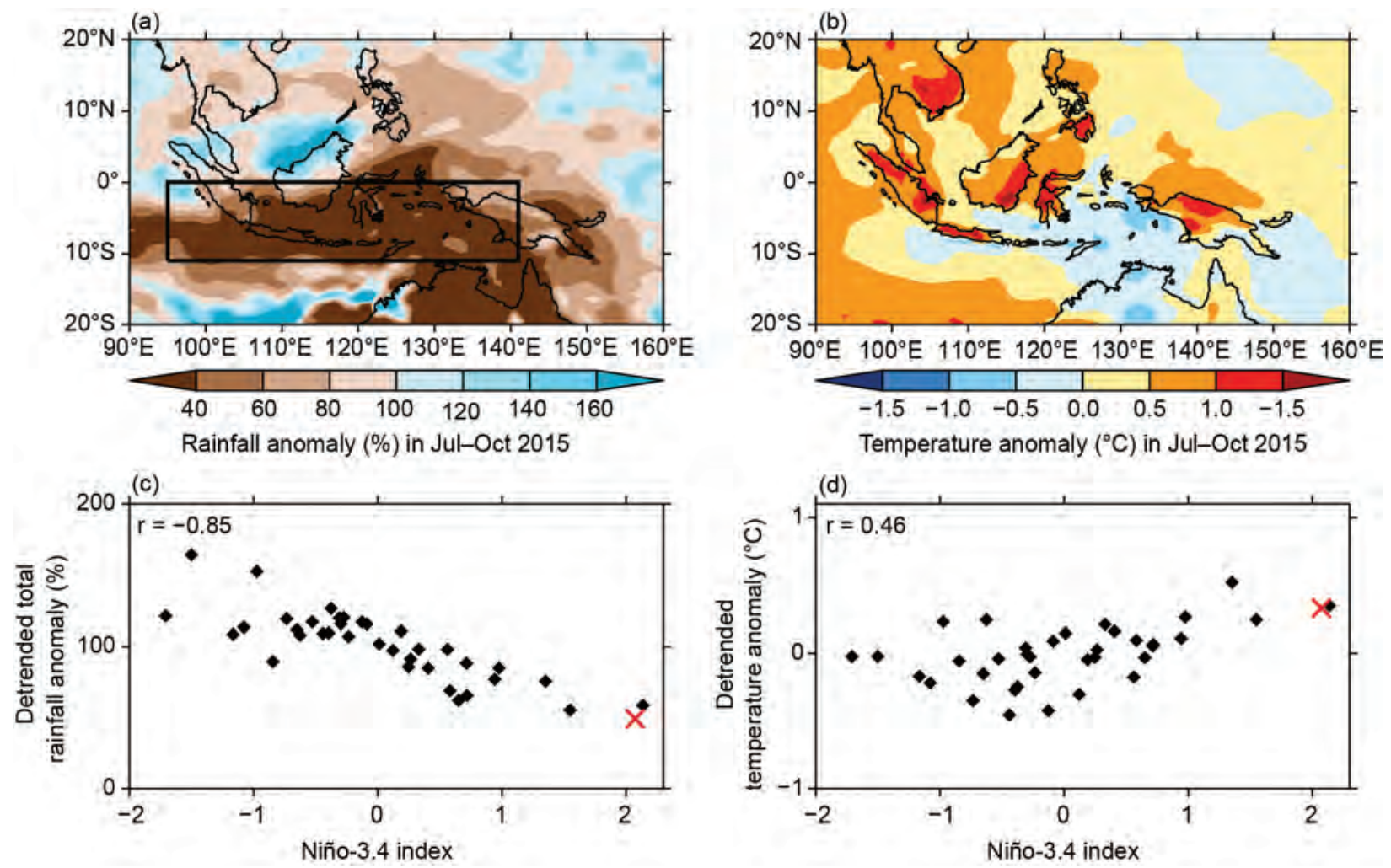

FIG. 22.I. (a) Precipitation and (b) temperature anomaly in Jul-Oct 2015 relative to a $1979-2005$ climatological average in ERA-Interim. The box in (a) denotes the region of study. Detrended area-average (c) precipitation and (d) temperature anomalies for the boxed region from 1979-20I5 in ERA-Interim plotted with average Jul-Dec Niño-3.4 index. Spearman rank correlation coefficients are shown and 2016 is marked (red crosses).

models used here is finer than $2^{\circ}$ ). July-October temperature and precipitation averages over Indonesia and July-December Niño-3.4 index values were extracted. Simulations from the "historical" experiment (including natural and anthropogenic forcings for 1861-2005) were compared with observation-based data over the common 1979-2005 period. To account for the shorter period over which the evaluation takes place, additional evaluation steps were included that test model ability to capture Indonesian climate variability and ENSO relationships (described in the Supplemental Material). Models with at least three historical simulations (listed in Supplemental Table S22.1) were tested for similarity to observational data.

The ten models that passed the evaluation were further analyzed. Equivalent Indonesian temperature and precipitation averages and Niño-3.4 index values were calculated from the historicalNat (natural forcings only for 1861-2005) and RCP8.5 (projected climate under a high greenhouse gas emissions scenario for 2006-30) simulations.

The historical and equivalent RCP8.5 simulations were joined to form simulations included in an allforcings ensemble (2000-30), which were compared with a natural-forcings ensemble (1861-2005) using the historicalNat runs. These ensembles were then used to investigate the change in likelihood of extreme heat (above $+0.7^{\circ} \mathrm{C}$ anomaly) and drought (below $60 \%$ of average precipitation) in Indonesia due to anthropogenic climate change and El Niño-Southern Oscillation.

In addition, we estimated the change in magnitude of hot and dry July-October periods in Indonesia due to climate change and the El Niño conditions. See the online Supplemental Material for more details and the results.

Uncertainty in results was measured through bootstrapping model simulations (see the Supplemental Material). Results reported here are conservative 10th percentile estimates with best estimates in parentheses.

Results. 1) Attribution to anthropogenic influences: low rainfall extremes

Based on our model analysis, precipitation deficits like those experienced during July-October 2015 in Indonesia were made at least 37\% (best estimate: $100 \%)$ more likely due to anthropogenic 
climate change. This result is based on the models that passed our evaluation tests and adequately capture Indonesian climate variability and ENSO relationships. The significant increase in frequency of low rainfall totals in the all-forcings ensemble compared with the natural-forcings ensemble is consistent with the simulated reduction in JulyOctober mean precipitation. These results contrast previous attribution analyses of precipitation deficits in other parts of the world, such as Australia (King et al. 2014), Brazil (Otto et al. 2015), and Texas (Rupp et al. 2015) that found limited evidence of a strong anthropogenic influence.

The observational precipitation time series (for 1901-2014) shows a downward trend in low extremes, albeit a nonsignificant trend (Fig. 22.2a), and no trend in mean July-October precipitation. The dry tail of the observations and the El Niño tail in the models agree well (Fig. 22.2a).

2) Attribution to anthropogenic influences: high temperature extremes

High temperatures like those observed in 2015 do not occur in our natural-forcings ensemble (as indicated by all green crosses being below the 2015 mark in Fig. 22.2c), but do exist in our all-forcings ensemble. Therefore, in our model-based analysis, the high temperatures are entirely attributable to anthropogenic influence. The probability is also vanishingly small in the observations (Fig. 22.2c), even though we can only go back to 1979 , which misses about $1 / 3$ of the warming signal. We also did not separate out El Niño years in the observations due to the small num- (a)

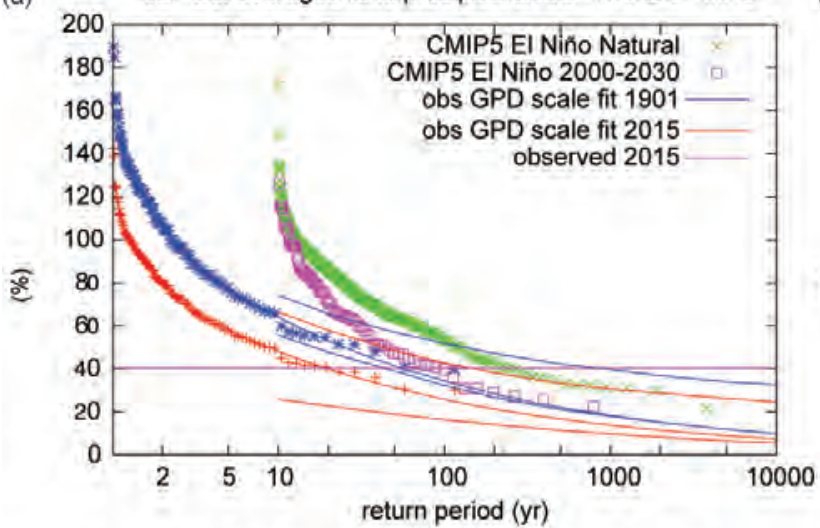

(b)

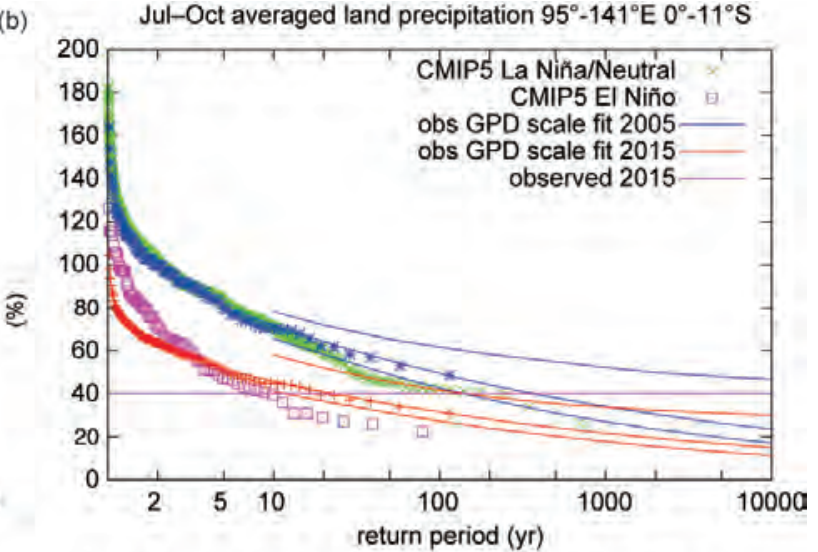

(c)

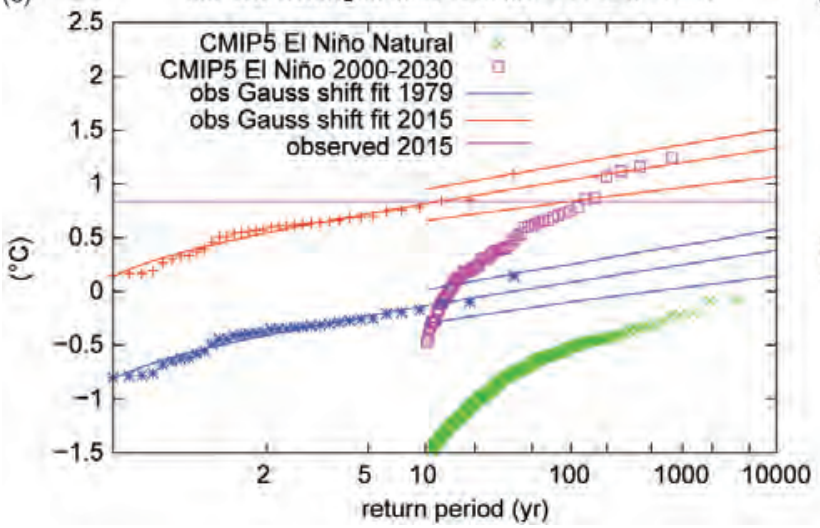

(d)

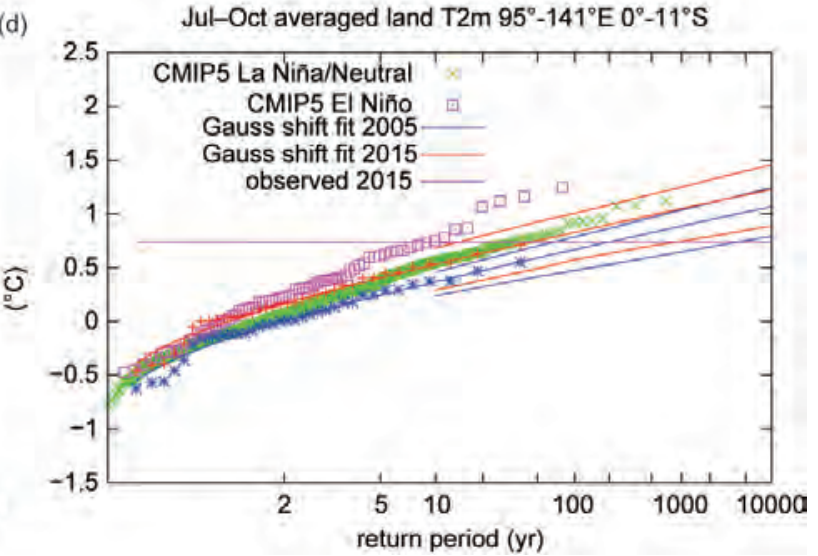

FIG. 22.2. (a),(b) The change in likelihood of dry Jul-Oct periods like 2015 in modeled and observed precipitation due to (a) anthropogenic influence and (b) ENSO. (c),(d) The same but for hot Jul-Oct periods like 20I5. (a) Scaled observed precipitation in the current climate fitted to a Generalized Pareto Distribution (GPD) function that scales with the smoothed global mean temperature for 1901 (blue lines and symbols) and 2015 (red lines and symbols), including $\mathbf{9 5 \%}$ confidence intervals. The crosses denote the observations shifted with fitted trend. The purple symbols denote EI Niño seasons in the model-simulated current climate, green simulated EI Niño seasons without anthropogenic forcings. (b) The same for EI Niño (red observations, purple models) against neutral, using $\mathbf{2 0 0 5}$ as an example neutral year (blue observations), and neutral plus La Niña (green models). (c) As in (a) but for temperature, fitted to a Gaussian distribution that shifts with the smoothed global mean temperature. The reanalysis only starts in 1979, which misses I/3 of the heating. (d) As in (b) but for temperature. 
ber of samples. The warming trend in ERA-Interim can also be seen in longer observational time series, such as Jakarta (Siswanto et al. 2015).

3) Attribution to El Niño: low rainfall extremes Given the strong ENSO relationship with Indonesian dry-season precipitation (Fig. 22.1c) and the strong El Niño of 2015-16, it is expected that the El Niño also influenced the likelihood of a rainfall deficit occurring. Comparing precipitation deficits in the all-forcings ensemble between El Niño seasons with neutral and La Niña seasons, we found at least a 300\% increase (best-estimate: $500 \%$ increase) in likelihood of having dry July-October periods in El Niño years. An analysis of the detrended long observed rainfall series shows that the probability of a dry season like July-October 2015 increases by at least a factor 20 over neutral years (Fig. 22.2b). The models have a somewhat broader distribution toward dry seasons than the observations.

4) Attribution to El Niño: high temperature extremes

In comparison, ENSO has a weaker (but statistically significant relationship) with Indonesian land temperatures. In the models, the likelihood of hot July-October periods in Indonesia is raised by at least 22\% (best estimate: 51\%) in El Niño seasons relative to neutral and La Niña events combined (Fig. 22.2d). The reanalysis shows a stronger effect, with the probability increased by at least $300 \%$ compared to a neutral year like 2005 (after detrending). This is again caused by the broader modeled distribution than the observed one (Fig. 22.2d).

Conclusions. Indonesia endured severe heat and drought during the dry season of 2015. By investigating the July-October high temperatures and low rainfall totals in ensembles of coupled climate models with and without anthropogenic forcings, an attribution of these extreme conditions to humaninduced climate change and the concurrent El Niño was conducted. The model-based and observational analyses show that El Niño conditions strongly increased the probability of a drier-than-normal dry season, and that the background warming trend due to anthropogenic climate change increased the likelihood of high temperatures. El Niño also caused somewhat higher land temperatures. The models also show a trend toward less rain and more extreme dry events, which is smaller than can be significantly detected in the observations to now.

Dry-season precipitation variability in Indonesia is strongly related to ENSO, while a very clear warm- ing trend is detectable there. Our results are in line with time of emergence studies in that regard (e.g. King et al. 2015; Mahlstein et al. 2011), which find an earlier warming signal in tropical regions such as Indonesia due to a high signal-to-noise ratio. A difficulty with performing this study was the lack of high-quality long-running observational climate data representative of our study area. The use of ERA-Interim reanalyses to evaluate the models and provide thresholds for the CMIP5-based analysis is not ideal. This difficulty is a problem across much of the developing world, where extreme weather and climate events also tend to have the strongest impacts. Further analysis on how to best conduct attribution studies where observations are sparse or have suspected inhomogeneities is required.

ACKNOWLEDGEMENTS. This research was supported by the ARC Centre of Excellence for Climate System Science (grant CE 110001028) and the NCI National Facility in Australia. G. J. van Oldenborgh was supported by the EUCLEIA project funded by the European Union's Seventh Framework Programme (FP7/2007-13) under grant agreement No. 607085. We acknowledge the World Climate Research Programme's Working Group on Coupled Modelling, which is responsible for CMIP, and we thank the climate modeling groups for producing and making available their model output.

\section{REFERENCES}

Dee, D. P., and Coauthors, 2011: The ERA-Interim reanalysis: configuration and performance of the data assimilation system. Quart. J. Roy. Meteor. Soc., 137, 553-597, doi:10.1002/qj.828.

Harger, J. R. E., 1995: Air-temperature variations and ENSO effects in Indonesia, the Philippines and El Salvador: ENSO patterns and changes from 18661993. Atmos. Env., 29, 1919-1942.

Harris, I., P. D. Jones, T. J. Osborn, and D. H. Lister, 2014: Updated high-resolution grids of monthly climatic observations - the CRUTS3.10 dataset. Int. J. Climatol., 34, 623-642, doi:10.1002/joc.3711.

Hendon, H. H., 2003: Indonesian rainfall variability: Impacts of ENSO and local air-sea interaction. J. Climate, 16, 1775-1790.

Huijnen, V., and Coauthors, 2016: Fire carbon emissions over maritime Southeast Asia in 2015 largest since 1997. Sci. Rep., 6, 26886, doi:10.1038/srep26886. 
King, A. D., D. J. Karoly, M. G. Donat, and L. V. Alexander, 2014: Climate change turns Australia's 2013 Big Dry into a year of record-breaking heat [in "Explaining Extreme Events of 2013 from a Climate Perspective"]. Bull. Amer. Meteor. Soc., 95 (9), S41S45.

- and Coauthors, 2015: The timing of anthropogenic emergence in simulated climate extremes. Environ. Res. Lett., 10, 094015, doi:10.1088/1748 $-9326 / 10 / 9 / 094015$.

Koplitz, S. N., and Coauthors, 2016: Public health impacts of the severe haze in Equatorial Asia in September-October 2015: Demonstration of a new framework for informing fire management strategies to reduce downwind smoke exposure. Environ. Res. Lett., 11, 094023, doi:10.1088/1748 $-9326 / 11 / 9 / 094023$.

Lawrimore, J. H., M. J. Menne, B. E. Gleason, C. N. Williams, D. B. Wuertz, R. S. Vose, and J. Rennie, 2011: An overview of the Global Historical Climatology Network monthly mean temperature data set, version 3. J. Geophys. Res., 116, D19121, doi:10.1029/2011JD016187.

Mahlstein, I., R. Knutti, S. Solomon, and R. W. Portmann, 2011: Early onset of significant local warming in low latitude countries. Environ. Res. Lett., 6, 034009, doi:10.1088/1748-9326/6/3/034009.

Otto, F. E. L., and Coauthors, 2015: Factors other than climate change, main driver of 2014/15 water shortage in southeast Brazil [in "Explaining Extreme Events of 2014 from a Climate Perspective"]. Bull. Amer. Meteor. Soc., 96 (12), S35-S40, doi:10.1175 /BAMS-D-15-00120.1.

Poli, P., and Coauthors, 2016: ERA-20C: An atmospheric reanalysis of the 20th century. J. Climate, 29, 40834097, doi: 10.1175/JCLI-D-15-0556.1.

Rayner, N. A., D. E. Parker, E. B. Horton, C. K. Folland, L. V. Alexander, D. P. Rowell, E. C. Kent, and A. Kaplan, 2003: Global analyses of sea surface temperature, sea ice, and night marine air temperature since the late nineteenth century. J. Geophys. Res., 108, 4407, doi:10.1029/2002JD002670.

Rupp, D. E., S. Li, N. Massey, S. N. Sparrow, P. W. Mote, and M. Allen, 2015: Anthropogenic influence on the changing likelihood of an exceptionally warm summer in Texas, 2011. Geophys. Res. Lett., 42, 2392-2400, doi:10.1002/2014GL062683.
Schneider, U., A. Becker, P. Finger, A. MeyerChristoffer, B. Rudolf, and M. Ziese, 2015: GPCC full data reanalysis version 7.0 at $1.0^{\circ}$ : Monthly landsurface precipitation from rain-gauges built on GTSbased and historic data. Deutscher Wetterdienst, doi:10.5676/DWD_GPCC/FD_M_V7_100.

Siswanto, S., G. J. van Oldenborgh, G. van der Schrier, R. Jilderda, and B. van den Hurk, 2015: Temperature, extreme precipitation, and diurnal rainfall changes in the urbanized Jakarta city during the past 130 years. Int. J. Climatol., 36, 3207-3225, doi:10.1002/joc.4548.

Taylor, K. E., R. J. Stouffer, and G. A. Meehl, 2012: An overview of CMIP5 and the experiment design. Bull. Amer. Meteor. Soc., 93, 485-498, doi:10.1175 /BAMS-D-00094.1. 


\title{
23. SOUTHERN AUSTRALIA'S WARMEST OCTOBER ON RECORD: THE ROLE OF ENSO AND CLIMATE CHANGE
}

\author{
Mitchell T. Black and David J. Karoly
}

Anthropogenic climate change was found to have a substantial influence on southern Australia's extreme heat in October 2015. The relative influence of El Niño conditions was less clear.

Introduction. Australia experienced its warmest October on record in 2015 (Australian Bureau of Meteorology 2015). This was primarily the result of an early season heat wave in the beginning of the month, concentrated over southern Australia (SAUS; Fig. 23.1a). The monthly anomaly for maximum temperature over SAUS $\left(5.16^{\circ} \mathrm{C}\right.$; Fig. $\left.23.1 \mathrm{~b}\right)$ was the largest ever recorded for the region for any month of the year. This unseasonably warm weather over SAUS led to an early start to the bushfire season and caused significant crop losses across one of Australia's most important agricultural regions, the Murray-Darling basin.

The October heat coincided with one of the strongest El Niño events on record. While warm and dry conditions over parts of Australia are typical of an El Niño event, the observed record-breaking temperatures may have been exacerbated by climate change. This study uses very large ensembles of atmosphereonly regional climate model simulations to assess the relative roles of the El Niño-Southern Oscillation (ENSO) and anthropogenic climate change in the October 2015 extreme heat across SAUS.

Data and methods. Our study made use of the weather@home Australia-New Zealand project (Black et al. 2016) to generate very large ensembles of regional climate model simulations over Australia. This setup uses the atmosphere-only model, HadAM3P, to drive a nested regional model (HadRM3P; $0.44^{\circ}$ resolution). For details of the modeling setup, see Black et al. (2016); only a brief description is provided here for context. First, the

AFFILIATIONS: BLACK AND KAROLY - School of Earth Sciences and ARC Centre of Excellence for Climate System Science, The University of Melbourne, Melbourne, Australia

DOI:10.1175/BAMS-D-16-0124.I

A supplement to this article is available online (10.1175 /BAMS-D-16-0124.2) model was run under two distinct climate scenarios: observed (all forcings, ALL) and counterfactual (natural forcings only, NAT) realizations of the year 2015. For the ALL simulations, the model was driven by observed sea surface temperatures (SSTs) and sea ice from the Met Office Operational Sea Surface Temperature and Sea Ice Analysis dataset (OSTIA; Donlon et al. 2012), as well as present-day atmospheric composition (well-mixed greenhouse gases, ozone, and aerosols). Very large ensembles were generated by running the model with perturbed initial conditions. For the NAT simulations, the model was driven by preindustrial (1850) atmospheric composition, while the SSTs were modified to remove different estimates of the warming attributable to anthropogenic greenhouse gases. Estimates of the SST changes due to human influence were separately calculated using eight CMIP5 models (Taylor et al. 2012; see online Supplemental Material). Therefore, eight alternative realizations of the NAT climate were created. By adjusting observed SSTs to remove the anthropogenic signal, the main modes of natural variability represented in the ALL SSTs (e.g., the phase of ENSO) are maintained in the NAT climate realizations. Therefore, any change of likelihood of heat events between the ALL and NAT scenarios can be directly attributed to anthropogenic forcing.

To assess the influence of ENSO on the occurrence of SAUS temperature records, additional simulations were generated by driving the weather@home model with composite SST patterns representative of each of the three phases of ENSO: El Niño, Neutral, and La Niña (see online supplemental material for details). Each of these three phases was modeled under both ALL and NAT climate realizations (as per the 2015 runs listed above). Previous work has shown that the weather@home model is able to correctly represent ENSO teleconnections over Australia (Black et al. 2016). We used all of the model simulations that 
were available at the time of this writing: at least 2700 members for each of the ALL scenarios (i.e., 2015 ALL, El Niño ALL, Neutral ALL, and La Niña ALL) and at least 650 members for each of the corresponding eight NAT realizations.

For brevity, this study focuses on SAUS because this region experienced exceptional October heat (Fig. 23.1a). A subset of SAUS, the Murray-Darling basin (MDB), is also examined as it is located in the east where the ENSO relationship with temperature is typically stronger (e.g., Min et al. 2013). Homogeneous temperature records for both regions were provided by the Australian Bureau of Meteorology (Figs. 23.1b,c), calculated from the Australian Climate Observations Reference Network-Surface Air Temperature (ACORN-SAT) dataset (Trewin 2013). For both SAUS and the MDB, areaweighted October average maximum temperatures were calculated for each of the ALL and NAT model simulations. As per Black et al. (2015), we correct for model bias $\left(0.13^{\circ} \mathrm{C}\right.$ for SAUS and $0.68^{\circ} \mathrm{C}$ for MDB) by adjusting the mean of the NAT distribution to equal that of the early ACORN-SAT observations (1910-39); this bias adjustment is then applied to the ALL distribution.

In line with other common approaches, we define an anomaly threshold based on the previous observed record $\left(+3.68^{\circ} \mathrm{C}\right.$ for SAUS and $+4.15^{\circ} \mathrm{C}$ for the MDB, both set in 2014; see Figs. 23.1b,c). To quantify the change in risk of extreme heat due to different forcing scenarios, we calculate the fraction of attributable risk (FAR; Allen 2003), defined as FAR $=1-\left(\mathrm{P}_{1} /\right.$ $\mathrm{P}_{2}$ ), where $\mathrm{P}_{1}$ and $\mathrm{P}_{2}$ represent the probabilities of exceeding the October temperature threshold in two different scenarios. In the first instance, we estimate the anthropogenic influence by setting $\mathrm{P}_{1}$ to be the probability of exceeding the October temperature threshold in the 2015 NAT scenarios, while $\mathrm{P}_{2}$ is the equivalent for the 2015 ALL scenario. Here, we aggregate the eight NAT realizations in order to calculate a best estimate of FAR. This process is repeated for the El Niño NAT and El Niño ALL
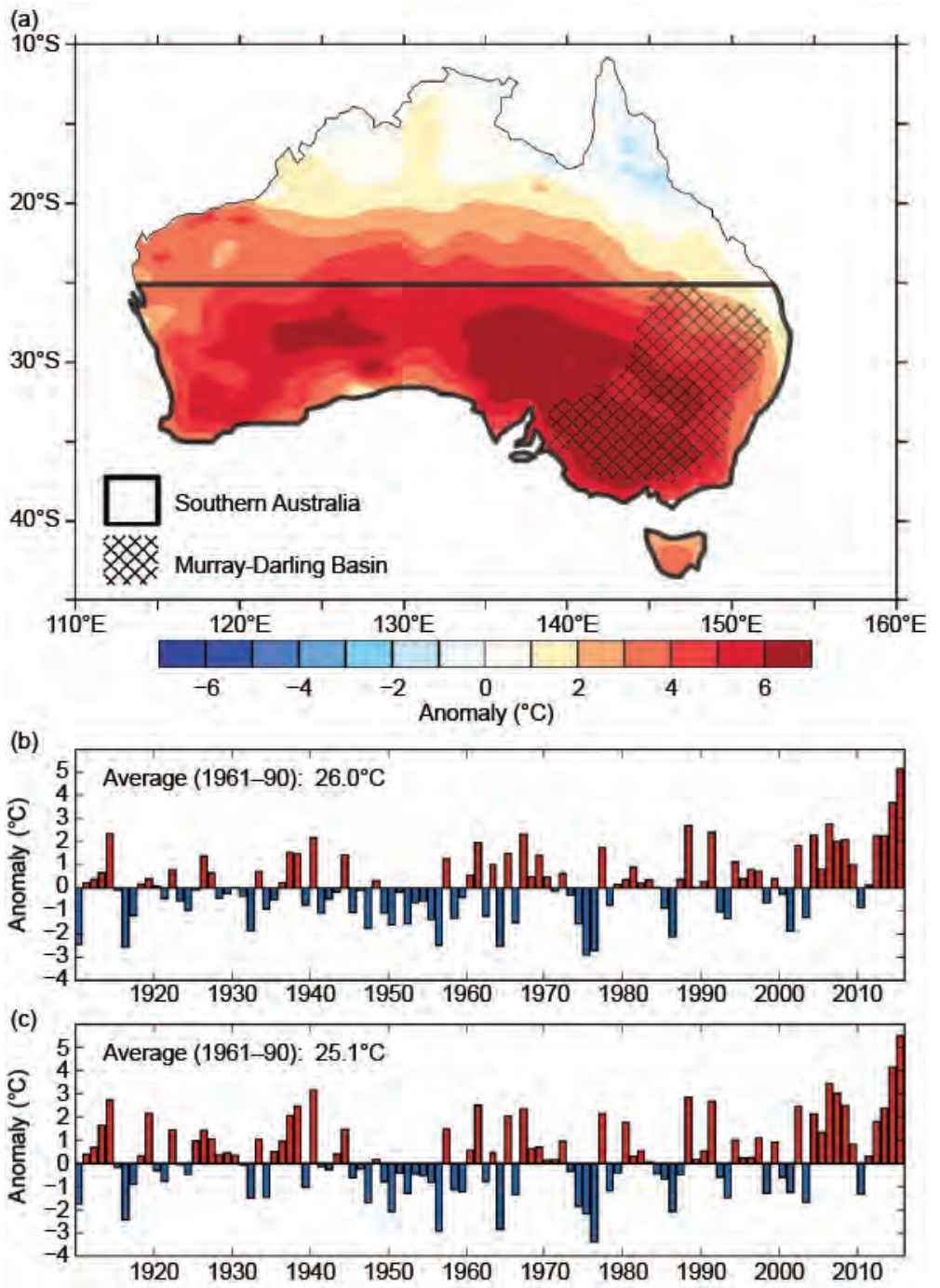

FIG. 23.I. Oct mean daily maximum temperatures from ${ }^{\circ} \mathrm{Cthe}$ Australian Bureau of Meteorology, expressed as anomalies relative to the 196I-90 base period. (a) Spatial anomaly field for Oct 2015. The southern Australian region (land area south of $25^{\circ} \mathrm{S}$ ) and the Murray-Darling basin (hatched region) are shown. (b) Timeseries of the southern Australian anomalies from 1910 to 2015, calculated from the Australian Climate Observations Reference NetworkSurface Air Temperature dataset (Trewin 2013). (c) As in (b), but for the Murray-Darling basin.

scenarios. Next, to estimate the influence of El Niño conditions on the change in risk of extreme heat, we calculate FAR using $P_{1}$ from the La Niña ALL simulations and $\mathrm{P}_{2}$ from the El Niño ALL simulations; this is also repeated for Neutral ALL $\left(\mathrm{P}_{1}\right)$ and El Niño ALL $\left(\mathrm{P}_{2}\right)$. Therefore, we are able to quantify the change in risk due to both anthropogenic forcing and the phase of ENSO. An assessment of FAR uncertainty was estimated by a bootstrap procedure (10000 times with replacement) and the 10th percentile FAR value is used to make conservative estimates of changes in 
risk associated with the different forcing scenarios. To assist with the interpretation of results, FAR values are also presented as estimated increase in likelihood.

Results. Figure 23.2a shows the model-derived distributions of SAUS October average maximum temperature for the various forcing scenarios. There is close agreement between the distributions for the 2015 ALL and El Niño ALL scenarios, as well as between the 2015 NAT and El Niño NAT scenarios, suggesting that the El Niño composite SSTs are a suitable analogue for the 2015 observed conditions. Even though the SSTs for the 2015 El Niño were extreme, the model results in Fig. 23.2a indicate that the associated temperature anomalies in Australia were consistent with a typical El Niño event. The ALL scenarios are clearly warmer than the NAT scenarios. The La Niña ALL distribution is notably cooler than both Neutral ALL and El Niño ALL, although the warm tails of the distributions are seen to converge. Figure 23.2a suggests that even under La Niña conditions, extreme SAUS and MDB temperatures as warm as in El Niño ALL and Neutral ALL can be achieved.

The corresponding FAR estimates for exceeding the previous SAUS temperature record are shown in Fig. 23.2b. When comparing the ALL scenarios against the NAT scenarios (first two columns of Fig. 23.2b), the 10th percentile FAR estimates are around

(b) Southern Australia

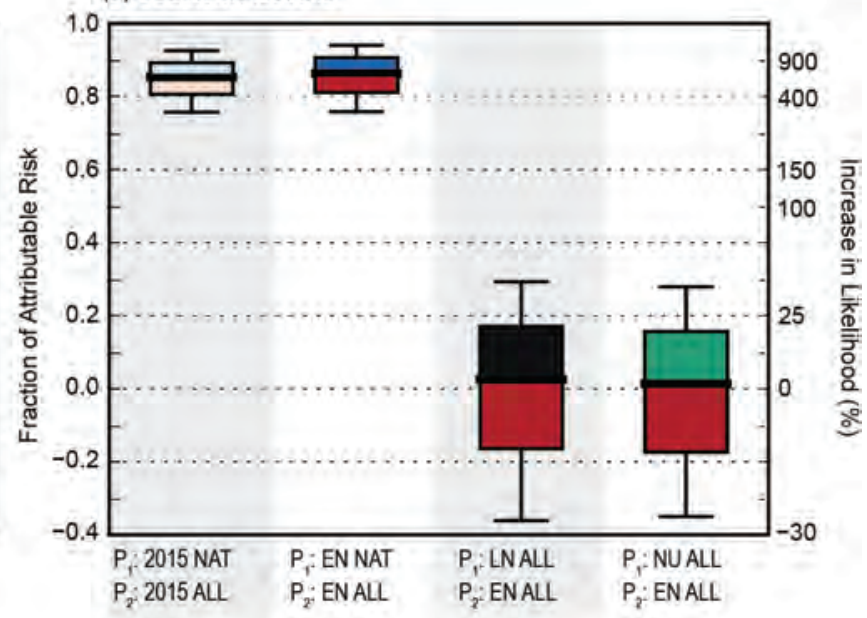

(d) Murray-Darling Basin

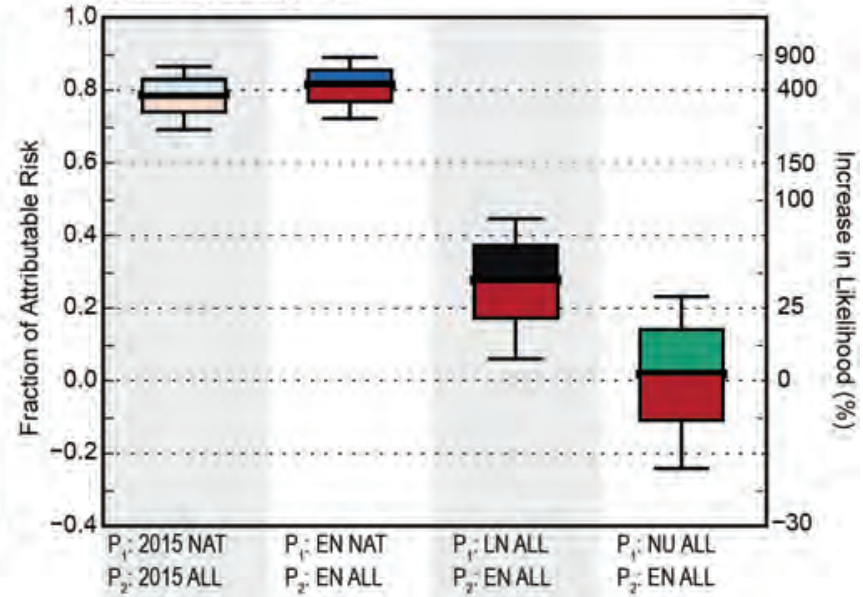

Fig. 23.2. (a) Distributions of southern Australian Oct average maximum temperatures for the various weather@ home modeling scenarios. The vertical line represents the previous temperature record (set in 2014). (b) Corresponding fraction of attributable risk $\left(F A R=I-P_{1} / P_{2}\right)$ calculated using different scenario combinations for $P_{1}$ and $P_{2}$, as indicated. Estimates of FAR are calculated using a bootstrapping approach (resampling distributions 10000 times with replacement); boxes show the median and interquartile range while the whiskers extend to the 10th and 90th percentiles. See text for details. (c),(d) As in (a),(b) but for the Murray-Darling basin. Abbreviations: EI Niño (EN), La Niña (LN), neutral (NU), all forcings (ALL), and natural forcings only (NAT). 
0.76 . Therefore, it is very likely (with $90 \%$ confidence) that anthropogenic climate change increased the likelihood of breaking the previous SAUS temperature record by at least $400 \%$. Meanwhile, FAR estimates comparing El Niño ALL against La Niña ALL (third column) and Neutral ALL (fourth column) result in the 10th percentiles being below zero. Therefore, we cannot conclude (with $90 \%$ confidence) that El Niño conditions increased the likelihood of setting a new SAUS temperature record. The results for the MDB (Figs. 23.2c,d) are similar to SAUS. When comparing the ALL and NAT scenarios for the MDB, the 10th percentile FAR values were of the order of 0.67 , that is a $300 \%$ increase in likelihood due to anthropogenic climate change. Meanwhile, the ENSO response is clearer over the MDB than for all of SAUS: FAR estimates when comparing El Niño ALL and La Niña ALL indicate it is very likely that El Niño conditions increased the likelihood of breaking the previous MDB record by $4 \%$ when compared to La Niña conditions.

Conclusions. This study demonstrates a novel approach for separating the role of ENSO and anthropogenic climate change within the context of an event attribution study. Using regional climate model simulations from the weather@home modeling setup,we identify that anthropogenic climate change had a substantial influence on southern Australia's extreme heat in October 2015. El Niño also contributed to the heat, but its relative influence was much weaker. These conclusions, of course, rely heavily on our assumption that our model is able to correctly represent extreme temperatures in southern Australia during El Niño events. However, this cannot be thoroughly tested due to a lack of observational samples. By generating an extremely large number of regional climate model simulations under different forcing scenarios, weather@home is shown to be a powerful tool for understanding the drivers of recent Australian temperature extremes.

ACKNOWLEDGEMENTS. The authors have been supported by funding from the Australian Research Council's Centre of Excellence for Climate System Science (Grant CE110001028). Weather@home ANZ is a collaboration between the University of Oxford, the Met Office, the ARC Centre of Excellence for Climate System Science in Australia, NIWA in New Zealand, the University of Melbourne, the University of Tasmania, and the Tasmanian Partnership for Advanced Computing. We thank the volunteers who donated their computing time to run weather@home.

\section{REFERENCES}

Allen, M., 2003: Liability for climate change. Nature, 421, 891-892, doi:10.1038/421891a.

Australian Bureau of Meteorology, 2015: Special climate statement 48: Australia's warmest October on record. Bureau of Meteorology, 25pp. [Available online at www.bom.gov.au/climate/current /statements/scs52.pdf.]

Black, M. T., D. J. Karoly, and A. D. King, 2015: The contribution of anthropogenic forcing to the Adelaide and Melbourne, Australia, heat waves of January 2014 [in Explaining Extreme Events of 2014 from a Climate perspective]. Bull. Amer. Meteor. Soc., 96 (12), S145-S148, doi:10.1175/BAMS-D-15-00097.1.

— , and Coauthors, 2016: The weather@home regional climate modelling project for Australia and New Zealand. Geosci. Model Dev., 9, 3161-3176, doi:10.5194/gmd-9-3161-2016.

Donlon, C. J., M. Martin, J. Stark, J. Roberts-Jones, E. Fiedler, and W. Wimmer, 2012: The Operational Sea Surface Temperature and Sea Ice Analysis (OSTIA) system. Remote Sens. Environ., 116, 140-158, doi:10.1016/j.rse.2010.10.017.

Min, S. K., W. Cai, and P. Whetton, 2013: Influence of climate variability on seasonal extremes over Australia. J. Geophys. Res. Atmos., 118, 643-654, doi:10.1002/jgrd.50164.

Taylor, K. E., R. J. Stouffer, and G. A. Meehl, 2012: An overview of CMIP5 and the experiment design. Bull. Amer. Meteor. Soc., 93, 485-498, doi:10.1175/BAMS -D-11-00094.1.

Trewin, B., 2013: A daily homogenized temperature data set for Australia. Int. J. Climatol., 33, 1510-1529, doi:10.1002/joc.3530. 


\title{
24. WHAT CAUSED THE RECORD-BREAKING HEAT ACROSS AUSTRALIA IN OCTOBER 20I5?
}

\author{
Pandora Hope, Guomin Wang, Eun-Pa Lim, Harry H. Hendon, and Julie M. Arblaster
}

Using a seasonal forecasting framework for attribution, we find that half of the record heat anomaly across Australia in October 2015 can be attributed to increasing $\mathrm{CO}_{2}$, with much of the rest due to internal atmospheric variability.

The Event. In 2015, Australia experienced another exceptionally warm spring, making the spring seasons of 2013, 2014, and 2015 the three warmest from 105 years of record (Trewin 2013). In 2015, October was the most extreme month (Fig. 24.1a), with the largest monthly mean daily maximum temperature (AusTmax) anomaly $\left(+3.44^{\circ} \mathrm{C}\right.$, relative to $1961-90 ; 33.54^{\circ} \mathrm{C}$ absolute) of any month, surpassing the September 2013 AusTmax record of $+3.41^{\circ} \mathrm{C}$. The monthly mean daily minimum temperature was also a record high for October $\left(+2.34^{\circ} \mathrm{C}\right)$, and the fourth largest positive anomaly of any month. More than half of the continent (54.7\%) recorded the highest-on-record October maximum temperatures, exceeding the previous record of $22.3 \%$ in 1988 . The heat was particularly focused in the south (Fig. 24.1a), associated with a number of weather systems that encouraged surface northerlies from the continental interior during the month (Australian Bureau of Meteorology 2015). Temperatures in the north were relatively cool. At inland locations, temperatures were consistently above average, leading to record warm monthly averages, but no daily records being set.

Climate conditions during October 2015 and their relationship to Australian Tmax. The global climate of October 2015 was extraordinary in various aspects, with many large-scale climate features in a phase generally linked to unusually warm temperatures across Australia. These included a strong El Niño (www.bom.gov.au/climate/enso

AFFILIATIONS: HoPE, WANG, LIM, AND HENDON-Research and Development Branch, Bureau of Meteorology, Melbourne, Victoria, Australia; ARBLASTER-National Center for Atmospheric Research, Boulder, Colorado, and the School of Earth, Atmosphere and Environment, Monash University, Melbourne, Victoria, Australia

DOI:10.1175/BAMS-D-16-0142.I

A supplement to this article is available online (10.1175 /BAMS-D-16-0142.2) /archive/ensowrap_20151110.pdf), with Niño-3.4 at $+2.2^{\circ} \mathrm{C}$, Niño- 3 at $+2.3^{\circ} \mathrm{C}$, and Niño- 4 at $+1.4^{\circ} \mathrm{C}$ above the 1961-90 average. Niño- 4 was the warmest October value since records began in 1870 (HadISST used for sea surface temperature-based indices; Rayner et al. 2003; KNMI climate explorer: climexp.knmi.nl). The southern Indian Ocean $\left(30^{\circ}-120^{\circ} \mathrm{E}\right.$ and $\left.0^{\circ}-60^{\circ} \mathrm{S}\right)$ was the warmest on record to date for any month, with an anomaly of $+0.63^{\circ} \mathrm{C}$ compared to the $1961-90$ average, and the Indian Ocean dipole (IOD) was strongly positive (dipole mode index: +0.76 , relative to $1961-$ 90; Saji et al. 1999). El Niño together with a positive IOD is typically associated with warm conditions over Australia during September to November (White et al. 2013), although the influence from El Niño becomes more important later in the year.

While seasonally varying oceanic conditions favored warm conditions across Australia, on the intraseasonal time scale many atmospheric features also favored warm conditions during October 2015 (see details on the climate state on the POAMA-2 pages at http://poama.bom.gov.au/). In spring, negative southern annular mode (SAM; Marshall 2003), phase 2 and 3 of the Madden-Julian oscillation (MJO; Wheeler and Hendon 2004) and blocking in the Tasman Sea are all associated with warm conditions across southern Australia (Marshall et al. 2013; Hendon et al. 2007). During October 2015, the subtropical ridge was intense, associated with blocking over the Tasman Sea as indicated by the subtropical ridge index (STRHI; Marshall et al. 2013), which was greater than two standard deviations above the mean in the first half of the month. The SAM varied through the month, but was negative during two periods of strong heat, in the first week and again around 20 October. From 23 October through the end of the month, the MJO became moderate to strong in Phase 2. The combination of these climatic features would be expected to bring heat to southern Australia. 
(a)

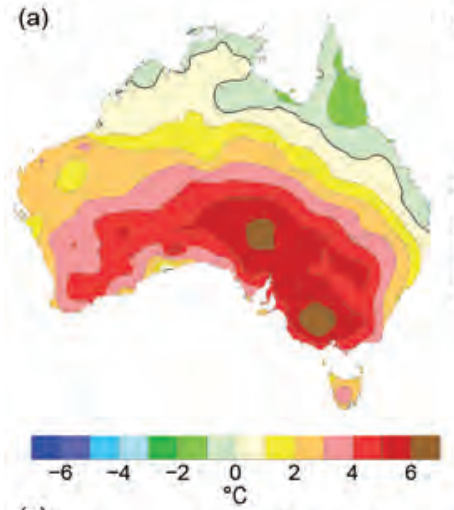

(c)

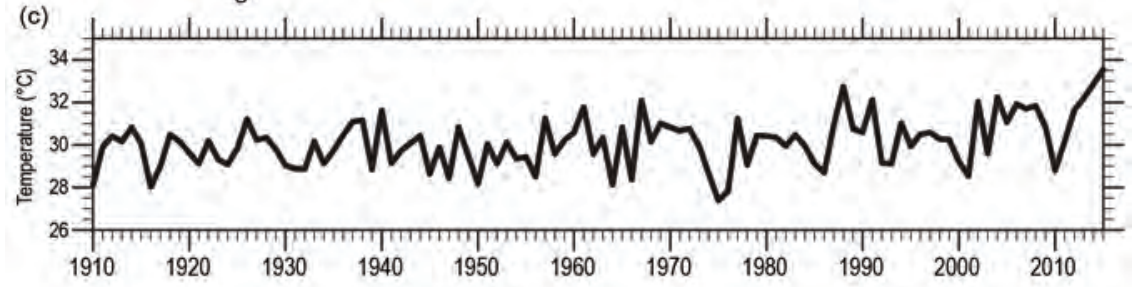

Fig. 24.I. (a) Map of observed anomaly of Oct 2015 mean Australian Tmax relative to 2000-14 climatology (Australian Water Availability Project; Jones et al. 2009). (b) The observed Oct AusTmax and ensemble mean Oct forecasts for current $\mathrm{CO}_{2}$ conditions and $1960\left(\right.$ low $\left.\mathrm{CO}_{2}\right)$ conditions. The ensemble range of II members forecast from I Oct each year is shown in pink shading for current $\mathrm{CO}_{2}$ conditions and blue for low $\mathrm{CO}_{2}$ conditions, and (c) time series of observed Oct AusTmax from 1910 to 2015.

Assessing the influence from increasing $\mathrm{CO}_{2}$. Black and Karoly (2016) assessed the level of influence from anthropogenic climate change on the October 2015 heat across southern Australia. Probabilities of the current climate were estimated using very large ensembles of simulations (over 2000 realizations) from the HadRM3P nested regional atmospheric GCM forced with 2015 sea surface temperatures (SSTs). The natural world probabilities were from similar experiments where a measure of the impact of anthropogenic forcing since preindustrial times had been removed (weather@home; Black et al. 2015). They calculated the fraction of attributable risk (FAR; Stott et al. 2004) of exceeding the previous temperature record for southern Australia. Defining FAR = $1-(\mathrm{P} 1 / \mathrm{P} 2)$, where $\mathrm{P} 1$ is the probability of exceeding the previous threshold in the "natural" world, and P2 is the probability of exceeding the previous threshold in the current world. They found a conservative FAR estimate of 0.76 . A FAR of 0.76 means that October 2015 was at least four times more likely to exceed the previous record, set in 2014 , of $29.68^{\circ} \mathrm{C}$ in the current world than in the natural world.

Here, extending the method of Hope et al. (2015), we use a fully coupled seasonal forecast modeling system to attribute the level of influence of both the last 55 years of increasing $\mathrm{CO}_{2}$ and natural (internal) variability on this event. The Australian Bureau of Meteorology's seasonal forecast model POAMA-2.4 (Cottrill et al. 2013; Hudson et al. 2013) was used. Note that the use of a coupled seasonal forecast system in this way is unique and has certain limitations and strengths compared to other methods. For instance, the initial-value nature of the framework allows little time for the growth of model-driven biases, while allowing the full coupled response of the ocean-atmosphere-land system. Currently, only changes in $\mathrm{CO}_{2}$ are considered and not other anthropogenic factors such as land-use change or aerosols. For full details of the method used here, refer to Wang et al. (2016).

For each of 24 September, 27 September, and 1 October 2015, an 11-member ensemble forecast of October 2015 under current $\mathrm{CO}_{2}$ levels (400 ppm) was initialized with observed atmosphere, ocean, and land conditions, forming a 33-member ensemble. A corresponding ensemble forecast was also initialized on the same dates, but with $\mathrm{CO}_{2}$ set to the 1960 level of $315 \mathrm{ppm}$ and with anomalies-corresponding to the signature of change due to the last 55 years of rising $\mathrm{CO}_{2}$-removed from the ocean, soil, and atmosphere to create a "low $\mathrm{CO}_{2}$ " forecast. For the threedimensional ocean, the signature of change due to rising $\mathrm{CO}_{2}$ levels was the difference between the ocean state in the final years of long integrations with fixed $\mathrm{CO}_{2}$ at 400 or $315 \mathrm{ppm}$. To calculate the signature of change in the atmosphere or land, differences were made between two sets of forecasts for October 2015 using either current initial conditions or the current initial conditions with $315 \mathrm{ppm}$ and the ocean state after subtracting the difference as calculated above. Two forecast climatologies, one for the current climate and one for the low $\mathrm{CO}_{2}$ climate, were produced with an ensemble of 11 members initialized on 1 October for each year from 2000-14. Although short, this 15year period includes a range of interannual variability due to the different states of ENSO. The climatology 
has 165 members (11 forecasts for each October, 15 in total). The time series of the ensemble mean forecasts and the forecast spread of the two experiments are shown in Fig. 24.1b. The probability distribution functions (PDFs) are shown in Fig. 24.2b.

The record heat across Australia in October 2015 was well predicted under current $\mathrm{CO}_{2}$ levels; the 2015 ensemble mean was warmer than any year in the 2000-14 climatology (Fig. 24.1b, red line). Although the ensemble mean anomaly was less than observed, one forecast ensemble member was warmer than observed (Fig. 24.2a). The forecast for October 2015 under the current climate was $2.0^{\circ} \mathrm{C}$ warmer than the low $\mathrm{CO}_{2}$ climatology mean (Fig. 24.2a, red dot compared to blue line) The ensemble mean of the October 2015 forecast in the low $\mathrm{CO}_{2}$ climate was the warmest ensemble mean against the low $\mathrm{CO}_{2}$ climatology (Fig. $24.1 b$, blue line). Thus even under low $\mathrm{CO}_{2}$ conditions, forecasts driven by the observed state of the internal atmospheric variability were the warmest on record.

An obvious measure of the contribution from increasing $\mathrm{CO}_{2}$ is simply the difference between the two means of the current and low $\mathrm{CO}_{2}$ forecast climatologies, which is $1.0^{\circ} \mathrm{C}$ and statistically significant ( $\mathrm{p}<0.01$ ) (Fig. 24.2, dashed lines). This aligns with the observed change of $1.1^{\circ} \mathrm{C}$ from around 1960 (1953-67) to recent years (2000-14), see Fig. 24.1c.

To calculate an estimate of the FAR, the previous record was taken as the warmest ensemble mean forecast in the climatology under current $\mathrm{CO}_{2}$ levels, with a value of $31.4^{\circ} \mathrm{C}$. Across the 33-member forecast ensemble of 2015, five members exceeded this threshold in the low $\mathrm{CO}_{2}$ climate, while 17 exceeded it in the current climate, leading to a FAR value of 0.71 . Alternatively, if the previous record was taken from observations $\left(32.1^{\circ} \mathrm{C}\right.$, set in 2014), none of the ensemble members of the 2015 forecast in a low $\mathrm{CO}_{2}$ climate exceeded this threshold, while six ensemble members exceeded it in the current climate, thus the FAR would be 1.0.

Assessing the influence from the climatic and synoptic conditions. In order to further explore the importance of the atmospheric state (e.g., MJO, the location of the subtropical ridge, SAM) as compared to the antecedent land conditions or the oceanic state (e.g., El Niño, IOD) for promoting the record warmth, further forecast experiments were done, removing the influence from either the land, ocean, or atmosphere initial conditions, following Arblaster et al. (2014) and Wang et al. (2016). The results (outlined in more detail in the online supplemental material) indicate that the overwhelming driver of the heat was the atmospheric state from the atmospheric initial conditions, as opposed to the ocean or land state. This suggests that the direct impact on warming from the strong El Niño and IOD was small, and the major impact was from intraseasonal drivers such as MJO activity in the tropical Indian Ocean, the negative SAM, and Tasman Sea blocking.

Conclusions. Using a seasonal forecast framework, the record heat of October 2015 across Australia was attributed to the last 55 years of $\mathrm{CO}_{2}$ induced warming and other factors. The warming from $\mathrm{CO}_{2}$ contributed roughly $1.0^{\circ} \mathrm{C}$ to the extreme heat forecast across Australia in October 2015, while a combination of Tasman Sea blocking, negative SAM, MJO, and a high positioned over the southeast of the country, on
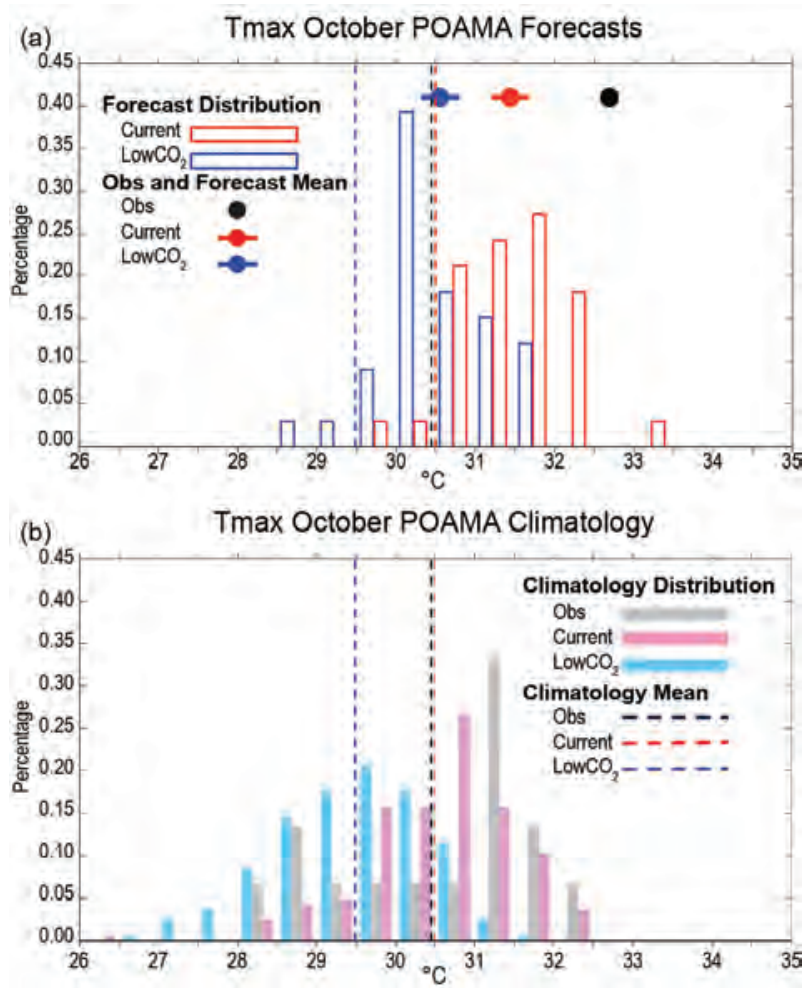

FIG. 24.2. (a) The distribution of the forecast Oct 2015 AusTmax is estimated with $\mathbf{3 3}$ member forecasts for current (red open bars) and low $\mathrm{CO}_{2}$ (blue open bars) climates. The mean value for the observed event in Oct 2015 is shown by the top black dot, with the event ensemble means for current in red and low $\mathrm{CO}_{2}$ in blue. (b) Oct AusTmax climatology distribution for 2000-14 from observations (gray bars), and the climatology estimated using II member Oct forecasts during 2000-14 for the current climate (pink solid bars) and the low $\mathrm{CO}_{2}$ climate of 1960 (light blue solid bars). The climatology means are shown in dashed lines: black for observations, red for current, and blue for low $\mathrm{CO}_{2}$. 
the background state of a strong El Niño and a positive IOD, all contributed to the remaining $1.0^{\circ} \mathrm{C}$ of the $2.0^{\circ} \mathrm{C}$ forecast anomaly against a 1960 , low $\mathrm{CO}_{2}$ climatology. The FAR estimate for October 2015 AusTmax being warmer than the previous record using this framework was 0.71 , similar to the 0.76 that Black and Karoly (2016) showed for southern Australia. The pattern of anomalously low pressure to the south of Australia and a high over the southeast of the continent appears to be a consistent feature of the extreme heat across southern Australia during the last three springs of 2013 (Arblaster et al. 2014), 2014 (Hope et al. 2015; Gallant and Lewis 2016), and 2015.

ACKNOWLEDGEMENTS. Thank you to reviews from Robert Colman, Debra Hudson, and two anonymous reviewers who improved the manuscript. This project was in part supported through funding from the Australian Government's National Environmental Science Programme.

\section{REFERENCES}

Arblaster, J. M., E. Lim, H. H. Hendon, B. C. Trewin, M. C. Wheeler, G. Liu, and K. Braganza, 2014: Understanding Australia's hottest September on record [in "Explaining Extreme Events of 2013 from a Climate Perspective"]. Bull. Amer. Meteor. Soc., 95 (9), S37-S41.

Australian Bureau of Meteorology, 2015: Special Climate Statement 52 (update): Australia's warmest October on record. Bureau of Meteorology, 21 pp. [Available online at www.bom.gov.au/climate /current/statements/scs52.pdf.]

Black, M. T., and D. J. Karoly, 2016: Southern Australia's warmest October on record: The role of ENSO and climate change [in "Explaining Extreme Events of 2015 from a Climate Perspective"]. Bull. Amer. Meteor. Soc., 97 (12), S118-S121, doi10.1175/BAMS -D-16-0124.1. (chapter 20 of EEE)

- _ _ and A. D. King, 2015: The contribution of anthropogenic forcing to the Adelaide and Melbourne, Australia, heat waves of January 2014 [“in Explaining Extreme Events of 2014 from a Climate Perspective"]. Bull. Amer. Meteor. Soc., 96 (12), S145-S148, doi:10.1175/BAMS-D-15-00097.1.

Cottrill, A., and Coauthors, 2013: Seasonal forecasting in the Pacific using the coupled model POAMA-2. Wea. Forecasting, 28, 668-680, doi:10.1175/WAF -D-12-00072.1.
Gallant, A. J. E., and S. C. Lewis, 2016: Stochastic and anthropogenic influences on repeated record-breaking temperature extremes in Australian spring of 2013 and 2014. Geophys. Res. Lett., 43, 2182-2191, doi:10.1002/2016GL067740.

Hendon, H., D. W. J. Thompson, and M. C. Wheeler, 2007: Australian rainfall and surface temperature variations associated with the Southern Hemisphere annular mode. J. Climate, 20, 2452-2467, doi:10.1175/JCLI4134.1.

Hope, P., E.-P. Lim, G. Wang, H. H. Hendon, and J. M. Arblaster, 2015: Contributors to the record high temperatures across Australia in late spring 2014 ["in Explaining Extremes. 2014 from a Climate Perspective”]. Bull. Amer. Meteor. Soc., 96 (12), S149S153, doi:10.1175/BMAS-D-15-00096.1.

Hudson, D., A. G. Marshall, Y. Yin, O. Alves, and H. H. Hendon, 2013: Improving intraseasonal prediction with a new ensemble generation strategy. Mon. Wea. Rev., 141, 4429-4449, doi:10.1175/MWR -D-13-00059.1.

Jones, D. A., W. Wang, and R. Fawcett, 2009: Highquality spatial climate data-sets for Australia. Aust. Meteor. Oceanogr. J., 58, 233-248.

Marshall, A., D. Hudson, M. Wheeler, O. Alves, H. Hendon, M. Pook, and J. Risbey, 2013: Intra-seasonal drivers of extreme heat over Australia in observations and POAMA-2. Climate Dyn., 43, 1915-1937, doi:10.1007/s00382-013-2016-1.

Marshall, G. J., 2003: Trends in the southern annular mode from observations and reanalyses. J. Climate, 16, 4134-4143.

Rayner, N. A., D. E. Parker, E. B. Horton, C. K. Folland, L. V. Alexander, D. P. Rowell, E. C. Kent, and A. Kaplan, 2003: Global analyses of sea surface temperature, sea ice, and night marine air temperature since the late nineteenth century. J. Geophys. Res., 108, 4407, doi:10.1029/2002JD002670.

Saji, N., G. Goswami, P. Vinayachandran, and T. Yamagata, 1999: A dipole mode in the tropical Indian Ocean. Nature, 401, 360-363.

Stott, P., D. Stone, and M. Allen, 2004: Human contribution to the European heatwave of 2003. Nature, $432,610-614$.

Trewin, B., 2013: A daily homogenized temperature data set for Australia. Int. J. Climatol., 33, 1510-1529, doi:10.1002/joc.3530. 
Wang, G., P. Hope, E.-P. Lim, H. H. Hendon, and J. M. Arblaster, 2016: Three methods for the attribution of extreme weather and climate events. Bureau of Meteorology Research Report 018, 32 pp. [Available online at www.bom.gov.au/research/research -reports.shtml]

Wheeler, M. C., and H. H. Hendon, 2004: An all-season real-time multivariate MJO index: Development of an index for monitoring and prediction. Mon. Wea. Rev., 132, 1917-1932.

White, C. J., D. Hudson, and O. Alves, 2013: ENSO, the IOD and the intraseasonal prediction of heat extremes across Australia using POAMA-2. Climate Dyn., 43, 1791-1810, doi:10.1007/s00382-013-2007-2. 


\title{
25. THE ROLES OF CLIMATE CHANGE AND EL NIÑO IN THE RECORD LOW RAINFALL IN OCTOBER 2015 IN TASMANIA, AUSTRALIA
}

\author{
David J. Karoly, Mitchell T. Black, Michael R. Grose, and Andrew D. King
}

Anthropogenic climate change and El Niño made small but significant contributions to increasing the likelihood of record low rainfall in October 2015 in Tasmania. Atmospheric variability was the main contributor.

Introduction. The island state of Tasmania, in southeast Australia, received record low average rainfall of 21 $\mathrm{mm}$ in October 2015, 17\% of the 1961-90 normal (Fig. 25.1a; Bureau of Meteorology 2015). This had major impacts across the state, affecting agriculture and hydroelectric power generation and preconditioning the landscape for major bushfires the following summer (Hobday et al. 2016). Rainfall in Tasmania is normally high throughout the year, with variations in Austral spring associated with mean sea level pressure (MSLP) and circulation variations due to El Niño, the Indian Ocean dipole (IOD), and the southern annular mode (SAM; Hill et al. 2009). Spring rainfall is declining and projected to decrease further in Tasmania (Hope et al. 2015)

This record low rainfall was associated with extreme high MSLP over much of southeast Australia (Fig. 25.1b) and record high October mean maximum temperature over southern Australia (Black and Karoly 2016). The wave train pattern of MSLP anomalies in October (Fig. 25.1b) from southern Australia across the South Pacific is typical of the Pacific South American (PSA) pattern (Mo and Higgins 1998). El Niño conditions, such as in late 2015, are associated with a shift in tropical Pacific rainfall and in waveguides in the extratropical Pacific that influence the PSA pattern (Karoly 1989) and rainfall in Tasmania.

We have investigated the roles of anthropogenic climate change, the 2015/16 El Niño, and internal

AFFILIATIONS: KAROLY, BLACK, AND KING-School of Earth Sciences and ARC Centre of Excellence for Climate System Science, University of Melbourne, Victoria, Australia; GROSECSIRO Climate Science Centre, Hobart, Tasmania, Australia DOI:I0.II75/BAMS-D-16-0139.I

A supplement to this article is available online (10.II75 /BAMS-D-I6-0139.2) atmospheric variability on this record low October rainfall using observational data, regional climate simulations driven by specified sea surface temperatures (SSTs) from the weather@home Australia and New Zealand (w@h ANZ) project (Black et al. 2015, 2016; Massey et al. 2015), and coupled climate model simulations from the Coupled
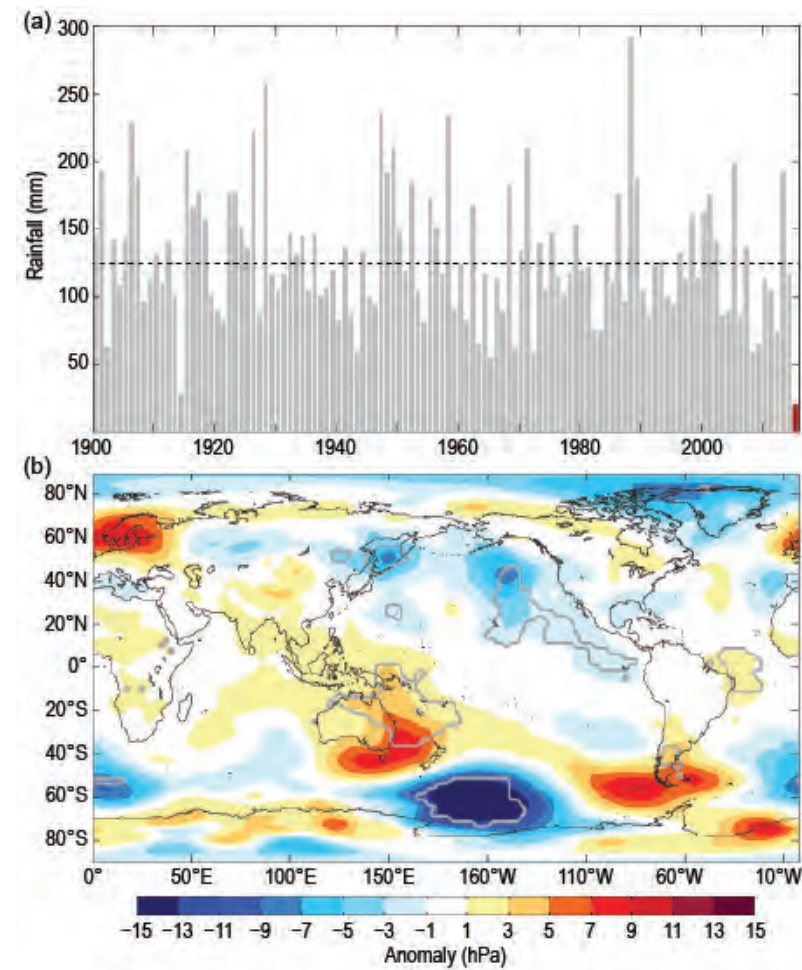

Fig. 25.I. (a) Observed Oct mean rainfall $(\mathrm{mm})$ for Tasmania for 1900-2015 from the Australian Bureau of Meteorology, with 2015 highlighted in red. The dashed line shows the 1900-2015 average. (b) Mean sea level pressure anomalies (MSLP, hPa) for Oct 2015 from NCEP-NCARI reanalyses (Kalnay et al. 1996). Regions with record high and low Oct MSLP values in the reanalyses are outlined by gray lines. 
Model Intercomparison Project phase 5 (CMIP5; Taylor et al. 2012).

Data and Methods. Monthly area-average rainfall data for Tasmania were obtained from the Australian Bureau of Meteorology. The October rainfall for 1900-2015 was obtained from high-resolution gridded data from the Australian Water Availability Project (AWAP; Jones et al. 2009). The dataset uses all available monthly rainfall station data, with sparser station coverage early in the period.

Very large ensembles of regional climate simulations of rainfall over Tasmania were used from the w@h ANZ project. This uses the atmosphereonly model, HadAM3P, to drive a nested regional model (HadRM3P; $0.44^{\circ}$ resolution). For details of the modeling setup, see Black et al. (2016). First, the model was run under two climate scenarios for 2015: observed (all forcings; ALL) and counterfactual (natural forcings only; NAT) realizations. For the ALL simulations, the model used observed SSTs and sea ice from the Operational Sea Surface Temperature and Sea Ice Analysis (OSTIA; Donlon et al. 2012), as well as present-day atmospheric composition (long-lived greenhouse gases, ozone, and aerosols). Very large ensembles were generated by running the model with perturbed atmospheric initial conditions. For the NAT simulations, the model was driven by preindustrial atmospheric composition and SSTs modified to remove different estimates of the warming attributable to anthropogenic forcing. Estimates of the SST changes due to anthropogenic forcing were separately calculated using eight CMIP5 models (Taylor et al. 2012; see online Supplemental Material), giving eight realizations of possible NAT SSTs. The main modes of natural variability represented in the ALL SSTs (e.g., the phase of El Niño) are maintained in the NAT SSTs. Therefore, any change in likelihood of low Tasmanian rainfall between these ALL and NAT scenarios can be directly attributed to anthropogenic forcing (Black et al. 2015).

To assess the influence of El Niño on Tasmanian rainfall, additional simulations were generated by driving the w@h ANZ model with composite SST patterns representative of El Niño, Neutral, and La Niña phases (see supplemental material). Each of these three phases was modeled under both ALL and NAT climate scenarios (as for the 2015 runs). Previous analysis has shown that the w@h ANZ model is able to represent El Niño teleconnections over Australia (Black et al. 2016).
We used all the model simulations that were available; more than 2700 members for each of the ALL scenarios (2015 ALL, El Niño ALL, Neutral ALL, and La Niña ALL) and more than 650 members for each of the corresponding eight NAT realizations (at least 5200 members for each NAT scenario).

Following Black et al. (2016), we corrected any model rainfall bias by scaling the Tasmanian October rainfall from the ALL simulations so that the mean of the distribution is equal to that of the recent AWAP observations (1985-2014). This bias adjustment is then applied to the NAT distribution.

To examine possible changes in the likelihood of extreme low October rainfall, we define a threshold based on the previous observed record $(56 \mathrm{~mm}$ in 1965; see Fig. 25.1a) rather than the 2015 record, to reduce selection bias. The 1914 low rainfall value was not used because of the smaller number of rainfall stations available then, which limits the reliability of the Tasmanian rainfall estimate given the varied topography across the state. The current rainfall station network across Tasmania has been relatively stable since the mid-1950s.

To quantify the change in likelihood of extreme low rainfall due to different forcing scenarios, we calculate the fraction of attributable risk (FAR; Allen 2003), defined as FAR $=1-\left(\mathrm{P}_{1} / \mathrm{P}_{2}\right)$. We estimate the anthropogenic (El Niño) influence by setting $\mathrm{P}_{1}$ to be the probability of rainfall lower than the October threshold in the NAT (La Niña and Neutral) simulations, while $\mathrm{P}_{2}$ is the equivalent for the ALL (El Niño) simulations. Hence, we are able to quantify the change in likelihood due to either anthropogenic forcing or El Niño. FAR uncertainty was estimated by bootstrap resampling groups of 1000 simulations from each of the ensembles (10000 times with replacement) and the 10th percentile FAR value is used to provide conservative estimates of changes in likelihood associated with the different forcing.

Coupled climate model data were extracted from the CMIP5 archive and evaluated for their performance in capturing observed variability of Tasmanian rainfall. The model data were regridded onto a $2^{\circ}$ grid and October rainfall over Tasmania and July-December Niño-3.4 SST values were extracted. Simulations from the "historical" experiment (including natural and anthropogenic forcings for 1861-2005) were compared with observations over 1951-2005. Models with at least three historical simulations were tested for similarity to observational data following King et al. (2016). The twelve models 
that passed this evaluation are listed in supplemental material. Given the coarse model resolution and poor representation of topography in western Tasmania, the simulated rainfall anomalies were assessed as percentage anomalies from the 1961-90 historical average, removing any rainfall bias.

October rainfall and Niño-3.4 data were extracted from the historicalNat (natural forcings only for 18612005) simulations and RCP8.5 (projected climate under a high greenhouse gas emissions scenario for 2006-35) simulations. The historical and matching RCP8.5 simulations were combined to provide an ALL forcing ensemble for 1995-2035 (40 years centered on 2015), which was compared with the NAT ensemble (1861-2005) using the historicalNat runs. These ensembles were then used to investigate the change in likelihood of low rainfall due to anthropogenic climate change.

Results. The observed October rainfall data show a significant but small correlation with El Niño and a small, nonsignificant drying trend. The linear regression estimate of the October 2015 rainfall anomaly associated with the Niño-3.4 SST value is $-26 \pm 10 \mathrm{~mm}$.

Assessment of the probability distributions of October rainfall from thew@h ANZ simulations (Fig. 25.2a) shows good agreement with observations and that the ALL ensembles are significantly drier than the NAT ensembles for both the 2015 and composite El Niño scenarios. The drying is about $8 \mathrm{~mm}$ for the median and about $5 \mathrm{~mm}$ for the 5 th percentile. A mean drying of about $6 \%$ is also found in the CMIP5 simulations (Fig. 25.2a).

The October rainfall distribution from the w@h ANZ El Niño ALL ensemble is also drier than the combined Neutral/La Niña ensemble (Fig. 25.2a), with a drying of about $5 \mathrm{~mm}$ for the 5 th percentile. This is much smaller than the observational-estimated anomaly for the 2015 El Niño. This El Niño analysis was not undertaken for the CMIP5 simulations due to the smaller number of El Niño years available.

Next, the change in likelihood of record low rainfall below the 1965 threshold is assessed for the different scenarios, using the FAR results shown in Fig. 25.2b. For the w@h ANZ simulations, anthropogenic forcing very likely increases the likelihood of low rainfall by at least $39 \%$ (median increase $75 \%$ ) for the 2015 scenario and by at least 18\% (median increase 59\%) for the composite El Niño scenario. For the CMIP5 simulations, the FAR results
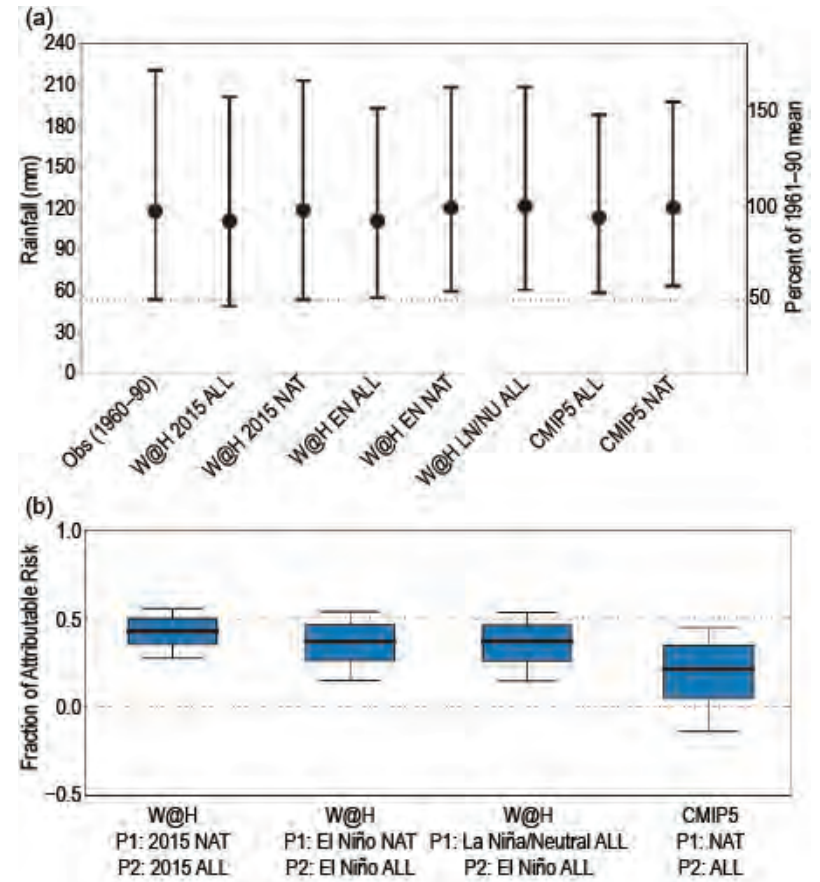

FIG. 25.2. (a) Distributions of Oct mean rainfall rate for Tasmania for the various model scenarios. Each vertical line spans the range from the 5 th percentile to the 95 th percentile, with the median marked. The dotted line is the Oct 1965 observed rainfall. (b) Corresponding distributions of FAR for rainfall below the 1965 threshold for the different scenario combinations for PI and P2. Boxes show the median and interquartile range while whiskers extend to the I0th and 90 th percentiles.

are less certain, with anthropogenic forcing possibly decreasing the likelihood by $12 \%$ or increasing it by up to $82 \%$, with a median increase of $25 \%$. Using the w@h ANZ simulations again, El Niño very likely increases the risk of low October rainfall by at least 18\% (median increase 59\%).

There are circulation differences between the w@h ANZ ALL and NAT simulations that are consistent with the response to anthropogenic forcing, including higher MSLP in middle latitudes and a significantly more positive SAM index in the ALL scenario, as found also in the CMIP5 simulations (Gillett et al. 2013).

Conclusions. Tasmania experienced its driest October on record in 2015. Anthropogenic climate change and the strong El Niño in 2015 very likely increased the chances of breaking the previous record low rainfall in 1965. In terms of contributions to the magnitude of this rainfall deficit, internal atmospheric variability as indicated by the PSA MSLP pattern (Fig. 25.1b) 
was likely the main contributor, with El Niño next and a smaller but significant contribution from anthropogenic climate change.

ACKNOWLEDGEMENTS. This research was supported by the ARC Centre of Excellence for Climate System Science (grant CE 110001028) and the National Environmental Science Programme Earth Systems and Climate Change Hub. In addition, weather@home ANZ involves collaboration with Oxford University, the Met Office, NIWA in New Zealand, and the Tasmanian Partnership for Advanced Computing. We acknowledge the WCRP Working Group on Coupled Modelling, which is responsible for CMIP5 and thank the climate modeling groups for making available their model output.

\section{REFERENCES}

Allen, M., 2003: Liability for climate change. Nature, 421, 891-892.

Black, M. T., and D. J. Karoly, 2016: Southern Australia's warmest October on record: The role of ENSO and climate change [in "Explaining Extreme Events of 2015 from a Climate Perspective"]. Bull. Amer. Meteor. Soc., 97 (12), S118-S121, doi10.1175/BAMSD-16-0124.1. (chapter 20 of EEE)

Black, M. T., D. J. Karoly, and A. D. King, 2015: The contribution of anthropogenic forcing to the Adelaide and Melbourne, Australia, heat waves of January 2014 [in "Explaining Extreme Events of 2014 from a Climate Perspective"]. Bull. Amer. Meteor. Soc., 96 (12), S145-S148, doi:10.1175/BAMS-D-15-00097.1.

__, _ _ and Coauthors, 2016: The weather@home regional climate modelling project for Australia and New Zealand. Geosci. Model Dev., 9, 3161-3176, doi:10.5194/gmd-9-3161-2016.

Bureau of Meteorology, 2015: Special Climate Statement 52: Australia's warmest October on record, version 2.1, updated 2 Dec 2015. Bureau of Meteorology, $25 \mathrm{pp}$. [Available online at www.bom.gov.au /climate/current/statements/scs52.pdf.]

Donlon, C. J., M. Martin, J. Stark, J. Roberts-Jones, E. Fiedler, and W. Wimmer, 2012: The Operational Sea Surface Temperature and Sea Ice Analysis (OSTIA) system. Remote Sens. Environ., 116, 140-158, doi:10.1016/j.rse.2010.10.017.
Gillett, N. P., J. C. Fyfe, and D. E. Parker, 2013: Attribution of observed sea level pressure trends to greenhouse gas, aerosol, and ozone changes. Geophys. Res. Lett., 40, 2302-2306, doi:10.1002/grl.50500.

Hill, K. J., A. Santoso, and M. H. England, 2009: Interannual Tasmanian rainfall variability associated with large-scale climate modes. J. Climate, 22, 43834397, doi:10.1175/2009JCLI2769.1.

Hobday, A., E. Oliver, J. McDonald and M. Grose, 2016: Was Tasmania's summer of fires and floods a glimpse of its climate future. The Conversation, 19 April 2016. [Available online at https:// theconversation.com/was-tasmanias-summer -of-fires-and-floods-a-glimpse-of-its-climate -future-58055.]

Hope, P., and Coauthors, 2015: Seasonal and regional signature of the projected southern Australian rainfall reduction. Aust. Meteor. Ocean. J., 65, 54-71.

Jones, D. A., W. Wang, and R. Fawcett, 2009: Highquality spatial climate data-sets for Australia. Aust. Meteor. Oceanogr. J., 58, 233-248.

Kalnay, E., and Coauthors, 1996: The NCEP/NCAR 40year reanalysis project. Bull. Amer. Meteor. Soc., 77, 437-470.

Karoly, D. J., 1989: Southern Hemisphere circulation features associated with El Niño-Southern Oscillation events. J. Climate, 2, 1239-1252.

King, A. D., G. J. van Oldenborgh, and D. J. Karoly, 2016: Climate change and El Niño increase likelihood of Indonesian heat and drought [in "Explaining Extreme Events of 2015 from a Climate Perspective"]. Bull. Amer. Meteor. Soc., 97 (12), S113-S117, doi10.1175/BAMS-D-16-0164.1. (Chapter 19 of EEE)

Massey, N., and Coauthors, 2015: weather@homedevelopment and validation of a very large ensemble modelling system for probabilistic event attribution. Quart. J. Roy. Meteor. Soc., 141, 1528-1545, doi:10.1002/qj.2455.

Mo, K. C., and R. W. Higgins, 1998: The Pacific-South American modes and tropical convection during the Southern Hemisphere winter. Mon. Wea. Rev., 126, 1581-1596.

Taylor, K. E., R. J. Stouffer, and G. A. Meehl, 2012: An overview of CMIP5 and the experiment design. Bull. Amer. Meteor. Soc., 93, 485-98, doi:10.1175/BAMS -D-11-00094.1. 


\title{
26. INFLUENCES OF NATURAL VARIABILITY AND ANTHROPOGENIC FORCING ON THE EXTREME 2015 ACCUMULATED CYCLONE ENERGY IN THE WESTERN NORTH PACIFIC
}

\author{
Wei Zhang, Gabriel A. Vecchi, Hiroyuki Murakami, Gabriele Villarini, Thomas L. Delworth, \\ Karen Paffendorf, Rich Gudgel, Liwei Jia, Fanrong Zeng, and Xiaosong Yang
}

\begin{abstract}
The extreme value of the 2015 western North Pacific (WNP) accumulated cyclone energy (ACE) was mainly caused by the sea surface warming in the eastern and central Pacific, with the anthropogenic forcing largely increasing the odds of the occurrence of this event.
\end{abstract}

Introduction. The 2015 tropical cyclone (TC) activity measured by the ACE [computed as the sum of the square of the maximum surface wind speed (MSW) over the TC duration when MSW is greater than 34 knots; e.g., Bell et al. 2000] was extremely high in the western North Pacific Ocean (Figs. 26.1a,b and 26.2a). The 2015 WNP ACE is the second highest since 1970 (with the highest being 1997) based on the Joint Typhoon Warning Center best track data for 1970-2014 and Unisys data for 2015 (http://weather.unisys.com /hurricane/), the highest since 1977 based on the Japan Meteorological Agency (JMA), and the highest since 1970 based on Shanghai Typhoon Institute (STI) data. Higher (lower) WNP ACE is generally observed during El Niño (La Niña) years, because TCs are formed more southeastward (northwestward) and stay longer (shorter) over the warm ocean surface (e.g., Camargo and Sobel 2005; Chan 2007). This shift in genesis and difference in tracks leads to a higher occurrence of the most intense typhoons, which is the main cause of a high ACE during El Niño years. An extremely strong El Niño event developed in 2015. While there has been major progress in the understanding of the El Niño-Southern Oscillation (ENSO)-WNP ACE association, the modulation of

\section{AfFiliations: Zhang, Veechi, Murakami, Delworth,} PAFFendoRf, JIA, AND YANG—NOAA/Geophysical Fluid Dynamics Laboratory, Princeton, New Jersey; Zhang, Veechi, Murakami, Delworth, Paffendorf, Gudgel, Jia, and Zeng-Atmospheric and Oceanic Sciences Program, Princeton University, Princeton, New Jersey; ZHANG AND VILLARINI-IIHR-Hydroscience \& Engineering, The University of lowa, lowa City, lowa; Yang-University Corporation for Atmospheric Research, Boulder, Colorado DOI:I0.II75/BAMS-D-16-0146.I

A supplement to this article is available online $(10.1175$ /BAMS-D-16-0146.2)
WNP ACE by anthropogenic forcing is still a challenging scientific question (e.g., Emanuel 2013; Lin and Chan 2015). Using observations and a suite of climate model experiments, this study attempts to assess whether and to what extent internal climate modes (e.g., ENSO) and anthropogenic forcing contributed to the extreme 2015 WNP ACE event.

Methodology. We use two coupled general circulation models (CGCMs): the Geophysical Fluid Dynamics Laboratory (GFDL) forecast-oriented low ocean resolution model (FLOR; Vecchi et al. 2014) and highresolution FLOR (HiFLOR; Murakami et al. 2015a; Zhang et al. 2016b). TCs are identified and tracked using a tracking algorithm based on various model variables (Zhang et al. 2016a,b; see online Supplemental Material). The climatological values of WNP ACE in the observations, FLOR, and HiFLOR are different partly because of different spatial resolutions and climate mean states; we therefore analyze the WNP ACE values in terms of exceedance probabilities (e.g., 0.95, 0.99) of all the sampled ACE values in observations and simulations. Following Murakami et al. (2015b) and Yang et al. (2015), we use a probabilistic approach to examine the probability of a WNP ACE event as:

$$
P(x)=\frac{\text { Number of years with } \mathrm{ACE} \geq x}{\text { Total number of years }}
$$

where $x$ is a selected WNP ACE value and $P(x)$ represents the probability with WNP ACE larger than or equal to $x$. We use the fraction of attributable risk (FAR; e.g., Allen 2003; Stott et al. 2004) to quantify the FAR to human influence or anthropogenic forcing. FAR is defined as FAR $=1-\left(P_{0} / P_{1}\right)$, where $P_{0}$ $\left(P_{1}\right)$ is the probability of exceeding the observed TC 
trend in the experiments without (with) anthropogenic forcing. We compute FAR using $P_{0}$ from a 1990 control experiment of FLOR and $P_{1}$ from a $2 \times \mathrm{CO}_{2}$ experiment with the same model (van der Wiel et al. 2016). We also compute $P_{0}\left(P_{1}\right)$ from the two experiments of HiFLOR with radiative forcing representative of $1940(2015 ; 1940$ is also a strong El Niño year).

Natural Variability. The extremely high 2015 WNP ACE is mostly due to a large number of category 4 and 5 (C45; wind speed exceeding 58.1 $\mathrm{m} \mathrm{s}^{-1}$ ) TCs (Fig. 26.1a). There were 13 C45 TCs in the WNP during 2015, more than twice the climatological value of 6.3. The 2015 C45 proportion, defined by the number of C45 TCs divided by the basin-total TCs, is 0.48 while the climatology (1970-2015) is 0.25 . The 2015 basin-total TC frequency (27) is slightly higher than climatology (25). The ENSO-WNP ACE association is supported by the high Niño-3.4 index in 2015, similar to those in 1987 and 1997 (Figs. 26.1b,c). The SST warming in 2015 extends westward to $160^{\circ} \mathrm{E}$, and this provides favorable conditions

for TC intensification because WNP TC intensification is influenced both by TC genesis location and ocean temperature (Wada and Chan 2008; Mei et al. 2015; Zhang et al. 2015). Previous studies suggested that factors such as the Pacific meridional mode (PMM), the Pacific decadal oscillation (PDO), and the Atlantic meridional mode (AMM) (see Supplemental Material) may also modulate WNP ACE (e.g., Chan 2008; Zhang et al. 2016a,c). The correlations between WNP ACE and the Niño-3.4 (significant at 0.01 level), PMM (significant at 0.01 level), and PDO (not significant at the 0.01 level) indices are positive, while the correlation between WNP
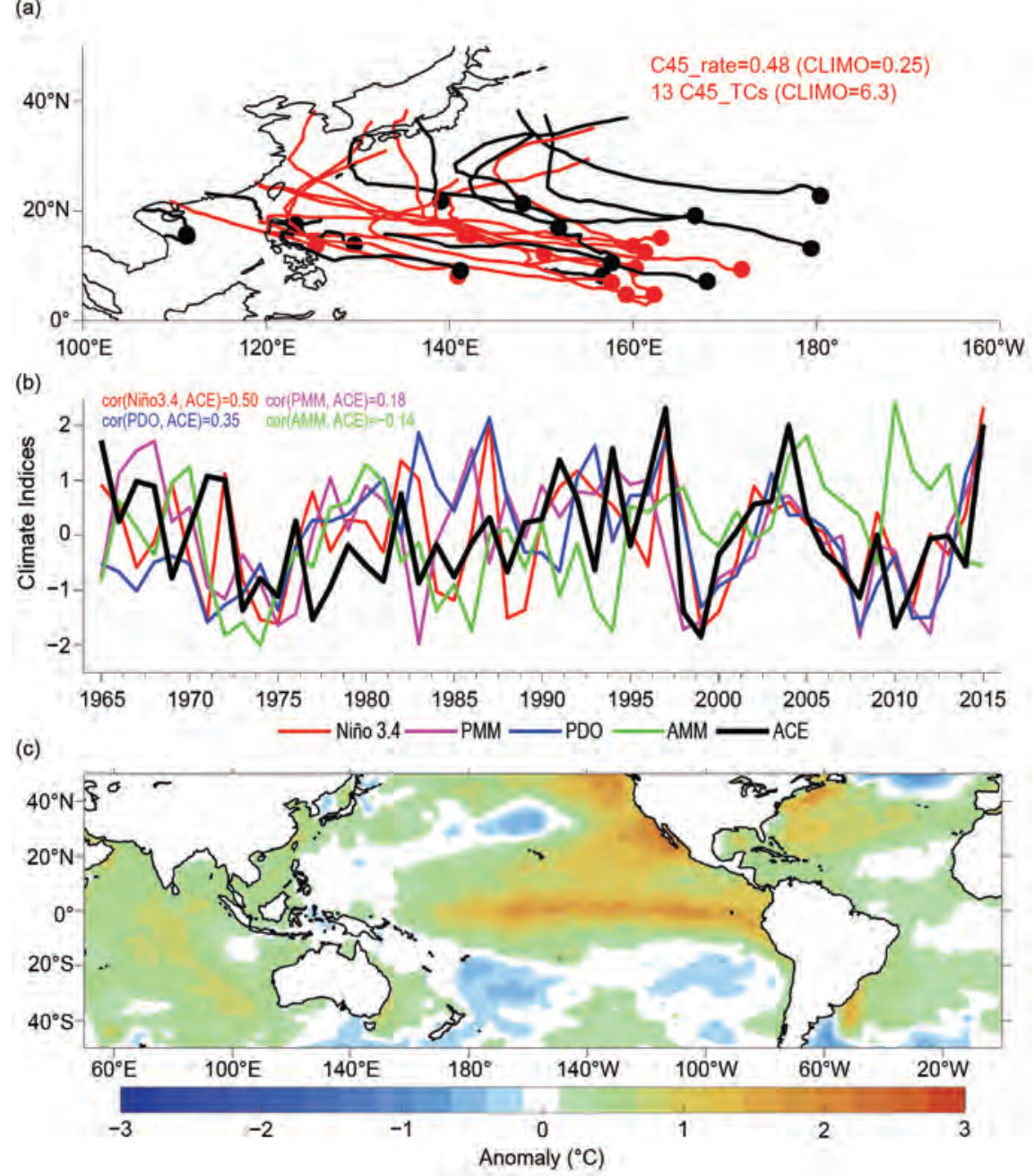

FIG. 26.I. (a) TC tracks in 2015 and C45 TCs (wind speed exceeding $58.1 \mathrm{~m} \mathrm{~s}^{-1}$ ) are shown in red. The $\mathbf{C} 45$ proportion in 2015 is $\mathbf{0 . 4 8}$ while the climatology (1970-2015) is 0.26, with I3 (6.3) C45 TCs in 2015 (climatology; see Supplemental Material for data sources). (b) Time series of different annually averaged normalized climate indices (see legend) and ACE (black); Cor (Niño-3.4, ACE) enotes the correlation coefficient between Niño-3.4 index and WNP ACE for 1970-2015, while the others are defined likewise. (c) Sea surface temperature anomalies $\left({ }^{\circ} \mathrm{C}\right.$ ) in 2015 computed with respect to the 1970-2000 base period.

ACE and the AMM is negative but not statistically significant (Fig. 26.1b, see Supplemental Material for more details of the indices). The Niño-3.4 and PMM indices in 2015 are strongly positive, contributing to the extreme 2015 WNP ACE. Therefore, internal climate modes, especially the strong El Niño, may have substantially contributed to the extreme 2015 WNP ACE by leading to an extremely high frequency of C45 TCs (Camargo and Sobel 2005).

Effect of Anthropogenic Forcing. We analyze two sets of experiments (i.e., 1990 control and $2 \times \mathrm{CO}_{2}$ experiments) with FLOR. The probability density functions 
(a)

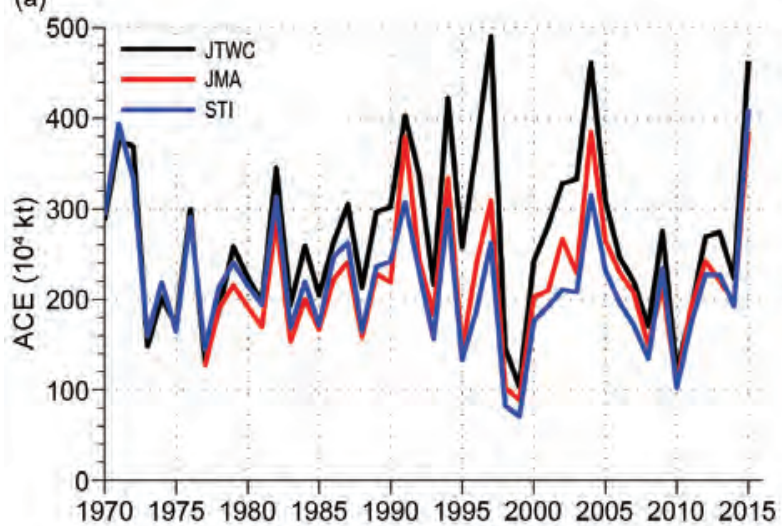

(c)

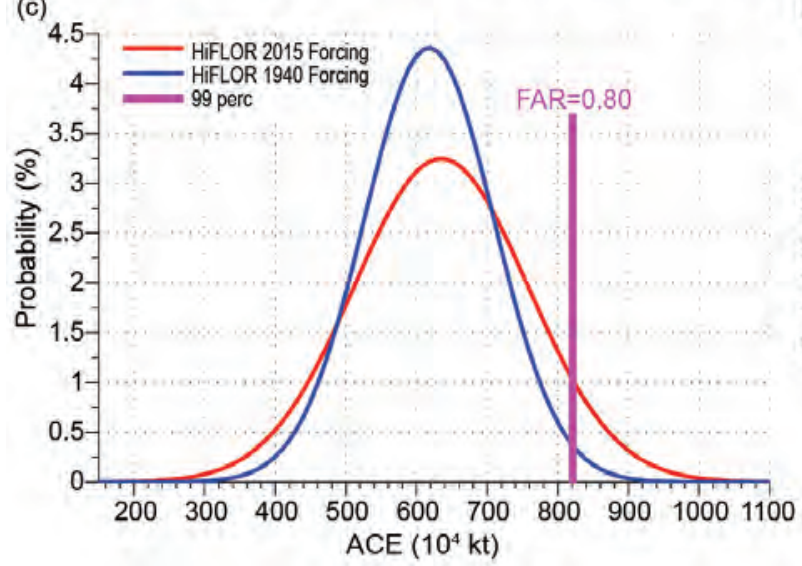

(b)

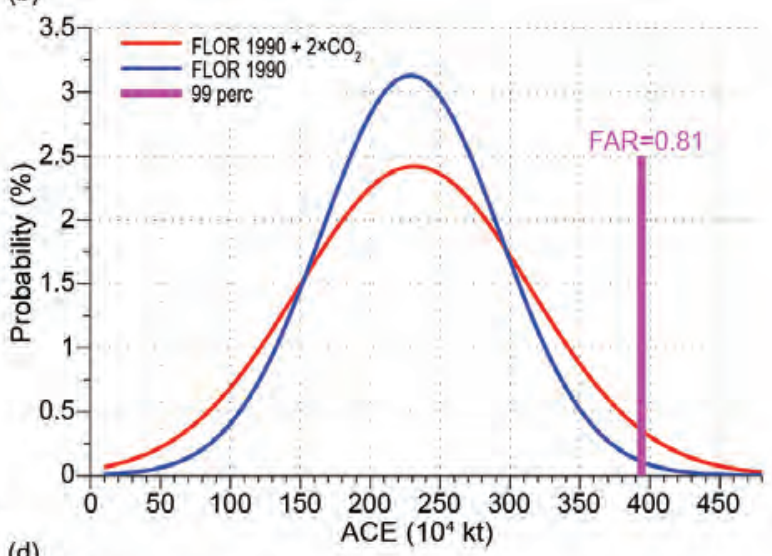

(d)

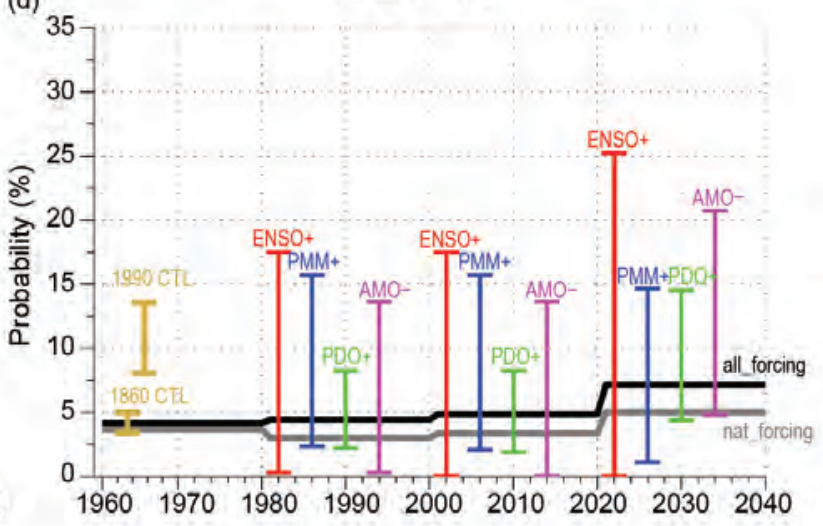

Fig. 26.2. (a) Annual WNP ACE based on observations. (b) PDFs of WNP ACE in 1990 (blue) and $2 \times \mathrm{CO}_{2}$ (red) experiments with FLOR. (c) PDFs of WNP ACE in the experiments with radiative forcing representative of 1940 (blue) and 2015 (red) in HiFLOR. The magenta bars represent the 99th percentile of the ACE values (similar to observations) in FLOR/HiFLOR. (d) $P(x=95$ th percentile) in FLOR-FA all_forcing/nat_forcing multidecadal experiments with upper/lower limits of error bars represent ENSO+/- (red), PMM+/- (blue), PDO+/- (green), and AMO-I+ (magenta). The brown bars represent $P(x=95$ th percentile) in two control experiments with the widths representing the 0.95 confidence intervals. The black and gray curves represent $P(x=95$ th percentile) in samples of all_forcing and nat_forcing experiments, respectively.

(PDFs) of WNP ACE in FLOR 1990 control and $2 \times$ $\mathrm{CO}_{2}$ experiments have similar mean values while their variances are different, with a fatter tail in the $2 \times \mathrm{CO}_{2}$ experiment (Fig. 26.2b). We select the ACE values in the 99th percentile of FLOR 1990 to calculate FAR, consistent with the percentile of the observed 2015 WNP ACE (Figs. 26.2a,b). The FAR in the 1990 control and $2 \times \mathrm{CO}_{2}$ experiments of FLOR are 0.81, indicating that anthropogenic forcing can substantially increase the risk of having extreme WNP ACE events higher than or equal to the 2015 event. To further substantiate this finding, we also analyze $P_{0}$ and $P_{1}$ in the two experiments of HiFLOR with radiative forcing representative of 1940 and 2015. The PDFs of WNP ACE in HiFLOR also have a fatter tail in the experiment with radiative forcing representative of 2015 compared with that of 1940 (Fig. 26.2c). The FAR in HiFLOR is 0.80 , close to 0.81 in the experiments with FLOR (Figs. 26.2b,c).

We ran 35-member simulations with all forcing (natural and anthropogenic under RCP 4.5 scenario) and 30-member multidecadal simulations with natural forcing from 1961 to 2040 (see Supplemental Material). For each 20-year period from 1961, 1300 $(20 \times 35+20 \times 30)$ samples (years) were available to calculate $P(x)$. We define a simulated positive (or negative) phase of ENSO, PDO, PMM, and AMO as these indices exceeding (falling below) one (minus one) standard deviation and estimate the amplitude of $P(x)$ between the two phases. Figure 26.2d illustrates the results for $P(x=95$ th percentile). $P(x=95$ th percentile) in all_forcing experiments increases from 1960 to 2040, suggesting that the external forcing tends to increase the odds of occurrence of extreme 
WNP ACE. There is a sharp increase in $P(x=95$ th percentile) during 2020-40 (Fig. 26.2d). In addition, the $P(x=95$ th percentile $)$ in nat_forcing experiments also largely increases in 1960-2060, except for a slight decrease from $1960-80$ to $1980-2000$. The $P(x=95$ th percentile) in all_forcing experiments are higher than those in nat_forcing experiments, indicating that anthropogenic forcing increases the risk of having extreme WNP ACE events. The results based on FLOR-FA 1860 and 1990 control experiments are also shown in the left of Fig. 26.2d, providing additional support to these conclusions. For each 20 -year subperiod in 1980-2040, ENSO produces the largest variability of WNP ACE (Fig. 26.2d). The variability associated with ENSO is larger than that associated with radiative forcing (Fig. 26.2d). Therefore, the extreme 2015 WNP ACE may be mainly modulated by natural climate modes, especially by the strong El Niño, with the anthropogenic forcing increasing the risk of 2015 having a season with an extremely high WNP ACE. This risk is predicted to continue to increase in the next few decades, increasing the probability of having seasons with a WNP ACE equal to or higher than 2015 in the future.

Discussions and Conclusions. We have observed an extremely active TC season in the WNP in 2015, with an extremely high ACE and frequency of C45 TCs. The 2015 season may be caused mainly by warm ocean surface temperatures in the tropical Pacific, characterized by a strong El Niño event, with other climate modes (e.g., PMM) potentially playing a role. We have found that anthropogenic forcing has substantially increased the risk of having WNP ACE higher than or equal to such an extreme event. Although the changes in WNP ACE under anthropogenic forcing are still unclear (e.g., Emanuel 2013; Lin and Chan 2015), both GFDL FLOR and HiFLOR do suggest that the annual WNP ACE tends to become more extreme because of anthropogenic forcing. The two models also suggest that the variability of WNP ACE attributable to climate modes will increase at a much higher rate than as a result of anthropogenic forcing. The frequency of strong El Niño events is projected to increase due to greenhouse warming (Cai et al. 2014), which in turn could potentially lead to a higher frequency of WNP seasons with high values of ACE.

ACKNOWLEDGEMENT. This material is based in part upon work supported by the National Science Foundation under Grants AGS-1262091 and AGS1262099.

\section{REFERENCES}

Allen, M., 2003: Liability for climate change. Nature, 421, 891-892.

Bell, G. D., and Coauthors, 2000: Climate assessment for 1999. Bull. Amer. Meteor. Soc., 81 (6), S1-S50.

Cai, W., and Coauthors, 2014: Increasing frequency of extreme El Niño events due to greenhouse warming. Nat. Climate Change, 4, 111-116, doi:10.1038 /nclimate 2100.

Camargo, S. J., and A. H. Sobel, 2005: Western North Pacific tropical cyclone intensity and ENSO. J. Climate, 18, 2996-3006.

Chan, J. C. L., 2007: Interannual variations of intense typhoon activity. Tellus, 59A, 455-460.

- 2008: Decadal variations of intense typhoon occurrence in the western North Pacific. Proc. Roy. Soc. London, 464A, 249-272.

Emanuel, K. A., 2013: Downscaling CMIP5 climate models shows increased tropical cyclone activity over the 21st century. Proc. Natl. Acad. Sci. USA, 110, 12219-12224, doi:10.1073/pnas.1301293110.

Lin, I. I., and J. C. L. Chan, 2015: Recent decrease in typhoon destructive potential and global warming implications. Nat. Commun., 6, 7182, doi:10.1038 /ncomms 8182 .

Mei, W., S.-P. Xie, F. Primeau, J. C. McWilliams, and C. Pasquero, 2015: Northwestern Pacific typhoon intensity controlled by changes in ocean temperatures. Sci. Adv., 1, e1500014, doi:10.1126/sciadv.1500014.

Murakami, H., and Coauthors, 2015a: Simulation and prediction of category 4 and 5 hurricanes in the high-resolution GFDL HiFLOR coupled climate model. J. Climate, 28, 9058-9079. 10.1175/JC LI-D-15-0216.1.

, G. A. Vecchi, T. L. Delworth, K. Paffendorf, L. Jia, R. Gudgel, and F. Zeng, 2015b: Investigating the influence of anthropogenic forcing and natural variability on the 2014 Hawaiian hurricane season [in "Explaining Extreme Events of 2014 from a Climate Perspective"]. Bull. Amer. Meteor. Soc., 96 (12), S115-S119, doi:10.1175/BAMS-D-15-00119.1.

Stott, P. A., D. A. Stone, and M. R. Allen, 2004: Human contribution to the European heatwave of 2003. Nature, 432, 610-614, doi:10.1038/nature03089.

Van der Wiel, K., and Coauthors, 2016: The resolution dependence of contiguous US precipitation extremes in response to $\mathrm{CO}_{2}$ forcing. J. Climate, 29, 7991-8012, doi:10.1175/JCLI-D-16-0307.1. 
Vecchi, G. A., and Coauthors, 2014: On the seasonal forecasting of regional tropical cyclone activity. J. Climate, 27, 7994-8016, doi:10.1175/JC LI-D-14-00158.1.

Wada, A., and J. C. L. Chan, 2008: Relationship between typhoon activity and upper ocean heat content. Geophys. Res. Lett., 35, L17603, doi:10.1029/2008GL035129.

Yang, X., G. A. Vecchi, T. L. Delworth, K. Paffendorf, R. Gudgel, L. Jia, S. D. Underwood, and F. Zeng, 2015: Extreme North America winter storm season of 2013/14: Roles of radiative forcing and the global warming hiatus [in "Explaining Extreme Events of 2014 from a Climate Perspective"]. Bull. Amer. Meteor. Soc., 96 (12), S25-S28, doi:10.1175 /BAMS-D-15-00133.1.

Zhang, W., Y. Leung, and K. Fraedrich, 2015: Different El Niño types and intense typhoons in the western North Pacific. Climate Dyn., 44, 2965-2977, doi:10.1007/s00382-014-2446-4.

—, and Coauthors, 2016a: The Pacific meridional mode and the occurrence of tropical cyclones in the western North Pacific. J. Climate, 29, 381-398, doi:10.1175/JCLI-D-15-0282.1.

— tropical cyclone responses to ENSO in the western North Pacific in the high-resolution GFDL HiFLOR coupled climate model. J. Climate, 29, 1391-1415, doi:10.1175/JCLI-D-15-0475.1.

-, G. A. Vecchi, G. Villarini, H. Murakami, A. Rosati, X. Yang, L. Jia, and F. Zengand, 2016c: Modulation of western North Pacific tropical cyclone activity by the Atlantic meridional mode. Climate Dyn., in press, doi:10.1007/s00382-016-3099-2. 


\title{
27. RECORD LOW NORTHERN HEMISPHERE SEA ICE EXTENT IN MARCH 2015
}

\author{
Neven S. Fučkar, François Massonnet, Virginie Guemas, Javier García-Serrano, Omar Bellprat, \\ Francisco J. Doblas-Reyes, and Mario Acosta
}

\begin{abstract}
The record low Northern Hemisphere (NH) winter sea ice maximum stemmed from a strong interannual surface anomaly in the Pacific sector, but it would not have been reached without long-term climate change.
\end{abstract}

Introduction. Since the late 1970s, the NH sea ice concentration (SIC), age, and thickness in most Arctic regions have experienced long-term decline superimposed with strong internal variability (Stroeve et al. 2012; Jeffries et al. 2013; Comiso and Hall 2014). March NH sea ice extent (SIE: integrated area of grid cells with monthly-mean SIC > 15\%) reached the lowest winter maximum in the satellite record in 2015 (Fig. 27.1a). This extreme of 15.13 million $\mathrm{km}^{2}$ is 1.12 million $\mathrm{km}^{2}$ below the $1980-2015$ average NH March SIE, and 0.33 million $\mathrm{km}^{2}$ below the linear fit over the same period, based on SIC from the EUMETSAT's Satellite Application Facility on Ocean and Sea Ice (OSI SAF; Eastwood 2014).

The March 2015 SIC anomaly pattern in Fig. 27.1d shows that the reduced SIC in the Barents and Greenland Seas is contrasted by the increased SIC in the Baffin Bay and the Labrador Sea leading to the $\mathrm{NH}$ SIE in the Atlantic sector $\left(\mathrm{NH}_{\text {Atl }} \mathrm{SIE}\right)$ of 0.28 million $\mathrm{km}^{2}$ above the linear fit. At the same time, negative SIC anomalies in the Bering Sea and Sea of Okhotsk in Fig. 27.1d pushed the NH SIE in the Pacific sector $\left(\mathrm{NH}_{\mathrm{Pac}} \mathrm{SIE}\right)$ to the record low of 0.61 million $\mathrm{km}^{2}$ below the linear fit, which is outside the $95 \%$ confidence interval of the linear-fit residuals. Hence, the 2015 $\mathrm{NH}_{\mathrm{Pac}}$ SIE strong interannual anomaly contributed most substantially to this NH SIE record low. The spatially nonuniform linear trend of the $\mathrm{NH}$ March SIC in Fig. 27.1e yields about three times faster longterm decline of the $\mathrm{NH}_{\mathrm{Atl}}$ SIE than the $\mathrm{NH}_{\text {Pac }}$ SIE.

AFFILIATIONS: FuČKar, Massonnet, Guemas, García-Serrano, Bellprat, ANd Acosta-Barcelona Supercomputing Center-Centro Nacional de Supercomputación (BSC-CNS), Earth Sciences Department, Barcelona, Spain; DOBLAS-ReYES-BSC-CNS, Earth Sciences Department, Barcelona, Spain, and Instituciò Catalana de Recerca i Estudis Avancats, Barcelona, Spain

DOI:10.1175/BAMS-D-16-0153.I

A supplement to this article is available online (10.II75 /BAMS-D-16-0153.2)
The 2015 SIC anomaly pattern with respect to this long-term linear fit (Fig. 27.1f) further indicates that negative interannual anomalies in the Pacific sector outside of the Arctic basin dominate over the positive ones west of Greenland in the Atlantic.

The anomaly and detrended anomaly patterns in Supplemental Fig. S27.1 show anticyclonic sea level pressure over the western Aleutian Islands associated with positive 2-m air temperature over the Sea of Okhotsk in March 2015 likely due to southerly surface wind that substantially contributed to the negative SIC there (Kimura and Wakatsuchi 1999), while the negative SIC in the Bering Sea is more directly related to collocated positive sea surface temperature (SST, Zhang et al. 2010). Such strong interannual surface anomalies in these two marginal seas therefore seem to have played an important role in the NH SIE record low, but what is the role of the underlying long-term change in the ocean and sea ice cover? They integrate the impact of climate change that is pronounced in the high north due to the Arctic amplification (Screen et al. 2012; Taylor et al. 2013). Would the 2014/15 fall-winter atmosphere yield this sea ice extreme if we reversed in time the long-term change in the ocean and sea ice state? We examine the contributions of the atmosphere and the long-term memory of the ocean and sea ice to the March 2015 record low of the NH SIE.

Method. A climate variable can be decomposed into the sum of the background state represented as a linear fit over the period of interest and an interannual anomaly with respect to this fit: $\operatorname{var}(t)=\left[a_{1} t+a_{0}\right]+$ $\operatorname{var}^{\prime}(t)$. To estimate the contributions of the evolution of the ocean and sea ice linear-fit background state over the last 36 years, and the 2014/15 fall-winter atmosphere to the NH March SIE minimum, we perform a set of control and sensitivity experiments 
(a)
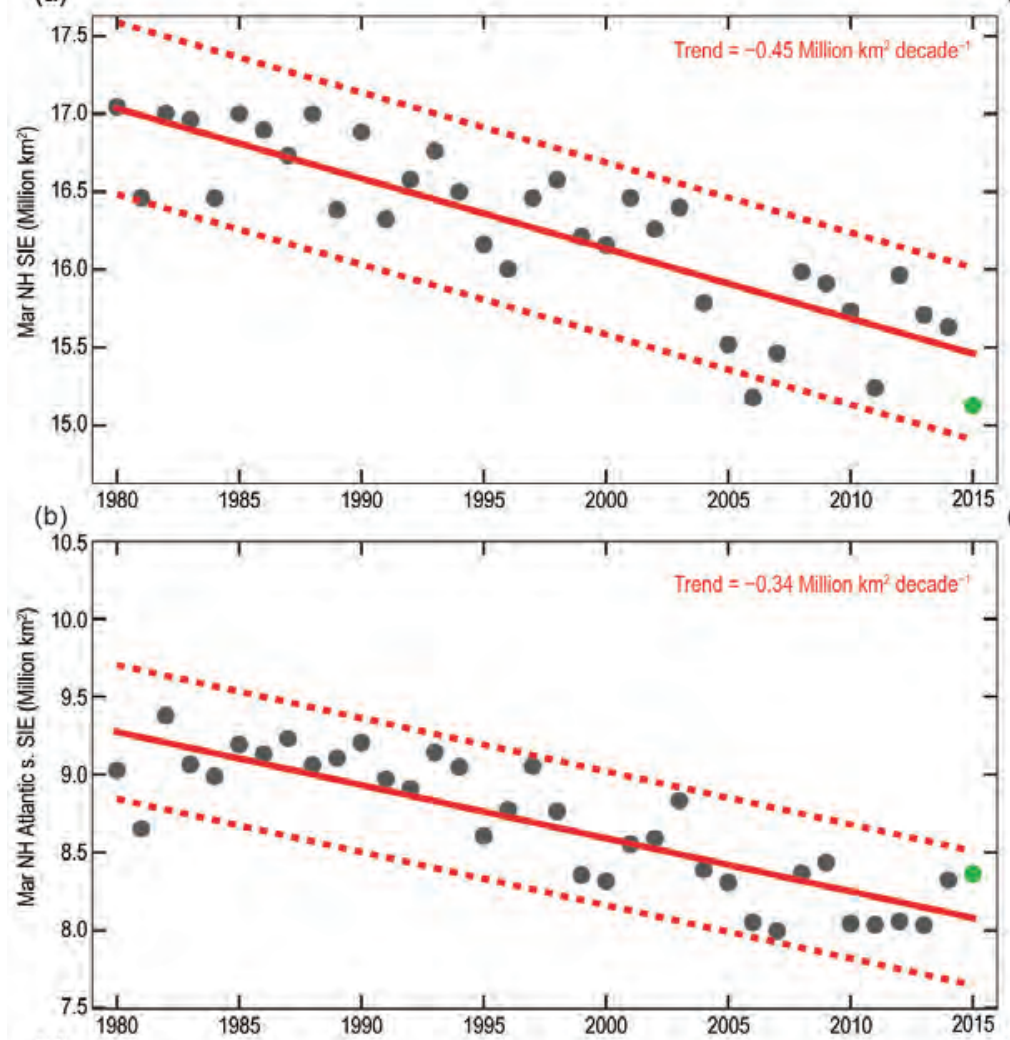

(c)

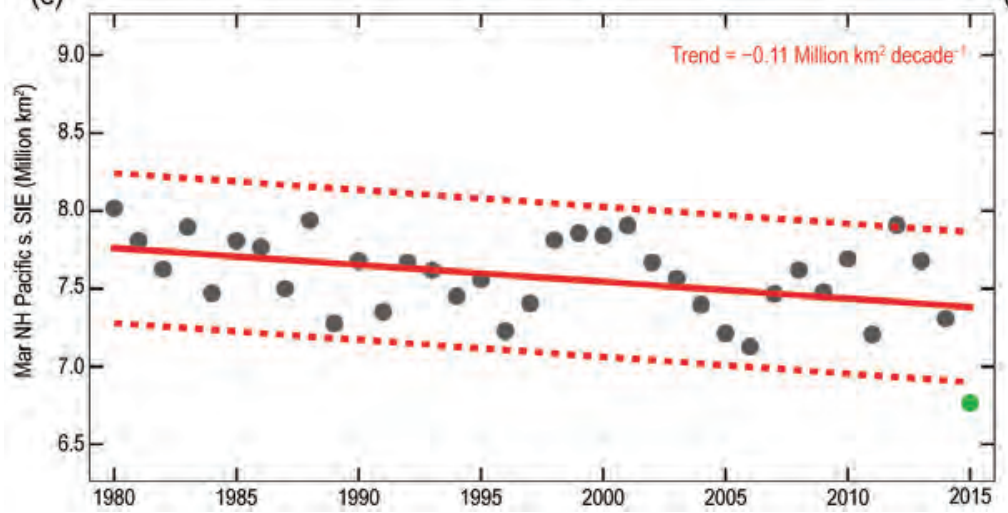

(d)

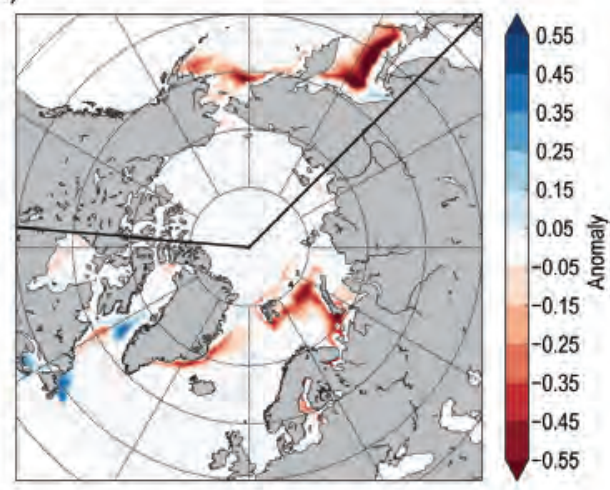

(e)

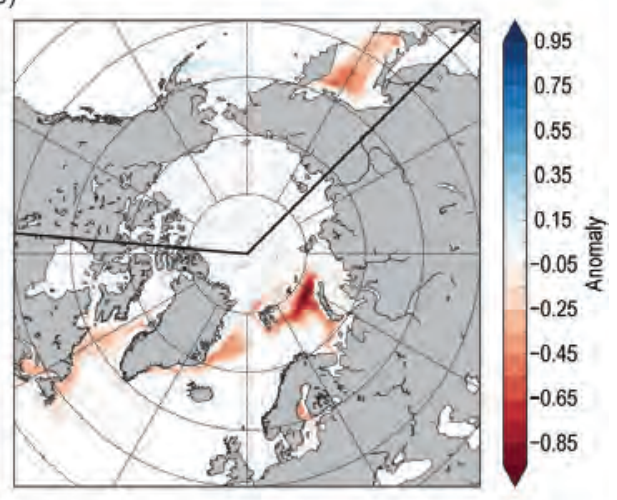

(f)

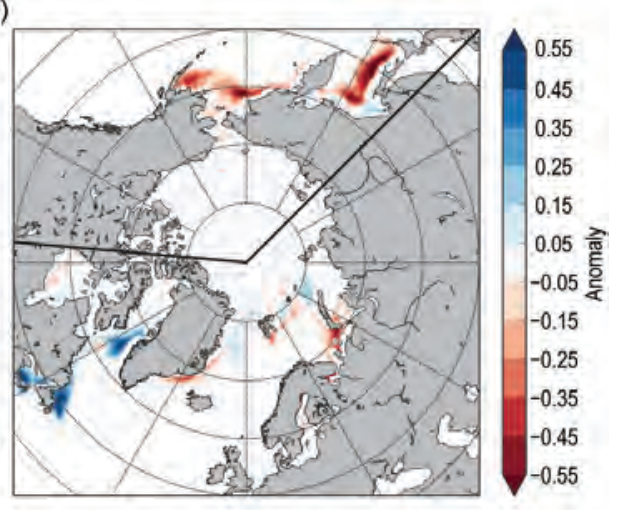

FIG. 27.I. (a)-(c) Black points show the total SIE, SIE in the Atlantic sector (from $95^{\circ} \mathrm{W}$ to $135^{\circ} \mathrm{E}$ ), and SIE in the Pacific sector (from $135^{\circ} \mathrm{E}$ to $265^{\circ} \mathrm{E}$ ) in the NH in Mar from 1980 to 2015 (which is exclusively marked in green), respectively, from OSI SAF. Solid (dashed) red lines show the linear fit with trends indicated in the upper right corner (the $95 \%$ confidence interval of the residuals of the linear fit). (d)-(f) The NH SIC anomaly in Mar 2015 with respect to the 1980-2015 average, linear change (linear trend times 36 years) where stippling denotes 5\% significance, and anomaly in Mar 2015 with respect to the linear fit over this period, respectively.

with a state-of-the-art ocean-sea ice general circulation model (OGCM). We utilize NEMO3.3-LIM3 OGCM (Madec et al. 2008; Vancoppenolle et al., 2009) forced by the ECMWF's ERA-Interim atmospheric reanalysis (Dee et al. 2011) as described in Massonnet et al. (2015)

First, we perform a set of 5-month-long retrospective control simulations (CTL) initialized on 1 November from 1979 to 2014 to assess the model skill in predicting the NH March SIE. We produce five ensemble members initialized from the five members of the ECMWF's Ocean Reanalysis System 4 (ORAS4; Balmaseda et al. 2013) and the associated five-member sea ice reconstruction produced with the same OGCM through the restoring methodology described in Guemas et al. (2014). CTL in March have 3.0, 2.4, and 5.5 times weaker ensemble-mean downward trends (along the start dates) than OSI SAF 
in the $\mathrm{NH}, \mathrm{NH}_{\mathrm{Atl}}$, and $\mathrm{NH}_{\mathrm{Pac}}$ SIE, respectively (see online supplemental material). Hence, we apply the trend bias correction method (Kharin et al. 2012; Fučkar et al. 2014) to obtain adjusted March 2015 forecasts of the $\mathrm{NH}, \mathrm{NH}_{\text {Atl }}$, and $\mathrm{NH}_{\text {Pac }}$ SIE ensemble means of 15.09 million $\mathrm{km}^{2}, 8.22$ million $\mathrm{km}^{2}$, and 6.86 million $\mathrm{km}^{2}$ (Figs. 27.2a, 27.2b, and 27.2c), respectively. CTL ensemble shows overconfidence, likely due to the small ensemble as well as missing physical processes, such as multicategory sea ice and interactive atmosphere. Small ensemble-mean errors in 2015 (less than $2 \%$ in each domain) indicate that the adjusted OGCM forecasts have appropriate skill for our analysis.

Next, we conduct two sets of four five-member sensitivity experiments with initial conditions (IC) and surface forcing fields specified in Table 27.1. In general, the forced OGCM forecast of the March state evolves from a past state to the 2015 state due to modifications in IC and forcing fields that can be decomposed into: (i) linearfit background state of IC; (ii) interannual anomaly in IC with respect to factor (i); (iii) linear-fit background state of surface forcing fields; and (iv) interannual anomaly in surface forcing fields with respect to factor (iii). The experiments e $82^{*}, \mathrm{e} 92^{*}, \mathrm{e} 02^{*}$, and $\mathrm{e} 12^{*}$ forecast the March state for four different years (1982, 1992, 2002, and 2012), starting from the ocean and sea ice IC on 1 November 1981, 1991, 2001, and 2011, respectively, with modified factor (ii). Specifically, we replace a past interannual anomaly of IC with the 1 November 2014 (20141101) IC anomaly (all calculated with respect to the 1979-2014 linear fit of 1 November ocean and sea ice IC). The experiments e82 through
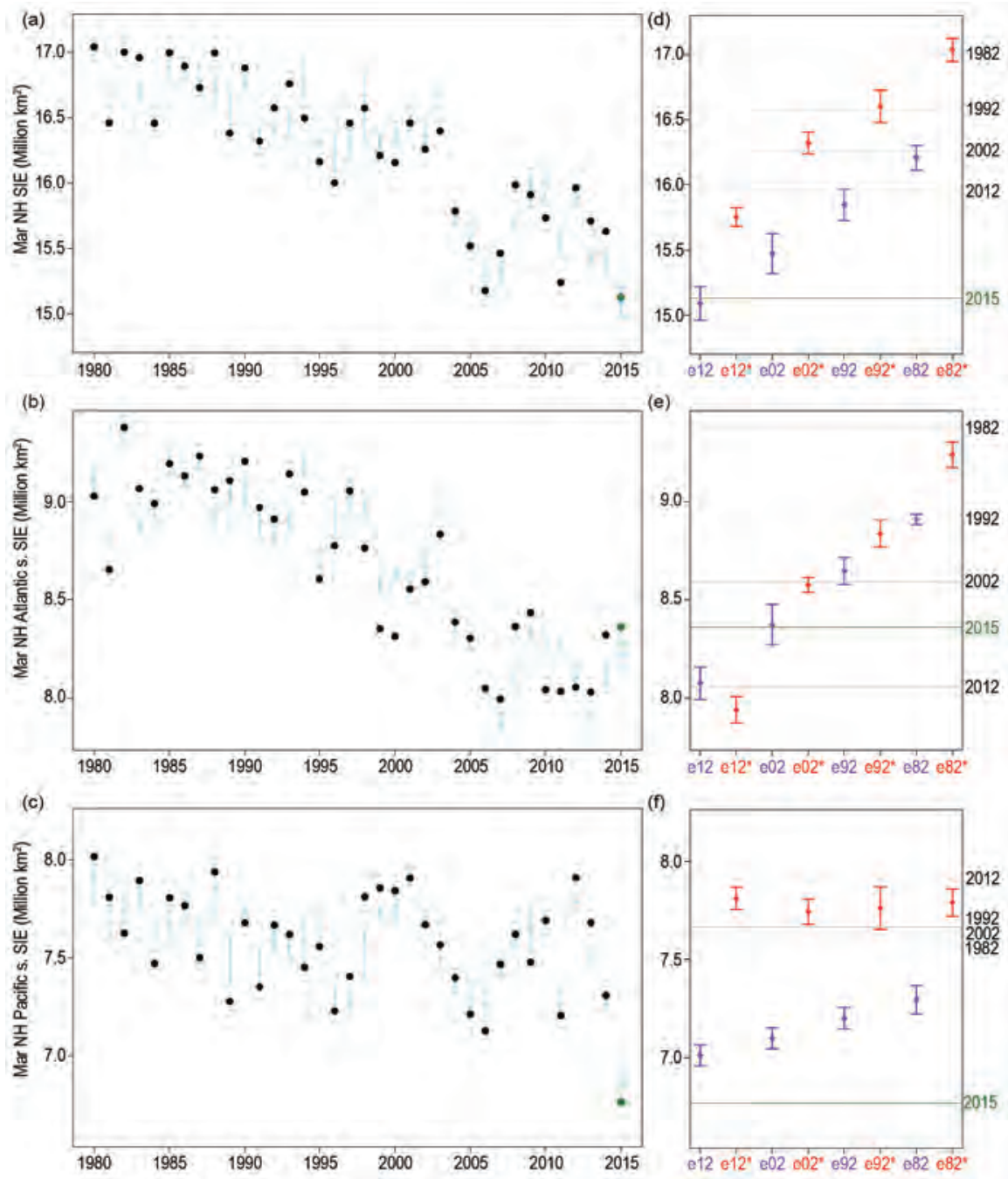

FIG. 27.2. (a)-(c) Full black circles (full light blue diamonds with the $95 \%$ confidence interval bars) show the total SIE, SIE in the Atlantic sector, and SIE in the Pacific sector in the NH in Mar from 1980 to 2015 , respectively, from OSI SAF (NEMO3.3-LIM3 adjusted CTL values). (d)-(f) The total SIE, SIE in the Atlantic sector, and SIE in the Pacific sector of the NH in Mar, respectively, of adjusted sensitivity experiments (means with the $95 \%$ confidence interval bars). Horizontal lines in the right panels indicate OSI SAF Mar NH SIE for the same domains (left) for the years indicated on the right.

e12 examine how much the selected March forecasts would change further if we use the same IC as in e82* through e12*, respectively, but also modify both factors (iii) and (iv): We apply the 2014/15 fall-winter surface forcing fields in e82 through e12.

Results. The adjusted $\mathrm{e} 82^{\star}$ through $\mathrm{e} 12^{\star}$ March forecasts enable us to examine the contribution of 20141101 interannual IC anomaly to the total change between the selected past years and 2015 through the ratios: [CTL(1982) - e82*] / [CTL (1982) - CTL(2015)], ..., $\left[\mathrm{CTL}(2012)-\mathrm{e} 12^{*}\right] /[\mathrm{CTL}(2012)-\mathrm{CTL}(2015)]$. 


\begin{tabular}{|c|c|c|}
\hline \multicolumn{3}{|c|}{$\begin{array}{l}\text { Table } 27.1 \text {. Summary of the determining characteristics } \\
\text { of each sensitivity experiment and the associated control } \\
\text { experiments. }\end{array}$} \\
\hline Name & $\begin{array}{l}\text { Global ocean and sea ice IC } \\
\text { linear fit + interannual } \\
\text { anomaly (yyyymmdd) }\end{array}$ & $\begin{array}{l}\text { Surface forcing fields } \\
\text { start - end } \\
\text { (yyyymm) }\end{array}$ \\
\hline & (ii) & (iii) and (iv) \\
\hline CTL(1982) & lin.fit(I98IIIOI) + anom.(I98IIIOI) & $198111-198203$ \\
\hline e82* & lin.fit(198III0I) + anom.(2014II0I) & $198111-198203$ \\
\hline e82 & lin.fit(|98IIIOI) + anom.(20I4IIOI) & $20|4| I-20 \mid 503$ \\
\hline CTL(1992) & lin.fit(I99III0I) + anom.(I99III0I) & $199111-199203$ \\
\hline e92* & lin.fit(1991II0I) + anom.(2014II0I) & $199111-199203$ \\
\hline e92 & lin.fit(|99III0I) + anom.(20I4II0I) & $201411-201503$ \\
\hline CTL(2002) & lin.fit(200IIIOI) + anom.(200III0I) & $200111-200203$ \\
\hline e02* & lin.fit(200IIIOI) + anom.(20I4IIOI) & $200111-200203$ \\
\hline e02 & lin.fit(200IIIOI) + anom.(20I4II0I) & $201411-201503$ \\
\hline CTL(20I2) & lin.fit(20IIIIOI) + anom.(20IIIIOI) & $201111-201203$ \\
\hline el $2 *$ & lin.fit(20IIIIOI) + anom.(20I4II0I) & $201111-201203$ \\
\hline el2 & lin.fit(20IIIIOI) + anom.(20I4II0I) & $201411-201503$ \\
\hline & (ii) & (iii) and (iv) \\
\hline CTL(20I5) & lin.fit(20I4II0I) + anom.(20I4II0I) & $20|4| \mid-201503$ \\
\hline
\end{tabular}

past-2015 change of $61.9 \%, 54.1 \%$, and $74.1 \%$ (on average between these sensitivity experiments) in the $\mathrm{NH}$, $\mathrm{NH}_{\mathrm{Atl}}$, and $\mathrm{NH}_{\mathrm{Pac}}$ SIE, respectively. Experiments e82 through e12 still contain the background IC state of the past years that typically prevents them from reaching the 2015 record (purple symbols are mostly far from the CTL 2015 values on the right in Fig. 27.2). The linear-fit slopes of the March forecasts from e82 to e12 of the $\mathrm{NH}, \mathrm{NH}_{\mathrm{Att}}$, and $\mathrm{NH}_{\mathrm{Pac}}$ SIE have values of $0.37,0.28$, and 0.09 million $\mathrm{km}^{2} 10-\mathrm{yr}^{-1}$, respectively. They show that the long-term linear change of the ocean and sea ice background state plays an important role, even in the Pacific sector (Fig. 27.2f) where the long-term trend is the weakest.

Conclusions. The performed experiments indicate that the most important factor driving the $\mathrm{NH}$ SIE to the record low in March 2015 was surface atmospheric conditions on average contributing at least $54 \%$ to the change from the past March states. The 1 November 2014 interannual anomaly of IC, which on average contributes less than $10 \%$, is the least important factor. A change along the 36-year linear-fit of IC, representing the accumulative

The recent interannual anomaly in the ocean and sea ice IC explains a minor part of the total past-2015 change of the $\mathrm{NH}, \mathrm{NH}_{\mathrm{Atl}}$, and $\mathrm{NH}_{\mathrm{Pac}}$ SIE: $2.1 \%, 9.0 \%$, and $-9.9 \%$ on average from e $82^{\star}$ to $122^{\star}$, respectively (red symbols on the right in Fig. 27.2 are close to the associated CTL forecasts on the left). The linear regressions of the March forecasts from e $82^{*}$ to $\mathrm{e} 12^{*}$ of the $\mathrm{NH}, \mathrm{NH}_{\mathrm{Atl}}$, and $\mathrm{NH}_{\mathrm{Pac}}$ SIE have significant slopes of $0.41,0.42$, and -0.01 million $\mathrm{km}^{2} 10-\mathrm{yr}^{-1}$, respectively.

The experiments e 82 through e12 compared with experiments e $82^{*}$ through $\mathrm{e} 12^{*}$, respectively, examine the contributions of 2014/15 fall-winter surface forcing fields to the total change between the selected past years and 2015 through the ratios: $\left(e 82^{*}-\mathrm{e} 82\right)$ / [CTL(1982) - CTL(2015)], ... and (e12* - e12) / [CTL(2012) - CTL(2015)]. This change in both (iii) and (iv) makes the dominant contribution to the total impact of the climate change in the ocean and sea ice, is the second most important factor for attaining the March 2015 extreme in our experiments. Even if we keep IC and forcing factors (ii) through (iv) in the 2014-15 conditions, but translate the background state of ocean and sea ice, IC factor (i), more than three years into the past (in e02, e92, and e82), it prevents our OGCM from reaching this record low. We conclude that March 2015 interannual surface anomalies in the Sea of Okhotsk and the Bering Sea are necessary transient, but not sufficient, conditions to achieve the record low of the NH SIE maximum in March 2015 without underlying climate change.

ACKNOWLEDGEMENTS. Fučkar and Massonnet are Juan de la Cierva fellows. Guemas, García-Serrano and Bellprat are Ramón y Cajal, Marie Curie, and ESA fellows, respectively. This study was supported by 
the funding from the EU's SPECS (308378), EUCLEIA (607085) and PRIMAVERA (641727) projects. The authors thank the editor and reviewers for constructive input and acknowledge the computer resources, technical expertise, and assistance provided by the Red Española de Supercomputación (RES) network and the Barcelona Supercomputing Center.

\section{REFERENCES}

Balmaseda, M. A., K. Mogensen, and A. T. Weaver, 2013: Evaluation of the ECMWF ocean reanalysis system ORAS4. Quart. J. Roy. Meteor. Soc., 139 1132-1161, doi:10.1002/qj.2063.

Comiso, J. C., and D. K. Hall, 2014: Climate trends in the Arctic as observed from space. Wiley Interdiscip. Rev.: Climate Change, 5, 389-409, doi:10.1002 /wcc. 277.

Dee, D. P., and Coauthors, 2011: The ERA-interim reanalysis: Configuration and performance of the data assimilation system. Quart. J. Roy. Meteor. Soc., 137, 553-597, doi:10.1002/qj.828.

Eastwood, S., Ed., 2014: Sea ice product user's manual. Ocean and Sea Ice Satellite Application Facility, 38 pp. [Available online at http://osisaf.met.no/docs /osisaf_ss2_pum_ice-conc-edge-type_v3p11.pdf.]

Fučkar, N. S., D. Volpi, V. Guemas, and F. J. DoblasReyes, 2014: A posteriori adjustment of near-term climate predictions: Accounting for the drift dependence on the initial conditions. Geophys. Res. Lett. 41, 5200-5207, doi:10.1002/2014GL060815.

Guemas, V., F. J. Doblas-Reyes, K. Mogensen, Y. Tang, and S. Keeley, 2014: Ensemble of sea ice initial conditions for interannual climate predictions. Climate Dyn., 43, 2813-2829, doi:10.1007/s00382-014-2095-7.

Jeffries, M. O., J. E. Overland, and D. K. Perovich, 2013: The Arctic shifts to a new normal. Phys. Today, 66, 35-40, doi:10.1063/PT.3.2147.

Kimura, N., and M. Wakatsuchi, 1999: Processes controlling the advance and retreat of sea ice in the Sea of Okhotsk. J. Geophys. Res., 104, 11137-11150, doi:10.1029/1999JC900004.

Kharin, V. V., G. J. Boer, W. J. Merryfield, J. F. Scinocca, and W. S. Lee, 2012: Statistical adjustment of decadal predictions in a changing climate. Geophys. Res. Lett., 39, L19705, doi:10.1029/2012GL052647.

Madec, G., and Coauthors, 2008 : NEMO ocean engine. Note du Pôle de modélisation de l'Institut PierreSimon Laplace No 27, 357 pp. [Available online at www.nemo-ocean.eu/About-NEMO/Reference -manuals.]
Massonnet, F., V. Guemas, N. S. Fučkar, F. J DoblasReyes, 2015: The 2014 high record of Antarctic sea ice extent [in "Explaining Extreme Events of 2014 from a Climate Perspective”]. Bull. Amer. Meteor. Soc., 96 (12), S163-S167, doi:10.1175/BAMS-D-15-00093.1.

Screen, J. A., C. Deser, and I. Simmonds, 2012: Local and remote controls on observed Arctic warming. Geophys. Res. Lett., 39, L10709, doi:10.1029/2012GL051598.

Stroeve, J. C., M. C. Serreze, M. M. Holland, J. E. Kay, J. Malanik, and A. P. Barrett, 2012: The Arctic's rapidly shrinking sea ice cover: A research synthesis. Climatic Change, 110, 1005-1027, doi:10.1007/s10584 -011-0101-1.

Taylor, P. C., M. Cai, A. Hu, J. Meehl, W. Washington, and G. J. Zhang, 2013: A decomposition of feedback contributions to polar warming amplification. J. Climate, 26, 7023-7043, doi:10.1175 /JCLI-D-12-00696.1.

Vancoppenolle, M., T. Fichefet, H. Goosse, S. Bouillon, G. Madec, and M. A. Morales Maqueda, 2009: Simulating the mass balance and salinity of Arctic and Antarctic sea ice. 1. Model description and validation. Ocean Modell., 27, 33-53, doi:10.1016/j .ocemod.2008.10.005.

Zhang, J., R. Woodgate, and R. Moritz, 2010: Sea ice response to atmospheric and oceanic forcing in the Bering Sea. J. Phys. Oceanogr., 40, 1729-1747, doi:0.1175/2010JPO4323.1. 


\title{
28. SUMMARY AND BROADER CONTEXT
}

\author{
Stephanie C. Herring, Andrew Hoell, Martin P. Hoerling, James P. Kossin, \\ Carl J. Schreck III, and Peter A. Stott
}

This year's event types include tropical cyclones, extreme sunshine, nuisance tidal flooding, snowpack drought, forest fires, and Arctic sea ice extent in addition to heat, cold, precipitation, and drought. The Summary Table (Table 28.I) is provided to give readers a general overview of the results. However, it is a highly simplified categorization of the results and does not include information about the size of the signal detected or the confidence in the results. This information is found within each individual report and provides essential context for understanding and interpreting results for any individual event. Also, while these reports may be the first analysis for many of these events, they may not be the last. Additional research on any of these events may uncover new information that helps provide a more complete understanding for the role of climate change.

Over the years, authors contributing to this report have also taken on the challenge of quantifying the impacts of climate change. We have increasingly emphasized this because to make attribution results informative to adaptation decisions, scientists must take on the questions of whether the risk or magnitudes of such events have increased or decreased, by how much, and what level of confidence supports the claims. Going forward, report authors will continue to clearly state not only the magnitude and nature of the impacts, but the confidence in their conclusions. While we have made great strides in communicating the exact role of climate change, we still struggle with ensuring that the confidence in the conclusions is also conveyed. This year we also added a methods column to the Summary Table 28.1. While we have limited data at this time, it will be interesting to see what methodological approaches are being applied for different event types and regions as the science evolves.

It was also exciting to see that even after five years and over 100 events examined, investigators are still finding new event types with which to explore the role of climate change. This year we had contributions on novel event types including extreme sunshine in the United Kingdom, "sunny day" flooding in the south-

AFFILIATIONS: HERRING-NOAA/National Centers for Environmental Information, Boulder, Colorado; HOELL AND HoERLING -NOAA/Earth System Research Laboratory, Physical Sciences Division, Boulder, Colorado; Kossin-NOAA/National Centers for Environmental Information, Madison, Wisconsin; SCHRECK-NOAA/National Centers for Environmental Information, Asheville, North Carolina, the Cooperative Institute for Climate and Satellites-North Carolina, North Carolina State University, Asheville, North Carolina; STOTT-Met Office Hadley Centre and University of Exeter, Exeter, United Kingdom

DOI:I0.II75/BAMS-D-16-03|4.I eastern United States, and snowpack drought in the U.S. mountain west. What might be a bright spot for the United Kingdom is that investigators found that extreme winter sunshine there, as observed in the record high 2014/15 season, has become more than 1.5 times more likely to occur under the influence of human-caused climate change. The southeastern United States has a less positive outlook when it comes to sunny day coastal flooding. Even without a cloud in the sky or a storm on the horizon, the Miami, Florida, region is more likely to experience tidal flooding because of long-term sea level rise caused by global warming. In the U.S. Cascade Mountains, a 2015 "snowpack drought" resulted from unprecedented warmth that caused cold-season precipitation to fall as rain rather than snow on the mountains. Investigators found that because of climate change this event could be recurrent in the future.

As observed in years past, all the papers that looked at heat events around the world-from Egypt, Australia, Europe, Indonesia, Asia, India, and Pakistan - all found that climate change played a role in increasing the severity of the event. In addition, many of these events were influenced by both El Niño and natural variability, and in all cases researchers were able to distinguish between these drivers. For example, while El Niño conditions normally have a cooling impact on Japan in July-August, the 2015 summer was still unexpectedly hot. Authors isolated the various influences and showed that intraseasonal disturbances including tropical cyclones were the main drivers, but that human-caused warming increased the likelihood by 1.5 to 1.7 times.

The results of individual event attribution studies can be put into context by looking at the broader 


\section{Table 28.I. Summary of Results}

\section{ANTHROPOGENIC INFLUENCE ON EVENT}

\begin{tabular}{|c|c|c|c|}
\hline & INCREASE & DECREASE & NOT FOUND OR UNCERTAIN \\
\hline Heat & $\begin{array}{l}\text { Global Temperature (Ch. 2) } \\
\text { South India \& Sri Lanka (Ch. 2) } \\
\text { Central Europe (Ch. II) } \\
\text { Europe (Ch. I2) } \\
\text { Ethiopia and Southern Africa (Ch. I5) } \\
\text { N.W. China (Ch. I9) } \\
\text { W. China (Ch. 20) } \\
\text { Japan (Ch. 2I) } \\
\text { Indonesia (Ch. 22) } \\
\text { S. Australia (Ch. 23) } \\
\text { Australia (Ch. 24) }\end{array}$ & & Central Equitorial Pacific (Ch. 2) \\
\hline Cold & & Northeastern U.S. (Ch. 7) & $\begin{array}{l}\text { Mid-South Atlantic U.S. (Ch. 7) } \\
\text { N. America (Ch. 8) }\end{array}$ \\
\hline $\begin{array}{l}\text { Heat \& } \\
\text { Humidity }\end{array}$ & $\begin{array}{l}\text { Egypt (Ch. I4) } \\
\text { India \& Pakistan (Ch. 16) }\end{array}$ & & \\
\hline Dryness & $\begin{array}{l}\text { Indonesia (Ch. 22) } \\
\text { Tasmania (Ch. 25) }\end{array}$ & & \\
\hline $\begin{array}{l}\text { Heavy } \\
\text { Precipitation }\end{array}$ & China (Ch. 18) & & $\begin{array}{l}\text { Nigeria (Ch. I3) } \\
\text { India (Ch. I7) }\end{array}$ \\
\hline Sunshine & United Kingdom (Ch. I0) & & \\
\hline Drought & $\begin{array}{l}\text { Canada (Ch. 9) } \\
\text { Ethiopia and Southern Africa (Ch. I5) }\end{array}$ & & \\
\hline $\begin{array}{l}\text { Tropical } \\
\text { Cyclones }\end{array}$ & Western North Pacific (Ch. 26) & & \\
\hline Wildfires & Alaska (Ch. 4) & & \\
\hline $\begin{array}{l}\text { Sea Ice } \\
\text { Extent }\end{array}$ & & Arctic (Ch. 27) & \\
\hline $\begin{array}{l}\text { HIGH TIDE } \\
\text { FLOODS }\end{array}$ & SOUtheastern U.S. (CH. 6) & & \\
\hline $\begin{array}{l}\text { SNOWPACK } \\
\text { DROUGHT }\end{array}$ & WASHINGTON U.S. (CH. 5) & & \\
\hline TOTAL & 23 & 2 & 5 \\
\hline
\end{tabular}




\section{METHOD USED}

Heat

Ch. 2: CMIP5 modeling

Ch. II: Observations; weather@home modeling

Ch. 12: HadGEM3-A modeling

Ch. 15: CMIP5 modeling

Ch. 19: CMIP5 modeling with ROF; FAR

Ch. 20: CMIP5 modeling with ROF; FAR

Ch. 21: MIROC5-AGCM modeling

Ch. 22: Observations; CMIP5 modeling

Ch. 23: weather@home modeling; FAR

Ch. 24: BoM seasonal forecast attribution system and seasonal forecasts

Ch. 7: Observations; CMIP5 modeling

Ch. 8: AMIP (IFS model) modeling

Heat \&

Ch. 14: weather@home modeling

Humidity

Ch. 16: Non-stationary EV theory; C20C+ Attribution Subproject

Dryness

Ch. 22: Observations; CMIP5 modeling

Ch. 25: Observations; Modeling with CMIP5 and weather@home

Ch. 13: Observations; Modeling with CAM5.I and MIROC5

Heavy

Precipitation

Ch. 17: Observations; Modeling with weather@home, EC-Earth and CMIP5

Ch. 18: HadGEM3-A-N216 modeling; FAR

Ch. 10: Hadley Centre event attribution system built on the high-resolution version of HadGEM3-A

Sunshine

Ch. 9: Observations; CMIP5 modeling; Trend and FAR analyses

Drought

Ch. 15: CMIP5 modeling, land surface model simulations, and statistical analyses

Tropical

Cyclones

Ch. 26: GFDL FLOR modeling; FAR

Wildfires

Ch. 4: WRF-ARW optimized for Alaska with metric of fire risk (BUI) to calculate FAR

Sea Ice

Extent

High TIDE

FLOODS

SNOWPACK

DROUGHT

Ch. 27: OGCM modeling

Ch. 6: Tide-gauge data; Time-dependent EV statistical model

Ch. 5: Observations; CESMI modeling

\section{ACRONYMS:}

AMIP: Atmospheric Model Intercomparison Project

BoM: Bureau of Meteorology, Australia

BUI: Buildup Index

CAM: Community Atmosphere Model, http:www.cesm.ucar.edu

CESM: Community Earth System Model

CMIP: Coupled Model Intercomparison Project

FAR: Fraction of Attributable Risk

EC-EARTH: https://verc.enes.org/

EV: Extreme Value
GFDL FLOR: Geophysical Fluid Dynamics Laboratory Forecast version Low Ocean Resolution

GHCN: Global Historical Climatology Network

IFS: Integrated Forecast System

MIROC5-AGCM: Model for Interdisciplinary Research on ClimateAtmospheric General Circulation Model

OGCM: Ocean General Circulation Model

ROF: Regularized Optimal Fingerprinting

weather@home: http:www.climateprediction.net/weatherathome

WRF-ARW: Advanced Research (ARW) version of the Weather Research and Forecasting (WRF) model 
literature. For example, investigators find that human-induced climate change has increased the likelihood of a fire season as extreme as the one that occurred in 2015 in Alaska, which is consistent with numerous studies in recent years that indicate climate change is increasing fire risk in parts of the United States (Melillo et al. 2014). The 2015 Alaska fire season burned the second largest number of acres since records began in 1940 .

Another example was the extreme tropical cyclone activity in 2015 in the western north Pacific (WNP) as measured by accumulated cyclone energy (ACE). In this report, a study finds that warm sea surface temperatures associated with El Niño played a major role, but human-caused climate change substantially increased the odds of the extremely active $2015 \mathrm{WNP}$ tropical cyclone season. The observed extreme ACE was mostly due to the anomalously high frequency of category 4-5 storms, which is consistent with projections of increased category 4-5 storms in the WNP region under anthropogenic warming (Walsh et al. 2016).

Five years in review. In this fifth year of the Special Supplement on Explaining Extreme Events from a Climate Perspective, we have hit an exciting milestone of over 100 papers examining extreme events over half a decade. Approximately $65 \%$ of these papers have shown that human-caused climate change influenced an event's frequency and/or intensity in a substantial and measurable manner. Around 35\% did not find an influence for climate change. While these reports represent a small and non-random sampling of extreme events from around the world, these results add to the preponderance of evidence that climate change is influencing extreme events (Field et al. 2012; Melillo et al. 2014).

It is worth commenting on some patterns we have started to see after five years. For example, of the 104 papers published in this report over the last five years, the event types most studied are overwhelmingly heat (29 papers, $28 \%$ ), precipitation (24 papers, $23 \%$ ) and drought (17 papers, 16\%). In total, these three event types comprise approximately two-thirds of all submissions.

Of the 29 papers that looked at heat events, only one did not find a role for climate change. In contrast, over the past five years this supplement has published 24 attribution studies on precipitation, and the majority ( $62 \%)$ did not find human influences on the event. This more divided set of precipitation results indicates that either the ability to detect a climate change signal is more challenging for precipitation events because of observational or modeling limitations, or that the impact of climate change on precipitation is more complex or less pronounced than it is for heat. The $\sim 62 \%$ of "no signal" found in these precipitation papers is also influenced by the broad variety of questions authors asked for precipitation events. For example, Tett et al. (2013) asked, "Are recent wet northwestern European summers a response to sea ice retreat?" They concluded the answer was no, but given the numerous ways climate change could influence precipitation in this region, a no result for the role of arctic sea ice should not be interpreted as an absence of any role at all for climate change. In general, precipitation analyses have looked at a small subset of the possible physical drivers. Also, the geographic location of each event must be taken into consideration when considering the confidence of a yes or no result. This is because changes in precipitation trends are anticipated to vary by location (Field et al. 2012), and the strength of the observational record, the ability of models to reproduce extremes, and the understanding of physical processes also can vary regionally.

Analyses of drought are also split with about 50\% finding and 50\% not finding a role for climate change, and again this overall percentage does not tell the full story. For example, multiple reports on the 2013 California drought looked at many variables. Swain et al. (2014) found an influence on geopotential heights that were associated with blockage of storms off the California coast, but the influence on actual changes in precipitation or temperature remain uncertain. Funk et al. (2014) found the long-term sea surface temperature warming did not contribute to the California drought risk. Wang and Schubert (2014) identified increases in anomalies that divert storms away from California (increase drought risk) but also found increases in humidity (decrease drought risk). These conflicting influences resulted in no net impact from climate change. So while these papers were neatly binned into the "no influence" category for the purposes of the Summary Table 28.1, a clear picture of how long-term climate change impacted the 2013 California drought is yet to emerge.

The overall message to our readers remains that when interpreting the results of individual event attribution assessments the binary yes or no answer may not tell the full story. Readers must have a clear understanding of the exact nature of the question the researchers were asking in their study and the areas 
of uncertainty to fully understand the implications of the results.

A look ahead. As we look ahead to the future of this report, a few very exciting opportunities are evident to the editors. On the attribution science front, the National Academy report (NAS 2016) on event attribution had several recommendations that this supplement could help implement. For example, the NAS report notes that standards have not yet been established for presenting results. They suggest that event attribution could be improved by the development of transparent, community standards for attributing classes of extreme events. That development would be an interesting discussion for future attribution community meetings. While community standards are under discussion, this report will continue to encourage authors to include an assessment of model quality in relation to the event class, use multiple lines of evidence, and clearly communicate the sensitivities of the result to how event attribution questions are framed. This information could be useful in developing these community standards.

In addition to improving event attribution science, we see opportunities for event attribution to become increasingly relevant to society through impacts attribution. This will include both intersecting with other scientific disciplines to apply attribution results to risk management in sectors such as human health, and including other aspects of human influence in understanding the causes of events. For example, flooding in the Canadian prairies in 2014 was more likely due to human impacts on precipitation along with land use changes that affect drainage mechanisms (Szeto et al. 2015). These types of mechanical factors reemphasize the various pathways beyond climate change by which human activity can increase regional risk of extreme events.

A look ahead would not be complete without acknowledging that the continued success and relevance of this report is dependent on the attribution science community. The editors would like to thank all of our contributing authors to date, because without the voluntary contributions of literally hundreds of authors from around the world this report would not be possible. From our beginnings in 2011 with just six papers to the over 100 published to date, no part of this journey has been more enjoyable for the editors than our engagement with the authors. Over the years this report has evolved in large part from both criticism and praise from contributors. The editors are grateful for the authors' thoughtful input and hope this dialog continues. Looking ahead we hope for their continued engagement as we work together to advance this exciting frontier of science.

\section{REFERENCES}

Field, C. B., and Coauthors, Eds., 2012: Managing the Risks of Extreme Events and Disasters to Advance Climate Change Adaptation. Cambridge University Press, $582 \mathrm{pp}$.

Funk, C., A. Hoell, and D. Stone, 2014: Examining the contribution of the observed global warming trend to the California droughts of 2012/13 and 2013/14 [in "Explaining Extremes of 2013 from a Climate Perspective”]. Bull. Amer. Meteor. Soc., 95 (9), S11S15.

Melillo, J. M., T. C. Richmond, and G. W. Yohe, Eds., 2014: Climate Change Impacts in the United States: The Third National Climate Assessment. U.S. Global Change Research Program, 841 pp., doi:10.7930 /J0Z31WJ2.

NAS, 2016: Attribution of Extreme Weather Events in the Context of Climate Change, National Academies Press, 186 pp., doi:10.17226/21852.

Swain, D. L., and Coauthors, 2014: The extraordinary California drought of 2013/2014: Character, context, and the role of climate change [in "Explaining Extremes of 2013 from a Climate Perspective"]. Bull. Amer. Meteor. Soc., 95 (9), S3-S7.

Szeto, K., J. Brimelow, P. Gysbers, and R. Stewart, 2015: The 2014 extreme flood on the southeastern Canadian Prairies [in "Explaining Extremes of 2014 from a Climate Perspective”]. Bull. Amer. Meteor. Soc., 96 (12), S20-S24, doi:10.1175 /BAMS-D-15-00110.1.

Tett, S. F. B., K. Deans, E. Mazza, and J. Mollard, 2013: Are recent wet northwestern European summers a response to sea ice retreat? [in "Explaining Extremes of 2012 from a Climate Perspective"]. Bull. Amer. Meteor. Soc., 94 (9), S32-S35.

Walsh, K. J. E., and Coauthors, 2016: Tropical cyclones and climate change. Wiley Interdiscip. Rev.: Climate Change, 7, 65-89, doi:10.1002/wcc.371.

Wang, H., and S. Schubert, 2014: Causes of the extreme dry conditions over California during early 2013 [in "Explaining Extremes of 2013 from a Climate Perspective”]. Bull. Amer. Meteor. Soc., 95 (9), S7S11. 
(2)

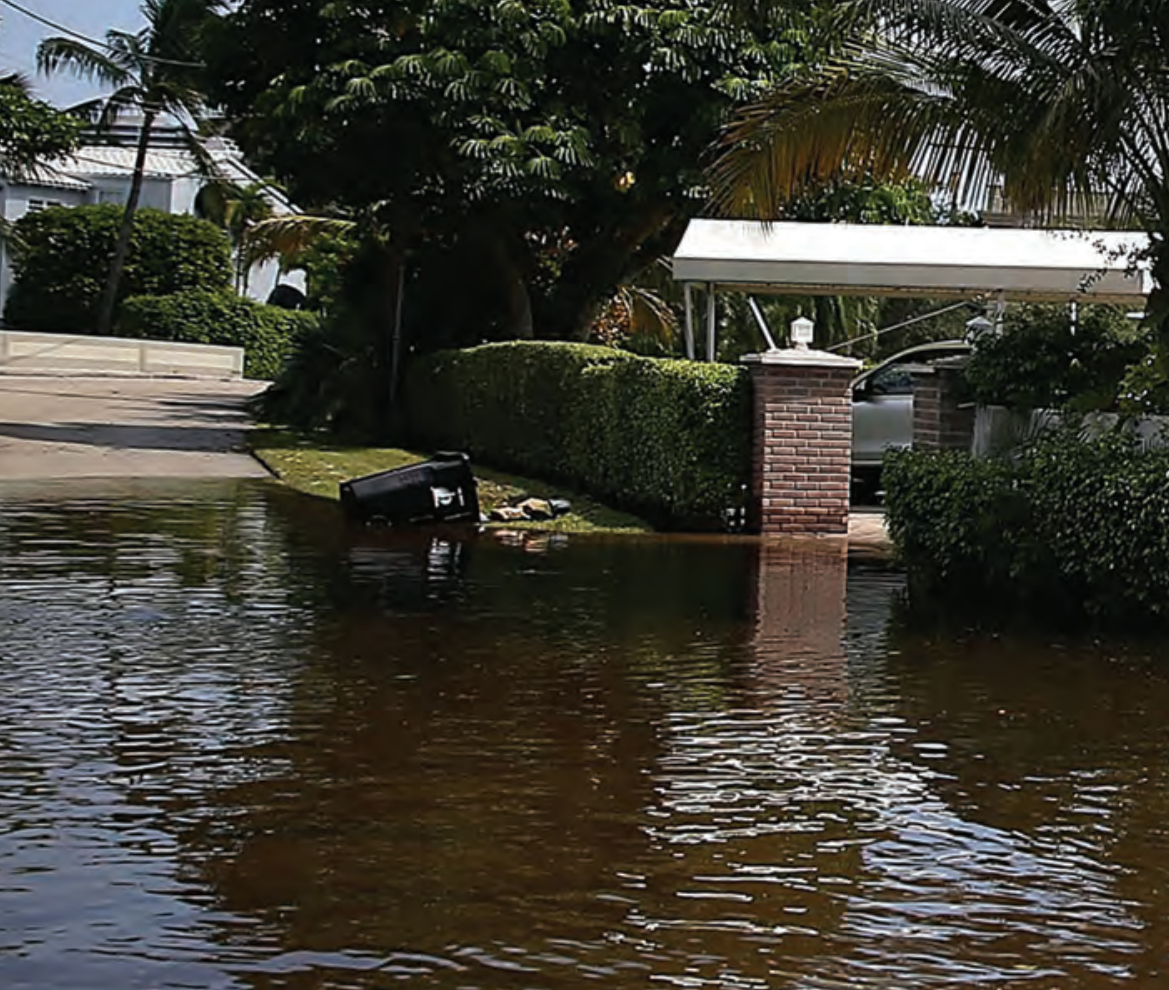

